UNIVERSIDAD NACIONAL DE LA PLATA

FACULTAD DE CIENCIAS NATURALES Y MUSEO

TESIS PARA OPTAR AL TÍTULO DE DOCTOR EN CIENCIAS NATURALES

\title{
CARACTERIZACIÓN DE ESPECIES DE LA FAMILIA PYTHIACEAE ASOCIADAS AL CULTIVO DE SOJA EN LA PROVINCIA DE BUENOS AIRES
}

\author{
Presentada por: \\ PABLO ENRIQUE GRIJALBA
}

Directora 1: Dra. Mónica M. Steciow

Directora 2: Dra. Azucena del C. Ridao

La Plata, 2018 


\section{AGRADECIMIENTOS}

A mi esposa Tucha e hijos (Fede, Santi y Pau) que me acompañan cada día.

A la Dra. Mónica Steciow por dirigirme en este trabajo, por sus sugerencias y comentarios.

A la Facultad de Ciencias Naturales y Museo (FCNYM) por brindarme la posibilidad de realizar este trabajo.

A la Dra. Azucena del Carmen Ridao (Unidad Integrada Balcarce INTA/UNMdP) por dirigirme en este trabajo, por su apoyo, conocimientos y sugerencias.

A la Dra. Gloria Abad, investigadora líder en Oomycetes en el "USDA- Molecular Diagnostic Laboratory (MDL)", por brindar todos sus conocimientos en forma desinteresada.

A la Dra. Paloma Abad Campos de la Universidad Politécnica de Valencia por aceptarme para una estancia en el tema: Oomycetes fitopatógenos.

A la Dra. Carolina Martínez del Instituto de Biotecnología INTA Castelar, por brindarme el apoyo y conocimiento para efectuar técnicas moleculares.

Al Lic. Eduardo Güillín por su colaboración en los análisis de genética poblacional y por compartir sus conocimientos en los trabajos efectuados.

A la Dra. Silvina Steward, del INIA La Estanzuela Rep. Oriental del Uruguay, por la provisión de ADN y cultivares diferenciales de Ph. sojae.

A la Dra. Hemilse Palmucci por compartir el descubrimiento y conocimiento de los Oomycetes Fitopatógenos. 


\section{INDICE GENERAL}

AGRADECIMIENTOS 2

INDICE GENERAL 3

INDICE DE TABLAS

INDICE DE FIGURAS 8

RESUMEN 12

$\begin{array}{ll}\text { ABSTRACT } & 15\end{array}$

$\begin{array}{ll}\text { INTRODUCCIÓN GENERAL } & 18\end{array}$

1. UBICACIÓN TAXONÓMICA DE LA FAMILIA PYTHIACEAE 20

2. CARACTERIZACIÓN MORFOLÓGICA DE LOS GÉNEROS Pythium, Phytophthora Y 24 Phytopythium

3. CARACTERIZACIÓN DEL CULTIVO DE SOJA EN LAS ZONAS EN ESTUDIO 28

4. ESTUDIOS EFECTUADOS EN ARGENTINA 30

5. HIPOTESIS 32

6. OBJETIVOS

6.1. OBJETIVO GENERAL 32

6.2. OBJETIVOS ESPECÍFICOS 32

MATERIALES Y MÉTODOS (COMUNES) 33

1. MUESTREO DE CAMPOS 33

2. GRANOS DE SOJA POSCOSECHA (Semillas) 34

3. TÉCNICAS DE AISLAMIENTO DE LOS FITOPATÓGENOS Y MANTENIMIENTO DE LA 34 COLECCIÓN

3.1. Aislamiento $\quad 35$

3.1.1. A partir de tejidos afectados $\quad 35$

3.1.2. Aislamientos a partir de suelos $\quad 35$

3.1.3. Aislamiento a partir de granos $\quad 35$

3.2. Mantenimiento de la colección 36

4. IDENTIFICACIÓN Y DESCRIPCIÓN DE LOS AISLAMIENTOS 36

4.1. Identificación y caracterización morfológica de los aislamientos 36

4.2. Identificación y caracterización de los aislamientos por métodos moleculares 36

$\begin{array}{ll}\text { 4.2.1. Extracción de ADN } & 37\end{array}$

$\begin{array}{ll}\text { 4.2.2. Amplificación de rADN } & 37\end{array}$

4.2.3. Purificación y secuenciación de rADN 38

5. CONSTRUCCIÓN DE ÁRBOLES FILOGENÉTICOS 38

CAPITULO I. ESPECIES DE Pythium Y DE Phytopythium PATÓGENAS y 39

ASOCIADAS A RAÍCES DE SOJA
INTRODUCCIÓN 
2. EPIDEMIOLOGÍA, SINTOMATOLOGÍA Y DAÑO 42

3. MANEJO 44

MATERIALES Y MÉTODOS 46

1. IDENTIFICACIÓN Y CARACTERIZACIÓN MORFOLÓGICA DE LOS AISLAMIENTOS 46

2. PRUEBAS DE PATOGENICIDAD 47

2.1. Ensayo de patogenicidad in-vitro $\quad 47$

2.2. Ensayo de patogenicidad in-vivo 47

2.3. Ensayo exploratorio de patogenicidad de Phytopythium 48

3. Respuesta de tres especies de Pythium frente a distintas temperaturas 48

3.1. Tasas diarias de crecimiento 48

4. Ensayos de Manejo con Pythium ultimum, P. irregulare y P. sylvaticum 49

4.1. Control químico, eficacia de diferentes formulados curasemillas 49

$\begin{array}{ll}\text { 4.1.1. Sensibilidad in vitro } & 49\end{array}$

4.1.2. Eficacia en semillas $\quad 50$

4.2 Relación entre el gen Rps 1k y la resistencia a Pythium ultimum y P. irregulare en $\quad 50$ soja

RESULTADOS

1. IDENTIFICACIÓN Y DESCRIPCIÓN DE LOS AISLAMIENTOS 52

1.1. Muestreo de campos, obtención e identificación de los aislamientos 52

1.2. Muestreo y obtención de aislamientos a partir de granos de soja e identificación. 53

1.3. Descripción de los aislamientos $\quad 54$

1.3.1. Especies del género Pythium $\quad 54$

1.3.1.1. Especies con esporangios lobulados o filamentosos 56

1.3.1.2. Especies con esporangios esféricos, subesféricos o elipsoidales $\quad 65$

1.3.1.2.1. Oogonios lisos $\quad 65$

1.3.1.2.2. Oogonios ornamentados $\quad 83$

1.3.2. Especies del género Phytopythium 94

1.4. Árbol filogenético de las especies de Pythium y Phytopythium más una secuencia 112 de Phytophthora sojae

2. PRUEBAS DE PATOGENICIDAD 112

2.1. Ensayo de patogenicidad in-vitro 112

2.2. Ensayo de patogenicidad in-vivo 112

2.3. Ensayo de patogenicidad exploratorio con cepas de Phytopythium 114

3. RESPUESTAS DE TRES ESPECIES DE Pythium FRENTE A DISTINTAS 117 TEMPERATURAS 
3.1. Tasas diarias de crecimiento.

4. ENSAYOS DE MANEJO CON Pythium ultimum, P. irregulare Y P. sylvaticum 120

4.1. Control químico, eficacia de diferentes formulados curasemillas 120

$\begin{array}{ll}\text { 4.1.1. Sensibilidad in vitro } & 120\end{array}$

4.1.2. Eficacia de diferentes formulados curasemillas $\quad 120$

$\begin{array}{ll}\text { 4.1.2.1. Ensayo A) } & 120\end{array}$

$\begin{array}{ll}\text { 4.1.2.2. Ensayo B) } & 121\end{array}$

4.2. Relación entre el gen Rps $1 \mathrm{k}$ y la resistencia a Pythium ultimum y P. irregulare en 121 soja

DISCUSIÓN 123

CAPITULO II. Phytophthora sojae AGENTE CAUSAL DE LA PODREDUMBRE DE 130 RAÍZ Y LA BASE DEL TALLO DE LA SOJA

INTRODUCCIÓN 131

1. AGENTE CAUSAL 133

1.1 Variabilidad de Phytophthora sojae 134

1.2. Síntomas de la enfermedad 137

2. CICLO DE LA ENFERMEDAD Y CONDICIONES PREDISPONENTES 138

3. MANEJO DE LA ENFERMEDAD 139

3.1. Resistencia raza específica 139

3.2. Resistencia parcial (RP) o no específica (tolerancia) 140

$\begin{array}{ll}\text { 3.3. Otras medidas de manejo } & 140\end{array}$

$\begin{array}{ll}\text { 3.3.1. Uso de fungicidas específicos } & 140\end{array}$

3.3.2. Rotación de cultivos $\quad 141$

$\begin{array}{ll}\text { 3.3.3. Buen drenaje } & 141\end{array}$

MATERIALES Y MÉTODOS 141

1. VIRULENCIA EN LA SUBREGIÓN PAMPEANA NORTE DURANTE EL INTERVALO 142 1998-2004

2. VIRULENCIA EN EL NBA Y SEBA DURANTE EL INTERVALO 2013-2016 143

2.1. Identificación de los aislamientos y almacenamiento 143

2.2. Evaluación de la virulencia de los aislamientos (Determinación de razas o 143 fórmulas de virulencia específica)

2.2.1. Corroboración del patrón de virulencia de la reacción de los genotipos 144 de soja diferenciales

2.3. Técnica de inoculación 144

3. RELACIÓN GENÉTICA ENTRE AISLAMIENTOS DE Ph. sojae PROVENIENTES DEL 145 NBA Y SEBA UTILIZANDO MARCADORES SSRS.

$\begin{array}{ll}\text { 3.1. Curvas de acumulación de haplotipos } & 148\end{array}$

$\begin{array}{ll}\text { 3.2. Caracterización por locus } & 149\end{array}$ 
$\begin{array}{ll}\text { 3.4. AMOVA } & 150\end{array}$

3.5. Análisis discriminante de componentes principales 150

3.6. Análisis de redes 151

RESULTADOS 153

1. VIRULENCIA EN LA SUBREGIÓN PAMPEANA NORTE DURANTE EL INTERVALO 153 1998-2004

2. VIRULENCIA EN EL NBA Y SEBA DURANTE EL INTERVALO 2013-2016 156

2.1. Identificación de los aislamientos y almacenamiento 156

2.2. Evaluación de la virulencia de los aislamientos (Determinación de razas o 156 fórmulas de virulencia específica)

2.2.1 Corroboración del patrón de virulencia de la reacción de los genotipos de $\quad 160$ soja diferenciales

3. RELACIÓN GENÉTICA ENTRE AISLAMIENTOS DE Ph. sojae PROVENIENTES DEL 161 NBA Y SEBA UTILIZANDO MARCADORES SSRs.

3.1. Curva de acumulación de haplotipos 161

3.2. Caracterización por locus 162

3.3. Diversidad haplotípica 163

3.3.1. Análisis por regiones 164

3.4. AMOVA 164

3.5. Análisis discriminante de componentes principales (ADPC). 165

$\begin{array}{ll}\text { 3.6. Análisis de redes } & 167\end{array}$

DISCUSIÓN 168

1. RELACIÓN GENÉTICA ENTRE AISLAMIENTOS DE Ph. sojae PROVENIENTES DEL $\quad 170$

NBA Y SEBA UTILIZANDO MARCADORES SSRs
CONCLUSIONES GENERALES

$\begin{array}{ll}\text { BIBLIOGRAFIA } & 175\end{array}$

ANEXO I. MEDIOS DE CULTIVO GENERALES Y SELECTIVOS 189

$\begin{array}{ll}\text { ANEXO II. ANÁLISIS ESTADÍSTICOS } & 191\end{array}$

ANEXO III. TAMAÑO DE BANDAS OBTENIDOS CON LOS 8 MICROSATÉLITES 193 ESPECÍFICOS.

ANEXO IV. ANÁLISIS DE SIGNIFICACIÓN DEL AMOVA. 202

\section{ÍNDICE DE TABLAS}

Tabla 1: Porcentajes de especies de Pythiun aisladas y determinadas entre 53 2013 a 2015 de lotes del NBA y SEBA de la provincia de Buenos Aires. 
Tabla 2: Porcentajes de especies de Pythiun aisladas y determinadas entre 2014 a 2016 de granos provenientes de lotes del NBA y SEBA.

Tabla 3: Patogenicidad promedio para dos especies de Phytopythium 113 (método de la capa e inundación).

Tabla 4: Patogenicidad in vitro e in vivo de las especies de Pythium y Phytopythium aisladas entre 2013-2016 en las zonas norte y sudeste de la provincia de Buenos Aires.

Tabla 5: Respuestas de diferentes especies de Pythium frente a distintas 119 temperaturas.

Tabla 6: Porcentaje de emergencia promedio y porcentaje de control de semillas de soja tratadas con fungicidas curasemillas y sembradas en suelo inoculado con Pythium spp.

Tabla 7: Emergencia de plántulas a los 21 días desde la siembra de genotipos de soja sin inóculo e inoculados con Pythium spp.

Tabla 8: Listado de los aislamientos de Phytophthora sojae utilizados para el chequeo de la relación genética utilizando marcadores SSRs. Se detalla origen y patotipo.

Tabla 8: Secuencias de iniciadores (primers) y características para los locus de microsatélites polimórficos desarrollados a partir de la secuencia de $P h$. sojae. Nombre del locus, número de acceso GenBank, secuencia del iniciador, motivo repetido, rango de tamaño, número de alelos determinados mediante el genotipado del aislamiento P6497 de Ohio, EEUU (extraído de Steward et al., 2011).

Tabla 9: Distribución de la virulencia de aislamientos de Phytophthora sojae de la sub-región Pampeana norte entre 1998-2004, probados sobre 8 o 14 genes Rps y 3 líneas experimentales (* probados en Harrow, Canadá).

Tabla 10: Distribución de la virulencia de 69 aislamientos de Phytophthora sojae obtenidos en la región NBA durante 2013-2016, chequeados en un grupo de ocho genes Rps.

Tabla 11: Distribución de la virulencia de 124 aislamientos de 156 Phytophthora sojae obtenidos en la región SEBA entre 2013-2016, chequeados en un grupo de ocho genes Rps.

Tabla 12: Reacción de genotipos diferenciales (indicando el alelo que poseen) a la inoculación de cinco aislamientos de Phytophthora sojae, mediante la técnica del hypocótile.

Tabl 13: Resumen de contenido informacional para los ocho microsatélites utilizados 
Tabla 14: Índices de diversidad genotípica por localidad, para 93162 aislamientos analizados con ocho marcadores microsatélites

Tabla 15: Índices de diversidad genotípica por región, para 93 aislamientos analizados con ocho marcadores microsatélites.

Tabla 16: Tamaño de bandas de los 93 aislamientos de Phytophthora sojae y 5 ADNs de EEUU obtenidos con 8 Microsatélites específicos

Tabla 17: Análisis Molecular de la Varianza (AMOVA) para 93 aislamientos de Phytophthora sojae provenientes de dos zonas de la provincia de Buenos Aires.

Tabla 18: Componentes de la covarianza del análisis efectuado para 93 aislamientos de Phytophthora sojae analizados con ocho marcadores microsatélites.

Tabla 19. Significación de la variación

\section{ÍNDICE DE FIGURAS}

Fig. 1: Especies y clados distinguidos en el género Phytophthora. Ph. sojae se incluye en el clado 7 (Kroon et al., 2012).

Fig. 2: Diagrama resumido de la filogenia de los Oomycetes. (a). Diagrama resumido del probable camino evolutivo de Oomycotas (b). Árbol filogenético esquemático mostrando los principales clados taxonómicos indicando la diversidad taxonómica (números en los cuadros) y la ecología predominante (Beakes y Thines, 2016

Fig. 3: Caracterización del cultivo de soja en las zonas argentinas. A. División de las regiones según características agroclimáticas. B. Regiones sojeras de la Republica Argentina. C. Regiones sojeras de la Republica Argentina. Franjas latitudinales de los grupos de madurez de la soja en la Argentina. D. Variación de la superficie promedio sembrada de la Región pampeana 1975-2004. Extaído de Pascale y Damario, 2004 e INTA, 1997. Fig. 4: Mapa de la provincia de Buenos Aires, los números indican las localidades muestreadas entre 2013-2016. NBA: 1 Fontezuela, 2 Pergamino, 3 Rojas, 4 Chacabuco, 5 Alberti, 6 Gorostiaga, 7 Mechita, 8 Capitán Sarmiento, 9 Arrecifes, 10 Rancagua, 11 Colon, 12 FAUBA, 13 Germania, 14 Los Toldos, 15 Solis, 16 S.A. de Areco, 17 Villa Lía. SEBA: 18 Necochea, 19 Balcarce, 20 General Pirán, 21 Lobería, 22 Bosch y 23 El Moro.

Fig. 5: A) y B) Sintomatología típica de muerte de plántulas en el campo causada por Pythium spp. C), D) y E) Detalle de plántulas afectadas. F). Plantas adultas en R1 (Fehr y Caviness, 1977), afectadas. G) Detalle de las raíces de plantas adultas en $\mathrm{R} 1$, izquierda afectada, derecha normal. 
Fig.6: Pythium spp. A) Patogenicidad en semilla. B) Patogenicidad en suelo. C) Técnica de desarrollo en Agrostis sp. D) Siembra de semillas en medio selectivo.

Fig. 7: Parte de la escala para evaluar patogenicidad in vitro (Jiang et al., 47 2012).

Fig. 8: Pythium aphanidermatum A. Colonia de 7 días de crecimiento en APD. B. Detalle de anteridio y oogonio. C. Oosporas. D. Esporangios toruloides.

Fig. 9: Pythium dissotocum A. Desarrollo de 7 días en APD. B. Apresorio. 61 C. Esporangios filiformes

Fig. 10: Pythium inflatum A. Esporangio B. Oogonio y anteridio C. 64 Oospora plerótica.

Fig. 11: Pythium sylvaticum A. Esporangio terminal con detalle de septo B-1 67 Esporangios terminales e intercalares.

Fig. 12: Pythium ultimum var. ultimum. A Esporangios intercalares 70

B Esporangio terminal C. Hinchamientos hifales D-E. Anteridios y oospora.

Fig. 13: Pythium ultimum var. sporangiiferum. A) Colonia de 3 días de 72

crecimiento en APD B) formación de la vesícula y pasaje del contenido del esporangio.

Fig. 14: Pythium catenulatum. Detalle de esporangios en cadena.

Fig. 15: Pythium longandrum a: Esporangios catenulados b: esporangios subterráneos c: Esporangios intercalares d: Oogonio con anteridio hipógino e: anteridio hipógino con dos tubos de fertilización; f,g: Oogonio y anteridio con celula anteridial lobada; h, j: Oogonio con célula anteridial larga y longitudinal. A, b y f: bar $=40 \mu \mathrm{m}$; c, e, g y j: bar: $20 \mu \mathrm{m}$ (extraído de Paul, 2001).

Fig. 16: Pythium paroecandrum A Oogonio y anteridios B. Oospora aplerótica.

Fig. 17: Pythium heterothallicum a 1-3 oogonio y anteridio. B 1-2 hinchamientos hifales (de Van der Plaats-Niterik, 1981).

Fig. 18: Pythium nunn A-B Hinchamientos hifales intercalares C. Anteridios y oogonio. D. Oospora.

Fig. 19: Pythium irregulare A Hinchamientos hifales intercalares B-C. Anteridios y oogonio. D. Oospora ornamentada.

Fig. 20: Pythium acanthicum A. Detalle de anteridio y oogonio. B. Oosporas.

Fig. 21: P. periplocum. A 1-4 oogonios ornamentados, b 1-2 esporangios (Van der Plaats Niterink, 1981).

Fig. 22: $P$. periplocum. Oospora ornamentada y anteridio.

Fig. 23: Pythium spinosum. A. Colonia en APG B. Hinchamientos hifales intercalares C. Anteridios y oogonio. D. Oospora ornamentada.

Fig. 24: Phytopythium chamaehyphon. A) Micelio algodonoso tipo

petaloide en APG. B) Oospora. C) Esporangio con papila. D). Esporangio con tubo de descarga.

Fig. 25: Phytopythium vexans: CBS 119.8 a-1-5). Oogonios y anteridios. b1-5). Oogonio con papila y tubo de descarga c-d) Figuras de Bary (1986 citado por Van der plaats-Niterink, 1981). c1-5) Oogonio con anteridio. d 1-9) Esporangios o hinchamientos hifales.

Fig. 26: Phytopythium helicoides. A. Micelio coraloide fino. B-C. Oogonio

y anteridio D y E. esporangio y tubo de descarga, F oospora. 
Fig. 27: Morfología de Phytopythium aff. mercuriale (STEU-U 6207). (a-

d) Esporangio viejo formando tubos germinativos. (e-h) Oogonio rodeado por nudo indefinido de anteridios. Escala bar $=35 \mu \mathrm{m}$ en $(\mathrm{a}-\mathrm{d}) \mathrm{y}(\mathrm{g}-\mathrm{h})$.

Escala bar $80 \mu \mathrm{m}$ en (e-f).

Fig. 28: Phytopythium frezzii sp. nov. A. Oospora. B. Colonia en APD. C

y D. Oogonio y anteridio campaniforme.

Fig. 29: Relación filogenética de Phytopythium frezzi sp. nov usando el método de Neighbor-Joining.

Fig. 30: Relación filogenética de todos los aislamientos usando el método de Neighbor-Joining.

Fig. 31: Patogenicidad en semillas de soja de cepas de $P$. ultimum, $P$. irregulare y $P$. aphanidermatum incubadas a tres temperaturas $(15,25$ y 25 ${ }^{\circ} \mathrm{C}$ ) (según escala propuesta por Jiang et al., 2012).

Fig. 32: Emergencia de plántulas de soja en suelo infestado con $P$. ultimum, $P$. irregulare y $P$. aphanidermatum incubados a 15,25 y $35^{\circ} \mathrm{C}$.

Fig. 33: Tasa de crecimiento de $P$. ultimum, $P$. irregulare y $P .119$ aphanidermatum incubados a 15,25 y $35^{\circ} \mathrm{C}$.

Fig. 34: En los ensayos de sensibilidad in-vitro, izquierda tratamiento con metalaxil, derecha testigo.

Fig. 35: Phytophthora sojae. A) Detalle de Oosporas en hipocótile. B) Esporangios. C) Micelio típico del tipo coraloide. D) Detalle de oogonio conteniendo oospora en su interior.

Fig. 36: Phytophthora sojae. A) y B) Aspecto general de un campo afectado. C) Síntoma de marchitamiento. D) Detalle de la podredumbre basal.

Fig. 37: Distribución de Phytophthora sojae en Argentina. Los números representan 20 localidades donde se recolectaron las muestras. Las letras representan las provincias: BA (BUENOS AIRES) 1 Arrecifes; 2 parcela experimental; 3 Pergamino; 4 El Socorro; 5 M. Ocampo; 6 Ramallo; 7 Rojas; 8 R. Obligado; 9 San Antonio de Areco; 10 Pilar. SFe (SANTA FE) 11 Bigand; 12 Godeken; 13 Hughes; 14 Muñoz; 15 Las Rosas. Cba (CORDOBA) 16 Marcos Juarez; 17 Saira. ER (ENTRE RIOS) 18 Victoria; 19 Villa. Teresita; 20 Gualeguaychu.

Fig. 38: Porcentaje de aislamientos de Phytophthora sojae obtenidos entre 1998-2004, y su interacción con los genes Rps. Blanco: probados en Harrow (Canadá) sobre un grupo de 15 cultivares diferenciales, y 3 líneas experimentales. Negro: probados en Argentina sobre un grupo de 8 cultivares diferenciales.

Fig. 39: Porcentaje de aislamientos de Phytophthora sojae obtenidos en la zona NBA y SEBA entre 2013-2016, y su interacción con los ocho genes Rps.

Fig. 40: Curva de acumulación de genotipos para 93 aislamientos de Phytphthora sojae obtenidos del norte (NBA) y sudeste (SEBA) de la provincia de Buenos Aires entre 2013-2016.

Fig. 41: Cantidad de GML y número de aislamientos por GML en cada localidad, para 93 aislamientos analizados con ocho marcadores microsatélites.

Fig. 42: Cantidad de GML (genotipos multi-locus observados) y número de aislamientos por GML en cada región $($ Norte $=$ NBA y Sur $=$ SEBA) para 93 
aislamientos de Phytophthora sojae analizados con 8 marcadores microsatélites.

Fig. 43: Algoritmo de optimización incluido en la función a-score, para 93165

aislamientos de Phytophthora sojae analizados con ocho marcadores microsatélites

Fig. 44: Grupos de similitudes genéticas determinados por DAPC, para 93166 aislamientos de Phytophthora sojae analizados con ocho marcadores microsatélites.

Fig. 45: Análisis de redes para 93 aislamientos de Phytophthora sojae analizados con ocho marcadores microsatélites. Los diferentes colores indican las localidades y su frecuencia relativa (según la participación en cada nodo). El tamaño de cada nodo es proporcional a la frecuencia de cada genotipo multi-locus en el dataset.

Fig.46: Significación de los porcentajes de la variación por unidad de 203 muestreo. 


\title{
CARACTERIZACIÓN DE ESPECIES DE LA FAMILIA PYTHIACEAE ASOCIADAS AL CULTIVO DE SOJA EN LA PROVINCIA DE BUENOS AIRES
}

\begin{abstract}
RESUMEN
Entre los principales agentes causales de enfermedades de raíces y plántulas de soja se citan a Phytophthora $(P h)$ sojae y Pythium $(P)$ spp. Estos géneros junto con Phytopythium (Phy) fueron reclasificados en el reino Stramenopila. Hasta el presente se han identificado 160 especies de Pythium, pero en la Argentina actualmente solo 22 se hallan descriptas. Las especies del clado K, filogenéticamente distintas del resto de las especies de Pythium, muestran características tanto de este género como de Phytophthora, por lo que se definió un nuevo género, Phytopythium. Pythium produce la pudrición de semillas y raíces, así como el damping off de pre y postemergencia. Ph. sojae causa la podredumbre de la raíz y base del tallo, en todo el ciclo ontogénico del cultivo y es un patógeno que presenta alta variabilidad fisiológica. En Argentina, se determinaron dos razas y varios aislamientos quebraron los principales genes de resistencia. Los objetivos del presente trabajo fueron: a) conocer la diversidad de especies de Pythium y Phytopythium y las razas de Ph. sojae presentes en dos zonas de la provincia de Buenos Aires, b) comprobar su patogenicidad y c) postular medidas de manejo eficientes para Pythium spp. Se muestrearon campos cultivados con soja durante las campañas agrícolas 2013/14, 2014/15 y 2015/16 en el norte (NBA) y sudeste (SEBA) de la provincia de Buenos Aires. Se efectuaron aislamientos a partir de plántulas o plantas afectadas, suelos y granos cosechados. Las especies de Pythium y Phytopythium se caracterizaron e identificaron mediante morfología y métodos moleculares; se comprobó la patogenicidad en ensayos in-vitro e in-vivo. Con tres especies, prevalentes, se probó la respuesta de crecimiento y patogenicidad, frente a distintas temperaturas. Se efectuaron ensayos de manejo con fungicidas curasemillas y mediante el chequeo del gen Rps 1k de resistencia a Ph. sojae. Con todas las especies aisladas y caracterizadas se hicieron estudios filogenéticos. Para Ph. sojae se completó la evaluación de la variabilidad del patógeno de la zona núcleo sojera del período 1998 a 2004. Se determinaron las razas o fórmulas de virulencia de $P h$. sojae existentes en cada zona, mediante un grupo de ocho líneas diferenciales de soja. También se estudió la relación genética entre un grupo de aislamientos provenientes del NBA y otro del SEBA utilizando marcadores microsatélites
\end{abstract}


(SSRs). De plántulas y suelo, del NBA se obtuvieron 181 aislamientos que correspondieron Pythium ultimum, $P$. irregulare, $P$. sylvaticum, $P$. inflatum, $P$. aphanidermatum, $P$. dissotocum, $P$. catenulatum, $P$. longandrum y Pythium sp., y a Phytopythium helicoides, Phy. frezzii sp. nov., Phy. chamaehyphon, Phy. aff. mercuriale y Phytopythium sp. Mientras que del SEBA, se obtuvieron 102 aislamientos, que correspondieron a Pythium ultimum, $P$. irregulare, $P$. sylvaticum y $P$. paroecandrum. De granos cosechados se obtuvieron dos aislamientos del SEBA: P. sylvaticum y P. nunn, y 38 del NBA: $P$. irregulare, $P$. paroecandrum, $P$. aff. heterothallicum, $P$. acanthicum, $P$. periplocum, Phy. vexans y Phy. spp. Las especies que presentaron patogenicidad en soja fueron $P$. ultimum sensu lato, $P$. irregulare, $P$. sylvaticum, $P$. aphanidermatum, $P$. paroecandrum; otras presentaron baja patogenicidad; P. inflatum, P. catenulatum, $P$. longandrum y P. aff. heterothallicum; Phy. helicoides, Phy. frezzii, Phy. chamaehyphon, Phy. vexans, Phy. aff. Mercuriale; resultaron ser no patógenas, P. acanthicun, P. nunn y $P$. periplocum. El fungicida metalaxil, presentó un muy buen nivel de control en comparación con la mezcla de fungicidas carbendazim+tiram y también cuando se lo comparó con difenoconazol y azoxistrobina. Azoxistrobina presentó mejor eficacia que difenoconazol. Las variedades de soja que tenían incorporado el gen Rps $1 \mathrm{k}$ de resistencia a $P h$. sojae no presentaron mayor número de plántulas emergidas que aquéllas que no lo tenían. Entre 1998-2004, en la región núcleo sojera se obtuvieron 193 aislamientos de $P h$. sojae, que fueron probados, 173 con el set de 8 genotipos diferenciales y los 20 restantes, en Canadá con un set expandido de 14 cultivares diferenciales, y tres líneas experimentales. Se detectaron 37 patotipos diferentes, incluyendo 18 razas descritas. Los fenotipos de virulencia no descritos constituían el $24 \%$ de las cepas. La raza 1 fue predominante, seguida de la raza 13. A partir de los 20 aislamientos probados en Canadá en el conjunto ampliado de diferenciales, se describieron 19 patotipos adicionales. Durante el periodo 2013-2016, se obtuvieron 192 aislamientos de Ph. sojae, 124 provenientes del SEBA y 68 del NBA. La raza 1 del patógeno se presentó solo en 4 aislamientos provenientes de plantas infestadas del SEBA $(3,2 \%)$, mientras que en el NBA solo 2 aislamientos provenientes de plantas o sea un 2,9\%. Porcentaje muy bajo en comparación a la prevalencia del 25 \% correspondiente al intervalo 1998-2004. En el SEBA se determinaron 40 fórmulas de virulencia, mientras que en el NBA 33, de las cuales 18 resultaron la misma. Las del SEBA representaron 9 razas conocidas $(1,3,4,9$, $14,25,34,38$ y 43) mientras que en las del NBA representaron $7(1,14,25,34,36,38$ y 43). Tanto en el SEBA como en el NBA, la mayoría de los aislamientos fueron virulentos 
sobre el gen $\operatorname{Rps} 1 \mathrm{a}(88,5 \%$ y $61 \%$ respectivamente); Rps1c $(67,3 \%$ y $61 \%$ respectivamente) y $R p s 1 \mathrm{k}(78,8 \%$ y $58,5 \%$ respectivamente). El gen menos quebrado fue en ambas zonas el Rps 6 con solo el 17,3\% y $15 \%$ respectivamente. La relación genética entre aislamientos de Ph. sojae provenientes de ambas zonas utilizando marcadores SSRs dio como resultado mayor diversidad en el NBA que en el SEBA. Se encontraron diferencias significativas entre localidades y entre muestras dentro de las localidades, pero no hubo diferencia en la composición genética de los aislamientos entre ambas zonas. Con el Análisis Discriminante de Componentes Principales se determinaron seis grupos genéticos, pero no se registró relación entre el origen geográfico de cada aislamiento y el grupo genético al que fue asignado. Los resultados del presente muestreo, las identificaciones realizadas de las especies de Pythium y Phytopythium y la determinación de las razas de $P h$. sojae, significan un aporte al conocimiento de la biodiversidad de estos Oomycetes asociados al cultivo de soja, en gran parte de la provincia de Buenos Aires, lo que será de mucha utilidad para el manejo de las enfermedades que provocan.

Palabras claves: Oomycetes, Glycine max, especies, razas, marcadores microsatélites. 


\title{
CHARACTERIZATION OF THE SPECIES OF THE PYTHIACEAE FAMILY ASSOCIATED WITH SOYBEAN IN BUENOS AIRES PROVINCE
}

\begin{abstract}
Phytophthora sojae $(P h)$ and Pythium $(P)$ spp. cause disease in soybean roots and seedlings. These genera together with Phytopythium (Phy) were reclassified in the kingdom Stramenopila. Up to now, 160 Pythium species have been identified, but in Argentina, only 17 have been described. Clade K species, phylogenetically different from all the Pythium species, show characteristics of both Pythium and Phytophthora. Pythium causes seed and root rot, and pre and post emergence damping off. Ph. sojae causes root and stem rot of soybeans at all growth stages, and is a pathogen that has high physiological variability. In Argentina, two races have been determined, and some isolates have deployed the main resistance genes. The aims of this study were: a) to know the diversity of Pythium and Phytopythium species and Ph. sojae races presented in two zones of Buenos Aires province. b) to check the pathogenicity and c) to postulate efficient management measures of Pythium spp. Soybean production fields were surveyed in the 2013/14, 2014/15 and 2015/16 growing seasons, in north (NBA) and southeast (SEBA) of Buenos Aires province. Isolates were obtained from soybean seedlings and diseased plants, soils and post-harvested soybean grains. Pythium and Phytopythium species were characterized and identified through morphological and molecular methodologies; pathogenicity tests were carried out in-vivo and in vitro. Three prevalent Pythium species were used to check the response to different temperatures. Assays with seeds fungicides were done, as well as tests of the Ph. sojae resistance Rps $1 \mathrm{k}$ gene. With all the species already isolated and identified, phylogenetic studies were carried out. The variability evaluation of $P h$. sojae in the main production soybean area in 1998-2004 period was finished. In each zone, races or virulence formulas of $P h$. sojae were determined with a set of 8 differential soybean lines. In addition, the genetic relationship between a group of isolates from NBA and one of SEBA was studied with SSRs molecular markers. From NBA seedlings and soils, 181 isolates were obtained, which corresponded to Pythium ultimum, P. irregulare, P. sylvaticum, P. inflatum, P. aphanidermatum, P. dissotocum, $P$. catenulatum, P. longandrum and Pythium sp., and Phytopythium helicoides, Phy. frezzii sp. nov., Phy. chamaehyphon, Phy. aff. mercuriale and Phytopythium sp. Meanwhile from
\end{abstract}


SEBA, 102 isolates were obtained, which corresponded to Pythium ultimum, $P$. irregulare, P. sylvaticum and P. paroecandrum. From post-harvested soybean grains, two SEBA isolates were obtained: P. sylvaticum and $P$. nunn, and 38 from NBA: $P$. irregulare, P. paroecandrum, P. aff. heterothallicum, P. acanthicum, P. periplocum, Phy. vexans y Phy. spp. The species with more soybean pathogenicity were P. ultimum sensu lato, $P$. irregulare, $P$. sylvaticum, $P$. aphanidermatum, $P$. paroecandrum, others presented low pathogenicity: P. inflatum, P. catenulatum, P. longandrum and P. aff. heterothallicum; Phy. helicoides, Phy. frezzii, Phy. chamaehyphon, Phy. vexans, Phy. aff. mercuriale; and $P$. acanthicun, $P$. nunn y $P$. periplocum were not pathogenic. Metalaxil fungicide presented a higher level of control compared to the mix carbendazim+tiram, and also to difenoconazol and azoxistrobina. Azoxistrobina was more efficient than difenoconazol. The varieties with the Rps $1 \mathrm{k}$ gene, resistant to Ph. sojae, did not present more emerged plants than the varieties without the gene. Between 1998 and 2004, in the main soybean production area, 193 isolates of $P h$. sojae were collected and tested, 173 with a set of 8 differential genotypes, and the other 20 were tested in Canada with an expanded set of 14 differential cultivars, and three experimental lines. Thirty-seven different pathotypes were detected, including 18 described races. The non-described virulence pathotypes constituted $24 \%$ of the total isolates. Race 1 was prevalent, followed by race 13. Nineteen additional pathotypes were described from 20 isolates tested in Canada with the expanded differential set. During 2013-2016 period, 192 Ph. sojae isolates were obtained, 124 from SEBA and 68 from NBA. Race 1 was only detected in four isolates from SEBA infested plants $(3,2 \%)$, and in only two isolates from plants of NBA $(2,9 \%)$, which is lower than the prevalence of $25 \%$ for the 1998-2004 period. In SEBA, 40 virulence formulas were determined, and 33 in NBA, 18 of which were equal. The SEBA isolates represented nine known races $(1,3,4,9,14,25,34,38$ and 43), whereas the NBA represented seven races $(1,14,25,34,36,38$ and 43). Both in SEBA and in NBA, most of the isolates were virulent on the following genes: Rps 1a $(88,5 \%$ and $61 \%$ respectively), Rps $1 \mathrm{c}(67,3 \%$ and $61 \%$ respectively) and $R p s 1 \mathrm{k}(78,8 \%$ y 58,5 $\%$ respectively). The less deployed gene was in both zones the Rps 6 with only 17,3\% and $15 \%$ respectively. The genetic relationship between $P h$. sojae isolates from both zones using SSRs markers showed greater diversity in NBA than in SEBA. Differences were found between localities and between samples within the same locality, but not in the genetic composition between isolates from both zones. Using the Discriminant Analysis of Principal Components, six genetic groups were determined, but no 
relationship was registered between the geographic origin of the isolates and the genetic group assigned. The results of the present survey, the identification carried out of the Pythium and Phytopythium species, and the race determination of Ph. sojae, signify a great contribution to the knowledge of the biodiversity of these Oomycetes associated with soybean, in most of Buenos Aires province, which is very useful to manage these diseases.

Key words: Oomycetes, Glycine max, species, races, microsats molecular markers. 


\section{INTRODUCCIÓN GENERAL}

La soja (Glycine max (L.) Merr.) es el cultivo oleaginoso (Fam. Leguminosae) más importante del mundo y constituye la principal fuente de proteínas en la dieta humana. Es originaria del este de Asia, se la domesticó en China (1550-1027 a.C) y fue introducida en América, en 1765 por Samuel Bowen, un marinero inglés que visitó China (Hartman et al., 1999).

La Argentina es el tercer país productor de soja después de Estados Unidos y Brasil, y es el mayor exportador de aceite y harina de soja con un $41 \%$ y $36,5 \%$ del mercado internacional respectivamente (Rossi, 2004). En la campaña 2015/16, el área sembrada fue de 20,5 millones de hectáreas y la producción fue de 58,8 millones de toneladas (MAGyP, 2017). A pesar que el cultivo de soja en Argentina data de muchos años, se incrementó a partir de 1970, principalmente debido a la demanda internacional, al desarrollo de cultivares de alto rendimiento, al ingreso de divisas al país, y a los productores.

Las enfermedades constituyen una de las adversidades que más limitan al cultivo de soja (Pioli, 2000). En el mundo se estima que las pérdidas en el rendimiento debido a este problema alcanzan entre el 10 y $15 \%$, siendo en la Argentina entre el 5 y $8 \%$ (Distefano, 2013). Además de afectar el rendimiento, muchas veces se ve afectada la calidad del producto. En los últimos años en Argentina, se ha visto un incremento en la intensidad de las enfermedades en soja (Carmona y Reis, 2012). Entre las posibles causas, se encuentran la siembra directa, el monocultivo, el aumento de densidad de siembra (hasta $20 \%$ ), el uso de cultivares susceptibles, la homogeneidad en el germoplasma y el cambio en el patrón de precipitaciones. La introducción de la siembra directa fue un gran avance tecnológico que le permitió a la Argentina expandir su frontera agrícola, preservando mejor suelos frágiles y a su vez disminuir costos, ya que se evita el laboreo del suelo (Sasal, 2013). Sin embargo una gran desventaja de este sistema es que el uso de insumos es mayor y que los rastrojos pueden constituir fuentes de inóculo de patógenos causantes de diferentes enfermedades; de esta manera, las llamadas "Enfermedades de fin de ciclo" (EFC), la mancha ojo de rana (MOR) y las pudriciones de raíz y tallo se convirtieron en las más importantes (Carmona et al., 2015). Estas últimas son, principalmente ocasionadas por microorganismos del suelo, que afectan a 
los cultivos en diferentes estados ontogénicos. La más común es conocida como “damping off”, provoca la muerte de plántulas, tanto en pre como en post emergencia, lo que puede afectar el establecimiento del cultivo y su rendimiento (Koenning y Wrather, 2010; Hartman et al., 2015). En estadios posteriores aparecen enfermedades tanto o más peligrosas.

El suelo constituye un medio ambiente mucho más complejo que el ambiente aéreo, principalmente debido a las múltiples interacciones de tres componentes bióticos: el hospedante, el patógeno y la microflora, todos ellos influenciados por los componentes abióticos del suelo. En cuanto al hospedante (cultivo de soja) puede ser susceptible y además es muy importante su estado fenológico o de desarrollo. Por ejemplo algunos "pseudohongos" como Pythium principalmente infectan semillas o plántulas jóvenes, mientras que otros como Phytophthora afectan también a plantas adultas. La microflora está constituida por innumerables microorganismos de suelo (bacterias, algas, protozoos, hongos y "pseudohongos"), que afectan la supervivencia y el desarrollo de los patógenos, como consecuencia de interacciones antagónicas (antibiosis, competencia y/o parasitismo). Con relación a los microorganismos patógenos, los que están presentes en casi todos los suelos son denominados "Habitantes del suelo" y aquéllos que están solo en algunos tipos de suelos, que provienen de esporas del exterior o de micelios desarrollados en restos de cultivos o en el suelo, son llamados "Invasores del suelo". La gran mayoría presenta inóculo no móvil, son llevados por herramientas o las raíces crecen hacia ellos. Otros como las Pythiaceae poseen esporas móviles que necesitan agua para su dispersión e infección, por lo cual cualquier manejo del cultivo que favorezca la compactación y acumulación de agua en el perfil, constituirán factores de riesgo para que aparezcan ciertas enfermedades (Grijalba, 2003).

En Argentina las enfermedades de raíces y de plántulas de soja provocan pérdidas de rendimiento estimadas en 90,6 miles de ton. métricas, mientras que las pérdidas por "La podredumbre de la raíz y base del tallo de la soja" (PRBTS) se estiman en 67,9 miles de ton. métricas (Wrather et al., 2010). Las pérdidas en el rendimiento debidas a Oomycetes patógenos comúnmente asociados con la podredumbre de raíces en soja, se estimaron en 1,5 millones de toneladas anuales en EEUU (Rojas et al., $2017 \mathrm{a}, \mathrm{b}$ ).

El damping off y la podredumbre de raíces por Pythium spp. son enfermedades comunes en todas las regiones sojeras de la Argentina; afectan a las plántulas en pre y/o post-emergencia, y a pesar que puede reducir la cantidad de plantas, normalmente no producen pérdidas económicas debido a que el cultivo compensa la falta de plantas. Por 
su parte la PRBTS es una enfermedad ampliamente distribuida en el mundo, donde ocasiona pérdidas de rendimiento en cultivares susceptibles, que puedan llegar a más del 50 \% (Hartman et al., 1999). Predominantemente se presenta en campos en los que el drenaje del suelo es lento y rápidamente se satura durante días, creando las condiciones ambientales ideales para la infección. En la Argentina, hasta 1994 fue considerada como una enfermedad potencial; actualmente se la ha mencionado en las provincias de Córdoba, Santa Fe, Buenos Aires, Entre Ríos, Tucumán y Corrientes (Grijalba y Gally, 2015).

\section{UBICACIÓN TAXONÓMICA DE LA FAMILIA PYTHIACEAE}

Las clasificaciones de los seres vivos en Reinos y dentro de éstos en sus diferentes categorías taxonómicas, han sufrido sucesivas modificaciones a lo largo del tiempo. Inicialmente se basaron en características morfológicas, nutricionales y ecológicas en común, agrupándose en cuatro Reinos: Protista, Monera, Animal y Vegetal. Whittaker (1969), propuso el Reino Fungi, quedando los organismos agrupados en cinco reinos (Alexopoulos et al., 1996) lo que reflejaba mejor las relaciones evolutivas. Luego con las técnicas moleculares y los consiguientes agrupamientos filogenéticos, se constató que no todos los organismos clasificados dentro del reino Fungi están tan cerca en su relación.

La Clase Oomycetes, sufrió sucesivos cambios en su ubicación taxonómica. Debido a la existencia de numerosas diferencias morfológicas y fisiológicas entre éstos y los hongos verdaderos, se los reubicó en el Reino Protoctista (Margulis y Schwartz, 1988; Margulis et al., 1989) y en el Reino Chromista, junto a las algas con clorofila a y c (Chrysophyta y Phaephyta) (Cavalier-Smith, 1986). En este contexto fueron denominados "pseudohongos" al ser considerados dentro de la Subdivisión Pseudofungi, Phylum Heterokonta del Reino Chromista (Kirk et al., 2001). Paralelamente Dick (2001) los ubicó en el Reino Stramenopila que incluye organismos con características morfológicas diversas, que comparten como rasgo ancestral común la presencia de zoosporas biflageladas, con dos flagelos distintos (heterokontas).

Entre las principales características que diferencian a los Oomycetes de los organismos integrantes del reino Fungi (hongos verdaderos) se halla: a) la presencia de pared celular compuesta por celulosa y beta glucanos en lugar de quitina fúngica (Bartnicki-Garcia, 1969; Bartnicki-Garcia y Wang, 1983), b) esporas biflageladas (zoosporas) (Desjardins et al., 1969; Hemmes, 1983), c) no sintetizan esterol (Barr, 1983; Bartnicki-Garcia, 1987; Erwin y Ribeiro 1996), d) la presencia de tabiques en las hifas es 
rara (micelio cenocítico) pero se forman normalmente para delimitar estructuras reproductivas o en micelios viejos; los núcleos están dispersos en el citoplasma; difiriendo de la mayoría de los hongos que tienen micelio tabicado (a excepción de los Zygomycetes, también cenocíticos), e) presentan crestas mitocondriales tubulares, f) acumulan reservas como beta 1-3 glucanos (micolaminarinas), g) a diferencia de los hongos verdaderos, que son haploides en la etapa de alimentación y la mayor parte de su ciclo de vida, las hifas de Oomycetes se componen de células diploides, produciéndose la meiosis en el interior de los gametangios (Sansome 1961, 1965; Dick, 2001), h) tienen diferente sensibilidad hacia los fungicidas convencionales (Latijnhouwers et al., 2003), i) poseen diferente composición de aldioles y polioles (alcoholes con dos o más hidroxilos), y j) presentan diferente vía de síntesis de la lisina y del triptofano por acción de la triptofano sintetasa.

Estudios genéticos y bioquímicos han corroborado estas diferencias entre Oomycetes y "hongos verdaderos" (Wang y Bartnicki-Garcia, 1980; Barr, 1992; Brasier, 1992; Baldauf et. al., 2000; Latijnhouwers et al., 2003).

Actualmente, coexisten las dos clasificaciones que ubican a los Oomycetes en los Reinos Chromista y Stramenopila, aunque la tendencia es considerarlos como pertenecientes al Reino Stramenopila (Palmucci, 2015). Ambos términos, Oomycetes (Winter, 1880) y Peronosporomycetes (Dick, 2001) son considerados como sinónimos (Kirk et al., 2008), sin embargo, la mayoría de los investigadores prefieren continuar utilizando el término Oomycetes para referirse a este grupo (Kirk et al., 2008; Lévesque, 2011).

Según Dick (2001), dentro de la Subclase Peronosporomycetidae hay dos órdenes: Peronosporales que incluye parásitos obligados de vegetales y Pythiales, que incluye tanto parásitos como saprófitos. Ambos órdenes se diferencian principalmente por sus zoosporangióforos, los cuales están bien diferenciados en Peronosporales, mientras que en Pythiales raramente lo están.

En el orden Peronosporales se ubican dos familias, Peronosporaceae y Albuginaceae. La primera, causante de los mildius que afectan el follaje y los frutos de numerosos hospedantes, incluye los géneros Plasmopara J. Schröt (Plasmopara viticola, mildiu de la vid); Peronospora Corda (P. manshurica, mildiu de la soja; $P$. destructor, mildiu de la cebolla); Bremia Regel (B. lactucae, mildiu de la lechuga) entre otros y la segunda a las royas blancas (Thines y Spring, 2005) con los géneros Albugo (Pers.) Rousell, Pustula y Wilsoniana (A. candida agente causal de la roya blanca de las crucíferas., Wilsoniana spp. afecta verdolaga y amarantáceas y Pustula spp. a compuestas 
como Pustula helianthicola sinónimo A. tragopogonis, que causa la roya blanca del girasol).

En el orden Pythiales, se hallan la familia Pythiaceae, donde se encuentran los géneros Pythium Pringsh y Phytophthora de Bary y la familia Pythiogetonaceae, con el género Pythiogeton Minden (Dick, 2001; Huang et al., 2013).

El género Pythium establecido por Pringsheim en 1858 fue dividido por Lévesque y de Cock (2004) en 11 clados, basados en análisis moleculares. Estos clados están bien relacionados con las características morfológicas. En particular, se observó que las especies del clado K eran filogenéticamente distintas del resto de las especies de Pythium y mostraban características combinadas tanto de Pythium como de Phytophthora por lo que se estableció el nuevo género Phytopythium.

Durante muchos años, considerando sus características morfológicas y nutricionales, el género Phytophthora ha sido ubicado taxonómicamente en el orden Pythiales junto con Pythium y géneros afines. Estudios moleculares han relacionado a las especies de Phytophthora usando uno o pocos locus genéticos, predominantemente la región ITS del ADN ribosómico nuclear y la citocromo oxidasa I y II de la mitocondria, y proponen una filogenia cercana con los géneros que producen los mildius, del orden Peronosporales y ubican a las especies en 10 grupos (clados) (Fig. 1) dentro del género (Kroons et al., 2012). Pero los investigadores, han sido incapaces de resolver las relaciones evolutivas más profundas entre los clados (Beakes y Sekimoto, 2009; Thines et al., 2009; Hulvey et al., 2010; Runge et al., 2011; Lamour, 2013; Beakes y Thines, 2016). Para completar estos estudios, se han usado múltiples locus tanto del genoma nuclear como mitocondrial (Martin y Tooley, 2003; Ivors et al., 2004; Kroon et al., 2004; Villa et al., 2006; Donahoo et al., 2006; Hulvey et al., 2010; Runge et al., 2011; Martin et al., 2012; Kroon et al. 2012; Beakes y Thines, 2016), y el esquema taxonómico presentado (Fig. 2) refleja que las Peronosporaceae incluyen actualmente a los mildius y a los géneros Halophytophthora, Phytophthora y Phytopythium e indican que Phytophthora está estrechamente relacionado con los mildius y es parafilético con respecto a ellos. Por todo ello, es probable que en los próximos años, se realice un nuevo reordenamiento de los géneros en los órdenes Peronosporales y Pythiales. 


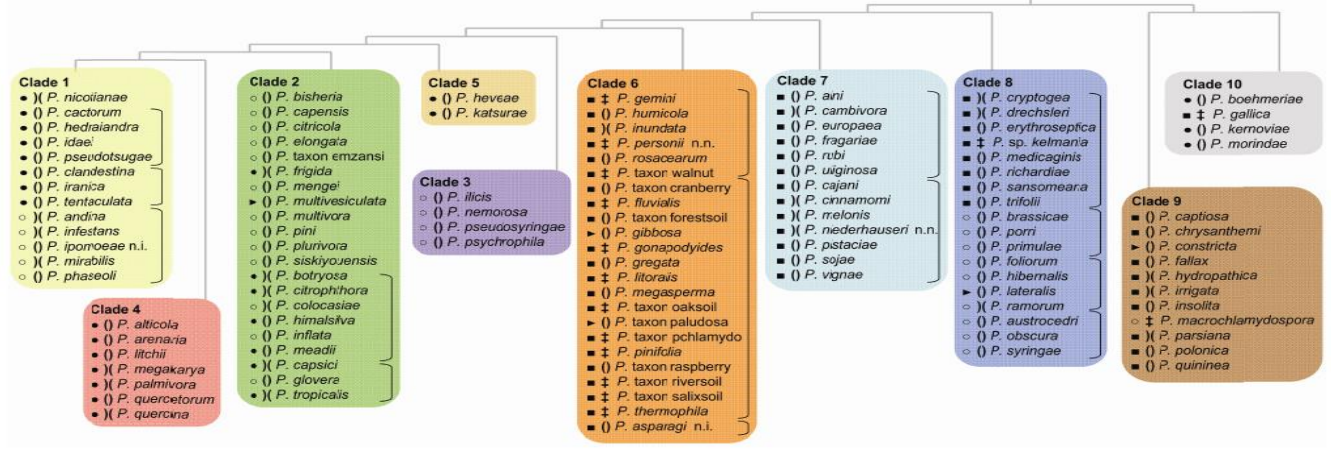

Figura 1. Especies y clados distinguidos en el género Phytophthora. Ph. sojae se incluye en el clado 7 (Kroon et al., 2012).

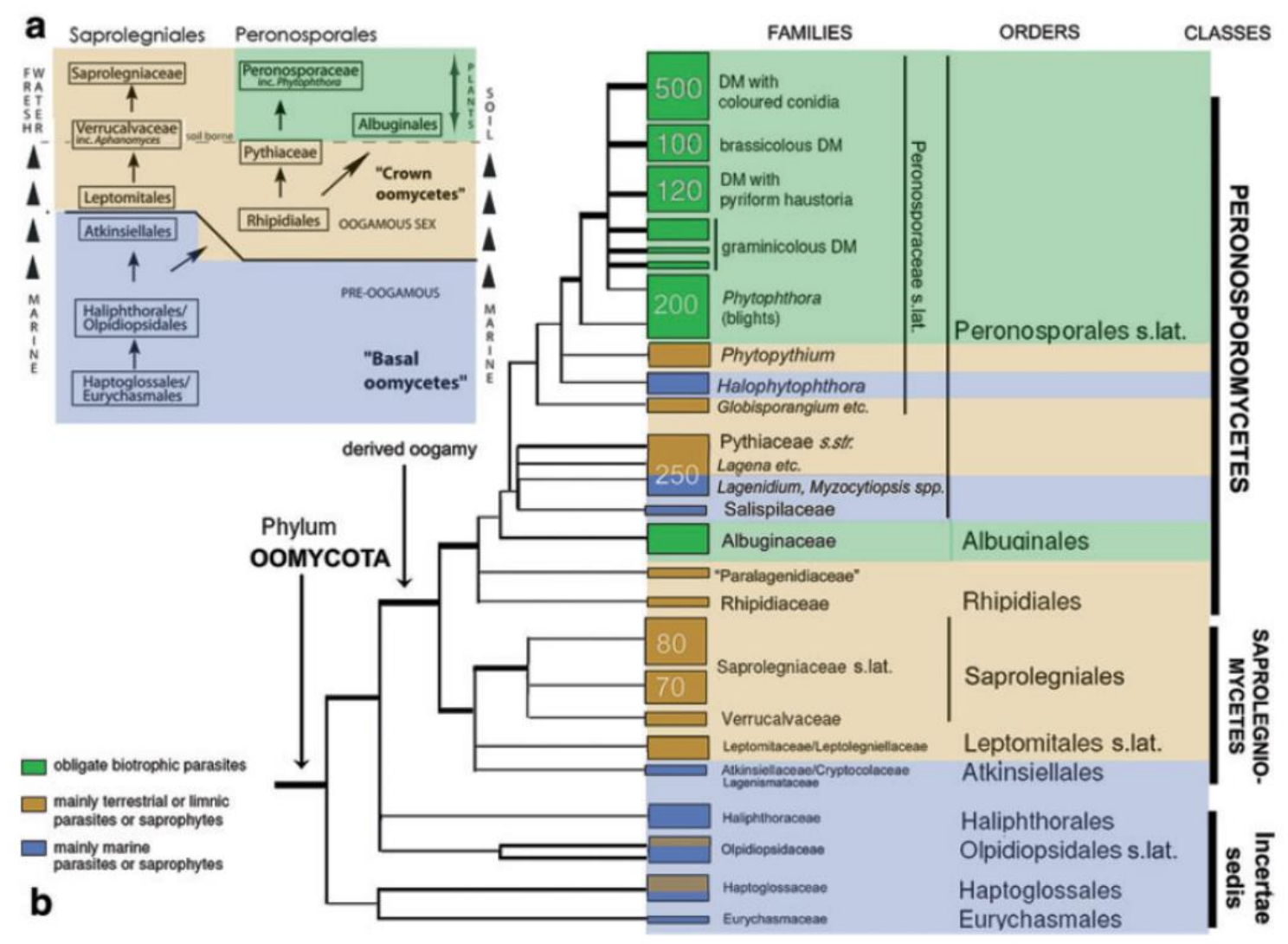

Figura 2. Diagrama resumido de la filogenia de los Oomycetes. (a) Diagrama resumido del probable camino evolutivo de Oomycotas (b) Árbol fílogenético esquemático mostrando los principales clados taxonómicos indicando la diversidad taxonómica (números en los cuadros) y la ecología predominante (Beakes y Thines, 2016). 


\section{CARACTERIZACIÓN MORFOLÓGICA DE LOS GÉNEROS Pythium,}

\section{Phytophthora Y Phytopythium.}

Los géneros Pythium, Phytophthora y Phytopythium están formados por talos con hifas cenocíticas (no tabicadas). Solo en talos viejos o para delimitar una estructura reproductiva se forma algún septo. Poseen mecanismos de reproducción de tipo asexual y sexual. Los diferentes tipos de estructuras vegetativas y reproductivas permiten la identificación de las especies. El lugar de formación de las zoosporas y su modo de liberación son las principales características diferenciales entre los géneros Pythium y Phythophthora (Frezzi, 1956, 1977; Erwin y Ribeiro, 1996; Palmucci, 2015).

Las especies de Pythium se caracterizan por un rápido crecimiento del micelio. Entre las principales estructuras que forman se encuentran (van der Plaats-Niterink, 1981), Vegetativas: a) Apresorio: célula terminal o intercalar que sirve para la fijación a la pared del hospedante; b) Clamidosporas: se forma a partir de la célula de una hifa o de una espora asexual, en posición terminal o intercalar. Presenta una doble pared. Se comporta como estructura de resistencia, pudiendo sobrevivir por largos períodos. Reproductivas asexuales: a) Esporangio: estructura con contenido citoplasmático que al madurar forma un tubo de pasaje a través del cual se vacía en una vesícula, dentro de la cual da lugar a la formación de las esporas asexuales (zoosporas). Puede ser a) globoso, limoniforme, subesférico o b) filamentoso a veces lobulado o toruloso. De posición terminal o intercalar; b) Esporangióforo: parte de la hifa que da origen al esporangio; c) Vesícula: proyección del contenido del esporangio, esférica o subesférica rodeada por una tenue membrana, continuación de la membrana interna del zoosporangio. En su interior se produce el clivaje del citoplasma formándose las zoosporas que a su madurez son liberadas por la ruptura de la membrana. Reproductivas sexuales: a) Oogonio: gametangio femenino que contiene la oósfera, la cual es fertilizada por la célula anteridial, dando lugar a la formación de la oospora, terminal o intercalar. La pared puede ser ornamentada o lisa. b) Anteridio: gametangio masculino de menor tamaño que el oogonio. En las distintas especies se diferencian en el número, forma y lugar de inserción (hifas del mismo talo o no, de la misma hifa o no); c) Oospora: estructura de resistencia (o de reposo) a condiciones adversas del medio que puede permanecer dentro del tejido muerto del hospedante infectado o en el suelo y que usualmente germina produciendo un esporangio. 
En las especies de Phytophthora el micelio crece más lentamente y es más ramificado, en algunos casos de tipo coraloide, toruloso, con protuberancias que permiten distinguirlo de otras especies. Esto puede variar considerablemente en los diferentes medios de cultivo y a veces en un mismo cultivo (Frezzi, 1977). Entre las principales estructuras que forma, hallamos (Erwin y Ribeiro, 1996): Vegetativas: a) Hinchamientos hifales ("swellings"): engrosamiento del diámetro de una hifa que puede ser descripto como globular, esférico, cilíndrico, tubular, coraloide o irregular. Se forman en los puntos de ramificación y no están separadas del micelio cenocítico por un tabique. b) Clamidosporas: estructuras de resistencia o reposo. Reproductivas asexuales: a) Esporangio: generalmente esférico, globoso, limoniforme, obturbinado; con presencia o no de papila. Al madurar el contenido citoplasmático se "diferencia" y forma las zoosporas cuya liberación se produce por ruptura de la membrana en la región papilar. b) Esporangióforo: parte de la hifa que da origen al esporangio. Su longitud, presencia o no, y tipo de ramificación, caducidad y tipo de proliferación, tienen valor taxonómico. $\underline{\text { Reproductivas sexuales: }}$ se consideran las mismas estructuras enunciadas anteriormente para Pythium.

En ambos géneros las esporas asexuales son zoosporas secundarias monomórficas, reniformes, con flagelos morfológicamente diferentes (heterokontas) de largo variable, dirigidos en sentidos opuestos, insertos en un surco lateral profundo (Alexopoulus et al., 1996). El flagelo anterior es barbulado o pleuronemático, con mastigonemas (finas fibrillas de $0,5-2 \mu \mathrm{m}$ ) y el posterior es liso de tipo látigo, con movimiento retráctil. La presencia de flagelos permite que la zoospora nade en las películas de agua sobre las hojas, en el agua del suelo, en medios hidropónicos o reservorios naturales de agua. Luego de un tiempo de nadar libremente en el agua, las zoosporas se orientan hacia el hospedante por quimiotaxismo, retraen sus flagelos, y secretan una matriz mucilaginosa la cual las adhiere a la superficie (enquistan) (Fry y Grünwald, 2010).

En algunas especies los esporangios germinan directamente para producir tubos germinativos, en este caso, los esporangios se denominan "conidios". En otras especies, los esporangios pueden germinar directamente o "indirectamente" para formar zoosporas, produciéndose generalmente a temperaturas más frías (Alexopoulos et al., 1996; Erwin y Ribeiro, 1996; Fry y Grünwald, 2010).

La reproducción sexual se caracteriza por la producción de oosporas. Éstas contienen los núcleos $2 \mathrm{n}$ como resultado de la unión entre los núcleos de dos 
gametangios: el oogonio y el anteridio. Mediante el mecanismo de contacto gametangial, un núcleo anteridial se transfiere al oogonio a través de un tubo de fertilización y se fusiona con un núcleo oogonial u oósfera. La meiosis ocurre en el gametangio antes de la fertilización (Alexopoulos et al., 1996; Erwin y Ribeiro, 1996). Las oosporas, que poseen paredes gruesas, son estructuras de resistencia a las condiciones adversas del ambiente (temperatura-humedad-agroquímicos) que sirven para la supervivencia y como estado de reposo de la especie (Shokes y McCarter, 1979; Pickett-Popoff y Panter, 1994; Martin y Loper, 1999; Sutton et al., 2006). En unas pocas especies, como por ejemplo $P$. tracheiphillum Matta y P. dimorphum Hendrix et Campbell, las clamidosporas de paredes gruesas, pueden también tener la misma función (Schroeder et al., 2013).

Los Oomycetes presentan especies homotálicas (desarrollan anteridios y oogonios en el mismo cuerpo vegetativo o micelio), o heterotálicas (requieren la participación de diferentes tipos de cruzamiento o "mating types" compatibles para reproducirse sexualmente (Campbell y Hendrix, 1967; Papa et al., 1967; van der Plaats-Niterink, 1981; Dick, 1990; Martin, 1995).

El elevado y creciente número de especies de Pythium, Phytophthora y Phytopythium, la variabilidad en los caracteres morfológicos, el escaso desarrollo de estructuras en algunas especies, la existencia de especies atípicas, las dificultades en la esporulación e insuficientes conocimientos para la identificación, confirman que en ciertos casos es necesaria la aplicación de estudios moleculares y filogenéticos para complementar los estudios morfológicos (Lévesque et al., 1998; Munford et. al., 2006).

La secuenciación del ADN y los bancos de secuencias genéticas, permitieron identificar especies por similitud al comparar secuencias propias. Si la secuencia de un gen particular o región del ADN, es similar o altamente similar a otra secuencia de confiable identificación (Type o Neotype), de un banco de genes, permite establecer que el aislamiento pertenece a la misma especie. Uno de los primeros genes utilizado, altamente conservado, fue el 5.8S rADN entre los espaciadores ITS1 e ITS2. Esta región se amplifica para secuenciar el $\mathrm{ADN}$ en la mayoría de las especies con iniciadores ("primers") universales (White et al., 1990). Posteriormente comenzaron a utilizarse otros genes o regiones, nucleares o mitocondriales. Para Pythium el gen codificante de la subunidad $\beta$ de la tubulina y los genes codificantes de la citocromo oxidasa 1 y 2 (Cox I y Cox II). Para Phytophthora: el gen codificante de la subunidad $\beta$ de la tubulina, el gen codifícante de la subunidad $\alpha$ del factor de elongación de la traducción 1 (eEF1a), y los genes mitocondriales, Cox I y Cox II (Martin y Tooley, 2003). Actualmente se halla 
secuenciado el genoma de Ph. sojae de 95 mb (Tyler et al., 2006) y el de Pythium ultimum de 42,8 mb (Lévesque et al., 2010).

Los análisis filogenéticos basados en secuencias de ADN, permiten agrupar a las especies y la asignación de individuos desconocidos a una especie conocida. Varios autores (Guindon y Gascuel, 2003; Lévesque y de Cock, 2004; Paul et al., 2008) han introducido modificaciones agrupando a las especies, y definiendo diferentes agrupamientos (clados). Los primeros trabajos fueron efectuados por Matsumoto et al. (1999), quienes mediante el análisis de secuencia de ITS del rADN comprobaron la relación filogenética de 30 especies de Pythium. Cooke et al. (2000), analizaron de la misma forma 50 especies de Phytophthora y propusieron ocho agrupamientos. Posteriormente Martin y Tooley (2003) estudiaron la filogenia de 27 especies de Phytophthora y de 24 especies de Pythium en base a los genes Cox I y Cox II, y Lévesque y de Cock (2004), realizaron el estudio filogenético de 116 especies de Pythium agrupándolas en 11 clados (A-K). Por su parte Gallegly y Hong (2008), relacionaron caracteres morfológicos con estudios moleculares (rADN Fingerprint Analisys) y Blair et al. (2008) elaboraron la filogenia de 82 especies de Phytophthora y dos de Pythium para interpretar la historia evolutiva del género, apoyada en la utilización de siete genes nucleares (28S rADN, 60S rADN L10, $\beta$ tubulina, factor de traducción y elongación $1 \alpha$, enolasa) y dos ribosomales (Cox I, Cox II), obteniendo diez agrupamientos. Recientemente, Kroon et al. (2012) ampliaron los estudios de Cooke et al. (2000) usando genes nucleares y mitocondriales. Actualmente el proyecto "Barcode of life" desarrolla un sistema de identificación basado en el ADN que puede catalogar a todas las especies (http://www.barcodeoflife.org/content/partners). Los códigos de barras de ADN utilizan un pequeño fragmento de $\mathrm{ADN}$ de un organismo (una porción de un solo gen-para identificar la especie a la que pertenece el organismo).

El género Phytopythium Abad, de Cock, Bala, Robideau, Lodhi y Lévesque (Bala et al., 2010), posicionado entre Pythium y Phytophthora en el Orden Peronosporales, familia Pythiaceae (de Cock et al., 2015), incluye especies de Pythium anteriormente ubicadas en el clado K (Lévesque y de Cock, 2004). Las especies de Pythium similares a Phytophthora y que se caracterizan por una fase biotrófica extendida durante la colonización de plantas, por ejemplo Pythium vexans se vieron a menudo como el vínculo entre los dos géneros y parecían justificar la inclusión de ambos dentro de las Pythiaceae. Sin embargo, recientes investigaciones moleculares indican que estas 
especies son distintas de los dos géneros y son el grupo hermano de un clado que contiene Halophytophthora, Phytophthora y los mildius (Hulvey et al., 2010).

\section{CARACTERIZACIÓN DEL CULTIVO DE SOJA EN LAS ZONAS EN ESTUDIO}

En la Argentina más del $82 \%$ de la soja se produce en la subregión Pampeana Norte (provincias de Córdoba, Entre Ríos, central y sur de Santa Fe, norte de Buenos Aires y norte de La Pampa). Un 11,8 \% adicional se produce en la región Noreste y 5,5 \% en la región Noroeste (Ploper, 2004).

Las regiones sojeras se han dividido de acuerdo a características agroclimáticas (Fig. 3 A-B). De acuerdo con la duración del ciclo vegetativo, como consecuencia de sus requerimientos fotoperiódicos y térmicos, los distintos cultivares de soja se han reunido en doce grupos de precocidad decreciente, escala de 000 a X, siendo las sojas del grupo 000 de ciclo más corto y las X muy largo. En cada lugar cualquiera sea su grupo, la satisfacción de las necesidades biometeorológicas, no se refleja en comportamientos fenológicos tan diferentes (Fig 3.C). El cultivo de soja en la región del Sudeste de la provincia de Buenos Aires (SEBA) comparada con la región Norte de la misma provincia (NBA) es relativamente nueva como lo demuestra la Fig. 3. D (Pascale y Damario 2004). 

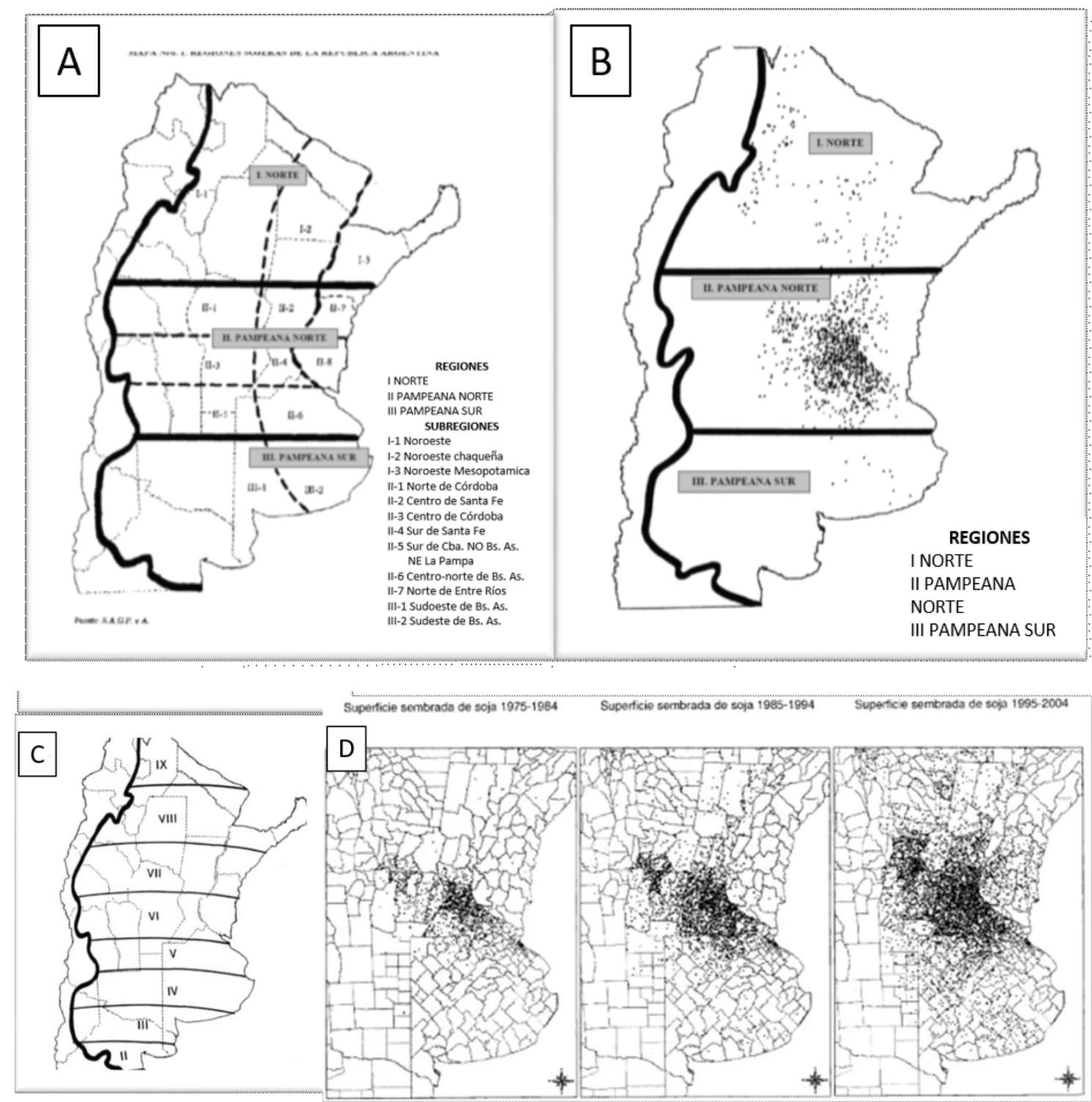

Figura 3. Caracterización del cultivo de soja en las zonas argentinas. A. División de las regiones según características agroclimáticas. B. Regiones sojeras de la Republica Argentina. C. Regiones sojeras de la Republica Argentina. Franjas latitudinales de los grupos de madurez de la soja en la Argentina. D. Variación de la superficie promedio sembrada de la Región pampeana 1975-2004. Extaído de Pascale y Damario, 2004 e INTA, 1997.

La región SEBA pertenece a la región sojera 3, pampeana Sur (Fig. 3 B), se extiende al sur de la bahía de Samborombón y desde la costa hasta los partidos de Azul y Benito Juárez, totalizando una superficie aproximada de $60.000 \mathrm{~km}^{2}$. Es una región de clima subhúmedo-húmedo con deficiencias estacionales de agua en invierno y verano. El clima es templado, con precipitaciones medias de $850 \mathrm{~mm}$ anuales que disminuyen de este a oeste, y vientos predominantes del este y noreste. La temperatura media anual es de $13,7^{\circ} \mathrm{C}$; la máxima media anual es de $22{ }^{\circ} \mathrm{C}$ y la mínima media anual llega a $8,1^{\circ} \mathrm{C}$ (Sá Pereira, 2008), presentando baja amplitud térmica debido a su proximidad al mar. En 
líneas generales la topografía es plana, ligeramente ondulada e interrumpida por el sistema serrano de Tandilia. El periodo libre de heladas va desde principios de noviembre hasta mediados de abril, habiéndose registrado heladas una vez cada siete años en los meses de marzo y noviembre. La principal limitante edáfica está constituida por la tosca y la alcalinidad en profundidad.

La región NBA pertenece a la región sojera 2, Pampeana Norte (Fig. 3 B). La Región Pampeana incluye las tres provincias más importantes del país, Buenos Aires, Córdoba y Santa Fe. La precipitación anual disminuye de este a oeste, variando a partir de $1.000 \mathrm{~mm}$ en el este a $800 \mathrm{~mm}$ en el oeste. Esta región es una gran planicie de relativamente poca altitud sobre el nivel del mar (las altitudes de esta llanura oscilan desde el nivel $0 \mathrm{~m}$ del mar-océano al Este y, hasta aproximadamente los $500 \mathrm{msnm}$ en sus áreas occidentales donde pasa a ser una penillanura. La temperatura media anual es de $16,8{ }^{\circ} \mathrm{C}$; la máxima media anual es de $23{ }^{\circ} \mathrm{C}$ y la mínima media anual llega a $10,8{ }^{\circ} \mathrm{C}$ (INTA, 1997). El norte de la provincia de Buenos Aires se caracteriza por un uso intensivo del suelo y por la continuidad de cultivos agrícolas, desplazando en muchos casos a la ganadería a los sectores de menor aptitud, y reduciendo la rotación agrícola-ganadera a secuencias agrícolas permanentes. Este avance de la agricultura, basado fundamentalmente en el cultivo de soja, plantea la amenaza de un balance negativo de carbón o edáfico, lo que puede afectar la sustentabilidad del sistema. Para revertir o atenuar la problemática planteada, se considera fundamental, además de prácticas como la siembra directa y la fertilización, el incremento de la proporción de gramíneas en los sistemas de producción (Bardín, 2010).

\section{ESTUDIOS EFECTUADOS EN ARGENTINA}

Mariano Frezzi, investigó sobre Pythium y Phytophthora entre los años 1937 y 1970, y ello se vió plasmado en sus libros -Frezzi, 1950, 1956 y 1977-, en los que realizó una completa caracterización morfológica de las especies, con detallados dibujos. Posteriormente hubo un gran vacio en el estudio de esta temática. En 2015 se efectúo la caracterización de especies fitopatógenas de Pythium de cultivos intensivos (Palmucci, 2015, Grijalba, 2015), pero en cultivos extensivos no son muchas las citas. Pastor et al. (2005) realizaron nuestreos desde Chaco hasta el Sur de la provincia de Buenos Aires, determinando la diversidad de Pythium spp. en suelos, pero nada dicen de la patogenicidad de las especies encontradas sobre cultivos extensivos. Con relación a soja, 
Vallone y Giorga (1997), Pastor et al. (2011) y Grijalba et al. (2011), citan pocas especies aisladas de la zona núcleo.

En el caso de Ph. sojae se destacan los estudios realizados por Dora Barreto y colaboradores en la década del' 90, principalmente sobre la determinación de razas, también de la zona núcleo sojera (Barreto et al., 1991, 1995, 1998 a, b; Barreto y Vallone, 1997), estudios que continuaron otros investigadores (Ploper et al., 1998, 1999; Gally et al., 2007; Grijalba et al, 2011, 2014). En relación al sudeste bonaerense, si bien la enfernedad ha sido observada en lotes comerciales (Ridao et al., 2005) la primera determinación de razas, con gran virulencia, se realizó en 2011 (Grijalba et al.).

De todo lo expuesto se observa que: de acuerdo con la bibliografía internacional, hasta el presente se han descrito 142 especies de Phytophthora y 160 especies de Pythium (Abad et al., 2012, Abad, 2014). En Argentina se han citado 22 especies de Pythium (Frezzi, 1956; Palmucci, 2015), dos de Phytopythium (Pythium clade K) y 21 especies patógenas de Phytophthora (Frezzi, 1950, 1957; Palmucci, 2015) aisladas de plantas enfermas. Dieciseis especies de Pythium fueron aisladas en la provincia de Córdoba y 9 en la provincia de Buenos Aires (Frezzi, 1956; Palmucci, 2015). Es así que, frente a la diversidad de especies conocidas en el mundo y a la falta de continuidad de los trabajos realizados sobre todo en los últimos años en el país, es esperable que existan enfermedades ocasionadas por distintas especies de Pythium, y nuevas razas de Ph. sojae, aún no diagnosticadas en el cultivo de soja, tanto en el NBA como en el SEBA y en correspondencia planificar medidas de manejo adecuadas.

A tal efecto se propone en el presente trabajo un muestreo dirigido con el objetivo de actualizar las especies de Pythium y Phytopythium asociadas al cultivo de la soja en dichas zonas y aislar cepas de $P h$. sojae para conocer su virulencia y comparar la relación genética entre aislamientos provenientes del NBA y SEBA utilizando, set de diferenciales y marcadores microsatélites.

El conocimiento de estos microorganismos y su distribución será de utilidad para estudios epidemiológicos, de comportamiento de genotipos, de estrategias de manejo, entre otros. La información lograda será de relevancia no solo en el ámbito nacional y regional, sino además un aporte al conocimiento global sobre estos organismos de gran importancia fitopatológica. A tal efecto se plantean las siguientes hipótesis y objetivos de trabajo: 


\section{HIPOTESIS}

- Una gran diversidad de especies de Pythium y Phytopythium, están asociadas al cultivo de soja en la provincia de Buenos Aires, y ésta varía entre las zonas geográficas muestreadas: norte (NBA) y sudeste (SEBA).

- Existen nuevas razas de $P h$. sojae que ampliarían aún más el panorama sanitario del cultivo de la soja en las zonas en estudio.

- Las especies de Pythium prevalentes pueden ser manejadas eficientemente con fungicidas no específicos a los Peronosporomycetes y con el gen Rps 1k de resistencia a $P h$. sojae para evitar la resistencia al fungicida metalaxil.

\section{OBJETIVOS}

\subsection{OBJETIVO GENERAL}

- Conocer la diversidad de especies de Pythium y Phytopythium, asociadas al cultivo de soja y las nuevas razas de Phytophthora sojae (Peronosporomycetes) presentes en dos zonas sojeras de la provincia de Buenos Aires, para actualizar dichos patosistemas en Argentina y así contribuir al manejo sustentable de las enfermedades que ocasionan.

\subsection{OBJETIVOS ESPECÍFICOS}

- Muestrear lotes de soja con síntomas de enfermedades ocasionadas por Oomycetes de suelo en las zonas SEBA y NBA.

- Describir y caracterizar las especies de Pythium y Phytopythium aisladas, mediante sus caracteres culturales, morfológicos y biométricos (estructuras vegetativas y estructuras reproductivas sexuales y asexuales).

- Comprobar la patogenicidad de las especies de Pythium y Phytopythium aisladas y determinar las razas o fórmulas de virulencia específicas de $P h$. sojae.

- Utilizar información complementaria de secuencias de rADN cuando sea necesario definir identificaciones de las especies complejas o nuevas, y construir árboles filogenéticos.

- Proponer medidas de manejo eficientes, para las especies de Pythium prevalentes. 


\section{MATERIALES Y MÉTODOS \\ (Comunes)}

\section{MUESTREO DE CAMPOS}

Los muestreos sistemáticos de los lotes comerciales de soja con plantas enfermas fueron llevados a cabo en todos los casos de forma dirigida, con la ayuda de los conocimientos de técnicos y productores de cada zona. Se realizaron durante las campañas agrícolas 2013/14, 2014/15 y 2015/16 en las regiones NBA y SEBA. En total se evaluaron más de 85 lotes y se recibieron muestras de suelo de otras áreas no visitadas. Las plantas muestreadas se encontraban desde estado vegetativo cotiledonar, $\mathrm{VC}$, hasta en estados reproductivos, R4-R7 (Fehr y Caviness, 1977).

Durante la campaña agrícola 2013/14 se muestrearon 11 lotes de producción de cuatro localidades (Fontezuela, Pergamino, Rojas y Germania) del NBA. Mientras que del SEBA se tomaron muestras de 15 lotes de producción y parcelas experimentales de tres localidades (Necochea, Balcarce y General Pirán). En la campaña agrícola 2014/15 fueron 10 las localidades del NBA (Fontezuela, Pergamino, Rojas, Chacabuco, Alberti, Gorostiaga, Mechita, Capitán Sarmiento, Arrecifes y Rancagua) donde se muestrearon 27 lotes de producción y parcelas experimentales, y se recibieron muestras de plantas de Colón y plántulas con damping off de Villaguay (Entre Ríos); se solicitó además muestras de suelo de dos lotes de producción donde se observó la sintomatología típica. Mientras que del SEBA se muestrearon cinco localidades (Necochea, Lobería, Balcarce, Bosch y El Moro) tomando muestras de 21 lotes de producción y parcelas experimentales (Fig. 4).

De cada lote donde se observó damping off, marchitamiento y podredumbre basal del tallo, se extrajeron al menos 50 plantas con síntomas y se recolectó el suelo alrededor de las plantas afectadas. Las plántulas o plantas con síntomas pero que presentaron duda sobre la presencia de Phytophthora, se pasaron por el Phytophthora ImmunoStrip ${ }^{\circledR}$, que es una herramienta preliminar para la determinación rápida del género. Las plantas y plántulas recolectadas, se mantuvieron en condiciones de baja temperatura $\left(6-10^{\circ} \mathrm{C}\right) \mathrm{y} \mathrm{se}$ procesaron dentro de las 48 a 72 horas para obtener los aislamientos. 


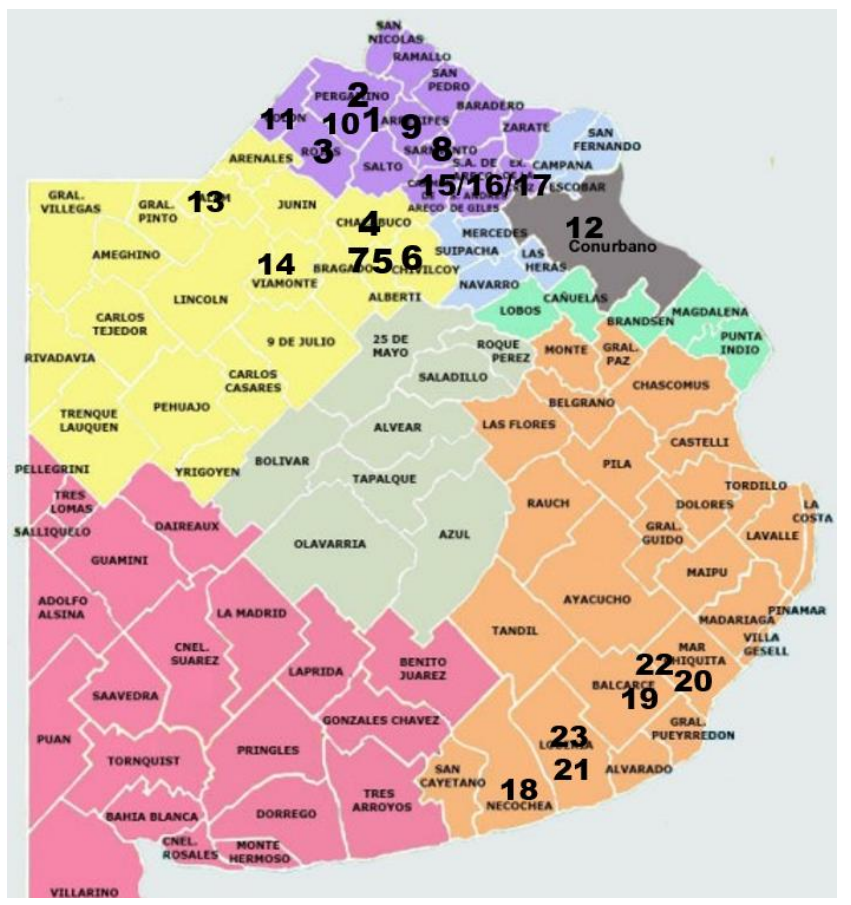

Figura 4. Mapa de la provincia de Buenos Aires, los números indican las localidades muestreadas entre 2013-2016. NBA: 1 Fontezuela, 2 Pergamino, 3 Rojas, 4 Chacabuco, 5 Alberti, 6 Gorostiaga, 7 Mechita, 8 Capitán Sarmiento, 9 Arrecifes, 10 Rancagua, 11 Colon, 12 FAUBA, 13 Germania, 14 Los Toldos, 15 Solis, 16 S.A. de Areco, 17 Villa Lía. SEBA: 18 Necochea, 19 Balcarce, 20 General Pirán, 21 Lobería, 22 Bosch y 23 El Moro.

\section{GRANOS DE SOJA POSCOSECHA}

Durante las campañas 2014/15 y 2015/16, se evaluó la transmisión por granos de soja poscosecha (semillas). La primera campaña se muestrearon cuatro lotes comerciales de la localidad de Necochea (SEBA) y en la segunda, un lote comercial de cada localidad: Los Toldos, Pergamino, Solís, San Antonio de Areco, Villa Lía, Capitán Sarmiento (NBA) (Fig. 4) y se recibieron muestras de vainas de Villaguay (Entre Ríos). Se recorrieron lotes que presentaban rodales de plantas muertas y próximos a la cosecha; de estos sectores (aledaños a los manchones con plantas muertas) se sacaron entre 10 y 20 plantas aparentemente sanas y se cosecharon solo las vainas inferiores.

\section{TÉCNICAS DE AISLAMIENTO DE LOS FITOPATÓGENOS Y MANTENIMIENTO DE LA COLECCIÓN.}

\subsection{AISLAMIENTO}

3.1.1 A partir de tejidos afectados. Para Pythium, a partir de plántulas enfermas se efectuaron aislamientos en APD (agar papa dextrosado) y AHM (agar harina de maíz) 
con el agregado de fungicidas y antibióticos-PARP (Van der Plaats-Niterink, 1981; Jeffers y Martin, 1986; Schmitthenner et al, 1994; Erwin y Ribeiro, 1996).

Los aislamientos de Ph. sojae se hicieron de la zona de avance de la lesión en los tallos y las ramificaciones, después de remover la epidermis. Se cortaron cinco a siete trocitos $(0.3-0.5 \mathrm{~cm})$ de tejido vascular que se transfirieron a cajas de Petri con medio sólido jugo V8 (AV8), MS (medio selectivo) o PARPH (Schmitthenner et al., 1994). En los casos en que no se usó PARP o PARPH, para evitar el desarrollo de bacterias se sembró el tejido afectado debajo del medio de cultivo, formando una burbuja (Schmitthenner, 1973).

Dos o tres días después de la siembra, puntas hifales se trasfirieron a cajas con los mismos medios de cultivo, pero sin fungicidas ni antibióticos, para su crecimiento.

3.1.2. Aislamientos a partir de suelos: Se utilizó la técnica denominada trampa o "Baiting Technique" (Dorrance et al., 2004). La misma consistió en sembrar 20 semillas de soja de los cultivares Harosoy, Williams o la isolínea Haro (1-7)1, susceptible a todas las razas de $P h$. sojae y sin resistencia a Pythium, en macetas plásticas de $10 \mathrm{~cm}$ diám. con el suelo infestado. Una vez germinadas, en el estado cotiledonar VC (Fehr y Caviness, 1977), se anegaron durante 8 horas. Posteriormente se retiró el agua y se esperó tres a cuatro días para observar plántulas anormales y de menor tamaño que las sanas. Éstas se descalzaron en busca de posibles síntomas. Se sembraron secciones de tejido infectado como se mencionó anteriormente. Para cada suelo se usaron entre dos y tres macetas.

3.1.3. Aislamientos a partir de granos de soja: Granos aparentemente sanos, 190 en la campaña 2014/15 y 950 en 2015/16, se sembraron sin desinfectar. La primera campaña en medio selectivo (Schmittener et al, 1994), 7 granos por caja de Petri en forma de sándwich entre dos capas de medio, y en 2015/16 sobre V8 PARP, se colocaron 10 granos por caja de Petri, posteriormente se incubaron a $22{ }^{\circ} \mathrm{C} \pm 2$ en oscuridad (Fig. 6 A).

En los tres métodos las siembras se realizaron en uno o más de los siguientes medios selectivos: agar papa glucosado (APG) o APD, AV8 y /o AHM, con agregado de antibióticos y fungicidas (van der Plaats-Niterink, 1981; Jeffers y Martin, 1986; Erwin y Ribeiro, 1996). De acuerdo a su disponibilidad y con el objetivo de lograr un mayor espectro de acción se utilizaron diferentes combinaciones de antibióticos y fungicidas: PARP (pimaricina, ampicilina, rifampicina) y PCNB (penta-cloro-nitro-benceno); PARPB (pimaricina, ampicilina, rifanpicina, PCNB, benlate) y/o neomicina, cloranfenicol y/o estreptomicina. Los antibióticos seleccionados fueron: a) activos contra bacterias Gram positivas: la ampicilina $(250 \mathrm{mg} / \mathrm{l})$, b) activos contra bacterias Gram 
negativas: la rifampicina $(10 \mathrm{mg} / \mathrm{l})$ y c) alguno de los activos para ambos grupos de bacterias: la neomicina $(100 \mathrm{mg} / \mathrm{l})$, el cloranfenicol $(30 \mathrm{mg} / \mathrm{l})$ y la estreptomicina (30 $\mathrm{mg} / \mathrm{l})$. Los antibióticos se agregaron antes de verter el medio en las cajas de Petri. La rifampicina se disolvió en etanol $95 \%$ y luego se agregó agua hasta alcanzar una concentración final de etanol al $50 \%$. Los fungicidas incorporados fueron benomil (20 $\mathrm{mg} / \mathrm{l}), \mathrm{PCNB}(100 \mathrm{mg} / \mathrm{l})$ y pimaricina $(5 \mathrm{mg} / \mathrm{l})$. El benomil es termoestable pudiendo ser incorporado al medio previo a su esterilización en autoclave (Erwin y Ribeiro, 1996).

Las cajas fueron incubadas a $22{ }^{\circ} \mathrm{C} \pm 2$ en estufa en oscuridad. Luego de $24-48$ horas se obtuvieron cultivos puros por transferencia de sectores con extremos de hifa que emergían de la superficie de la placa, a medios APG-APD, AHM o AV8, utilizados para la caracterización de las colonias (Anexo I).

\subsection{MANTENIMIENTO DE LA COLECCIÓN}

Los aislamientos puros fueron repicados bajo cámara de flujo laminar a:

a) cajas de Petri conteniendo agar agua (AA), AHM o APG, manteniéndose durante 4-8 semanas. Las cajas fueron selladas con parafilm.

b) tubos eppendorf o crioviales conteniendo agua destilada estéril, donde se transfirieron 6-8 bloquecitos de 3-4 $\mathrm{mm}$ de agar con el micelio hasta llenado del tubo y se almacenaron en heladera a $15^{\circ} \mathrm{C}$, donde permanen viables durante 3 a 6 meses.

c) tubos de ensayo conteniendo medio de cultivo APG o AA en pico de flauta y agua destilada estéril. Se efectuaron repiques trimestrales.

\section{IDENTIFICACIÓN Y DESCRIPCIÓN DE LOS AISLAMIENTOS 4.1. IDENTIFICACIÓN Y CARACTERIZACIÓN MORFOLÓGICA DE} LOS AISLAMIENTOS: Se desarrolla en cada capítulo, I Pythium y Phytopythium, y II Phytophthora sojae.

\subsection{IDENTIFICACIÓN Y CARACTERIZACIÓN DE LOS} AISLAMIENTOS POR MÉTODOS MOLECULARES.

En los casos en que se consideró necesario se utilizó la información de las secuencias del Espaciador Transcrito Interno del DNA ribosomal (ITS rADN) para corroborar o completar la identificación de los diferentes agentes patógenos.

\subsubsection{EXTRACCIÓN DE ADN}


El ADN del micelio de los aislamientos fue extraído de cultivos puros con 7-10 días de crecimiento en el medio APD para Pythium y Phytpythium y en AV8 para Ph. sojae. Se utilizó un kit comercial (WizardGenomic, PromegaInc), según instrucciones del proveedor y el método rápido de extracción (Collado-Romero et al., 2006).

\subsubsection{AMPLIFICACIÓN DEL RADN}

Los trabajos se efectuaron en: a) El "United States Department of Agriculture/ Animal and Plant Health Inspection Service/Plant Protection and Quarantine/Molecular Diagnostics Laboratory" (USDA/APHIS/PPQ/MDL), bajo la supervisión de la Dra Gloria Abad, científica líder del USDA, b) el Laboratorio del Grupo de investigación en Hongos Fitopatógenos (Instituto Agroforestal Mediterráneo) de la Universidad Politécnica de Valencia (España) bajo la supervisión de la Dra. Paloma Abad Campos, c) en la Facultad de Agronomía Universidad de Buenos Aires y d) en el Departamento de biotecnología del INTA Castelar. Todas las cepas se encuentran depositadas en el cepario de la cátedra de Fitopatología, Facultad de Agronomía, Universidad de Buenos Aires.

La región ITS del rADN nuclear de los aislamientos se amplificó usando primers ITS4 (TCCTCCGCTTATTGATATGC) e ITS5 GGAAGTAAAAGTCGTAACAAGG) (White et al., 1990), que se han probado universales para el grupo de hongos y Oomycetes. Se trabajó con $19 \mu \mathrm{l}$ de una solución obtenida de acuerdo al siguiente protocolo: Molc. $\mathrm{H} 20$ 10,00 $\mu$ 1, 10x buffer 2,5 $\mu \mathrm{l}, \mathrm{MgCl} 2$ 0,75 $\mu$, primers ITS-5 F (10 $\mu \mathrm{M}) 2,50$ e ITS-4 R $(10 \mu \mathrm{M}) 2,50$, dNTPs $(10 \mathrm{mM})$ 0,5 $\mu 1$, Pt Taq 0,25 $\mu 1$. Por cada tubo se agregaron $19 \mu \mathrm{l}$ de la solución madre y $6 \mu \mathrm{l}$ de la muestra para una dilución 1:10. Las condiciones usadas para la realización del PCR fueron las siguientes (Programa 2, Termociclador Biometra T3000): desnaturalización 1 min $25 \mathrm{~s}$ a $95{ }^{\circ} \mathrm{C}$, seguida de 35 ciclos consistentes en $35 \mathrm{~s}$ de desnaturalización a $93{ }^{\circ} \mathrm{C} ; 30 \mathrm{~s}$. de alineamiento y unión con el cebador a $52{ }^{\circ} \mathrm{C} ; 1$ min extensión a $72{ }^{\circ} \mathrm{C}$ y un paso final de $10 \mathrm{~min}$ de extensión a $72{ }^{\circ} \mathrm{C}$ seguido por $4{ }^{\circ} \mathrm{C}$ en hielo. Cada corrida incluyó una reacción sin ADN (control negativo) para monitorear la contaminación potencial por ADN exógeno. Los productos de amplificación se verificaron mediante electroforesis en un gel de agarosa al $1 \%$ con el agregado de buffer TBE 0,5× (0,045 MTrizma base, 0,045 M ácido bórico, 0,001 M EDTA, pH 8,0) y se visualizaron en un transiluminador con fluorescencia UV después de la tinción con bromuro de etidio. Las imágenes de los geles se grabaron usando un procesador de imágenes (Gel Documentation System-Image Store 5000, UVP, UK), y se almacenaron como archivos TIFF. 


\subsubsection{PURIFICACIÓN Y SECUENCIACIÓN DEL rADN}

Los productos de PCR se trataron mediante el Kit 50 de purificación de PCR (Qiagen Inc., Chatsworth, CA) y posteriormente se enviaron a secuenciar al laboratorio MCLAB (San Francisco), al laboratorio Macrogen Europa (Holanda) o al Laboratorio de Biología Celular y Molecular del Instituto de Genética Ewald A. Favret, de INTA-CASTELAR.

Con la finalidad de minimizar errores la secuenciación se efectuó en las dos direcciones, obteniéndose las cadenas 5' - 3'y 3'- 5'. Las secuencias consenso o contigs se obtuvieron utilizando el programa GeneToolLife 1.0 (Layon, 2000) resolviendo las posibles ambigüedades. Las secuencias obtenidas de los taxones en estudio se compararon en banco de genes on line, con las de otras especies de Pythium o Phytophthora publicadas en el servidor GenBank-BLAST del NCBI (National Centre of Biotechnology Information (Altschul et al., 1997), obteniéndose el nivel de similitud. Todas las comparaciones en el GenBank-Blast se efectuaron considerando las secuencias de las especies tipo, holotipo o extipo (type, holotype o extype) (Abad et al., 2010; Abad, 2014), las secuencias correspondientes al Proyecto Barcode of life (http://www.barcodeoflife.org/content/partners), o las aportadas por grupos de investigación de reconocida trayectoria.

Se analizó la información obtenida de los análisis morfológicos y moleculares para consensuar la identificación de la especie. Las secuencias correspondientes a las principales patologías serán remitidas al GenBank para obtener el número de acceso correspondiente.

\section{CONSTRUCCIÓN DE ÁRBOLES FILOGENÉTICOS}

Cuando se consideró necesario se construyó un único árbol de consenso estricto. El soporte de ramas se estimó usando el método de re-muestreo bootstrap (1000 repeticiones) que se expresó como un porcentaje de esas repeticiones en los nodos del árbol obtenidos (Felsestein, 1985). Además se calculó la proporción en la diferencia de bases entre aislamientos (utilizando la distancia p) con el programa MEGA 6.0 (Tamura et al., 2013). La distancia p es la proporción (p) de sitios nucleotídicos en los cuales se diferencian dos secuencias o grupos de secuencias (Nei y Kumar, 2000). 


\section{CAPITULO I}

\section{ESPECIES DE Pythium Y DE Phytopythium PATÓGENAS y ASOCIADAS A RAÍCES DE SOJA}




\section{INTRODUCCIÓN}

La mayor prevalencia de enfermedades de plántulas ocasionadas por especies de Pythium se ha asociado con el aumento en las prácticas de labranza reducida (Pankhurst et al., 1995). En Argentina, la rápida expansión del área con siembra directa pasó de nueve millones de ha en 1999 a 25 millones en 2009, y se sigue mostrando un creciente interés de esta tecnología en la agricultura (AAPRESID, 2009). Reducir el laboreo deja más superficie del suelo cubierto con restos de cosecha, lo que evita el rápido secado, como también impide el rápido aumento de temperatura del suelo en primavera, retardando la germinación y el crecimiento de las plántulas (Van Doren y Triplett, 1973; Griffith et al., 1977).

El damping off de pre y post emergencia y la podredumbre de raíces y semillas producida por Pythium spp. son comunes en todas las áreas productoras de soja; a menudo contribuyen al pobre establecimiento de plantas y consecuentemente a la pérdida de rendimiento (Yang, 1999). En EEUU, el tizón de las plántulas es la tercera enfermedad de soja en importancia, que afecta el rendimiento del cultivo (Wrather et al., 2010), estimándose la disminución en 1,5 millones de toneladas por año (Rojas et al., 2017 a, b). En Argentina, los Oomycetes, también contribuyen significativamente a la pérdida de rendimiento de cada cultivo (Palmucci et al., 2011 a; Carmona et al., 2015). Estos patógenos causan problemas en el estand de plantas en cualquier lugar donde se siembra la soja. Pythium spp. reducen la emergencia del cultivo y matan las plántulas emergidas, dando como resultado menor cantidad de plantas y reducción del vigor de las sobrevivientes. La compensación de plantas vecinas minimiza, en parte, la pérdida de rendimiento potencial como consecuencia del número reducido de plantas (Hartman et al., 2015). En muchos casos, los daños por Pythium pueden ser tan extensos que es necesario la resiembra del lote. El riesgo de la enfermedad se ve favorecido por la humedad del suelo, la baja temperatura, y la siembra temprana bajo siembra directa (Broders et al., 2007); siendo la temperatura un factor importante que afecta la patogenicidad de ciertas especies de Pythium (Rojas et al., 2016 b). 


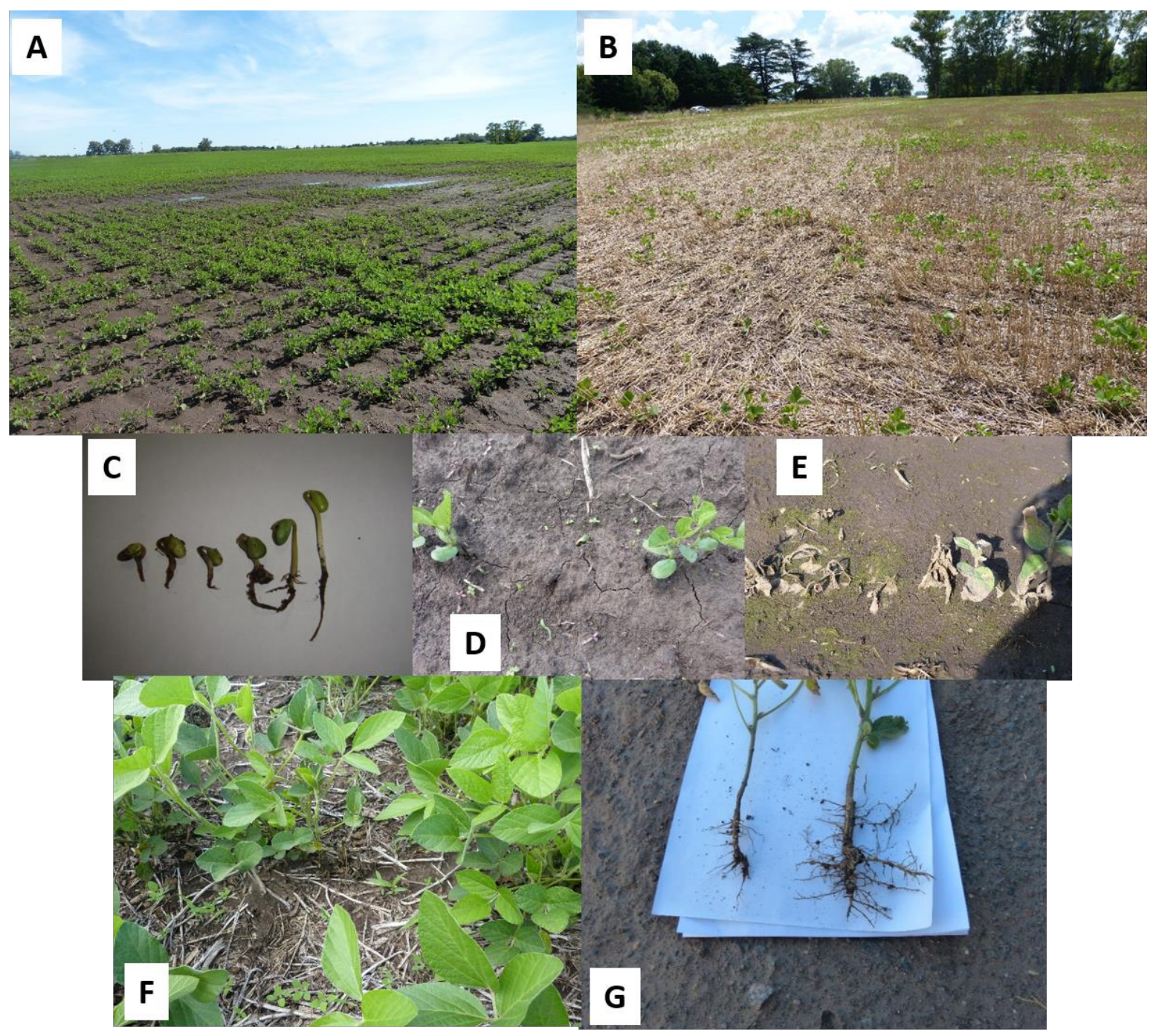

Figura 5. A) y B) Sintomatología típica de muerte de plántulas en el campo causada por Pythium spp. C), D) y E) Detalle de plántulas afectadas. F) Plantas adultas en R1 (Fehr y Caviness, 1977), afectadas. G) Detalle de las raíces de plantas adultas en R1, izquierda afectada, derecha normal.

\section{AGENTES CAUSALES}

Hasta el presente se han identificado 160 especies de Pythium (Abad, 2010). En nuestro país, en 1956 Frezzi describió 16 especies (Frezzi, 1977) y actualmente solo se hallan descriptas 22 (Ploper et al., 2010; Palmucci 2015).

Como patógenos de soja de distintas áreas del mundo, se han aislado e identificado, más de 30 especies de Pythium. Algunas de las especies más comunes y virulentas incluyen: P. aphanidermatum, $P$. irregulare, $P$. sylvaticum, $P$. ultimum, $P$. dissotocum, $P$. inflatum, $P$. miriotilum y $P$. torulosum. Además, los aislamientos dentro de una especie pueden diferenciarse mucho en su virulencia en soja, y también muchas especies de 
Pythium, que han sido aisladas asociadas al cultivo de soja, no son patogénicas (Hartman et al., 2015).

Para la Argentina también son varias las especies del género Pythium reportadas atacando al cultivo de soja, entre ellas se pueden citar a: $P$. ultimun, $P$. irregulare, $P$. sylvaticum, P. inflatum, P. debaryanum, P. rostratum, P. catenulatum y a Phytopythium helicoides, entre otros, siendo las dos primeras las más prevalentes (Pastor et al., 2011; Grijalba et al., 2011).

Los miembros de Pythium clado K, como fue descripto por Lévesque y de Cock (2004), pertenecen al género Phytopythium (Peronosporales), que es morfológicamente intermedio entre los géneros Phytophthora y Pythium.

La mayoría de las especies del género Phytopythium producen esporangios similares a los de las formas papiladas de Phytophthora, globosos, subglobosos, ovoides y se producen por proliferación interna, característica que nunca muestran estas formas papiladas. La combinación de la proliferación interna y la formación de papila son características de los esporangios de Phytopythium y de algunas especies de Pythium. Esta papila es diferente de la papila de los esporangios de Phytophthora, ya que en el género Phytopythium, los esporangios son inicialmente no papilados, y recién en la madurez la papila se desarrolla. Ésta no se manifiesta como un "engrosamiento apical hialino", como en Phytophthora (Blackwell, 1949), sino que se caracteriza porque puede crecer para formar un tubo de descarga más corto o más grande en el extremo del cual se forma una vesícula, dentro de la cual se diferencian las zoosporas, como en Pythium. En algunas especies, uno o más tubos de descarga se forman, no a partir de la papila sino más basales en el esporangio. En otras, la papila crece y puede ramificarse. Además, el género Phytopythium se caracteriza por la forma de los anteridios, que son elongados, cilíndricos, a veces con constricciones y el tubo de la fertilización se desarrolla principalmente en posición medial. Ocasionalmente se producen anteridios en forma de maza con inserción apical (Bala et al., 2010; de Cock et al., 2015).

\section{EPIDEMIOLOGÍA, SINTOMATOLOGÍA Y DAÑO}

Cuando las semillas se siembran en suelos infestados y son atacadas por Pythium se produce la podredumbre de la semilla y/o damping off de pre-emergencia que se evidencia como falta de plantas (Fig. 5. A, B y D). Las plántulas que ya han emergido generalmente son atacadas en sus raíces y algunas veces en el tallo a la altura de la línea 
del suelo. Las áreas invadidas presentan una podredumbre húmeda, de coloración castañas o amarronadas (Yang, 1999) (Fig. 5. C y E). La parte basal del tallo de la plántula se vuelve más blanda y mucho más delgada, y como resultado, la plántula cae al suelo. Otras plántulas afectadas por Pythium spp. pueden exhibir pocos síntomas más allá de un escaso desarrollo tanto de la raíz principal como de las raíces secundarias. Pythium spp. con frecuencia infecta las raíces cerca de las puntas y de esta forma gran parte del tejido afectado puede desprenderse cuando las raíces son removidas del suelo (Fig. 5. F y G). Los síntomas más severos son los asociados con la germinación y las primeras etapas del desarrollo de las plántulas, porque Pythium spp. afecta tejidos jóvenes de la planta, y el nivel de infección decrece con la edad.

Las oosporas o hinchamientos hifales (dependiendo de la especie) son las estructuras de supervivencia primarias que se encuentran en el suelo. El crecimiento saprofítico en materia orgánica y la actividad parasitaria en otros cultivos, malezas y en plantas voluntarias, pueden ser factores importantes en la persistencia de Pythium spp. La infección de las plántulas de soja puede ocurrir al poco tiempo después de la siembra, cuando los propágulos dormidos del patógeno germinan en respuesta a exudados de semilla y raíces del hospedante con condiciones ambientales favorables para el patógeno. La infección ocurre generalmente en suelos muy húmedos, donde la concentración de oxígeno es baja, lo que estimula que los exudados radiculares sean más ricos en azúcares y aminoácidos, lo que favorece la dirección de las zoosporas hacia las raíces. Se ha observado que el damping off aumenta con la siembra directa, debido principalmente al aumento de la humedad y a la disminución de la temperatura del suelo, y muchas veces también al aumento del inóculo inicial. El patógeno puede ponerse en contacto con el hospedante a través del crecimiento hifal, o a través de la producción de esporangios y zoosporas biflageladas, que nadan hacia la semilla, la punta de la raíz o los hipocótiles en desarrollo. El patógeno invade la plántula y crece rápido, tanto intracelular como intercelularmente, colonizando el tejido, causando una podredumbre húmeda. La producción de esporangios o de oosporas pueden ocurrir rápidamente en tejidos colonizados, sin embargo las infecciones secundarias son limitadas (Hartman et al., 2015). Actualmente se está intentando sembrar lo más temprano posible con grupos de madurez cortos; los suelos fríos por debajo de $15^{\circ} \mathrm{C}$, también constituyen un factor de riesgo. La temperatura óptima de crecimiento es distinta según las especies de Pythium, por ende las especies que van a predominar en el lote dependen de la ubicación geográfica, del campo, y de las fechas de siembra. Por ejemplo $P$. debaryanum, $P$. torulosun y $P$. 
ultimum, infectan con temperaturas bajas $\left(20^{\circ} \mathrm{C}\right.$ o menores) (Thomson et al., 1971; Yang, 1999), afectando a la soja sembrada temprano. Sin embargo $P$. aphanidermatum y $P$. myriotylum infectan a la soja a temperaturas altas $\left(30^{\circ} \mathrm{C}\right.$ o mayores) (Littrell y McCarter, 1970; Thomson et al., 1971) y predominan en soja de segunda o en siembras tardías (Yang, 1999).

\section{MANEJO}

Las enfermedades causadas por Pythium son muy difíciles de controlar porque los patógenos producen oosporas que son resistentes a condiciones adversas y que pueden sobrevivir por muchos años en el suelo. También los patógenos tienen alta capacidad saprofítica y un amplio rango de hospedantes, incluyendo maíz (Zea mays), trigo (Triticum aestivum), algodón (Gossypium hirsutum) y otros (Hartman et al., 2015).

Se utilizan diversas prácticas de manejo para controlar a las especies de Pythium fitopatógenas, como ser evitar suelos saturados o inundados, o temperaturas de suelo desfavorables después de la siembra, la labranza para mejorar el drenaje, sembrar semillas de alta calidad y hacer tratamientos de semillas con fungicidas. Uno de los fungicidas más efectivos contra Pythium spp. es el metalaxil (McGee, 1992). Este es un fungicida sistémico que lo absorben las plántulas en emergencia y se transloca por el xilema.

Rosso et al. (2005) encontraron que cultivares de soja con el gen Rps 1k, de resistencia a $P h$. sojae, presentaban significativamente menor decoloración de raíces e incidencia de Pythium en parcelas de campo que aquéllos que no tenían el gen. Posteriormente se determinó que el gen de resistencia a $P$. aphanidermatum denominado $R P A 1$, estaba cerca pero no contenía al gen $R p s 1 \mathrm{k}$ y posiblemente podría conferir resistencia a diferentes especies de Pythium patógenas de soja (Rupe et al., 2011). Si bien esta bibliografía indica algún tipo de resistencia a $P$. aphanidermatum, dicha especie, hasta la actualidad, no fue encontrada ni reportada, para nuestro país afectando al cultivo de la soja, solo se la cita en cultivos intensivos y en invernáculo (Palmucci et al., 2011). Hasta el presente no hay resistencia genética disponible para este género y se deben implementar distintos tipos de medidas dentro de un manejo integrado. Entre ellas se puede citar, mejorar el drenaje del suelo principalmente en un sistema de siembra directa y evitar el riego durante los primeros diez días después de la siembra. Cuanto antes se produzca la emergencia de la semilla menos posibilidades tendrá de sufrir ataques de Pythium por lo que sembrar en suelos por encima de $18{ }^{\circ} \mathrm{C}$ es altamente recomendable. 
Pero la principal medida es a través del tratamiento de la semilla con fungicidas específicos para Pythiáceas. 


\section{MATERIALES y MÉTODOS}

\section{IDENTIFICACIÓN Y CARACTERIZACIÓN MORFOLÓGICA DE LOS AISLAMIENTOS}

La identificación y caracterización de las especies de Pythium y Phytopythium se efectuaron teniendo en cuenta la morfología de la colonia en APG, AHM y V8, y las estructuras vegetativas y reproductivas sexuales y asexuales (Blackwell, 1949; Frezzi, 1950 y 1956; Waterhouse, 1963; Van der Plaats-Niterink, 1981; Dick, 2001; Stamps et al., 1990; Erwin y Ribeiro, 1996). Se estimuló la formación de esporangios y estructuras sexuales por medio de diferentes técnicas, entre otras, el uso de hoja de gramínea en agua: 3-4 secciones de 0,5 $\mathrm{cm}$ de diámetro de agar con micelio de 7 días de crecimiento, se colocaron en cajas de Petri que contenían agua destilada estéril con 15-20 trocitos de Agrostis sp. de 0,5 a $1 \mathrm{~cm}$ de longitud, hervidos durante 10-15 min (Fig. 6. B). Después de 48- $72 \mathrm{~h}$, los segmentos colonizados se observaron en microscopio óptico (Abad et al., 1994).

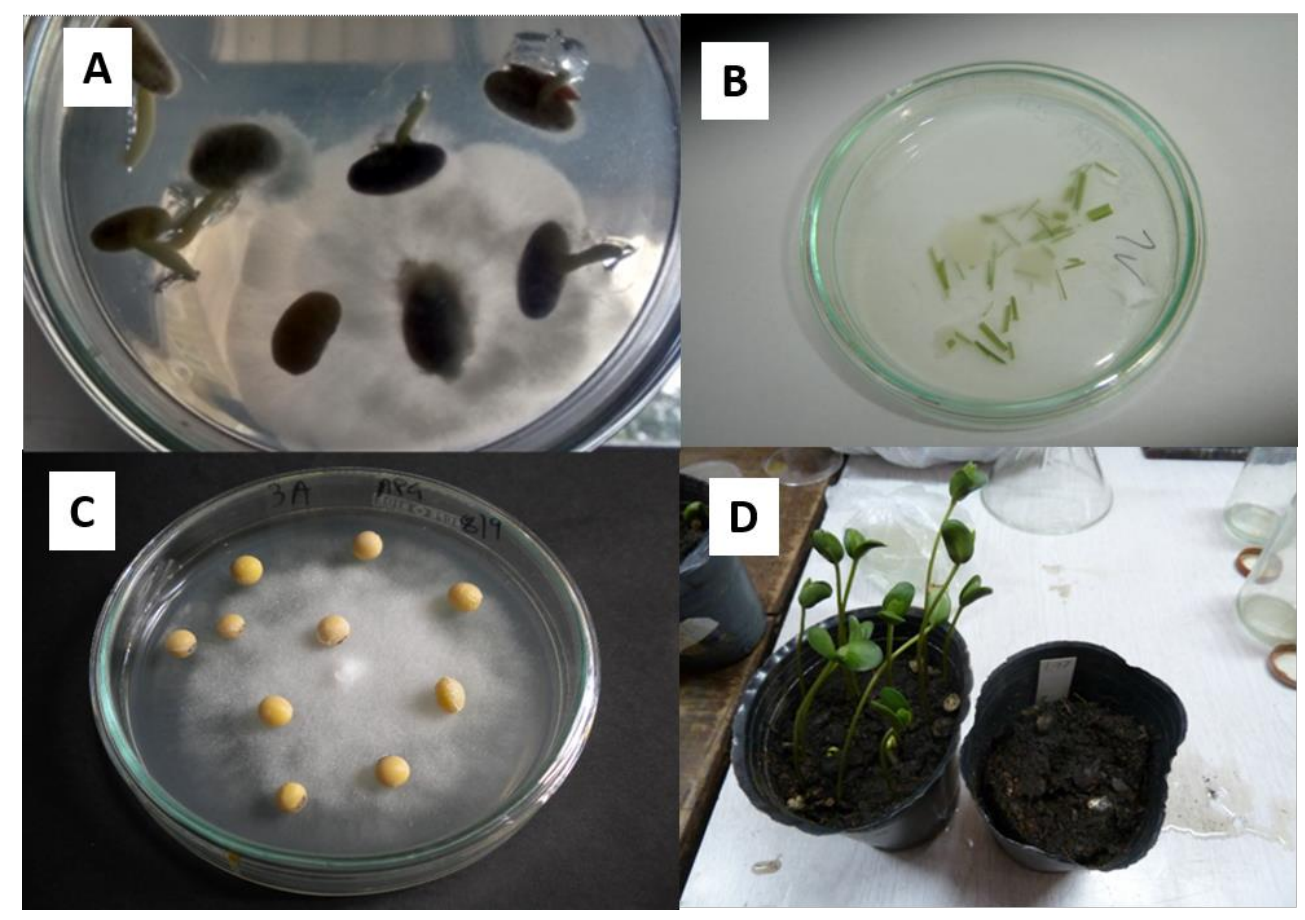

Figura 6. Pythium spp. A) Siembra de granos cosechados en medio de cultivo. B) Técnica de desarrollo en Agrostis sp. C) Patogenicidad en semilla. D) Patogenicidad en suelo. 


\section{PRUEBAS DE PATOGENICIDAD}

Las pruebas de patogenicidad se efectuaron con todas las especies determinadas y en aquellas de las que se obtuvieron muchos aislamientos (como P. ultimum, $P$. irregulare y P. sylvaticum), se eligieron tres o más de los mas representativos.

\subsection{Ensayo de patogenicidad in-vitro (latin-vitro=glass), Podredumbre de semillas}

(PS): Cada uno de los aislamientos seleccionados se sembró en el centro de cajas de Petri. Cuando las colonias completaron el diámetro de las cajas (2 días después aproximadamente) se colocó, en cada una, 10 semillas previamente desinfectadas con hipoclorito de sodio al 1,5\% (Fig. 6. C). Las cajas se incubaron en oscuridad a $22{ }^{\circ} \mathrm{C} \pm 2$ y se realizaron 4 repeticiones por cada uno de los aislamientos. A los 7 días desde la siembra se contaron las semillas y/o plántulas muertas, las plántulas infectadas (con síntomas leves) y las plántulas normales, según la escala propuesta por Jiang et al. (2012). Donde: 0: semilla sin síntomas; 1: semillas con la radícula de color negra amarronada; 2 : reducción de la radícula con lesiones de importancia; 3: semilla significativamente infectada y radícula de color amarronado a negro; 4: semilla muerta (Fig. 7).

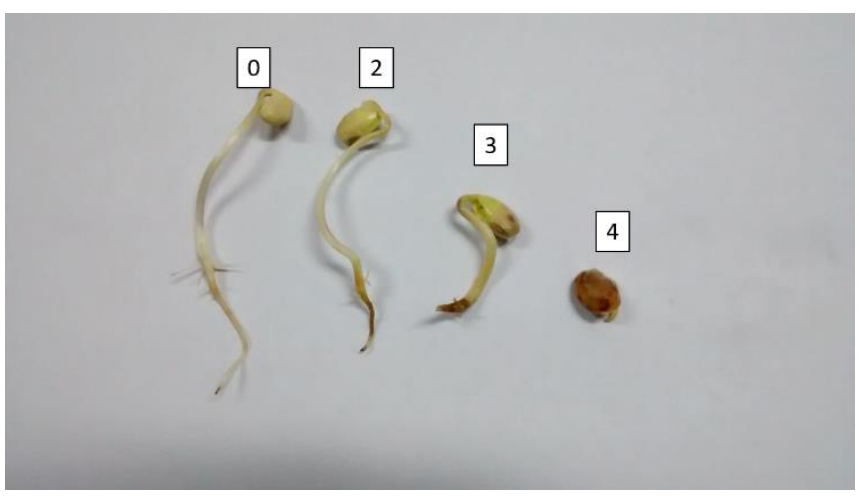

Figura 7. Parte de la escala para evaluar patogenicidad in vitro (Jiang et al., 2012).

2.2 Ensayo de patogenicidad in-vivo (semillas) Damping off (DO): En macetas plásticas de $12 \mathrm{~cm}$ diám., conteniendo sustrato comercial (Hi-Soil ®) tindalizado (dos veces con vapor de agua, en autoclave con espita abierta, durante una hora), se colocó el contenido de una caja de Petri de $9 \mathrm{~cm}$ de cada aislamiento desarrollado en APD, durante 7 días a $22{ }^{\circ} \mathrm{C}$. Se tapó con un centímetro de espesor de sustrato tindalizado donde se sembraron 15 semillas de soja (previamente desinfectadas con hipoclorito de sodio al 2 $\%$ ), las que se taparon también con un centímetro de espesor de sustrato tindalizado (Fig. 6. D). Las macetas se colocaron en cámara bioclimática a $22{ }^{\circ} \mathrm{C} \pm 2$ y $12 \mathrm{~h} / 12 \mathrm{~h}$ 
(luz/oscuridad). Durante el ensayo se mantuvo el nivel de humedad constante entre saturación y capacidad de campo. Se efectuaron 5 repeticiones por tratamiento y los testigos correspondientes con el agregado de APG sin el fitopatógeno. La patogenicidad se evaluó a los 15 días mediante el recuento de las plántulas normales emergidas, éstas se descalzaron en busca de posibles síntomas como puntas de raicillas negras o podredumbre en el cuello de la raíz.

\subsection{Ensayo exploratorio de patogenicidad de Phytopythium}

Se efectuó un ensayo piloto con dos cepas de Phytopythium (Phy. frezzii sp. nov. y Phy. helicoides) para comprobar si inundando las macetas, la patogenicidad de estas cepas aumentaba o al menos presentaba un comportamiento distinto. Se efectuaron 5 repeticiones, el ensayo solo se efectuó una vez. Los resultados obtenidos para cada especie se analizaron mediante un análisis de varianza y posterior prueba de comparaciones múltiples Test de Tukey, se empleó un nivel de significancia del $5 \%$, usando el programa InfoStat (Di Rienzo et al., 2015).

\section{RESPUESTA DE TRES ESPECIES DE Pythium FRENTE A DISTINTAS TEMPERATURAS}

Se seleccionaron 11 aislamientos de Pythium de tres especies: 4 de P. ultimum (cepas 77; 90; 98; 102), 4 de $P$. irregulare (cepas 78;79;85;87) y 3 de $P$. aphanidermatum (cepas $7 ; 12 ; 64)$. Se midió su tasa diaria de crecimiento en APD y se realizaron dos pruebas de patogenicidad (in-vitro e in-vivo) a $15^{\circ} \mathrm{C}, 25^{\circ} \mathrm{C}$ y $35^{\circ} \mathrm{C}$, como temperatura inferior, media y superior del rango óptimo de crecimiento de la soja (Kantolic y Carmona, 2012).

3.1 Tasas diarias de crecimiento: Se efectuaron repiques de $0,5 \mathrm{~cm}$ de diám. (efectuados con sacabocados), desde los bordes de crecimiento de colonias de cada cepa de cada especie, se los sembró en el centro de cajas de Petri conteniendo APG y se incubó a las distintas temperaturas. Posteriormente se procedió a medir la tasa de crecimiento diaria ( $\mathrm{cm} /$ día) mediante regla milimetrada, hasta que cada aislamiento ocupó toda la caja de Petri. Dicha tasa de crecimiento se midió realizando una cruz en la base de la caja, con el cruce de los ejes en la porción central del repique, se observó cada $24 \mathrm{~h}$ realizando marcas, y cada medición fue el promedio del crecimiento en cada eje. Se efectuaron 5 repeticiones por tratamiento. La patogenicidad tanto in-vitro como in-vivo se midió de la 
forma antes mencionada, salvo que las cajas y macetas se incubaron a las tres temperaturas. Los resultados obtenidos de la tasa de crecimiento y la patogenicidad invivo se analizaron mediante un análisis de varianza y posterior prueba de comparaciones múltiples, Test de Tukey. En todos los casos se empleó un nivel de significancia del $5 \%$, con el programa InfoStat (Di Rienzo et al., 2015). El ensayo se repitió dos veces.

En una primera etapa se compararon los aislamientos de las especies $P$. ultimum y $P$. irregulare, para constatar algún tipo diferencia según su zona de procedencia. Luego se compararon entre sí las tres especies para cada una de las temperaturas ensayadas.

\section{ENSAYOS DE MANEJO CON $P$. ultimum, $P$. irregulare $Y$ P. sylvaticum}

Para el ensayo de sensibilidad in vitro, se seleccionaron 40 aislamientos (20 de Pergamino y 20 de Balcarce) pertenecientes a las especies $P$. ultimum, $P$. irregulare y $P$. sylvaticum. Mientras que para los ensayos de eficacia a los formulados curasemillas y para determinar la relación entre el gen $R p s$ 1k y la resistencia, se seleccionaron 10 aislamientos con patogenicidad del $100 \%$ in vitro y más de $80 \%$ in vivo, de las especies de mayor prevalencia, cinco de P. irregulare y cinco de P. ultimum.

4.1 Control químico, eficacia de diferentes formulados curasemillas (Grijalba y Ridao, 2017)

4.1.1 Sensibilidad in vitro: Los fungicidas utilizados fueron los recomendados para el cultivo de soja para el control de Pythium spp. (CASAFE 2007): 1) metalaxil con una dosis de 10 ppm en APD y 2) carbendazim+tiram con una dosis de 100 ppm en APD (Dorrance et al., 2004). Para ello se sembró un trocito de $0,5 \mathrm{~cm}$ de diám. de cada aislamiento, en el centro de cada caja de Petri de $9 \mathrm{~cm}$. Se efectuaron los testigos correspondientes y 4 repeticiones para cada tratamiento. La variable respuesta fue el crecimiento miceliar.

Esta metodología de metalaxil se efectúo para todas las especies, pero para las que se obtuvieron varios aislamientos, se probó solo en los más representativos (tres o más) de cada especie.

\subsubsection{Eficacia en semillas:}

Se efectuaron dos ensayos, A) en base a los fungicidas recomendados para esta enfermedad en la Argentina y utilizados para el ensayo de sensibilidad in vitro: metalaxilM (35\% p/v): $50 \mathrm{~cm}^{3} / 100 \mathrm{~kg}$ de semilla y carbendazim+tiram con una dosis de 200 $\mathrm{cm}^{3} / 100 \mathrm{~kg}$ de semilla $\mathrm{y} \mathrm{B}$ ) en base a fungicidas de amplio uso en Argentina: 
azoxistrobina (10\%), $250 \mathrm{~cm}^{3} / 100 \mathrm{~kg}$ de semilla, y difenoconazol (3\%), $300 \mathrm{~cm}^{3} / 100 \mathrm{~kg}$ de semilla. Cada uno formulado como curasemillas (de acuerdo a las indicaciones de la compañía química proveedora). En ambos ensayos la semilla fue sembrada a los dos días de ser tratada, mediante el método de aplicación semihúmedo.

La inoculación se efectuó colocando una capa de sustrato tindalizado en el fondo de una bandeja plástica $(10$ × 20 × $5 \mathrm{~cm})$, luego se colocó inóculo de cada uno de los 10 aislamientos (aprox. $15 \mathrm{cc}$ de APD colonizado), que fueron tapados con otra capa de sustrato tindalizado. Sobre esta última se sembraron 25 semillas de soja, cubiertas con una nueva capa de sustrato tindalizado. Para los testigos solo se colocó APD sin desarrollo de micelio. Los tratamientos fueron asignados a las unidades experimentales (bandejas) de acuerdo a un diseño completamente aleatorizado con 3 repeticiones por tratamiento. Las evaluaciones se realizaron a los 21 días desde la siembra mediante el cálculo de incidencia de la enfermedad por maceta, y el porcentaje de control de cada fungicida. Los resultados obtenidos se analizaron mediante un ANOVA y las medias fueron comparadas aplicando el Test DGC con un nivel de significancia del $5 \%$ (INFOSTAT, 2009). La eficiencia de los fungicidas se determinó mediante la fórmula de Abbott (1925):

$$
\% \text { control }=(\mathrm{IT}-\mathrm{it} / \mathrm{IT}) \times 100
$$

Donde IT = infección del testigo, it = infección del tratamiento con fungicida

\subsection{Relación entre el gen Rps $1 \mathrm{k}$ y la resistencia a Pythium ultimum y $P$.} irregulare en soja (Grijalba et al., 2017)

Se verificó la relación del gen $R p s 1 \mathrm{k}$ de resistencia a $P h$. sojae, con las especies de Pythium prevalentes en la provincia de Buenos Aires, ya que hasta el momento $P$. aphanidermatum no había sido reportado en el cultivo de soja.

Un semillero local proveyó cuatro genotipos de soja de similar pedigree, dos con el gen $R p s ~ 1 k$, de resistencia a $P h$. sojae (identificados como $\mathrm{SE}+1 \mathrm{y} \mathrm{SE}+2$ ), y dos sin el gen (identificados como SE-1 y SE-2). Para corroborar la presencia o no del gen estudiado, los genotipos se inocularon mediante la técnica del hipocótile con los aislamientos de $P h$. sojae F13-1 (fórmula de virulencia $R p s$ 1a-1c-1k-3a-7) y F13-3 (fórmula de virulencia Rps 1c-3a-7) obtenidos en 2013 a partir de plantas con síntomas, de la localidad de Fontezuela (provincia de Buenos Aires). Los mismos se chequearon con un set de ocho genotipos diferenciales (ver cap II punto 2.2 pg. 141).

Se seleccionaron 10 aislamientos, cinco de $P$. irregulare (cepas 78, 79. 85, 86 y 87) y cinco de P. ultimum (cepas $71,77,90,98$ y 102). La técnica utilizada para la 
determinación del gen RPA1 fue la inoculación del hipocótile (Schmitthenner y Bhat, 1994), la que deja de lado resistencias de campo o generales (Agrios, 2005), entre ellas la resistencia a la penetración por parte de las zoosporas y/o del micelio infectivo, por lo que para la infestación se usó la técnica descripta en el ensayo de patogenicidad in-vivo (semillas) (ver $2.2 \mathrm{pg} 33)$.

Los resultados obtenidos se analizaron mediante un análisis de varianza para un modelo con dos factores y posterior prueba de comparaciones múltiples DGC (Di Rienzo et al., 2015). En todos los casos se empleó un nivel de significancia del $5 \%$. Se verificaron los supuestos del modelo mediante pruebas de Shapiro Wilks y Levene. Se empleó InfoStat (INFOSTAT, 2009) como software. El ensayo se repitió dos veces. 


\section{RESULTADOS}

\section{IDENTIFICACIÓN Y DESCRIPCIÓN DE LOS AISLAMIENTOS}

\subsection{Muestreo de campos, obtención e identificación de los aislamientos}

Durante la campaña 2013/14 se obtuvieron 96 aislamientos del NBA y 51 del SEBA. En el NBA se reconocieron siete especies de Pythium: P. ultimum, P. irregulare, $P$. sylvaticum, $P$. inflatum, $P$. aphanidermatum, $P$. catenulatum y $P$. longandrum más un Pythium sp. sin determinar; y tres de Phytopythium: Phy. helicoides Phy. frezzii sp. nov. y Phy. vexans más un Phytopythium sp. sin identificar, además de un aislamiento que se clasificó como Achlya. Las dos especies prevalentes fueron P. ultimum y P. irregulare con $45,4 \%$ y $22,7 \%$ respectivamente. Del SEBA se obtuvieron tres especies de Pythium: P. ultimum, $P$. irregulare y $P$. sylvaticum, y un Pythium sp., siendo las prevalentes también P. ultimum y P. irregulare, con 76,5 \% y 15,7 \%. Durante la campaña 2014/15 se obtuvieron 85 aislamientos del NBA pertenecientes a siete especies de Pythium: $P$. ultimum, P. irregulare, P. sylvaticum, P. inflatum, P. aphanidermatum, P. dissotocum y P. spinosum, y dos de Phytopythium: Phy. chamaehyphon y Phy. aff. mercuriale, más un Phytopythium sp. También las dos especies prevalentes fueron P. ultimum y P. irregulare con $36,4 \%$ y $20,5 \%$ respectivamente. Del SEBA se obtuvieron 51 aislamientos de cuatro especies de Pythium: P. ultimum, P. irregulare, P. sylvaticum y P. paroecandrum, siendo las prevalentes también $P$. ultimum y $P$. irregulare, con un $56,4 \%$ y $30,8 \%$ respectivamente (Tabla 1$)$. 
Tabla 1: Porcentajes de especies de Pythiun y Phytopythium aisladas y determinadas entre 2013 y 2015 de lotes del norte y sudeste de la provincia de Buenos Aires.

\begin{tabular}{|c|c|c|c|c|}
\hline & \multicolumn{2}{|c|}{ 2013/14 } & \multicolumn{2}{|c|}{$2014 / 15$} \\
\hline Género y especie & NBA & SEBA & NBA & SEBA \\
\hline & Porcentaje (\%) & Porcentaje (\%) & Porcentaje (\%) & Porcentaje (\%) \\
\hline P. ultimum & 45,4 & 76,5 & 36,4 & 56,4 \\
\hline P. irregulare & 22,7 & 15,7 & 20,5 & 30,8 \\
\hline P. sylvaticum & 16,5 & 5,9 & 19,3 & 7,7 \\
\hline P. inflatum & 4,1 & & 3,4 & \\
\hline P. aphanidermatum & 2,1 & & 9 & \\
\hline P. longandrum & 2,1 & & & \\
\hline P. dissotocum & & & 3,4 & \\
\hline P. catenulatum & 1 & & & \\
\hline P.paroecandrum & & & & 5,1 \\
\hline P. spinosum & & & 1,1 & \\
\hline Pythium sp. & 1 & 1,9 & & \\
\hline Phy. helicoides & 1 & & & \\
\hline Phy. frezzii sp. nov. & 1 & & & \\
\hline Phy. chamaehyphon & & & 3,4 & \\
\hline Phy. vexans & 1 & & & \\
\hline Phy. aff. mercuriale & & & 1,1 & \\
\hline Phytopythium sp. & 1 & & 1,1 & \\
\hline Achlya & 1 & & & \\
\hline
\end{tabular}

$\mathrm{NBA}=$ Norte de la provincia de Buenos Aires; SEBA=Sudeste de la provincia de Buenos Aires

\subsection{Muestreo y obtención de aislamientos a partir de granos de soja e identificación}

En 2014/15 se obtuvieron dos aislamientos de Pythium en Necochea (SEBA): $P$. sylvaticum y P. nunn. En 2015/16 se lograron 38 aislamientos de Los Toldos, Capitán Sarmiento, Solís y Pergamino (NBA), identificados como $P$. irregulare, $P$. paroecandrum, $P$. aff. heterothallicum, $P$. acanthicum, P. periplocum, un Pythium sp. sin determinar, Phy. vexans, Phy. chamaehyphon y un Phytopythium sp. sin determinar. Un aislamiento no correspondió a un Oomycete sino a Mortierella (Tabla 2).

Tabla 2: Porcentajes de especies de Pythiun y Phytopythium aisladas y determinadas entre 2014 y 2016 de granos de soja provenientes de lotes del norte y sudeste de la provincia de Buenos Aires.

\begin{tabular}{|l|l|l|}
\hline & SEBA & NBA \\
\hline Género y especie & $\mathbf{2 0 1 4 / 1 5}$ & $\mathbf{2 0 1 5} / \mathbf{1 6}$ \\
\hline & Porcentaje (\%) & Porcentaje (\%) \\
\hline P. sylvaticum & 50 & \\
\hline P. nunn & 50 & \\
\hline P. irregulare & & 10,5 \\
\hline Py. paroecandrum, & & 10,5 \\
\hline Py. periplocum & & 7,9 \\
\hline Py. aff. heterothallicum & & 2,6 \\
\hline Py. acanthicum & & 26 \\
\hline Pythium sp. & & 5,3 \\
\hline Phy. vexans & & 31,6 \\
\hline Phy. chamaehyphon & & 2,6 \\
\hline Phytopythium sp & & 2,6 \\
\hline Mortierella sp. & & 2,6 \\
\hline NBA.Norte da provincia & & \\
\hline
\end{tabular}

$\mathrm{NBA}=$ Norte de la provincia de Buenos Aires; SEBA=Sudeste de la provincia de Buenos Aires 


\subsection{Descripción de los aislamientos}

Las especies identificadas se han ordenado para su descripción por género (Pythium y Phytopythium) y dentro de éstos, en Pythium por tipo de esporangio, conforme a las clasificaciones de Frezzi $(1956,1977)$ y en el género Phytopythium no se efectuó ninguna división.

Para cada especie, se indica el origen de los aislamientos, la caracterización cultural, morfológica y molecular, el rango de hospedantes, la distribución mundial y los antecedentes en Argentina. Finalmente, con todas las secuencias obtenidas se elaboró un árbol filogenético para todas las especies.

Los aislamientos se identificaron morfológicamente de acuerdo a las descripciones de: Frezzi (1956), van der Plaats-Niterink (1981), Dick (1990) y Palmucci (2015), salvo especies de reciente determinación lo cual se indica en su descripción.

La identificación o confirmación molecular se efectuó secuenciando las regiones ITS4/ITS5 de cada tipo de aislamiento y su posterior comparación con secuencias homólogas en el GenBank. Con las especies nuevas o con las que presentaron algún inconveniente y se secuenció otro gen, que se aclara en su descripción. Los aislamientos se efectuaron a partir de plántulas con damping off o de suelo, utilizando métodos trampa.

Muchas de las fotos aquí presentadas son compartidas con Palmucci (2015), ya que se tomaron de aislamientos propios y típicos, parte en el laboratorio de United States Department of Agriculture/ Animal and Plant Health Inspection Service/Plant Protection and Quarantine/Molecular Diagnostics Laboratory" (USDA/APHIS/PPQ/MDL), bajo la supervisión de la Dra G. Abad. La otra parte se efectúo en el Laboratorio del Grupo de investigación en Hongos Fitopatógenos (Instituto Agroforestal Mediterráneo) de la Universidad Politécnica de Valencia (España) bajo la supervisión de la Dra. Paloma. Abad Campos y en la Facultad de Agronomía Universidad de Buenos Aires. Todas las cepas se encuentran depositadas en el cepario de la cátedra de Fitopatología, Facultad de Agronomía, Universidad de Buenos Aires.

\subsubsection{Especies del género Pythium}

\subsubsection{Especies con esporangios lobulados o filamentosos \\ P. aphanidermatum \\ P. dissotocum}


P. inflatum

1.3.1.2. Especies con esporangios esféricos, subesféricos o

elipsoidales

1.3.1.2.1. Oogonios lisos

P. sylvaticum

P. ultimun

P. ultimun var. sporangiiferum

P. catenulatum

P. longandrum

P. paroecandrum

$P$. heterothallicum

P. nunn

\subsection{Oogonios ornamentados}

P. irregulare

P. acanthicum

P. periplocum

P. spinosum 


\title{
1.3.1.1. Especies con esporangios lobulados o filamentosos
}

\section{Pythium aphanidermatum (Edson) Fitzpatrick (1923)}

\author{
Syn: Rheosporangium aphanidermatum Edson (1915)
}

Pythium butleri Subramaniam (1919)

Nematosporangium aphanidermatum var. hawaiiense Sideris (1931)

Nematosporangium aphanidermatum (Edson) Jacz (1931)

Fue descripto por primera vez por Edson en 1915, ocasionando damping off en plántulas de Beta vulgaris (remolacha) en Estados Unidos, asignándole el nombre de Rheosporangium aphanidermatus como nuevo género y especie en la familia Saprolegniaceae. Posteriormente fue incluído en el género Pythium por Fitzpatrick (1923), quien propuso el nombre de Pythium aphanidermatun, actualmente reconocido. Es una especie cosmopolita, afecta a diversas familias y géneros botánicos. Por la alta temperatura máxima en la que crece $\left(>40^{\circ} \mathrm{C}\right)$ es frecuente su aparición afectando cultivos bajo invernáculo (Grijalba et al., 2015). Causa damping off, pudrición de raíces y tallo, tizón de frutos.

\section{$\underline{\text { a. Origen de los aislamientos }}$}

$P$. aphanidermatum se aisló de plántulas y de suelos de campos comerciales de Mechita, Rojas, Capitán Sarmiento, Gorostiaga (NBA) y Villaguay (Entre Ríos). Muchos de los campos tuvieron que resembrarse debido a este patógeno y fue muy notoria la pérdida de plantas en las zonas con rastrojos de trigo (soja de segunda). 


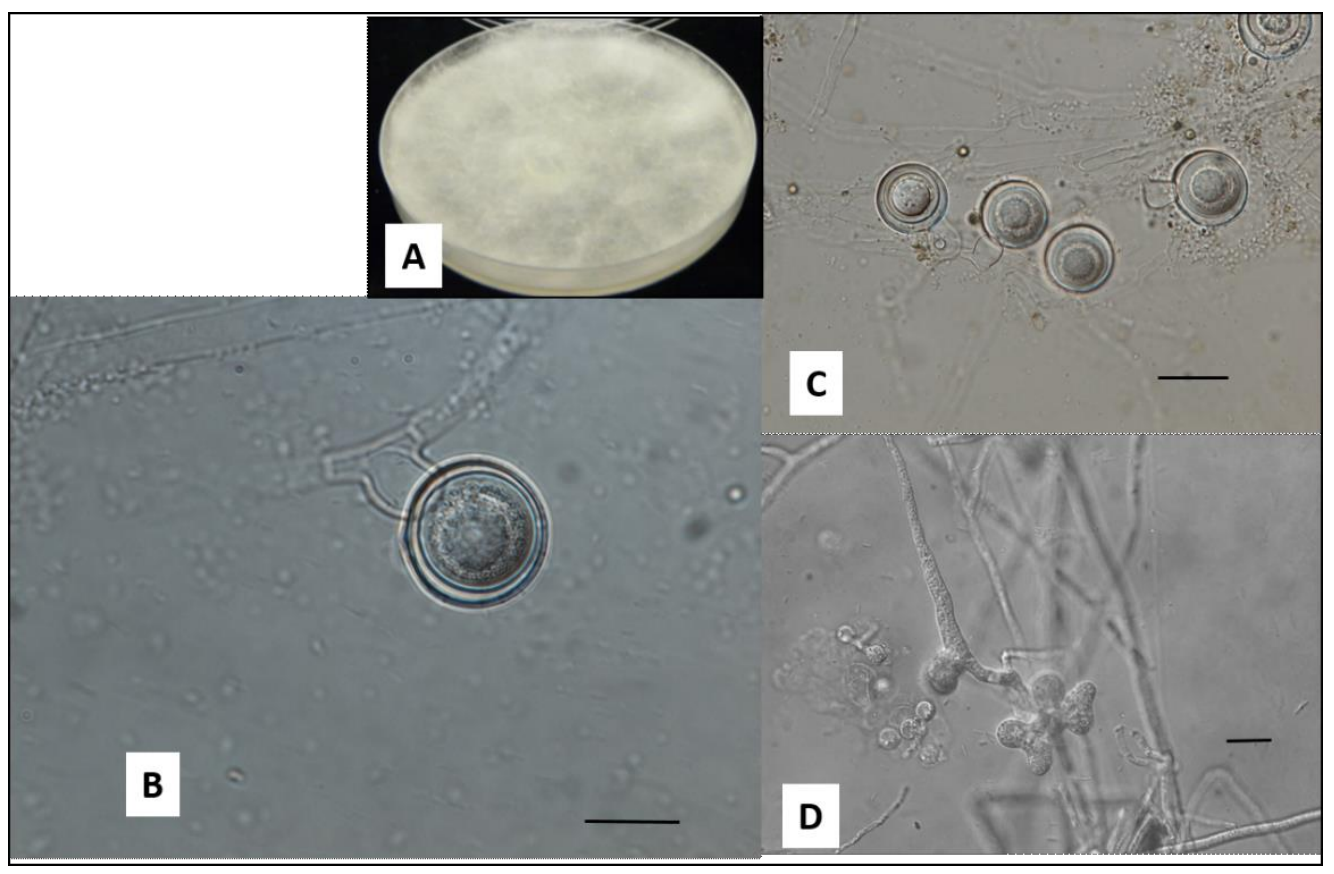

Figura 8. Pythium aphanidermatum A. Colonia de 7 días de crecimiento en APD.

B. Detalle de anteridio y oogonio. C. Oosporas. D. Esporangios toruloides. BAR=20 $\mu \mathrm{m}$

\section{b. Caracterización cultural y morfológica}

Todos los aislamientos presentaron idénticas características morfológicas y culturales.

La colonia formó micelio blanco aéreo en AHM sin patrón de crecimiento definido, de crecimiento algodonoso en APG (Fig. 8 A). Micelio cenocítico, hialino, ramificado, hifa principal mayor a $8 \mu \mathrm{m}$ diám. Esporangios filamentosos, lobulados o torulosos. Forma zoosporas entre $25^{\circ}$ y $30^{\circ} \mathrm{C}$. Posee oogonios globosos de pared lisa y fina, principalmente terminal, 15-27 (prom. 24) $\mu \mathrm{m}$ diám.; con oosporas apleróticas (16-) 1923 (-27) (prom. 21) $\mu \mathrm{m}$ diám; con un1 anteridio por oogonio (raramente 2), mayormente monoclinos o diclinos, intercalares, ocasionalmente terminales, separados de la hifa por tabiques, campaniformes, con amplio contacto apical con el oogonio (Fig. 8 B-D).

\section{c. Caracterización molecular}

Se obtuvieron secuencias de 867 pares de bases. Las secuencias de las cepas P15-7 y P1564 se seleccionaron y se compararon con secuencias homólogas del GenBank. Presentaron un $99 \%$ de similitud con la cepa neo-tipo de Pythium aphanidermatum CBS 118.80 (\#AY598622). 


\section{>15-7 Pythium aphnidermatum}

TTCCGTAGGTGAACCTGCGGAAGGATCATTACCACACCATAAAACTTTCCACGTGAACCGTT GAAATCATGTTCTGTGCTCTCTTTCGGGAGGGCTGAACGAAGGTGGGCTGCTTAATTGTAGT CTGCCGATGTATTTTTCAAACCCATTTACCTAATACTGATCTATACTCCAAAAACGAAAGTTT ATGGTTTTAATCTATAACAACTTTCAGCAGTGGATGTCTAGGCTCGCACATCGATGAAGAAC GCTGCGAACTGCGATACGTAATGCGAATTGCAGAATTCAGTGAGTCATCGAAATTTTGAACG CACATTGCACTTTCGGGTTATGCCTGGAAGTATGCCTGTATCAGTGTCCGTACATCAAACTTG ССТTTCTTTTTCTGTGTAGTCAGGGAGAGAGATGGCAGAATGTGAGGTGTCTCGCTGGCTCC CTTTTCGGAGGAGAAGACGCGAGTCCCTTTAAATGTACGTTCGCTCTTTCTTGTGTCTAAGAT GAAGTGTGATTCTCGAATCGCGGTGATCTGTTTGGATCGCTTTGCGCATTTGGGCGACTTCGG TTAGGACATTAAAGGAAGCAACCTCTATTGGCGGTATGTTAGGCTTCGGCCCGACGTTGCAG CTGACAGAGTGTGGTTTTCTGTTCTTTCCTTGAGGTGTACCTGAATTGTGTGAGGCAATGGTC TGGGCAAATGGTTGCTGTGTAGTAGGGTTTTGCTGCTCTTGGACGCCCTGTTTTCGGATAGGG TAAAGGAGGCAACACCAATTTGGGACTGTTTGCAATTTATTGTGAACAACTTTCTAATTGGA CCTGATATCAGGTAAGATTACCCGCTGAACTTAAGCATATYAATAAGCGGAGGAA

$P$. aphanidermatum se ubica en el clado A (Lévesqué y de Cock, 2004) junto a $P$. deliense. Ambas especies se caracterizan por tener esporangios lobados, rápido crecimiento y 1-2 anteridios monoclinos frecuentemente intercalares. Aislados de dicotiledóneas en climas cálidos. $P$. deliense se diferencia por tener un pie del oogonio curvado hacia el anteridio y oogonios y oosporas de menor tamaño (oogonio prom. 21,9 $\mu \mathrm{m}$ y oospora prom. $17 \mu \mathrm{m}$ diám.).

\section{d. Rango de hospedantes y distribución mundial}

Afecta a numerosas familias botánicas, entre otros hospedantes afecta, algodón, caña de azúcar, cafeto, cactáceas, cártamo, cítricos, espinaca, frijol, gramíneas, jengibre, papa, piña, remolacha azucarera, soja, tabaco, numerosas plantas ornamentales (estrella federal, crisantemo), y de suelo y agua (van der Plaats-Niterink, 1981).

Es una especie distribuída mundialmente, citada en los siguientes países: En África (Congo, Egipto, Fernando Poo, Ghana, Costa de Marfil, Kenia, Malawi, Malí, Mauricio, Mozambique, Nigeria, Rhodesia, Senegal, Sierra Leona, Sudáfrica, Sudán, Tanzania, Togo, Zambia); en Asia (Abu Dhabi, China, India, Indonesia, Sumatra, Irán, Israel, Japón, Malasia, Pakistán, Filipinas, Sri Lanka, Taiwán, Tailandia, Azerbaiyán, Vietnam); en Australasia y Oceanía (Australia, Hawai, Nueva Caledonia, Papúa Nueva Guinea); en Europa (Austria, Gran Bretaña, Checoslovaquia, Chipre, Francia, Grecia, Italia, Países Bajos, Polonia, Unión Soviética, Yugoslavia); en América del Norte (Canadá, México, Estados Unidos); en América Central y las Antillas (Antillas, Costa Rica, Jamaica, Panamá, Puerto Rico); en América del Sur (Argentina, Brasil, Chile, Perú, Venezuela) (CAB International, 1981). 
P. aphanidermatum se comporta como patógeno muy agresivo a altas temperaturas. Entre las enfermedades que ocasiona se destacan: Damping-off de pre y post emergencia, en diferentes hospedantes; la "Pudrición algodonosa de frutos de Cucurbitáceas" (Drechsler, 1925); la "Pudrición del tallo y raíz de maíz; el "Tizón algodonoso del césped" (Weels et al., 1954, Hall et al., 1980 citados por Abad et al., 1994;). El nombre de tizón algodonoso hace referencia al crecimiento de micelio aéreo blanco y mullido sobre las lesiones. Esta enfermedad fue reportada por primera vez en Estados Unidos en la década de 1930 y en sucesivos años afectando campos de golf. Sin embargo, es ahora reconocida como un problema en el césped en parques, jardines y campos de deportes. La enfermedad se ha detectado en las especies de gramíneas (céspedes) de los Estados Unidos, Canadá, Alemania, Francia y Japón (Allen et al., 2004).

En Argentina fue aislado por primera vez en 1950, en la Provincia de Córdoba, de plantas grandes de Pisum sativum (arveja) con podredumbre radical. En 1953 provocó marchitamiento y muerte de plantas adultas de poroto debido a podredumbre parcial o total de raíces y necrosis del tallo, en cultivos de Villa Ascasubi (Prov. de Córdoba). Fue reportado en Manfredi (Prov. de Córdoba) ocasionando muerte de plantas grandes de Capsicum annum (pimiento), podredumbre total de raíces y necrosis del tallo de Cereus aethiops (hachón-cactus) y causando la muerte de plantas de Euphorbia marginata (copo de nieve) con podredumbre de raíces (Frezzi, 1956). Además fue citada afectando cultivos de Beta vulgaris (remolacha); Citrullus lanatus (sandía); Cucumis melo (melón); Cucurbita maxima (zapallo); Cucurbita pepo (calabacín-zucchini); Fragaria vesca (frutilla silvestre); Medicago sativa (alfalfa), Melia azedarach (paraíso); Morus alba (mora) y Phaseolus vulgaris (poroto). En los últimos años fue aislado de Allium cepa (cebolla) (Kiehr et al., 2002); Amaranthus caudatus (amaranto) (Noelting y Sandoval, 2003); Allium schoenoprasum (ciboulette); Ocimum basilicum (albahaca) y Solanum melongena (berenjena) (Colombo et al., 2005). Pastor et al. (2005) lo aisló de muestras de suelo. En el cinturón hortícola de Bahía Blanca se han encontrado lotes de Cucurbita moschata (zapallo Anco) con podredumbre de frutos (Kiehr y Delhey, 2013). Tambien se la ha citado afectando plantas adultas de tomate (Grijalba et al., 2015) y Palmucci (2015) lo cita afectando plantas de Euphorbia pulcherrima (estrella federal) en la localidad de Garín (Partido de Pilar); afectando plantas de Nicotiana tabacum (tabaco) procedentes de la Provincia de Salta y de Jujuy y afectando cultivos de Spinacea oleracea (espinaca) de la localidad de Los Hornos (La Plata, Provincia de Buenos Aires). 


\section{Pythium dissotocum Drechsler (1930)}

Syn: Pythium araiosporum Sideris (1932).

Pythium oryzae S. Ito y Tokunaga (1933).

Pythium perigynosum Sparrow (1936).

La especie fue descripta por Drechsler (1930) en EEUU, según las características del aislamiento original procedente de raíces afectadas de Saccharum officinarum L. Puede causar podredumbres radiculares, damping off, y ser parásito de peces.

\section{a. Origen de los aislamientos}

Los aislameintos se obtuvieron de muestras de suelos de campos comerciales de Alberdi y Mechita (NBA) y de Necochea (SEBA) durante la campaña 2014/15

\section{b. Caracterización cultural y morfológica}

Presenta micelio blanco aéreo sin patrón radial en AHM, de crecimiento vigoroso en APG y con patrón radial en agar de papa-zanahoria (APZ) (Fig. 9 A). Micelio cenocítico, hialino, ramificado. Hifa principal mayor a $7 \mu \mathrm{m}$ diám., con apresorios cilíndricos o en forma de maza. Esporangios de tipo filamentoso, terminales, formando estructuras dendroides alargadas, poco dilatadas (en algunos casos se parecen a hifas, diferenciándose de ellas por su contenido protoplasmático más denso). Formación de zoosporas entre 5-20 ${ }^{\circ} \mathrm{C}$. En hojas de Agrostis desarrolló estructuras sexuales sin dificultad: oogonios terminales, intercalares, separados de la hifa por un tabique, o laterales, lisos, esféricos, (18-) 21-24 (-25) (prom. 22,5) $\mu \mathrm{m}$ diám; anteridios comúnmente 1 o 2 por oogonio, sésiles o pedicelados, originados próximos al oogonio, claviformes, curvos, dilatados en su inserción a la hifa y más delgados hacia el oogonio, monoclinos o diclinos, hipóginos en oogonios intercalares; oosporas apleróticas o casi pleróticas, (16-) 19-22 (-24) (prom. 20,5) $\mu \mathrm{m}$ diám., con una pared del oogonio de 2,5 $\mu \mathrm{m}$ diám. promedio (Fig. 9 B y C). 


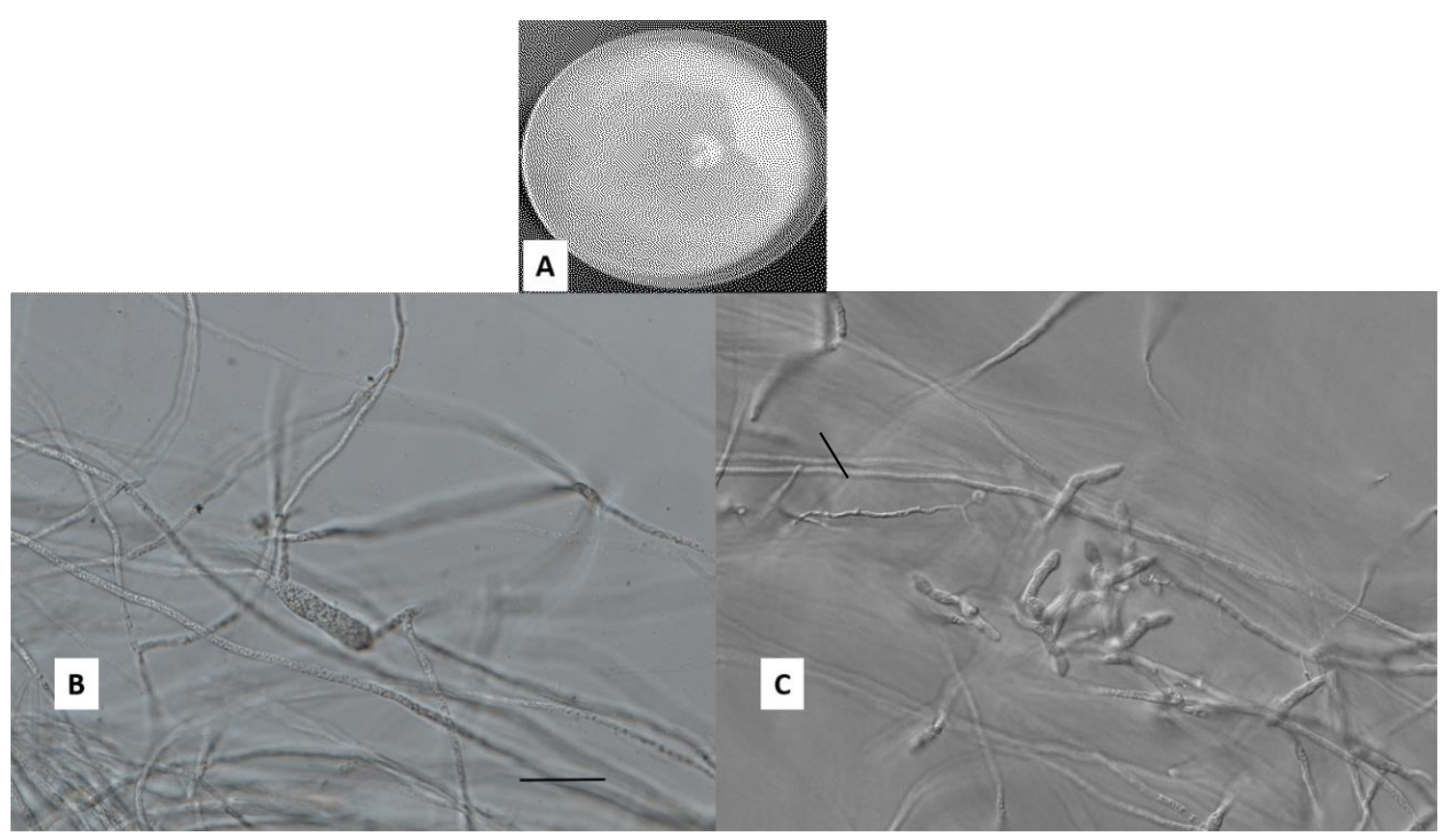

Figura 9. Pythium dissotocum A. Desarrollo de 7 días en APD. B. Apresorio. C.

Esporangios filiformes. $\mathrm{BAR}=20 \mu \mathrm{m}$.

\section{c. Caracterización molecular}

Las secuencias de la región ITS4/ITS5 de los aislamientos P15-72 y P15-73 resultaron de 825 pares de bases, seleccionándose P15-73 para su comparación con secuencias homólogas en el GenBank. Presentó un 99 \% de similitud con la cepa $P$. dissotocum AY598634.2 cultivo tipo CBS 166.68 , y $100 \%$ de similitud con varias cepas de $P$. dissotocum voucher.

>15-73 Pythium dissotocum TACCACACCAAAAAAACTTTCCACGTGAACCGTTGTAACTATGTTCTGTGCTCTCTTCTCGGA GAGAGCTGAACGAAGGTGGGCTGCTTAATTGTAGTCTGCCGATGTACTTTTAAACCCATTAA ACTAATACTGAACTATACTCCGAAAACGAAAGTCTTTGGTTTTAATCAATAACAACTTTCAG CAGTGGATGTCTAGGCTCGCACATCGATGAAGAACGCTGCGAACTGCGATACGTAATGCGA ATTGCAGAATTCAGTGAGTCATCGAAATTTTGAACGCACATTGCACTTTCGGGTTATGCCTG GAAGTATGCCTGTATCAGTGTCCGTACATCAAACTTGCCTTTCTTTTTTTGTGTAGTCAAGAA GAGAGATGGCAGACTGTGAGGTGTCTCGCTGACTCCCTCTTCGGAGGAGAAGACGCGAGTC CCTTTAAATGTACGTTCGCTCTTTCTTGTGTTTAAGATGAAGTGTGACTTTCGAACGCAGTGA TCTGTTTGGATCGCTTTGCTCGAGTGGGCGACTTCGGTTAGGACATTAAAGGAAGCAACCTC TATTGGCGGTATGTTAGGCTTCGGCCCGACTTTGCAGCTGACTGGAGTTGTTTTCTGTTCTTT CCTTGAGGTGTACCTGTCTTGTGTGAGGCAATGGTCTGGGCAAATGGTTATTGTGTAGTAGG AAGTTGCTGCTCTTAAACGCTCTAGCTTCGGTTAGAGTAAAGGAGGCAACACCAATTTGGGA TAGTCGTTGATTTATCAATGGCGCTCTTTCTAATTGGACCTGATATCAGGCAAGACTACCCGC TGAACTTAAGCATATC

Lévesque y de Cock (2004) ubican a $P$. dissotocum en el clado B2 que incluye a las especies de Pythium con esporangios filamentosos, no inflados o ligeramente inflados, 
con oogonios lisos, su mayoría menores de $30 \mu \mathrm{m}$ diám. y una tasa de crecimiento moderada (la mayoría 10-20 mm/día). Además demuestran que para las secuencias de ITS, P. coloratum, P. lutarium, P. marinum y P. dissotocum son idénticas, y P. diclinum difiere por un par de bases (pb). Estas especies son morfológicamente bastante similares en sus estructuras sexuales (esporangios filamentosos, ligeramente inflados, salvo $P$. marinum). Por consiguiente, debido a las similitudes que presentan, tanto morfológicas como en sus secuencias de ITS, Lévesque y de Cock (2004) concluyeron que $P$. coloratum, $P$. lutarium, $P$. marinum y $P$. diclinum son probablemente sinónimos de $P$. dissotocum.

\section{d. Rango de hospedantes y distribución}

P. dissotocum está citado en numerosos hospedantes: Daucus carota (Apiaceae); Lactuca sativa, Parthenium argentatum (Asteraceae); Beta vulgaris, Spinacea oleracea (Chenopodiaceae); Cucumis sativus (Cucurbitaceae); Kummerowia stipulacea, Lupinus digitatus, L. polyphyllus, Medicago sativa, Phaseolus vulgaris, Pisum sativum, Vicia faba (Fabaceae); Pelargonium cv. (Geraniaceae); Hydrilla verticillata (Hydrocharitaceae); Iris sp. (Iridaceae); Garya illinoensis (Juglandaceae); Hyacinthus cv., Tulipa cv. (Liliaceae); Papaver somniferum (Papaveraceae); Oryza sativa, Saccharum officinarum, Triticum aestivum (Poaceae); Fragaria $\times$ ananassa, F. vesca, Prunus persica (Rosaceae); Citrus nobilis (Rutaceae); Capsicum annuum, Lycopersicon esculentum (Solanaceae); Pilea pumila (Urticaceae). Neogobius fluviatilis, Neogobius gymnotrachelus, Perccottus glenii, Pseudorasbora parva (Superclase Pisces) (Spencer, 2004a). También selo menciona afectando cilantro (Coriandrum sativum L.) (Apiaceae) creciendo en cultivo hidropónico en Puerto Rico (Romero et al., 2012).

En el año 2004 el CABI (Centre for Agricultural Bioscience International) reportó su distribución en los siguientes países: de África (Sudáfrica); de. América: (Canadá, Estados Unidos); de Asia (China, India, Indonesia, Japón, Corea, Líbano, Rusia); de Australasia y Oceanía (Australia, Queensland) y de Europa (Gran Bretaña, Islandia y Holanda) (Spencer, 2004a).

Ha sido aislado de agua en URSS (Meshcheryakova, 1970; Meshcheryakova y Logvinenko, 1970, citados por Lodhi, 2007) y Países Bajos (Holanda) (van der PlaatsNiterink, 1981); de sistemas de irrigación en Inglaterra (Pittis y Colhoun, 1984) y en Egypto (Abdelzaher et al., 1994); de aguas del lago Dawmat Al-Jandal en Arabia Saudita, junto a otras especies de Pythium, comportándose como moderadamente patógeno (Al- 
Sheikh et al., 2012). En Pakistán, Lodhi $(2007,2013)$ en un relevamiento de Oomycetes en la provincia de Sindh, recolectó $P$. dissotocum de estanques (distrito Nawabshah), lagos y agua de canales.

En Argentina P. dissotocum fue aislado por primera vez en 1953, de Morus alba L. (morera blanca) con damping off, en la localidad de Villa Corina (Prov. de Córdoba). En 1955, de raíces necrosadas de Gladiolus communis L. (gladiolo) en Urundel (Prov. de Salta) y de Solanum lycopersicum $=$ Lycopersicum sculentum Mill. (tomate) severamente afectado por damping off en Caimancito (Prov. de Jujuy) (Frezzi, 1956). Palmucci (2015) lo cita ocasionando damping off en plantines de Nicotiana tabacum, en la provincia de Salta.

\section{Pythium inflatum Matthews (1931)}

\section{a. Origen de los aislamientos}

Fueron aislados de muestras de suelos de campos comerciales de Pergamino (NBA) durante la campaña 2013/14 y de Gorostiaga y Capitán Sarmiento (NBA) durante la campaña 2014/15

\section{b. Caracterización cultural y morfológica}

Según van der Plaats Niterink (1981) las colonias en AHM muestran un patrón ligeramente radiado. Las hifas principales son de $4 \mu \mathrm{m}$ diám. Los esporangios son filamentosos o inflados, formando un crecimiento irregular o globoso (Fig. 10 A). Los oogonios son globosos, terminales a intercalares de (19-)20-24(-27) (promedio 22,5) $\mu \mathrm{m}$ diám. Presenta 1 o 2 anteridios por oogonios, diclinos. Las oosporas son pleróticas o cercanas a eso, (18-) 19-24 (-25) (promedio 21,5) $\mu \mathrm{m}$ diám. Las paredes de más de $3 \mu \mathrm{m}$ diám. (Fig. 10 B y C). 


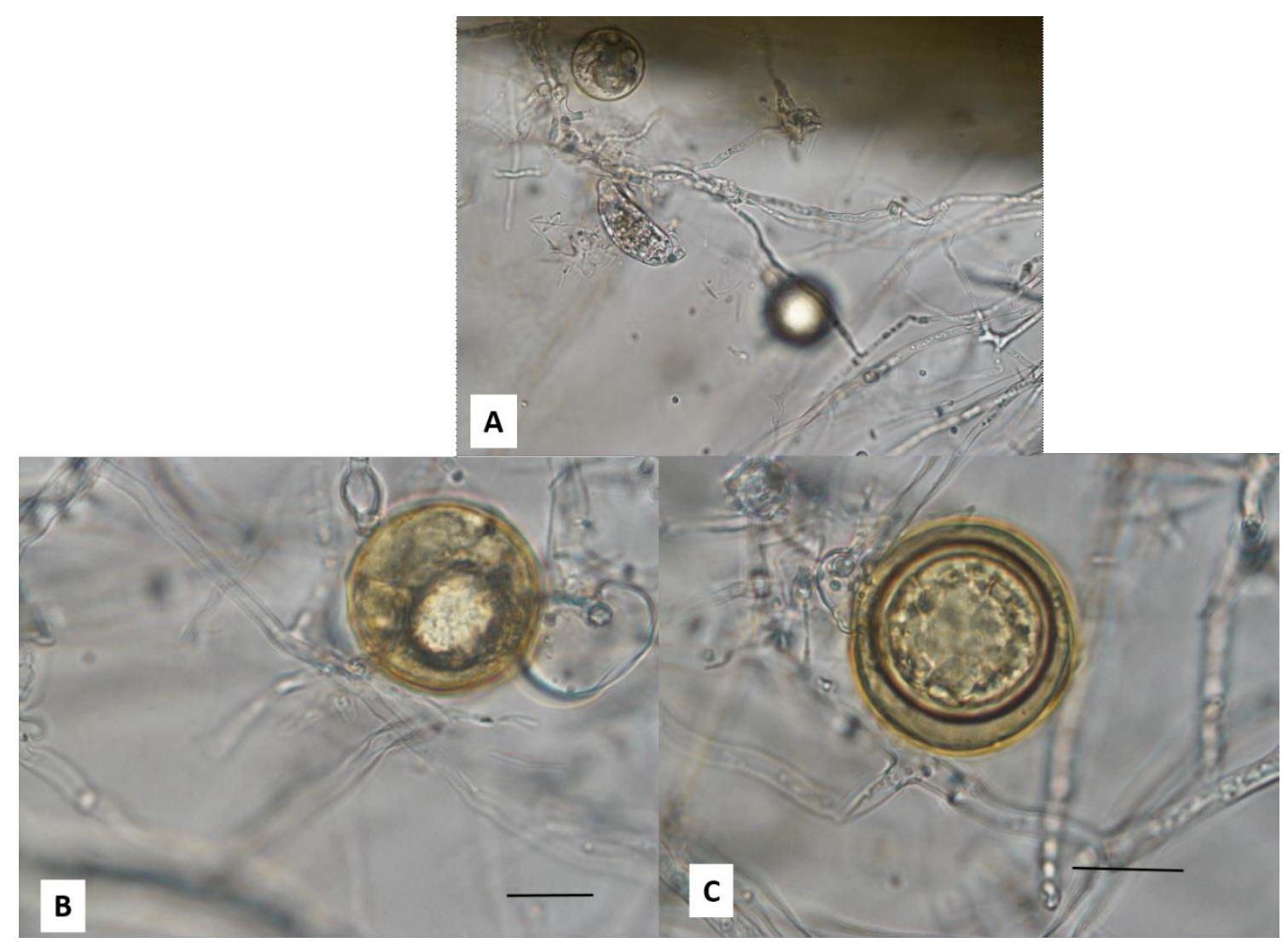

Figura 10. Pythium inflatum A. Esporangio B. Oogonio y anteridio C. Oospora plerótica. $\mathrm{BAR}=10 \mu \mathrm{m}$.

\section{c. Caracterización molecular}

Se obtuvieron secuencias de 807 pares de bases, seleccionándose CS15-31 para su comparación con secuencias homólogas en el GenBank. Presentó un 99 \% de similitud con la cepa tipo de P. inflatum CBS 168.68 (\# AY598626.2 GenBank).

> Pythium inflatum CS15-31

TAACAAGGTTTCCGTAGGTGAACCTGCGGAAGGATCATTACCACACCATAAAACTTTCCACG TGAACCGTTACAATTATGTTCTGTGCTCTCTCTCGGGAGGGCTGAACGAAGGTGGGCGCATG TATGTGTGTCTGCCGATGTACTTTTCAAACCCATTACTAAATACTGAACTATACTCCGAGAAC GAAAGTTTTTGGTTTTAATCAATAACAACTTTCAGCAGTGGATGTCTAGGCTCGCACATCGA TGAAGAACGCTGCGAACTGCGATACGTAATGCGAATTGCAGAATTCAGTGAGTCATCGAAA TTTTGAACGCACATTGCACTTTCGGGATATTCCTGGAAGTATGCTTGTATCAGTGTCCGTACA TCAAACTTGCCTTTCTTTTTTTGTGTAGTCAAGGAGAGAAATGGCAGAATGTGAGGTGTCTC GCTGGCTCCCTCTTCGGAGGAGAAGACGCGAGTCCCTTTAAATGTACGTTCGCTCTTTCTTGT GTCTAAGTAGAAGTGTGACTATCGAACGCAGTGATCTGTTTGGATCGCTTTGCGCGAGTGGG CGACTTCGGTTAGGACATTAAAGGAAGCAACCTCTATTGGCGGTATGTTAGGCTTCGGCCCG ACTTTGCAGCNGACAGTGTGTTGTTTTCTGTTCTTTCCTTGAGGTGTACCTGTTTGTGTGAGG CAATGGTCTGGGCAAATGGTTATTGTGTAGTAGATGGTNGCTGCTCTTGGGCGCCCTACTCG TAGGGTAAAGAAGGCAACACCAATTTGGGATAGTCTGTGGATTTATTCATGGGCGCTTTT 
Lévesque y de Cock (2004) ubican a P. inflatum en el clado B1d. Las especies de este clusters tienen esporangios inflados, filamentosos y moderadamente gruesos (más de 6,5 $\mu \mathrm{m})$. La mayoría de las veces se aíslan de monocotiledóneas principalmente céspedes. En este cluster están las especies $P$. graminicola, $P$. perilum, $P$. inflatum y $P$. plurisporum que tienen relativamente altas temperaturas cardinales (óptimo $30{ }^{\circ} \mathrm{C}$ y máximo $40{ }^{\circ} \mathrm{C}$ ). De las dos secuencias depositadas en el Genbank como P. inflatum (GI 6468670, Matsumoto et al., 1999 y GI 12863084) y se iguala con la cepa de esta especie descripta por van der Plaats Niterink (1981).

\section{d. Ocurrencia y patogenicidad}

P. inflatum fue originariamente aislado de algas verde amarillas (Vaucheria sp.). Posteriormente se determinó en mustras de agua de Alemania y Russia, de muestras de suelo de Islandia, en caña de azucar en Taiwan, en frutilla en Japón y en Dodonea viscosa en Nueva Zelanda. Resultó no patógena en semillas y plántulas de tomate en el campo, pero originó una infección moderada de raíces en plantas de tomate, en laboratorio (Van der Plaats Niterink (1981)

\subsubsection{Especies con esporangios esféricos, subesféricos o elipsoidales}

\subsection{Oogonios lisos}

\section{Pythium sylvaticum Campbell y Hendrix (1967)}

Syn=Globisporangium sylvaticum Campbell y Hendrix Uzuhashi, Tojo y Kakish. (2010)

El primer reporte de esta especie, que fue aislada a partir del suelo, fue realizado por Hendrix y Campbell, en 1967 en Estados Unidos. 


\section{a. Origen de los aislamientos}

Fueron aislados de numerosas muestras de suelos de campos comerciales del NBA y SEBA durante la campaña 2013/14 y 2014/15 y además en esta última campaña fue aislado a partir de granos cosechados de soja del SEBA.

\section{b. Caracterización cultural y morfológica}

Todos los aislamientos obtenidos presentaron idénticas características morfológicas y comportamiento cultural. En APG a $20{ }^{\circ} \mathrm{C}$ desarrolló abundante micelio blanco algodonoso, de rápido crecimiento, con hifas aéreas en el borde de la caja de Petri. En AZ creció inmerso con patrón radial. En AHM formó micelio blanco aéreo sin un patrón de crecimiento. Presentó micelio cenocítico con abundantes apresorios simples o complejos con forma de hoz o de clava (falcados). No se observaron esporangios ni zoosporas. Presentó hinchamientos hifales frecuentemente esféricos o limoniformes, terminales o intercalares, de $20 \mu \mathrm{m}$ diám. promedio (Fig. 11 A-C). En Agrostis sp. oogonios lisos, terminales e intercalares, 16-22 (prom. 20) $\mu \mathrm{m}$ diám.; 2-4 anteridios por oogonio, diclinos, ramas anteridiales ramificadas; oosporas apleróticas, 16 - 20 (prom. 18) $\mu \mathrm{m}$ diám.

$P$. sylvaticum es una especie usualmente heterotálica que ocasionalmente puede comportarse como homotálica. No produce oogonios en medio de cultivo, salvo después de un largo período de mantenimiento y especialmente en aislamientos de comportamiento femeninos.

\section{c. Caracterización molecular}

La secuencia P14-73 de 984 pb, presentó una similitud del 100 \% con la secuencia de la cepa AY598645 correspondiente a P. sylvaticum, neo-tipo CBS 453.67, obtenido por Lévesque y de Cock (2004).

$P$. sylvaticum se ubica en el clado F, el cual contiene especies de amplia distribución mundial, como $P$. spinosum, $P$. irregulare, $P$. mamillatum, $P$. paraecandrum entre otras (Lévesque y de Cock, 2004). 


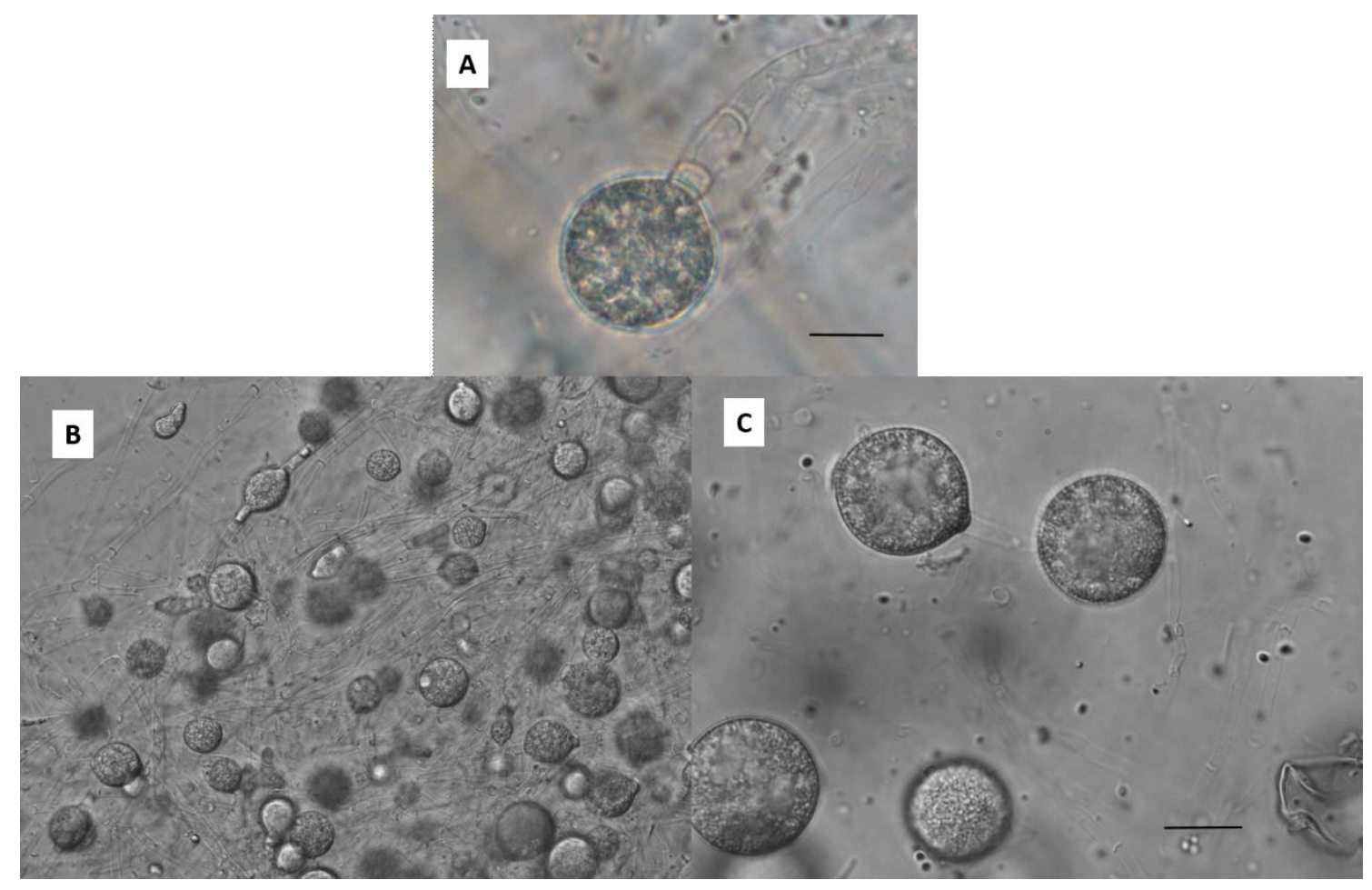

Figura 11. Pythium sylvaticum. A Esporangio terminal con detalle de septo B-C Esporangios terminales e intercalares. $\mathrm{BAR}=10 \mu \mathrm{m}$

>Pythium sylvaticum $\mathrm{P} 14-73$

TTCCGTAGGTGAACCTGCGGAAGGATCATTACCACACCTAAAAAACTTTCCACGTGAACTGT CGTTATTTGTTGTGTGTCTGCGCGTTGCTGGCGTGCGTTTGCTTACGCTTCGGTGTTTGCGAG TGCGTGCTGGCGGTGCGCGGACTGAACGAAGGTCGTGTTGCTGTGTGCCTGCTGCACTGCTG ACTTTGCATTGATTTGCATGGTCTTGGCGGAGCGGCGGGTGCTGTGCGTGCGCGGCTGACTT ACTTTTTCAAACCCCATACCTAACTTACTGATTATACTGTGAGAACGAAAGTTCTTGCTTTTA ACTAGATAACAACTTTCAGCAGTGGATGTCTAGGCTCGCACATCGATGAAGAACGCTGCGA ACTGCGATACTAATGCGAATTGCAGAATTCAGTGAGTCATCGAAATTTTGAACGCATATTGC ACTTCCGGGTTATGCCTGGAAGTATGTCTGTATCAGTGTCCGTAAATCAAACTTGCCTTTCTT CCTTCCGTGTAGTCGGTGGAGGANAGTTGCAATGTGAAGTGTCTCGCTGTGGTTGGTATATT TGTTTATGCACAACTTGCGAGTCCTTTTAAATGGACACGACTTTCTCTTTTTTGTATCTGCGC GGTGCTGTGCGTGAACGCGGTGGTTTTCGGATCGCTCGCGGCTGTCGGCGACTTCGGTGAAT GCATTATGGAGTGGACCTCGATTCGCGGTATGTTGGGCTTCGGCTGGACAATGTTGCTTATT GGGTGTCTGTTCCGCGTTCGCCTTGAGGTGTACTGGTGGCTGTGGGATTGAACTGGTTACTGT TGTTAGTAATGTGCGGCTCGTTGTCGTGNGTGCATCTGTGTTTTTTGCACTTGTGCAATTGGC AGAAGAGGAGTCTCAATTTGGGAAATTAGTGTACTCCNGGTTTGATCCTGCGTGTATATCTC AATTNGGACCTGATATCAGACAAGACTACCCGCTGAACTTAAGCATATT

\section{d. Rango de hospedantes y distribución mundial}

Entre sus hospedantes se halla: Apium graveolens, Daucus carota (Apiacae); Dieffembachia sp. (Araceae); Lactuca sativa (Asteraceae); Brassica campestris subsp. pekinenesis, Brassica oleracea (Brassicaceae); Beta vulgaris (Chenopodiaceae); Spinacea oleracea (Amaranthaceae), Cucumis sativus (Cucurbitaceae); Chamaecyparis sp. Juniperus conferta (Cupressaceae); Dioscorea batatas (Dioscoreaceae); 
Rhododendron sp. (Ericaceae); Glycine max, Lens culinaris, Medicago sativa, Phaseolus vulgaris, Pisum sativum (Fabaceae), Pelargonium sp. (Geraniaceae); Allium cepa, Tulipa sp. (Liliáceae); Abies sp., Pinus thunbergii (Pinaceae); Hordeum vulgare, Triticum aestivum (Poaceae); Fragaria $\times$ ananassa, Malus doméstica, Sorbusaria (Rosaceae); Capsicum annuum (Solanaceae); Valerianella locusta (Valerianaceae) (Spencer, 2004 b). Además se hallan citados como hospedantes a lino, rábano y pepino, algodón, Pinus, Picea y Liquidambar (Van der Plaats Niterink, 1981).

Presenta la siguiente distribución geográfica: África (Kenya, Sudáfrica); América (Canadá, Estados Unidos, Costa Rica); Asia (Japón); Australasia (Nueva Zelanda); Europa (Alemania, Bulgaria, Eslovenia, España, Francia, Gran Bretaña, Holanda, Irlanda, República Checa, Suiza). Según Van der Plaats-Niterink (1981) P. sylvaticum ha sido aislado de suelo en Estados Unidos y Canadá, en Holanda, en Alemania; de canales de riego en Estados Unidos y de canales y lagos en Holanda. Entre las referencias más recientes se encuentra citado en Inglaterra afectando plantas ornamentales; en Japón ocasionando podredumbre de raíces y tallo del crisantemo (Dendranthema x morifolium); en Noruega afectando plantas forestales; en Pakistán en cultivo de cebolla; en Sudáfrica como causante de podredumbre radicular en vegetales; en Suiza sobre espinaca; en Taiwán afectando crucíferas y en Estados Unidos afectando manzano y causando podredumbre de la base del tallo y tizón de las hojas de Miscanthus sinensis (Poaceaea) y podredumbre del tubérculo de papa. En Polonia fue citada afectando huevos de especies de peces. En Argentina fue registrado en plantas de Lavandula dentata y de Lavandula $x$ intermedia causando Podredumbre de raíces y marchitamiento en cultivos de La Plata, provincia de Buenos Aires (Wolcan y Grego, 2004) y Palmucci (2015) lo cita afectando Cyclamen persicum y Lavandula angustifolia.

\section{Pythium ultimum Trow var. ultimum (1901)}

Syn: Globisporangium ultimum (Trow) Uzuhashi, Tojo y Kakish. (2010)

Pythium ultimum var. ultimum fue aislado por primera vez por Trow (1901) y considerada como una especie no patógena. Posteriormente fue identificado afectando plantas de soja (Lehman y Wolf, 1926, citado por Van der Plaats-Niterink, 1981). Presenta amplia distribución mundial afectando una diversa gama de hospedantes. 


\section{a. Origen de los aislamientos}

Fueron aislados de numerosas muestras de plantas y suelos de campos comerciales tanto del NBA y SEBA durante la campaña 2013/14 y 2014/15.

\section{b. Caracterización cultural y morfológica}

En APG a $20^{\circ} \mathrm{C}$ desarrolló una colonia blanca densa algodonosa, de tipo aracnoide, con moderado micelio aéreo en los bordes de la caja de Petri. Presentó hifas cenocíticas con abundante producción de apresorios grandes y curvos (Fig. 12 A y B). Esporangios y zoosporas ausentes; hichamientos hifales globosos, terminales o intercalares (Fig. 12 C), 16-27 (prom. 21) $\mu \mathrm{m}$ diám.; oogonio liso, terminal, predominantemente esférico, raramente intercalar, 16-25 (prom. 21) $\mu$ m diám.; 1-2 anteridios monoclinos, usualmente uno por oogonio, con forma claviforme o reniforme, típicamente sésil, originado de la hifa oogonial, ubicado próximo al oogonio; oospora esférica, de pared lisa, aplerótica, 12 -23 (prom. 18,5) $\mu \mathrm{m}$ diám. (Fig. 12 D y E).

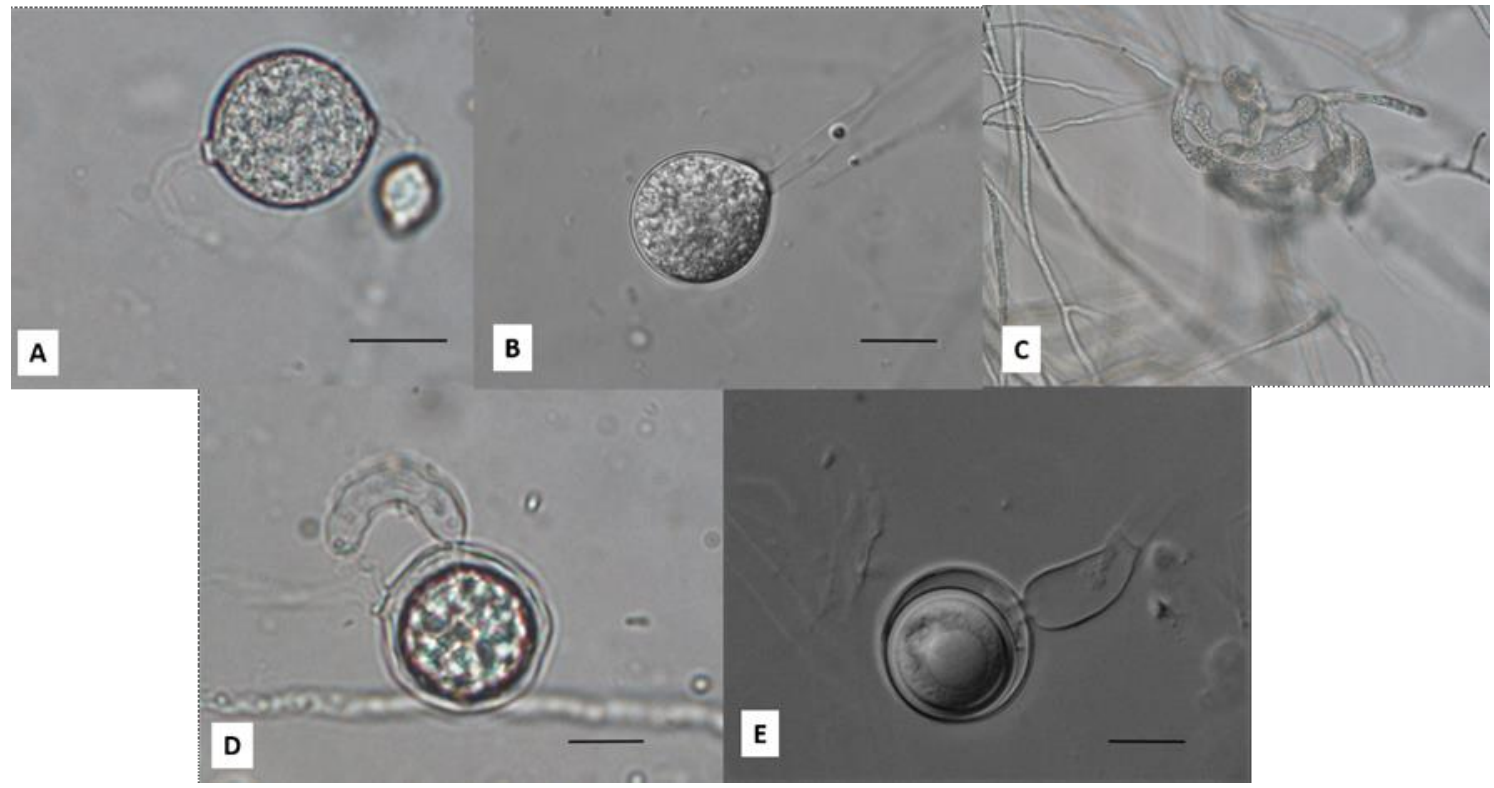

Figura 12. Pythium ultimum var. ultimum. A Esporangios intercalares B Esporangio terminal C. Hinchamientos hifales D-E Anteridios y oospora. $\mathrm{BAR}=10 \mu \mathrm{m}$.

\section{c. Caracterización molecular}

Se obtuvieron secuencias de 768 pares de bases, seleccionándose la secuencia de la cepa L17-Pin para su comparación con secuencias homólogas en el GenBank. Presentó un $100 \%$ similitud con la secuencia AY598657.2 correspondiente al aislamiento tipo CBS 398.51. 
>6.Pythium ultimum var. ultimum L17-Pin

AAAACTGTCCACGTGAACTGTAAGCAAGTCTAGCGCTGTGACTGAGCTGGTGTTTTCATTTTT GGACACTGGAACGGGAGTCAGCAGGACGAAGGTTGGTCTGTTGTAATGCAAGTTATGATGG ACTAGCTGATGAACTTTTGTTTTTAAACCCTTACCTAAATACTGATTTATACTGTGGGGACGA AAGTCCTTGCTTTTACTAGATAACAACTTTCAGCAGTGGATGTCTAGGCTCGCACATCGATG AAGAACGCTGCGAACTGCGATACGTAATGCGAATTGCAGAATTCAGTGAGTCATCGAAATTT TGAACGCATATTGCACTTTCGGGTTATGCCTGGAAGTATGTCTGTATCAGTGTCCGTAAATCA AACTTGCCTTTCTTTTTCTGTGTAGTCAGGGATGGAATGTGCAGATGTGAAGTGTCTCGCATG GTTGCGTTCGTTTTTTCGATCGAGAATCTGTCGAGTCCTTTTAAATGGACACGGTCTTTTCTA TGGTTTCTATGAAGTGTAATGGTTGGAAGGCAGTGATTTTCGGATTGCTGGCGGCTTTTGGC GACTTCGGTATGAACGTATGGAGACTAGCTCAATTCGTGGTATGTTAGGCTTCGGCTCGACA ATGTTGCGTAATTGTGTGTGGTCTTTGTTTGTGCCTTGAGGTGTACTAGAGGTTGTCGGTTTG AACCGTAAGTGATTGTTTAGTAGAGCATTTTCACGATGTATGGAGACGCTGCATTTAGTTGC GTAGAGAGATTGATTTGGG

P. ultimum var. ultimum se ubica en el clado I, junto a P. ultimum var. sporangiiferum, P. splendens y P. heterothallicum. P. ultimum var sporangiiferum es poco frecuente y es la única especie que presenta zoosporangios y zoosporas, en tanto las otras se distribuyen en todo el mundo y presentan sólo hinchamientos hifales de variado tamaño. P. ultimum var. ultimum y $P$. ultimum var. sporangiiferum son homotálicas, mientras que $P$. heterothallicum y P. splendens son heterotálicas (Lévesque y de Cock, 2004).

\section{d. Rango de hospedantes y distribución mundial}

Ha sido reportado en 719 hospedantes (Farr y Rossman, 2012). P ultimum var. ultimum fue citado en África (Angola, Congo República de Egipto, Kenia, Libia, Malawi, Nigeria, Sudáfrica, Tanzania, Uganda, Zimbawe); en Asia (Burma, China, Cyprus, India, Irán, Iraq, Israel, Japón, Korea, Laos, Filipinas, Tailandia, Turquía, Vietnam); en Australasia y Oceanía (Australia, Hawái, Nueva Zelandia); en Europa (Gran Bretaña, Islandia, Bulgaria, Checoslovaquia, Dinamarca, Finlandia, Francia, Alemania, Grecia, Irlanda, Italia, Holanda, Noruega, Suecia, Unión Soviética, Yugoslavia); en América (Canadá, México, Estados Unidos, Costa Rica, Haití, Puerto Rico, Trinidad, Argentina, Brasil) (CABI, 1981. Mapa 207. En http://www.cabi.org/dmpd/).

En Argentina se ha citado asociada a 99 hospedantes (Palmucci 2015). Se encontraron antecedentes de P. ultimum, ocasionando damping off en almácigos de Gypsophila sp. en la provincia de Córdoba (Frezzi, 1956) y de Dianthus caryophillus en La Plata, provincia de Buenos Aires (Carranza, 1979). Además, en la provincia de Córdoba en 1947 y 1953, P. ultimum causó la muerte de plantas grandes de Euphorbia marginata Pursh., debido a la podredumbre total de las raíces y al damping off, también provocó la muerte de plantas grandes de E. splendens Boger (espina de cristo), a causa de 
podredumbre total de raíces y parte del tallo. Palmucci (2015) citó P. ultimum var. ultimum en Actinidia deliciosa (kiwi) (de La Plata); en Euphorbia pulcherrima (Estrella federal) (de Garín); en Gazania rigens (gazania) (de Escobar); en Ocinum basilicum (albahaca) (en Ciudad de Buenos Aires) y en Dianthus caryophillus (clavel) (de Escobar).

\section{Pythium ultimun var. sporangiiferum}

Syn: Globisporangium ultimum var. sporangiiferum (Drechsler) Uzuhashi,Tojo y Kakish (2010).

\section{a. Origen de los aislamientos}

Fueron aislados de plántulas y de suelos de campos comerciales de Pergamino y Rojas (provincia de Buenos Aires) durante las campañas 2013/14 y 2014/15.

\section{b. Caracterización cultural y morfológica}

En APG a $20{ }^{\circ} \mathrm{C}$ desarrolló una colonia de similares características a las descriptas para P. ultimun var. ultimun (Fig. 13 A). También presentó hifas cenocíticas con abundante producción de apresorios grandes y curvos. Esporangios subesféricos intercalares o terminales de (23-) 27-32 (Prom. 28.5) $\mu \mathrm{m}$ diám con 1-2 tubos de descarga, usualmente uno (Fig. 13 B); oogonios esféricos, lisos, generalmente terminales, a veces intercalares, (15-) 19-24 (-26) (Prom. 22.3) um diám.; 1-2 anteridios monoclinos, usualmente uno por oogonio, claviformes o reniformes, típicamente sésil, originado de la hifa oogonial, ubicado próximo al oogonio; con oospora esférica, de pared lisa, aplerótica, 12-23 (Prom. 18,5) $\mu \mathrm{m}$ diám. 


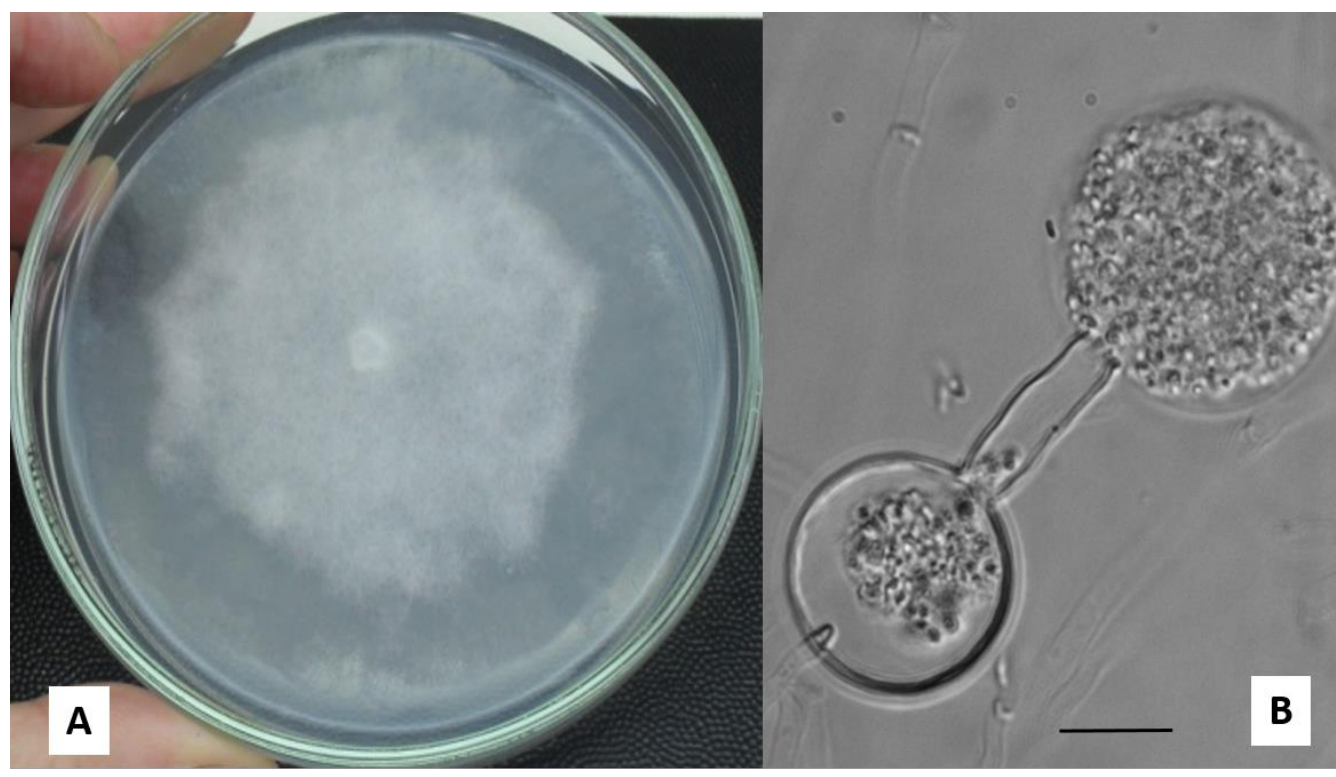

Figura 13. Pythium ultimum var. sporangiiferum. A) Colonia de 3 días de crecimiento en APD B) formación de la vesícula y pasaje del contenido del esporangio. $\mathrm{BAR}=10$ $\mu \mathrm{m}$.

\section{c. Caracterización molecular}

Se obtuvieron secuencias de 909 pares de bases, seleccionándose la secuencia de la cepa P13-13 para su comparación con secuencias homólogas en el GenBank. Presentó un $99 \%$ de similitud con la secuencia AY598656 correspondiente al aislamiento tipo CBS 219.65

$>13$ Pythium ultimum.var. sporangiiferum

ACAAGGTTTCCGTAGGTGAACCTGCGGAAGGATCATTACCACACTTTAAAACTGTCCACGTG AACTGTAAGCAAGTCTAGCGCTGTAACTGATCTAGTGTTTTCCTATTTTTGGGACACTGGAAT ACAGGATTCAGCAGGACGAAGGTTAGTCTCTCGTAATGCAAATTAGGAGGACTAGCTGATG AACTTTTCTTTTTAAACCCTTACCTAAATACTGATTTATACTGTGGGGACGAAAGTCCTTGCT TTTACTAGATAACAACTTTCAGCAGTGGATGTCTAGGCTCGCACATCGATGAAGAACGCTGC GAACTGCGATACGTAATGCGAATTGCAGAATTCAGTGAGTCATCGAAATTTTGAACGCATAT TGCACTTTCGGGTTATGCCTGGAAGTATGTCTGTATCAGTGTCCGTAAATCAAACTTGCCTTT CTTTTTTCTGTGTAGTCAGAGATGGAAAATGTGCAGATGTGAAGTGTCTCGCATGGTTGCGTT CGTTCGTTTTCGATCGACAATCTGTCGAGTCCTTTTAAATGGACACGGTCTTTCTATGGTTTC TATGAAGTGTGATGTTCGGAAGGCAGTGATTTTCGGATCACTGGCGGCTTTTGGCGACTTCG GTATAAACGTATGGAGATTACCTCAATTCGCGGTATGTTAGGCTTTGGCTCGACAATGTTGC GTAATTGTGTGTGGTCTTTGTTTGTGCCTTGAGGTGTACTAGAGGTTGTCGGTTTGAACTGTA AATGATTGTTTAGTAGGACATTTTCGCGATGTATGGAGACGTTGCATTTGGTTGCGTAGAGA GATTGATTTGGGAAAATTCTGTACTTTTGGCAATTGTTTGCTAAATGTATCTCAATTGGACCT GATATCAGACAAGACTACCCGCTGAACTTAAGCAT

P. ultimum var. sporangiiferum, se ubica en el clado I (Lévesque y de Cock, 2004). 


\section{d. Rango de hospedantes y distribucion mundial}

P. ultimum var. sporangiiferum fue citado en Estados Unidos (Ark y Middleton, 1949) aislado de Cattleya. Posteriormente fue registrado en Inglaterra y Grecia por Kouyeas (1964), quien no consideró las diferencias suficientes para retener a las dos variedades (P. ultimum var. ultimum y P. ultimum var. sporangiiferum) en P. ultimum.

En Argentina, Frezzi (1956) no diferenció entre P. ultimum var. sporangiiferum y var. ultimum. Todas las referencias fueron designadas como P. ultimum. Palmucci (2015) la cita ocasionando marchitamiento y podredumbre radicular de Poligala myrtifolia

\section{Pythium catenulatum Matthews} (1931)

\section{a. Origen del aislamiento}

El aislamiento 13/17 fue aislado a partir de muestras de suelos de campos comerciales de Pergamino (NBA) durante la campaña 2013/14.

\section{b. Caracterización cultural y morfológica}

Las colonias en AHM a $25{ }^{\circ} \mathrm{C}$ presentan un patrón arrosetado y sobre APZ un patrón finamente floreado. Las hifas principales midieron $4 \mu \mathrm{m}$ diám. Los esporangios consistieron en hinchamientos irregulares, como partes de ramas del micelio (Fig. $14 \mathrm{~A} \mathrm{y}$ B), a 20-25 ${ }^{\circ} \mathrm{C}$ formaron vesículas con 10-20 o más zoosporas. Las zoosporas enquistadas fueron de $9 \mu \mathrm{m}$ diám. Los hinchamientos hifales a menudo presentes en cadena de 3 a 8 , y entre 10 y $20 \mu$ m diám., cada uno germinando con 1-3 tubos germinativos- Los oogonios terminales e intercalares, a veces producidos en cultivos simples, pero la mayoría de las veces es necesario dos aislamientos compatibles. Los oogonios de (19-) 20-25(-27) $\mu \mathrm{m}$ (promedio 22,8 $\mu \mathrm{m}$ ) diám. La mayoría de la veces de 5 a 12 anteridios por oogonio, diclinos u ocasionalmente monoclinos en aislamientos homotálicos, clavados o de cuello curvado, teniendo contacto apical con el oogonio; los tallos anteridiales ramificados produciendo una o más células anteridiales. Las oosporas mayormente pleróticas, ocasionalmente apleróticas, de paredes de aprox. 1,5 $\mu \mathrm{m}$ diám.

La descripción se basa en la cepa CBS 843.68 (y cultivo dual con la cepa CBS 842.68) 


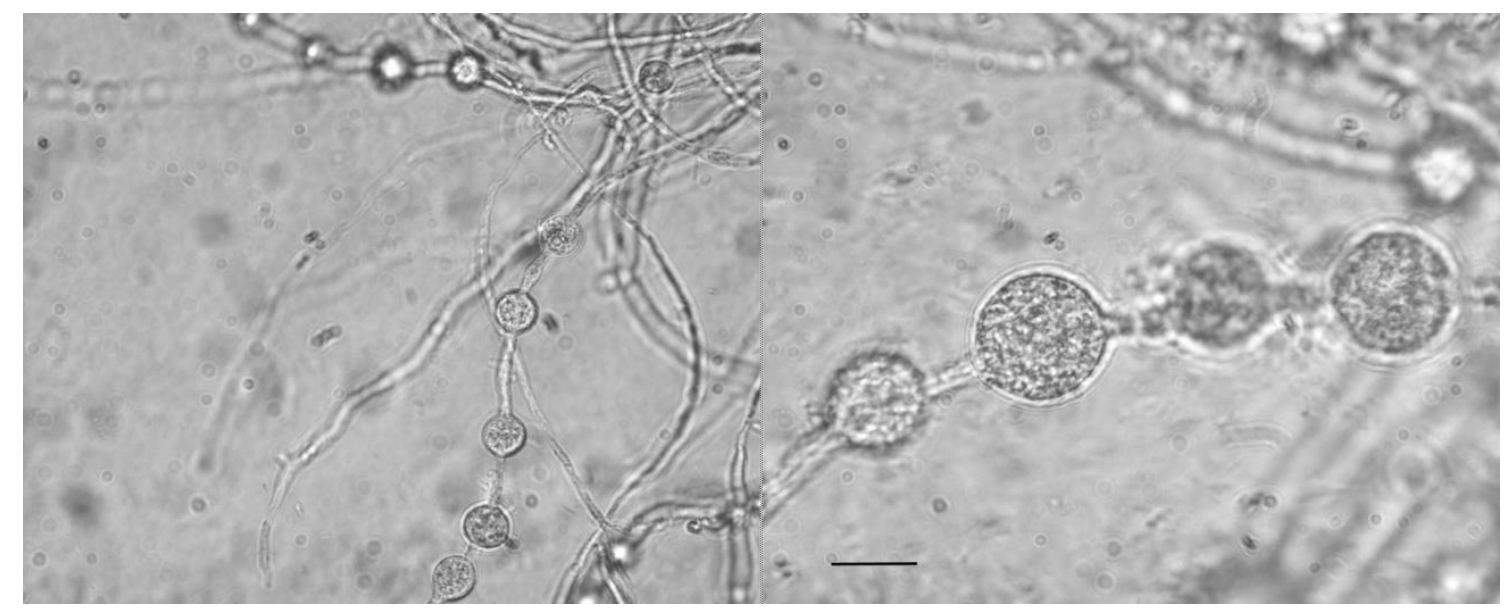

Figura 14. Pythium catenulatum. Detalle de esporangios en cadena. $\mathrm{BAR}=10 \mu \mathrm{m}$.

\title{
c. Caracterización molecular
}

Se obtuvieron secuencias de 855 pares de bases, seleccionándose la secuencia de la cepa P13-17 L9 para su comparación con secuencias homólogas en el GenBank. Presentó un $99 \%$ de similitud con la secuencia AY598675.2 correspondiente al aislamiento tipo CBS 842.68.

\begin{abstract}
> P13 17 L9 Pythium catenulatum
CAAGGTTTCCGTAGGTGAACCTGCGGAAGGATCATTACCACACCATAAAAACTTTCCACGTG AACCGTTACAATTATGTTCTGTGCTCTCTCTCGGGAGGGCTGAACGAAGGTGGAGCTGCATG TCAAAGTGCGGTTTCTGCCGATGTACTTTTAAACCCATTACACTAATACTGAACTATACTCCG AGAACGAAAGTTTTTGGTTTTAATCAATAACAACTTTCAGCAGTGGATGTCTAGGCTCGCAC ATCGATGAAGAACGCTGCGAACTGCGATACGTAATGCGAATTGCAGAATTCAGTGAGTCAT CGAAATTTTGAACGCACATTGCACTTTCGGGATATTCCTGGAAGTATGCTTGTATCAGTGTCC GTACATCAAACTTGCCTTTCTTTTTTTGTGTAGTCAAGGAGAGAAATGGCAGAATGTGAGGT GTCTCGCTGACTCCCTCTTCGGAGGAGAAGACGCGAGTCCCTTTAAATGTACGTTCGCTCTTT CTTGTGTCTAAGATGAAGTGTGACTTTCGAACGCAGTGATCTGTTTGGATCGCTTTGCGCGA GTGGGCGACTTCGGTTAGAACATTAAAGGAAGCAACCTCTATTGGCGGTATGTTAGGCTTCG GCCCGACTTTGCAGCTGACAGTGTGTTGTTTTCTGTTCTTTCCTTGAGGTGTACCTGTCTTGTG TGAGGCAATGGTCTGGGCAAATGGTTATTGTGTAGTAGAATTTTGCTGCTCTTGGACGCCCT ACTCGTAGGGTAAAGAAGGCAACACCAATTTGGGACTAGTCTGTTTCGGCAGGCGCATTTTC AATTTGGACCTGATATCAAGCAAGATTACCCGCTGAACTTAAGCA
\end{abstract}

$P$. catenulatum se ubica en el clado B1a, junto a $P$. angustatum, $P$. torulosum y $P$. folliculosum, presentan esporangios filamentosos inflados, a excepción de P. angustatum. Tienen una tasa de crecimineto moderada $(9-15 \mathrm{~mm} / \mathrm{d})$. Estas especies mayormente han sido aisladas de monocotiledoneas, algas verdes briofitas y de suelo, ocasionalmente de dicotiledoneas y coníferas. Su dsitribución es en todo el mundo (Lévesque y de Cock, 2004). 


\section{d. Ocurrencia y patogenicidad}

En USA $P$. catenulatum fue originalmente aislada de rastrojos en agua, posteriormente se aisló de suelo y de céspedes. Ha sido mencionada, en India en campos de arroz.

En Argentina, Frezzi (1956) la cita produciendo podredumbre de raíces y damping off en tomate, melón, pimiento y goma guar (Cyamopsis tetragonoloba) y también causó tizón de plántulas y podredumbre de raíces en caña de azúcar (van der Plaats-Niterink, 1981).

\section{Pythium longandrum Paul (2001)}

\section{a. Origen del aislamiento}

Fue aislado de muestras de suelos de campos comerciales de Fontezuela (partido de Pergamino) NBA durante la campaña 2013/14

\section{b. Caracterización cultural y morfológica}

Presenta micelio hialino, bien ramificado. Hifas principales hasta 7$8 \mu \mathrm{m}$ diám. Las colonias inmersas en APZ, muestran un patrón de crecimiento radiado fino. Los esporangios (Fig. 15 a-j) son globosos a algo alargados, principalmente intercalares y catenulados, pero a veces terminales y subterminales; miden 16-36 $\mu \mathrm{m}$ diám. (promedio de 29,4 $\mu \mathrm{m}$ ). Zoosporas no se observaron, pero se observaron esporangios que pueden germinar directamente para dar un nuevo micelio sin pasar por la fase de esporulación. Anteridios hipóginos y monóclinos con célula anteridial inflada (de allí su nombre). Oospora simple, aplerótica y plerótica, esféricas de 17- $23 \mu \mathrm{m}$ diám. 

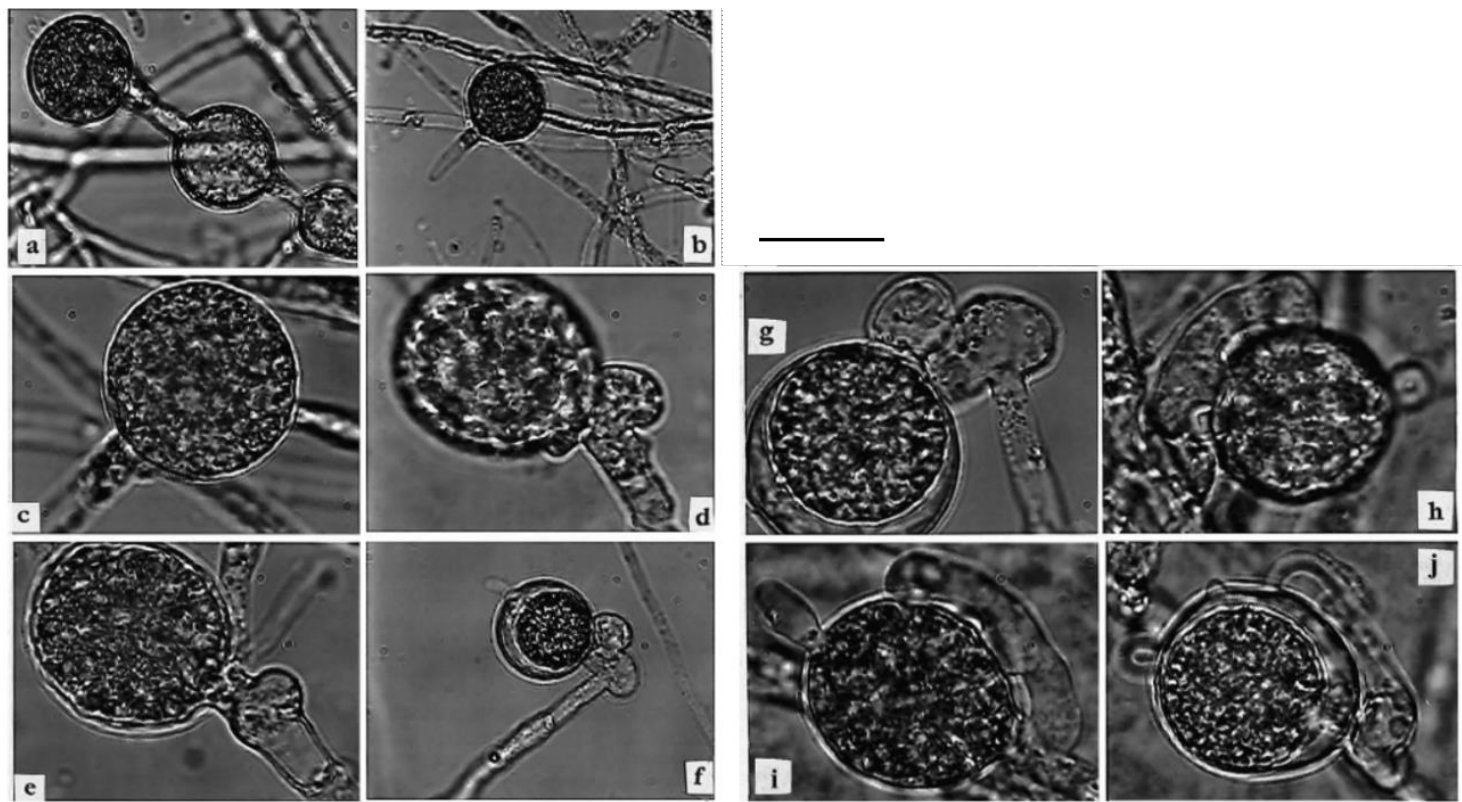

e
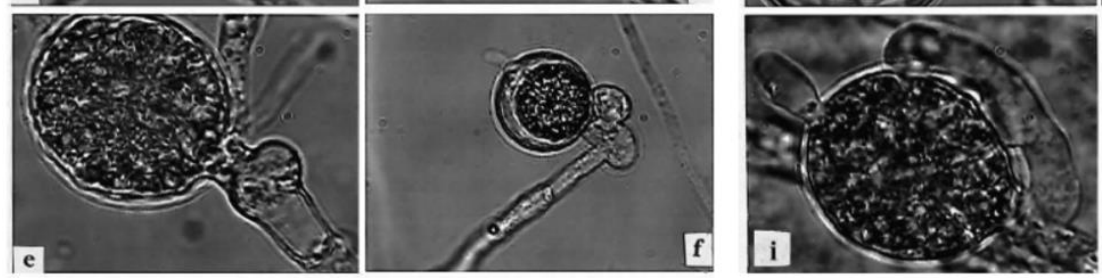

Figura 15. Pythium longandrum a: Esporangios catenulados b: esporangios subterráneos c: Esporangios intercalares d: Oogonio con anteridio hipógino e: anteridio hipógino con dos tubos de fertilización; f,g: Oogonio y anteridio con celula anteridial lobada; $\mathrm{h}, \mathrm{j}$ : Oogonio con célula anteridial larga y longitudinal. A, b y f: BAR $=40 \mu \mathrm{m}$; c, e, g y j: $\mathrm{BAR}=20 \mu \mathrm{m}$ (extraído de Paul, 2001).

\section{c. Caracterización molecular}

Se obtuvo una secuencia de 900 pb, que correspondió a la cepa F13-4 y la cual se comparó con secuencias homólogas en el GenBank. Presentó un 99 \% de similitud con la secuencia AY039713.2 tipo y original de la descripción de la especie. Y además presentó un $99 \%$ de similitud con la secuencia HQ643679.1 correspondiente al aislamiento de $P$. longandrum voucher CBS112355.

>1 Py F13-4 Pythium longandrum clade E.

CCACACCTAAAAACTCTCCACGTGAACTGTTTGTATCAGATTAGCGCCGAGATTTTCGTGCG TGTTTGTGGTATCGCTATGTATTCGTACGTGGCGTTAGCAAGCATTGTATGGAGCTTGGCTGA TCGAAGGTCGGTGCACACCTTGTGTGTGTGTTGGCTGATTAACCTTTCAAACCCTTTCAATAA ATACTGATTATACTGTGAGGACGAAAGTCTTTGCTTTTATCTAGATAACAACTTTCAGCAGTG GATGTCTAGGCTCGCACATCGATGAAGAACGCTGCGAACTGCGATACGTAATGCGAATTGC AGAATTCAGTGAGTCATCGAAATTTTGAACGCATATTGCACTTTCGGGTTATACCTGGAAGT ATGTCTGTATCAGTGTCCGTACATCAAACTTGCCTCTTTTTGTCGGTGTAGTCCGATCGAGAG TATGGCAGACGTGAGGTGTCTCGCGACTCGTATATCATTGTGTGTGTAAATCGTAAGAGATA CATACAGAAGGTAGTATATAACTTGTTGCGAGTCCCTTTAAAACGACACGATCTTTCTATTTG CTTTCTATGGAGCGTGTATTTCGAACGCGGTGGTCCTCGGATCGCTTGCAGTCGGCAGCGAC TTCAGTGAAGACATAGTGAAGAAACCTCTATTCGCGGTACGTTAGGCTTCGGCTCGACAATG TTGCGTTCTAGTGTGTGGACTCCGTTTTCGCTTTGAGGTGTACTGTTCGGTTGTGGGTTTGAG CCTTGGTATTGCTTTGTTAGTAGAGATATCTCGATTTTCTGTAGTTTGATTCTGCATACACGC AAGTGTGTGTGGTAGAGAGTATCTATTTGGGAAATTTTGTACTGCGTGCGCTTTCGAGTGTGT GTATGTATCTCAATTGNACCTGATA

$P$. longandrum pertenece al clado E, junto a P. acrogynum, P. hypogynum, $P$. echinulatum, $P$. erinaceus, $P$. radiosum, y P. rostratum. Este grupo se caracteriza por 
esporangios ovoides a alargados, que no proliferan; en su mayor parte un anteridio hipógıno único; oosporas pleróticas, y crecimiento lento $(7-12 \mathrm{~mm} / \mathrm{d})$. Las especies de este clado han sido aisladas principalmente del suelo. $P$. echinulatum y $P$. rostratum se distribuyen en todo el mundo, pero las otras especies se han encontrado sólo una vez (Lévesque y de Cock, 2004). P. longandrum fue aislado primeramente de muestras de suelo en Francia (Paul, 2001)

\section{Pythium paroecandrum Drechler (1930)}

Syn: Globisporangium paroecandrum (Drechsler) Uzuhashi, Tojo y Kakish (2010).

\section{a. Origen de los aislamientos}

Fueron aislados de muestras de suelos de campos comerciales de Necochea y Balcarce (SEBA) durante la campaña 2014/15 y de muestras de granos cosechados de soja provenientes Pergamino y Solís (NBA) durante la campaña 2015/16.

\section{b. Caracterización cultural y morfológica}

Colonias sumergidas en AHM y en APZ muestran un patrón de crecimiento radiado. Hifas principales de $9 \mu \mathrm{m}$ diám. Apresorios a menudo presentes. Esporangios sub-globosos o elipsoidales, intercalares o terminales, de 12-33 $\mu \mathrm{m}$ diám. Tubos de descarga 4-20 (-100) $\mu \mathrm{m}$ long. X $4 \mu \mathrm{m}$ diäm., a veces ensanchado en el apice. Los oogonios sub-globosos, casi siempre intercaleres, a menudo en cadenas, raramente terminales, lisas, (14-)17-24(-27) (promedio 19) $\mu \mathrm{m}$ diám. 1-2 hasta 5 anteridios por oogonio, monoclinos, a veces sésiles, diclinos, ocasionalmente intercalares o hypóginos (Fig. 16 A). Las oosporas son apleróticas, de paredes lisas, (13-)15-21(-23) (prom. 17) $\mu \mathrm{m}$ diám., pared de 1,0-1,5 $\mu \mathrm{m}$ de ancho (Fig. 16 B). 


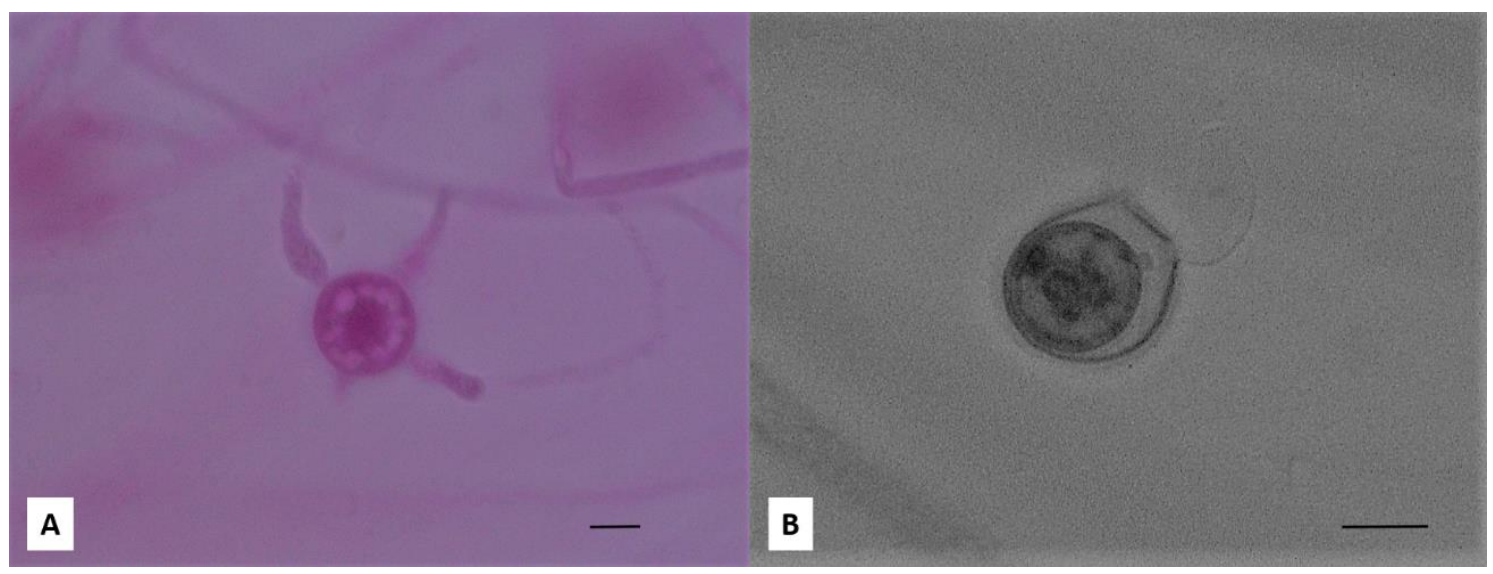

Figura 16. Pythium paroecandrum A Oogonio y anteridios B. Oospora aplerótica. $\mathrm{BAR}=10 \mu \mathrm{m}$.

\title{
c. Caracterización molecular
}

Se obtuvieron secuencias de 925 pb, que correspondió a la cepa B 15-132 y la cual se comparó con secuencias homólogas en el GenBank. Presentó un 99 \% de similitud con la secuencia de la cepa CBS 157.64 (\#GenBank AY598644.2) correspondiente a la cepa tipo de $P$. paroecandrum.

\begin{abstract}
$>132$ Pythium_paroecandrum GTGAACCTGCGGAAGGATCATTACCACACCTAAAAAACTTTCCACGTGAACTGTCGTTATTT GTTGTGTGTGTGCGCGTTGCTGGCGTGCGTTTGCTTACGCTTCGGTGTTTGCGAGTGCGTGCT GTCGGTGCGCGGACTGAACGAAGGTCGTGTGTTTGCTGTGTGCCTGCTGCACCGCTGACTTT GCATTCATTTGCATGGTCTTGGCGGAGCGGCGGGTGCTGTGCGTGCGCGGCTGACTTATCTTT TTCAAACCCCATACCTAAATGACTGATTATACTGTGAGAACGAAAGTTCTTGCTTTAAACTA GATAACAACTTTCAGCAGTGGATGTCTAGGCTCGCACATCGATGAAGAACGCTGCGAACTGC GATACGTAATGCGAATTGCAGAATTCAGTGAGTCATCGAAATTTTGAACGCATATTGCACTT CCGGGTTATGCCTGGAAGTATGTCTGTATCAGTGTCCGTAAATCAAACTTGCGTTTCTTCCTT CCGTGTAGTCGGTGGAGGAGAGTTGCAGATGTGAAGTGTCTCGCTGTGGTTGGCGTTCGTTA TTTGTAATGAATGCAGAGCTTGCGAGTCCTTTTAAATGGACACGACTTTCTCTTTTTTGTATC TGCGCGGTGCTGTGCGTGAACGCGGTGGTTTTCGGATCGCTCGCGGCTGTCGGCGACTTCGG TGAATGCATGATGGAGTGGACCTCGATTCGCGGTATGTTGGGCTTCGGCTGGACAATGTTGC TTATTGTGTGTCTGTTCCGCGTTCGCCTTGAGGTGTACTGGTGGCTGTGGGATTGAACTGGTT ACTGTTGTTAGTAGTGTGTGTGGCGCGTTGTCGTGGATGCATCTGTGTTTTTGCATACTTGTG TGTGTGCAATTGTACAGAAGAGGAGTCTCAATTTGGGAAAAATTTGTGTAC
\end{abstract}

$P$. paroecandrum pertenece al clado F. Este clado se compone de importantes patógenos vegetales con una distribución mundial, excepto P. kunmingense y P. cylindrosporum, que han sido raramente aislados. La mayoría de las especies no producen o raramente producen zoosporas. Forman esporangios globosos, no proliferantes o hinchamientos hifales globosas (sólo P. irregulare desarrolla ambos) y tienen crecimiento rápido (a menudo más de $25 \mathrm{~mm} / \mathrm{d}$ ) y temperaturas cardinales moderadas. 
P. kunmingense, P. spinosum, P. cylindrosporum, P. irregulare, P. mamillatum y $P$. paroecandrum forman un subclado que no está fuertemente apoyado por el valor de bootstrap. Sin embargo, todas estas especies, con excepción de P. paroecandrum, tienen oogonios con un número variable de espinas, la mayoría de forma digitada, y diferente de la ornamentación predominantemente aguda en oogonios de las otras especies ornamentadas. Todas las especies restantes en el clado F desarrollan oogonios lisos y todas, excepto P. debaryanum, son heterotálicas (Lévesque y de Cock, 2004).

\section{d. Ocurrencia y patogenicidad}

P. paroecandrum fue originalmente aislado en EEUU de ajo silvestre (Allium vineale). No es muy común pero ampliamente distribuida. En EEUU fue citada en Aloe, en duraznero, en alfalfa, en crisantemo y en zanahoria. En Australia fue citada sobre trigo, en República Checa sobre cactus, en Holanda sobre bulbos de flores y conejito, en Irlanda sobre tulipanes. Ha sido aislada frecuentemente de suelos: en EEUU, Alemania, Holanda y Líbano.

En inoculaciones experimentales $P$. paroecandrum fue levemente patogénico sobre plántulas de varias fanerógamas: trebol, durazno, alfalfa, crisantemo, pino, zanahoria y maiz. P. paroecandrum fue mas patogénico a $28^{\circ} \mathrm{C}$, en contraste con $P$. ultimum que causa el mayor daño a $23,5^{\circ} \mathrm{C}$ (Van der Plaats-Niterink, 1981).

\section{Pythium aff. heterothallicum Campbell y Hendrix (1968)}

Syn: Globisporangium heterothallicum (Campbell y Hendrix) Uzuhashi, Tojo y Kakish (2010).

\section{a. Origen del aislamiento}

Fue aislado de muestra de granos cosechados de soja provenientes de Pergamino (NBA) durante la campaña 2015/16.

\section{b. Caracterización cultural y morfológica}

Las colonias en AHM forman micelio aéreo, en APZ tienen un crecimiento radial o arrosetado. La hifa principal tiene más de $7 \mu \mathrm{m}$ diám. No produce esporangios y 
zoosporas. Posee abundantes hinchamientos hifales, globosos o limoniformes, terminales o intercalares, mayores de 21 (-25) $\mu \mathrm{m}$ diám (Fig. 17 b 1-2). Oogonios globosos, terminales o intercalares, a menudo solo producidos en cultivos duales de aislamientos compatibles, (20-) 22-29(-32) (prom. 24) $\mu \mathrm{m}$ diám. Anteridios diclinos, más de 8 por oogonios, frecuentemente formando un nudo envolvente alrededor del oogonio (Fig. 17 a 1-3). La célula anteridial levemente inflada, ramificada, a menudo bifurcada cerca del oogonio. Oosporas apleróticas, 18-25(-28) (promedio 21) $\mu \mathrm{m}$ diám., pared de 1,5-2 $\mu \mathrm{m}$ diám.

Descripción basada en CBS 450.67 y cultivo dual con CBS 451.67.

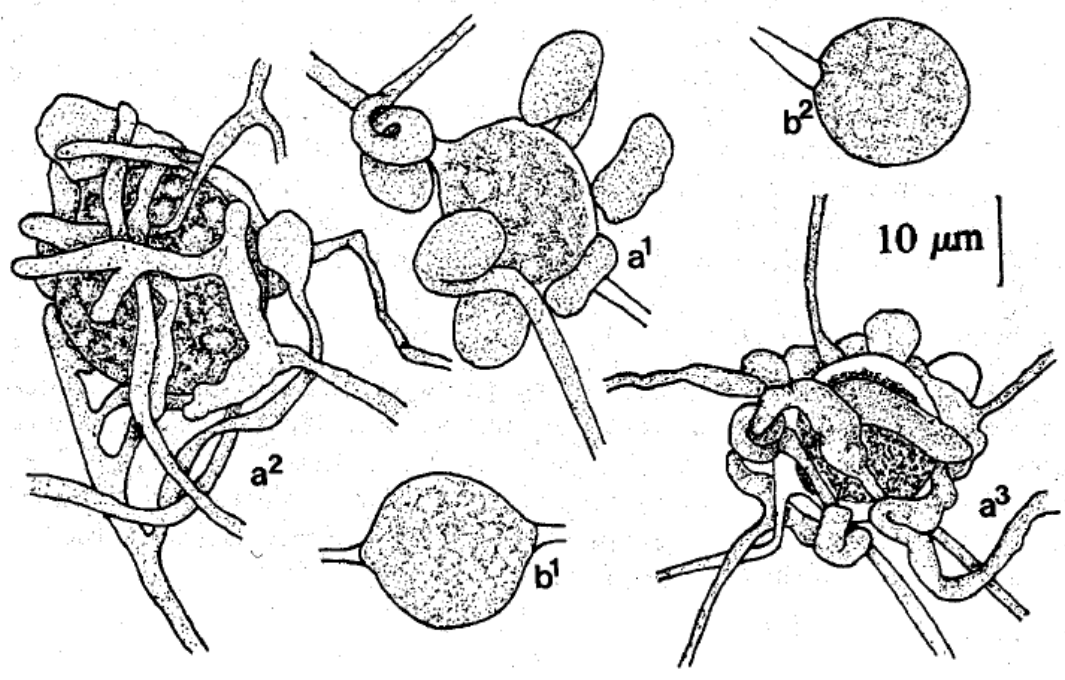

Figura 17. Pythium heterothallicum a 1-3 oogonio y anteridio. B 1-2 hinchamientos hifales (de Van der Plaats-Niterik, 1981).

\section{c. Caracterización molecular}

Se obtuvo una secuencia de 852 pb, que correspondió a la cepa SE 16-4 y la cual se comparó con secuencias homólogas en el GenBank. Presentó un 99 \% de similitud con la secuencia de la cepa $P$. heterothallicum voucher ABD: 155 (\# GenBank MF115338.1) y $99 \%$ similitud con JF431916.1 Pythium aff. heterothallicum cepa OW1761, pero solo $95 \%$ de similitud con la cepa tipo CBS 450.67 (\# GenBank AY598654.2). Por lo cual convendría secuenciar uno o dos genes extras, para corroborar su identidad. 
ACGAAAGTTCTTGCTTTAAACTAGATAACAACTTTCAGCAGTGGATGTCTAGGCTCGCACAT CGATGAAGAACGCTGCGAACTGCGATACGTAATGCGAATTGCAGAATTCAGGGAGTCATCG AAATTTTGAACGCATATTGCACTTTCGGGTTAGACCTGGAAGTATGTCTGTATCAGTGTCCGT ACATCAAACTTGCCTCTCTTTTTTCTGTGTAGTCAGGATTGGAGACGTGCAGATGTGAAGTGT CTCGCGCACTTGCGTCTTCGGACGACAAGCAAGCGAGTCCTTTTAAACCGACACGATCTTTC TATTGTTTTGNTGAAGNGTATTGCTCGAACGCGGTGATTTTCGGATCGCTCGCAGTCGTCGGC GACTTCGGTGAGAACATACAGGAGGAAACCTCGATTCGCGGTATGTTCGGCTTCGGCTCGAC AATGTTGCTTATTGGGTGTGGAATCTGTTTTCGCCTTGAGGTGTACTGATGGTTGTGTGCTTG AACTGGGAGTTGGTGTGTAGTAGAGTGGTGCNNNNTGCATGGTTACGCTCTTTTGTATATAG AAAGATGTCTATTTGGGAAATTTGTATGTTTGGCAACTCGTTGCTGAATGTATCTCAATTGGA CCTGATATCAGACAAGACTACCCGCTGAACTTAAGCATAT

$P$. heterothallicum pertenece al clado I. Los taxones que pertenecen a este clado son $P$. heterothallicum, P. splendens, $P$. ultimum var. ultimum y P. ultimum var. sporangiiferum. No existen caracteres morfológicos comunes para este clado. P. ultimum var. sporangiiferum es raro, mientras que las otras especies tienen una distribución mundial. Poco se sabe sobre la patogenicidad de $P$. heterothallicum, pero las otras especies son principalmente patógenas de las dicotiledóneas. P. ultimum var. sporangiiferum es la única especie que desarrolla esporangios y zoosporas; los otros tres en cambio tienen hinchamientos de varios tamaños. Ambas variedades de P. ultimum son homotálicas, mientras que las otras dos especies son heterotálicas.

\section{d. Ocurrencia y patogenicidad}

$P$. heterothallicum fue originalmente aislado a partir de suelo de Canadá. Ha sido principalmente citado en suelo como saprófito pero aparece en varias partes del mundo. Ha sido citado en EEUU, en Holanda, en Nueva Zelanda, Republica Checa, Alemania, Kenia y Costa Rica. Nada se conoce acerca de su patogenicidad.

\section{Pythium nunn Lifshitz, Stanghellini y Baker (1984)}

Syn: Globisporangium nunn (Lifshitz, Stanghellini y Baker) Uzuhashi, Tojo y Kakish (2010).

\section{a. Origen del aislamiento}

El aislamiento fue obtenido a partir de granos cosechados de soja de Necochea (SEBA) durante la campaña 2014/15.

\section{$\underline{\text { b. Caracterización cultural y morfológica }}$}

La identificación morfológica se basó en las claves de van der Plaats-Niterink (1981) y la descripción de la especie de Lifshitz et al. (1984). 
La hifa principal tiene más de $6.5 \mu \mathrm{m}$ diám. No produce esporangios y zoosporas. Posee abundantes hinchamientos hifales, globosos o limoniformes, terminales o intercalares, entre 12.2-22.5 (prom. 16.2) $\mu \mathrm{m}$ diám. (Fig. 18 A y B). Oogonios globosos, terminales, 18.5-23.0 (prom. 20.8) $\mu$ m diám. Anteridios monóclinos o diclinos, de 1 a 5 por oogonios (Fig. 18 C). Célula anteridial inflada o curvada. Oosporas apleróticas, 18.0-20.5 (prom. 19.2) $\mu \mathrm{m}$ diám., pared menor de $2.0 \mu \mathrm{m}$ de grueso (Fig. $18 \mathrm{D})$. Temperaturas cardinales $7-42{ }^{\circ} \mathrm{C}$ (óptimo $34{ }^{\circ} \mathrm{C}$ ). Tasa diaria de crecimiento a $25^{\circ} \mathrm{C}$ en APZ $14.0 \mathrm{~mm} /$ día. Descripción basada en CBS 808.98 (AY598709; Lévesque and de Cock 2004; Lifshitz et al., 1984).

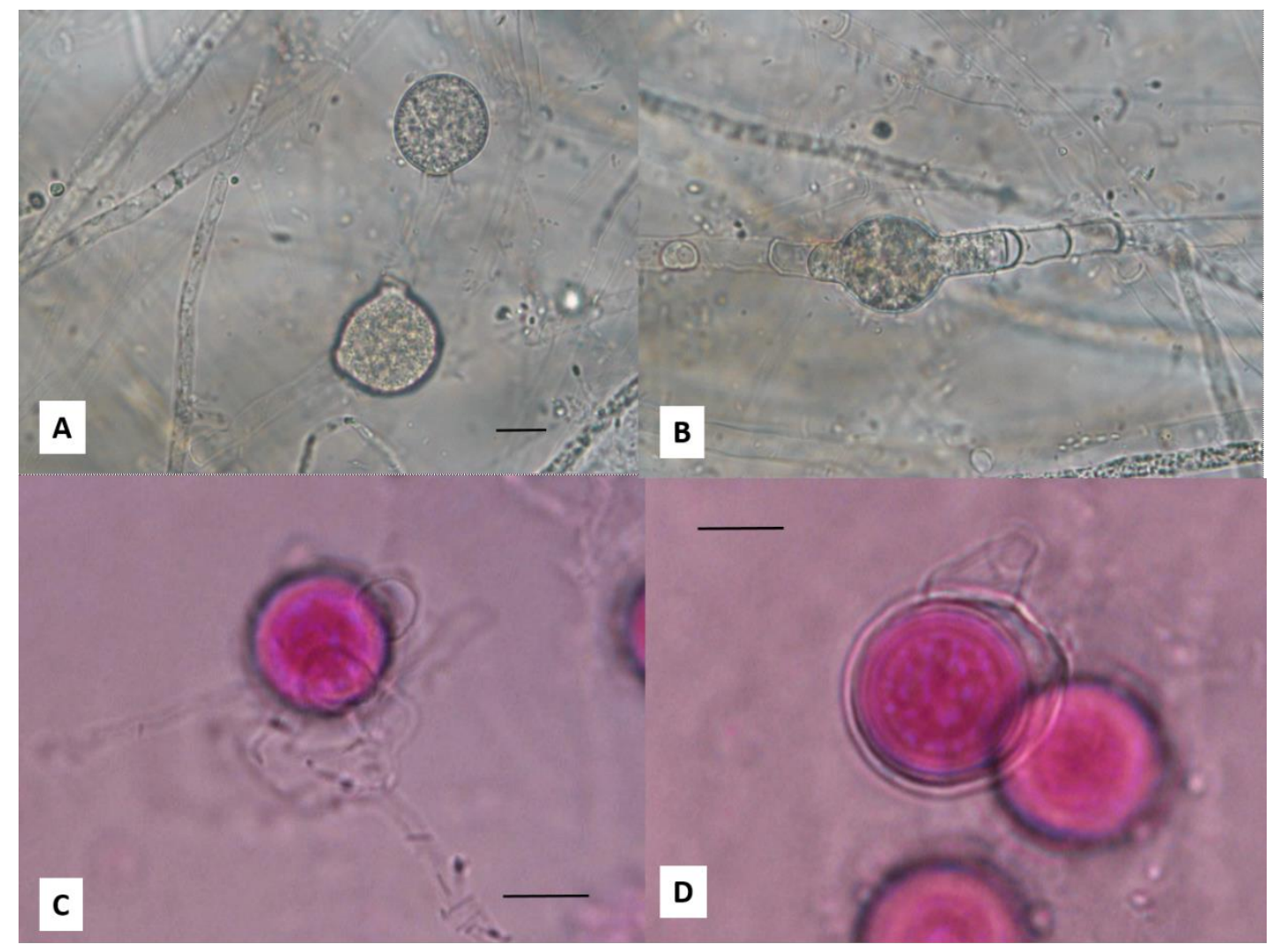

Figura 18. Pythium nunn A-B Hinchamientos hifales intercalares C. Anteridios y oogonio. D. Oospora. BAR=10 $\mu \mathrm{m}$.

\section{c. Caracterización molecular}

Se obtuvo una secuencia de 923 pb, que correspondió a la cepa SE-15Nec, la cual se comparó con secuencias homólogas en el GenBank. Presentó un 98 \% de similitud con la secuencia de la cepa tipo P. nunn CBS 808.96 (\# GenBank AY598709.2) 


\begin{abstract}
$>$ Pythium nunn
TACCACACCAAAAAAACTTTCCACGTGAACCGTTCTGTCCGTTTTGTGCCGTTGCTGTTGTCG TGATTCGACGAGAAGAGCAGCGGCTAAACGAAGGCTGTGAGCTTCGTGCTTGCGGTCGATTT ATTCTTTCAAACCCCATACGTTAAGAACTGAAGTATACTGTGAGGACGAAAGTCCTTGCTTT GAACTAGATAGCAACTTTCAGCAGTGGATGTCTAGGCTCGCACATCGATGAAGAACGCTGC GAACTGCGATACGTAATGCGAATTGCAGGATTCAGTGAGTCATCGAAATTTTGAACGCATAT TGCACTTTCGGGTTATGCCTGGAAGTATGTCTGTATCAGTGTCCGTACCTCAACCTTGCCTTT CTTTTCCGGTGTAGTCCGGAGCGGAAACGTGCAGACTTGAAGTGTCTCGCTTGTTGGTTTGC GAAAGCAATTTTGCAACACAGCTGGGCGAGTCCTTTGAAATGGACACGATCTTTCTACTGTT TTCTACGGAGTGTGGCGCTCGAAAAGCGGCGGTTTCCTTCGGGATCGCTCGCAGTTTGGACG GCGACTTTGGCGAATGCATATGGGAAGCAGACTCGACTCGCGGTACGTTAGGCGTGTTGCTG TTGCTTTTTTGCAACGGCGGCGTGCTGAACAATGTTGCGTGTTGTGGTCTTGTTTCCTGTGTT CGCTTCGAGGTGTACTGTCTATTGGCTGTGAGAGTGAACCTTTGTGGGATGTGTATGCCGTC GTTCGGTAGAGCGGTGCGTGGTACTCTTTTGTGGGAATGCCATGGCTTTCGCGGCTTTTGGTA AAGTAGTGAGACGCAATTTGGGAAGTATTGTGTGTACTCGCGCGTGCAGCGCGTGTATGATC ATCTCAATTGGACCTGATATCAGACAAGACTACCCGCTGAACTTAAGCATAT
\end{abstract}

Hay varios reportes de la actividad antagónica de $P$. nunn contra $P$. ultimum var. ultimum (Lifshitz et al., 1984; Paulitz y Baker 1988)

\title{
1.3.1.2.2 Ogonios ornamentados
}

\section{Pythium irregulare Buisman (1927)}

Syn: Pythium equiseti Sadebeck (1874)

Pythium irregulare var. irregulare Buisman (1927)

Pythium irregulare var. hawaiiense Sideris (1932)

Pythium polymorphon Sideris (1932)

Pythium fabae G. Cheney (1932)

Pythium kunmingense Yu (1973)

Globisporangium irregulare (Buisman) Uzuhashi, Tojo y Kakish. (2010).

P. irregulare Buisman fue aislado por primera vez en Holanda (Buisman, 1927) de raíces necrosadas de arveja (Pisum sativum), semillas de lupino (Lupinus sp.) y de zapallo (Cucumis sativus). Es una especie cosmopolita, patógena de numerosos cultivos.

\section{a. Origen de los aislamientos}

Los aislamientos se obtuvieron tanto de plántulas con sintomatología típica como de muestras de suelos. Durante la campaña 2013/14 se obtuvieron 22 aislamientos de Fontezuela, Pergamino y Rojas (NBA) y 8 aislamientos de Necochea, Balcarce y General Pirán (SEBA). Durante la campaña 2014/15 se obtuvieron 18 aislamientos del NBA y 12 aislamientos del SEBA de todas las localidades muestreadas. Durante la campaña 
2015/16 se obtuvieron de granos cosechados de soja provenientes de Pergamino y Capitán Sarmiento (NBA).

\section{b. Caracterización cultural y morfológica}

A los 7 días de la siembra en APG a $20^{\circ} \mathrm{C}$, desarrolló una colonia algodonosa, de crecimiento radiado con abundante micelio aéreo en los bordes de la caja de Petri. En AHM formó tenue micelio aéreo. Presentó esporangios terminales o intercalares esféricos de 10-28 (prom. 19) $\mu \mathrm{m}$ diám. En agua germinaron rápidamente observándose zoosporas. Presencia de hinchamientos hifales terminales o intercales de forma variada. En APG y AHM se observaron abundantes oogonios de 10-29 (prom. 20) $\mu \mathrm{m}$ diám., esféricos, subesféricos, limoniformes, terminales o intercalares, con la pared lisa, con 1-3 proyecciones cónicas, rectas o algo curvas, con ápice redondeado o ligeramente curvado; 1-3 anteridios por oogonio, generalmente monóclinos, claviformes, algo curvos, originados a cierta distancia del pie del oogonio, algunos ocasionalmente sésiles, hipóginos y oosporas apleróticas de pared lisa de 10-22 (prom. 17) $\mu \mathrm{m}$ diám (Fig. 19 AD).

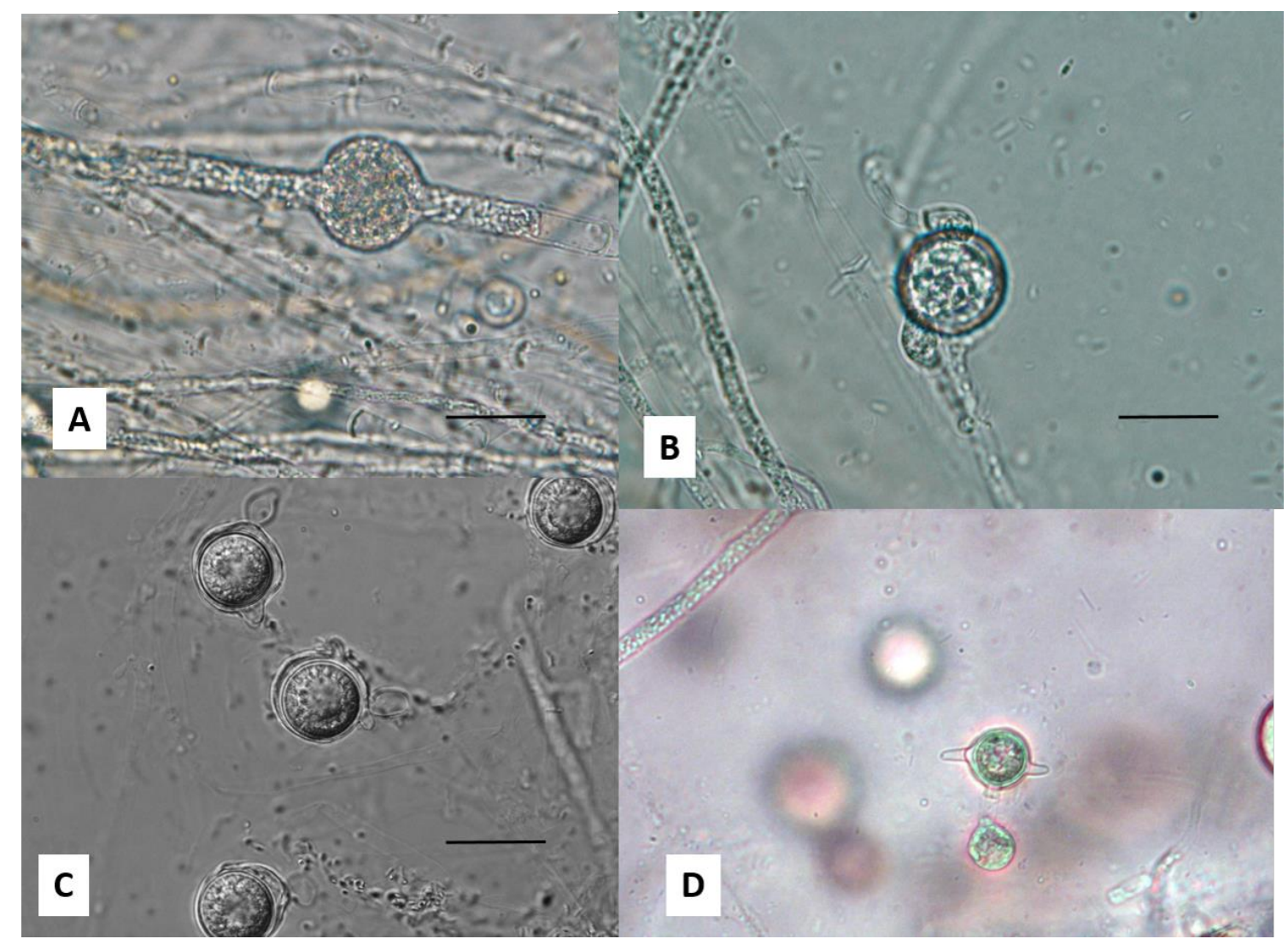

Figura 19. Pythium irregulare A Hinchamientos hifales intercalares B-C. Anteridios y oogonio. D. Oospora ornamentada. BAR $=20 \mu \mathrm{m}$. 


\section{c. Caracterización molecular}

Se obtuvieron secuencias de 923 pb, se utilizó la secuencia de la cepa Py 13-47 para su comparación con secuencias homólogas en el GenBank. Presentó un $99 \%$ similitud con la cepa tipo CBS 250.28. (\# Genbank HQ643596) y también $99 \%$ de similitud con la cepa CBS74996 (\# GenBank HQ643602)

\section{>47. Pythium irregulare}

AAAAACTTTCCACGTGAACTGTCGTTATTTGTTGTGTGTGTGCGTGTTGGTAGCATGCGTGTT TGCTTACGCTTTGGTGTTTGCGAGTGCGCGTACTGTCGGTGCGCAGACTGAACGAAGGTCGT GTGTTGCTGTGTGCCTGCTGCACTGCTGACTTTGCATTGATTTGCATGGTGTTGGCGGAGCGG CGGGTGCTGTTGCGTGCGCGGCTGACCTATTTTTTTCAAACCCCATACCTAAATGACTGATTA TACTGTGAGAACGAAAGTTCTTGCTTTTAACTAGATAACAACTTTCAGCAGTGGATGTCTAG GCTCGCACATCGATGAAGAACGCTGCGAACTGCGATACGTAATGCGAATTGCAGAATTCAG TGAGTCATCGAAATTTTGAACGCATATTGCACTTCCGGGTTATGCCTGGAAGTATGTCTGTAT CAGTGTCCGTAAATCAAACTTGCGTTTCTTCCTTCCGTGTAGTCGGTGGAGGAGAGTTGCAG ATGTGAAGTGTCTCGCTGTGGTTGGTGTTCGTTGTTTGCAATGAATGCACAGCTTGCGAGTCC TTTTAAATGGACACGACTTTCTCTTTTTTGTATGTACGCGGTGCTGTGCGTGAACGCGGTGGT TTTCGGATCGCTCGCGGCTGTCGGCGACTTCGGTGAATGCATAATGGAGTGGACCTCGATTC GCGGTATGTTGGGCTTCGGCTGGACAATGTTGCTTATTGTGTGTCTGTTCCGTGTTCGCCTTG AGGTGTACTGGTGGCTGTGGGATTGAACTGGTTACTGTTGTTAGTAGTGTGTGTGGCACGTT GTCGTGGATGCATCTGTGTTTTTGCATACTTGTGTGTGTGCAATTGTACAGAAGAGGAGTCTC AATTTGGGAAAAGTTTTGTATACTCCGGGTTGATCCTGCGTGTACATC

$P$. irregulare se ubica en el clado $\mathrm{F}$ que comprende especies fitopatógenas de rápido crecimiento, con distribución mundial. Se caracterizan por la presencia de esporangios globosos, no proliferantes e hinchamientos hifales. La mayoría de las especies de este agrupamiento no producen, o raramente producen zoosporas (Lévesque y de Cock, 2004).

\section{d. Rango de hospedantes y distribución mundial}

Luego del primer aislamiento realizado de plantas de Pisum sativum, C. sativus y Lupinus sp., ha sido aislado de numerosos hospedantes, entre otros: Allium spp., Ananas comusus, Antirrhinum sp., Apium graveolens, Atropa belladona, Beta vulgaris, Capsicum annuum, Citrullus sp., coníferas, Daucus carota, Eucaliptus sp., Fragaria $x$ ananassa, Gossypium hirsutum, Ipomoea sp., Iris sp., Jacintus sp., Lactuca sativa, Linum usitatissimum, Medicago sativa, Nicotiana sp., Persea americana, Phaseolus vulgaris, Rhododendrom sp., Rheum rhabarbarum, Saccharum officinarum, Scilla spp., Solanum lycopersicum, Spinacea oleraceae, y del suelo, turba y agua (van der Plaats-Niterink, 1981). Se hallan citadas 230 relaciones hospedante-patógeno (Farr y Rossman, 2014 citado en USDA-Fungal nomenclature database). 
Se halla distribuido en: Europa (Alemania, Bélgica, Bulgaria, Chipre, Dinamarca, Escocia, España, Finlandia, Francia, Italia, Lituania, Noruega, Países Bajos, Polonia, Reino Unido, Rusia, Serbia, Suecia, Suiza, Ucrania); Asia (Corea, China, Filipinas, India, Irán, Iraq, Israel, Japón, Líbano, Malasia, República Popular Democrática, República de Corea (Corea del Sur), Sabah, Taiwán, Vietnam); África (Egipto, Ghana, Sudáfrica, Túnez); América del Norte (Canadá, EE.UU); América Central y el Caribe (Puerto Rico);

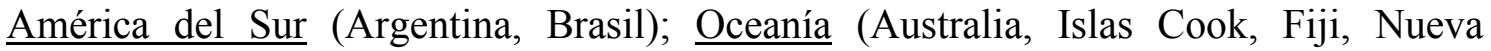
Caledonia, Nueva Guinea, Nueva Zelanda, Papúa, Polinesia francesa, Tasmania, Vanuatu) (CABI/EPPO, 2011).

En Argentina fue identificado afectando plantas de cebada (Hordeum vulgare) con menor desarrollo y clorosis seguida de necrosis parcial o total de las hojas (Frezzi, 1956). Además se hallan citados 36 hospedantes afectados por $P$. irregulare: Alternanthera sp. (alternantera), Arachis hypogaea (maní); Avena sativa (avena), Camellia thea (camelia), Cupressus lusitanica (ciprés lambertiana), Cynara scolymus (alcaucil), Daucus carota (zanahoria), Dianthus caryophillus (clavel), Eruca sativa (rúcula), Erythrina crista-galli (seibo), Eucalyptus occidentales (eucalipto), Foeniculum vulgare (hinojo), Gaillardia aristata (gallardia), Glycine max (soja), Gypsophila sp. (gipsófila), Lactuca sativa (lechuga), Lupinus sp. (lupino), Solanum lycopersicum (tomate), Medicago sativa (alfalfa), Nicotiana tabacum (tabaco), Petroselinum crispum (perejil), Phaseolus vulgare (poroto), Phoenix dactylifera (palmera datilera), Pinus halepensis (pino de Alepo), Pisum sativum (arveja), Solanum melongena (berenjena), Sorghum vulgare (sorgo), Thuja sp. (tuya), Thuja occidentales var. compacta (tuya compacta), Tragopogon porrifolius (salsifí), Trifolium repens (trébol blanco), Zinnia sp. (zinnia). Palmucci (2015) lo indica produciendo podredumbre de raíces y base del tallo en Primula obconica, Impatiens wallerana y Scindapsus aureus y afectando plantas de Primula obconica, Impatiens wallerana, Scindapsus aureus y Epipremnum aureum.

\section{Pythium acanthicum Drechsler (1930)}

\section{$\underline{\text { a. Origen de los aislamientos }}$}

Los aislamientos fueron obtenidos a partir de granos cosechados de soja provenientes de Solís y San Antonio de Areco (NBA), durante la campaña 2015/16. 


\section{b. Caracterización cultural y morfológica}

Colonias suemergidas en AHM, volviéndose amarillentas despues de algún tiempo, en APZ mostró patrón arrosetado. La hifa principal mayor de $5 \mu \mathrm{m}$ diám. Esporangios intercalares y ocasionalmente terminales, subglobosos, pero a menudo formando complejos de dos o más, intercalares, subglobosos o porciones irregulares conectadas con partes de las hifas. Tubo de descarga (10-)20(-200) $\mu \mathrm{m}$. long; las zoosporas se forman a $20^{\circ} \mathrm{C}, 15-20$ en una vesícula, enquistadas 8-10 $\mu \mathrm{m}$ diám. Oogonios terminales o intercalares, globosos, (17-)21-24(-27) (prom. 22) $\mu \mathrm{m}$ diám., pared fina y ornamentada, proyecciones cónicas, con ápice sin puntas, (1-)2,2-3,0(-5) $\mu \mathrm{m}$ lomg. Uno a veces dos anteridios por oogonio (Fig. 20 A), típicamente monóclinos, raramente diclinos, evanescentes después de la fertilización, tallo anteridial que se originan a una distancia mayor de $25 \mu \mathrm{m}$ debajo del oogonio, la mayoría de las veces con prolongaciones de ramas vegetativas, célula anteridial clavada e inflada, recta o curvada, a menudo con una o dos constricciones, aplicados al oogonio con la punta o enteramente con la célula. Oospora pleróticas, o casi pleróticas, pero siempre libres a partir de la pared oogonial, sin color o levemente amarillo, (16-)18-23(-25) (prom. 21) $\mu \mathrm{m}$ diám., pared 1-2,8 $\mu$ m diám (Fig. 20 B).

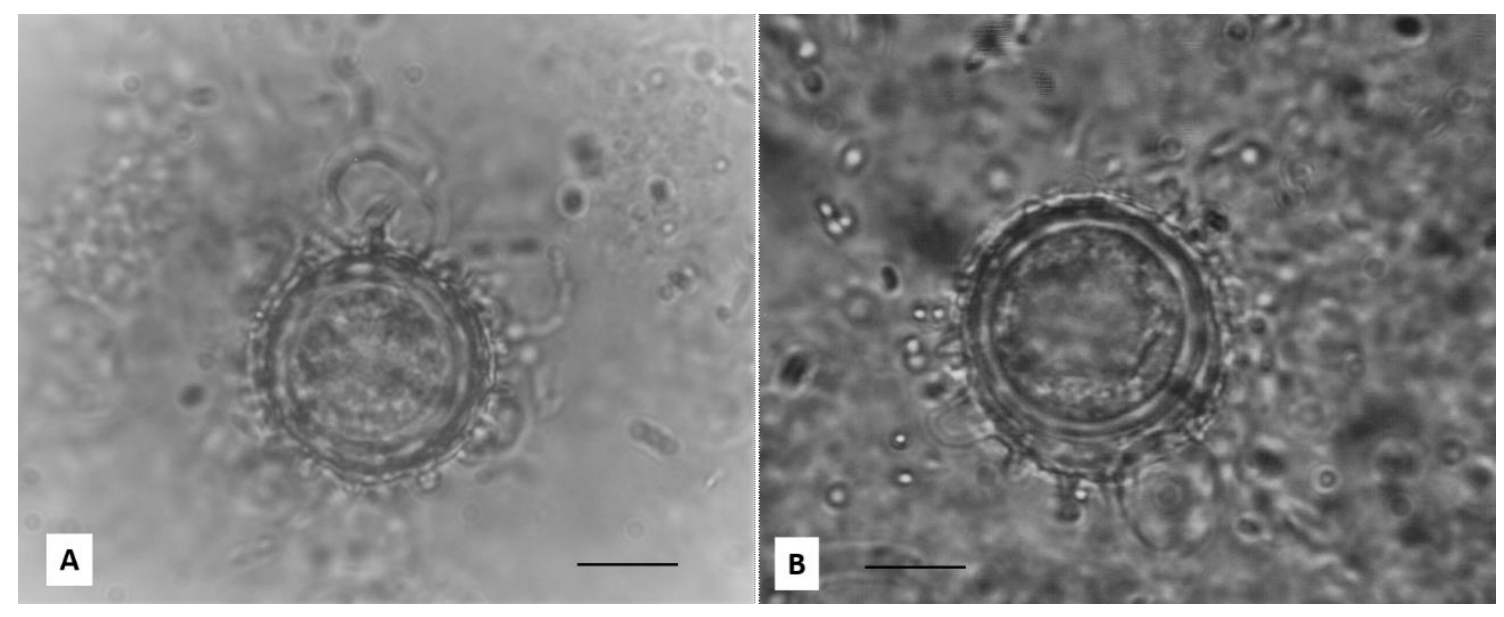

Figura 20. Pythium acanthicum A. Detalle de anteridio y oogonio. B. Oosporas. BAR= $10 \mu \mathrm{m}$

\section{c. Caracterización molecular}

Se obtuvieron secuencias de 818 pb, se utilizó la secuencia de la cepa Se 16-30 para su comparación con secuencias homólogas en el GenBank. Presentó un 98 \% similitud con la cepa tipo CBS 284.31 (\# Genbank AY598617.2). 
$>$ Pythium acanthicum Se 16-30

CATTACCACACCTAAAAACTTTCCACGTGAACCGTTATAACTATGTTCTGTGTCTCGTCTTGT CAAAAGATTTGAGGCTGAACGAAGGTGAGTCTGTGTCGATTTTTATTGATGCGGATTCGCTG ATGTTATTTTAAACACCTATTACTTTATACTGAACTATACTCCGAATACGAAAGTTTTTGGTT TTAACAATTAACAACTTTCAGCAGTGGATGTCTAGGCTCGCACATCGATGAAGAACGCTGCG AACTGCGATACGTAATGCGAATTGCAGAATTCAGTGAGTCATCGAAATTTTGAACGCATATT GCACTTTCGGGTTATGCCTGGAAGTATGCCTGTATCAGTGTCCGTACATCAAACTTGCCTTTC TTTTTTTGTGTAGTCAAAATTGGAGATGGCAGAATGTGAGGTGTCTCGCGCTGTCTTTTTCAG ATGGTTCGAGTCCCTTTAAATGTACGTTGATTCTTTCTTGTGTCTGCGAATTGCGACGCTATG CTCTTTGTGATCGNTTTAGATTGCTTTGCGCTGGTGGGCGACTTCGGTTAGGACATATGGAAG CAACCTCAATTGGCGGTATGTTCGGCTTTGCCTGACGTTAAGCTAAGCGAGTGTGGTTTTCTG TTCTTTCCTTGAGGTGTACCTGTCGTGTGTGANGTCGGTTTGAGCTATATGGTTGCTTGGTTG TGTGGTCTAGCGTTTTCAGACGCCTGCTTCGGTAGGTAAAGGAGACAACACCGATTTGGGAC GGAGAGTAGTTTACTCTCTTTTTCACTTTGGACCTGATATCAGGTAAGACTACCCGCTGAACT TAA

\section{c. Ocurrencia y patogenicidad}

P. acanthicum ha sido registrada a partir de Citrus vulgaris en EEUU, Argentina, Queensland y Rusia; sobre Dahalia sp., Pisum sativum, Phaseolum vulgare, Solanum melongena y Curcuma domestica en Sud Africa, EEUU, Rep. Checa y Rusia y en diferentes vegetales en Nueva Zelandia y Queesland; en caña de azúcar en Japón, en especies forestales, como pino, Carya illinoensis, Camelia sp., Azalea y Rosa spp. en EEUU y Tanzania, En Cryptomeria japonica, juniperus chinensis, Setcreasea sp. y Hebe sp. en Nueva zelandia, y en suelo en Inglaterra, USA, Nueva Zelandia, Australia, Micronesia y Holanda.

De acuerdo con Drechsler (1930), P. acanthicum puede causar podredumbre del final del pimpollo y podredumbre de frutos en sandia. Robertson (citado por Van der PlaatsNiterink, 1981) encontró que fue altamente patógeno en semillas de tomate, pero débilmente patógeno en otros hospedantes, sugiriendo que varias cepas de esta especie pueden variar en su patogenicidad. Fue no patógena en plántulas de maíz (Van der PlaatsNiterink, 1981). En Argentina fue citado produciendo podredumbre de frutos y raíces de sandía (Frezzi,, 1956) y podredumbre de frutos y raices. En maní, lavanda y orégano, y ocasionando marchitamiento, en Fragaria sp. (Tello et al., 2002, Sandoval et al., 2009 y Sillón et al., 2002 citados por Palmucci, 2015).

\section{Pythium periplocum Drechsler (1930)}

\section{$\underline{\text { a. Origen de los aislamientos }}$}

Los aislamientos fueron obtenidos a partir de granos cosechados de soja provenientes de Solís (NBA) durante la campaña 2015/16. 


\section{b. Caracterización cultural y morfológica}

Las colonias en AHM y APZ producen escaso micelio aéreo, en APZ sin patrón especial de crecimiento. Hifa principal más de $9 \mu \mathrm{m}$ diám. Esporangios terminales e intercalares, consistiendo en elementos ramificados, lobados o digitados formando un gran complejo (Fig. 21 b 1-2). Tubos de descarga a menudo muy largos, ocasionalmente más de $500 \mu \mathrm{m}$ long. Las zoosporas enquistadas 8-11 $\mu \mathrm{m}$ diám. Oogonios terminales e intercalares, (19-)24-27(-29) (prom. 26) $\mu \mathrm{m}$ diám. ornamentados con espinas romas, espinas 2-4 (-5) $\mu \mathrm{m}$ long. y 1,53 $\mu \mathrm{m}$ diám. en la base (Fig. 21 a 1-4). De 1 a 4 anteridios por oogonio, diclinos, ocasionalmente clavados, la mayoría más de $30 \mu \mathrm{m}$ long., lobados o ramificados, aplicados cerca y a menudo más o menos enredados al oogonio. Oosporas apleróticas, sub-globosas, (18-)20-24(-26) (prom. 22) $\mu \mathrm{m}$ diám., pared más de $3 \mu \mathrm{m}$ diám (Fig. 22).

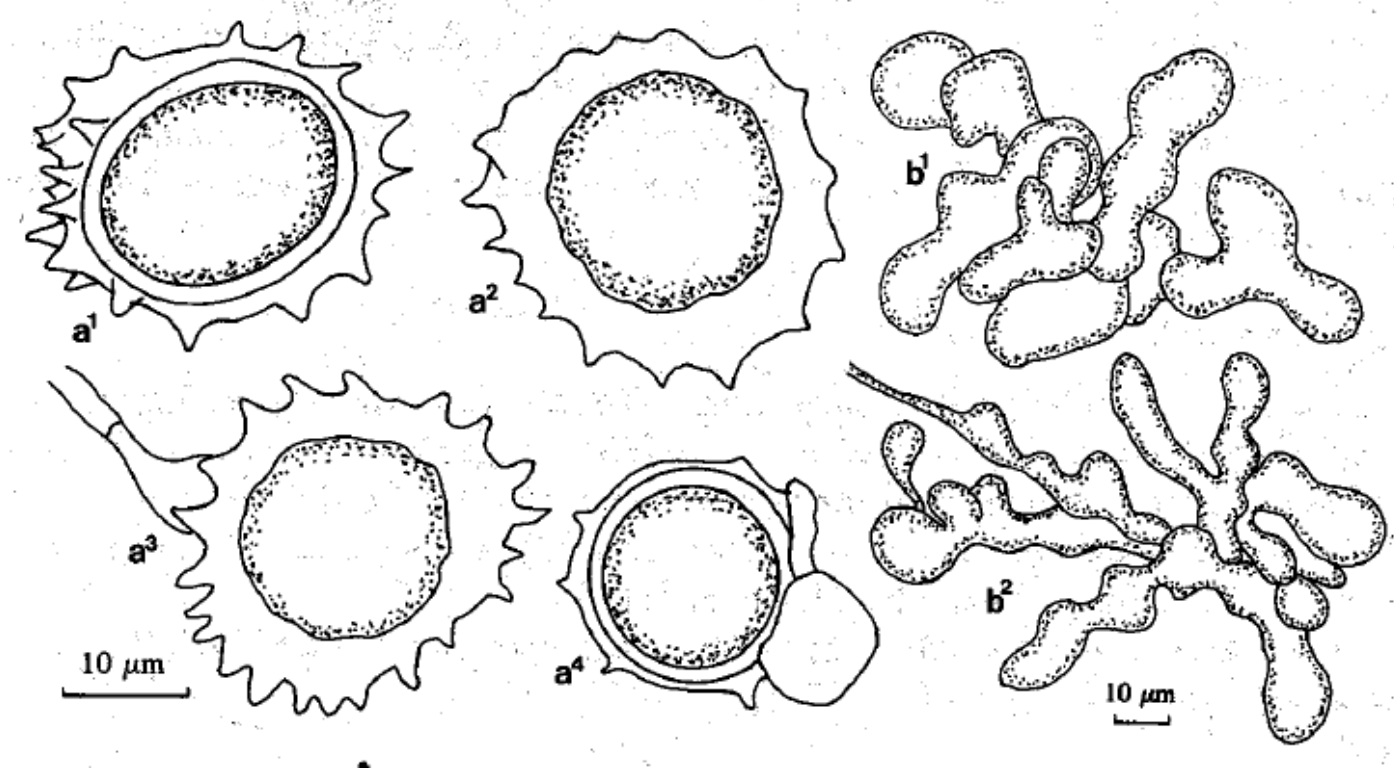

Figura 21. P. periplocum. A 1-4 oogonios ornamentados, b 1-2 esporangios (Van der Plaats Niterink, 1981). 


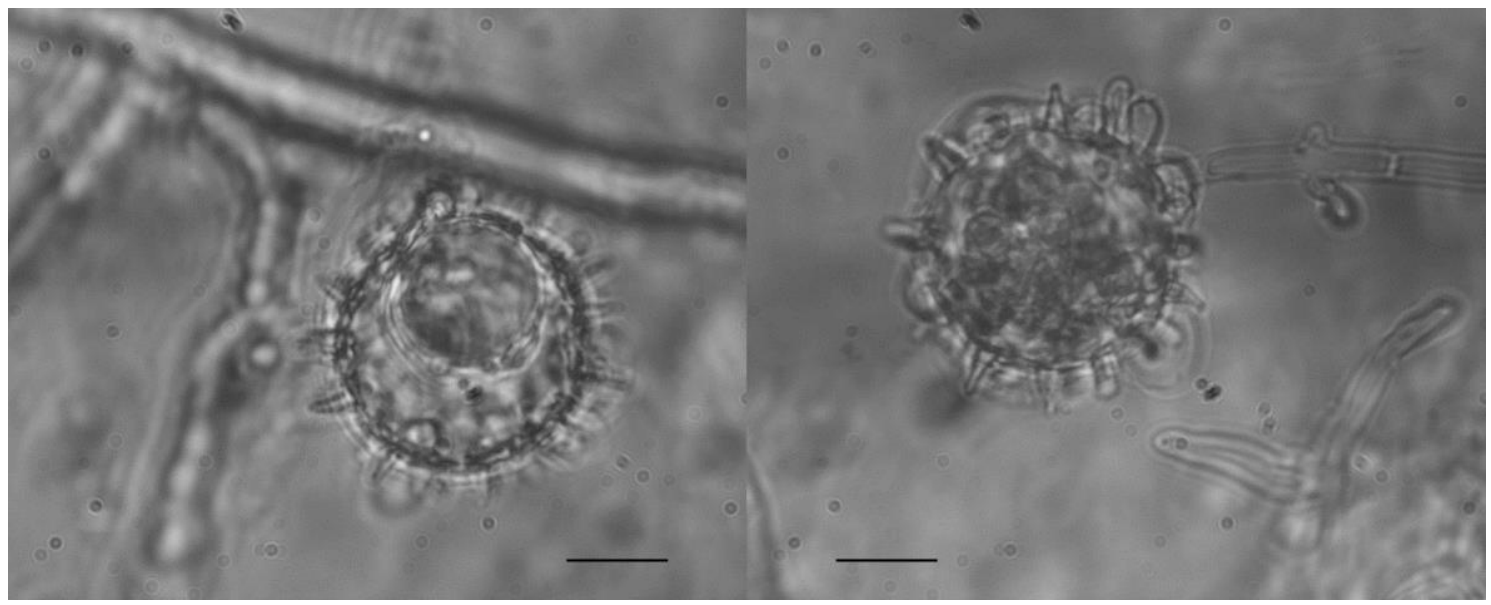

Figura 22. $P$. periplocum. Oospora ornamentada y anteridio. $\mathrm{BAR}=10 \mu \mathrm{m}$

\section{c. Caracterización molecular}

Se obtuvieron secuencias de 825 pb, se utilizó la secuencia de la cepa SE 16-38 para su comparación con secuencias homólogas en el GenBank. Presentó un $99 \%$ similitud con la cepa tipo P. periplocum voucher CBS17068 (\# Genbank HQ643741.1). Pero solo presentó un $95 \%$ de similitud con la cepa tipo de $P$. periplocum CBS 289.31 18S (\# AY598670.2)

$>$ Pythium periplocum SE.38 E11

ATTACCACACCTAAAAACTTTCCACGTGAACCGTTATAACTATGTTCTGTGCTTCGTCTTCATCGTAAGAT TTGAGGCTGAACGAAGGTGAGTCTGCGTCCATTTTGGATGCGCATTTGCTGATGTGATTTTAAACACCT ATTACTTAATACTGAACTATACTCCGAATACGAAAGTTTTTGGTTTTAACAATTAACAACTTTCAGCAGT GGATGTCTAGGCTCGCACATCGATGAAGAACGCTGCGAACTGCGATACGTAATGCGAATTGCGCAATT CAGTGAGTCATCGAAATTTTGAACGCATATTGCACTTTNGGGTTATGCCTGGAAGTATGCCTGTATCAG TGTCCGTACATCAAACTTGTCTTTCTTTTTTTGTGTAGTCAAAATTAGAGATGGCAGAATGTGAGGTGTC TCGCGCTGTCTTTTTTAAAAAGATGGTTCGAGTCCCTTTAAATGTACGTTGATTCTTTCTTGTGTCTGCGA ATTGCGACGCTATGCTCTTTGTGATCGGTTTAGATTGCTTTGCGCTGGTGGGCGACTTCGGTTAGGACA TATGGAAGCAACCTCAATTGGCGGTATGTTCGGCTTTGCCTGACGTTAAGCTAAGCGAGTGTGGTTTTC TGTCTTTTCCTTGAGGTGTACCTATTGTGTGTGAGGTTGGTTTAGGCTATATGGTTGCTTGGTTGTGTGG TTTAGCGTTTTCAGACGCCTGCTTCGGTAGGTAAAGGAGACAACACCAATTTGGGACTGAGAGTTTACT CTCTTTTTCACTTTGGACCTGATATCAGGTAAGACTACCCGCTGAACTTAAGCATATCAT

P. periplocum pertenece al clado D junto con P. acanthicum, P. amascullinum, $P$. hydnosporum y P. oligandrum 


\section{Pythium spinosum Sawada (1926)}

Syn: Globisporangium spinosum (Sawada) Uzuhashi, Tojo y Kakish. (2010).

\section{$\underline{\text { a. Origen del aislamiento }}$}

El aislamiento fue obtenido a partir de muestras de suelos de la localidad de Capitán Sarmiento (provincia de Buenos Aires) durante la campaña 2015/16.

\section{b. Caracterización cultural y morfológica}

La colonia en APG desarrolló un micelio blanco con abundantes hifas aéreas de aspecto algodonoso, sin patrón de crecimiento (Fig. 23 A). Micelio cenocítico fino con hifas principales menores a $7 \mu \mathrm{m}$ diám., con ramificaciones secundarias bastante separadas entre sí y a su vez muy ramificadas, tabicadas al envejecer. No se observaron apresorios. Desarrolló “esporangios" denominados hinchamientos hifales por no formar zoosporas (van der Plaats-Niterink, 1981; Lodhi, 2007), terminales o intercalares de forma esférica o limoniforme, pared fina, mayormente lisa, 10-23 (prom. 20) $\mu \mathrm{m}$ dám; oogonios terminales o intercalares, amarillentos, globosos o fusiformes, 14-21 (prom. 17,38) $\mu \mathrm{m}$ diám., ornamentados con numerosas proyecciones o espinas de forma digitada, 4,5-8,5 $\mu \mathrm{m}$ diám. con ápice romo; 1-3 anteridios por oogonio, mayormente monoclinos, ocasionalmente diclinos, pedicelados, evanescentes luego de la fertilización, con una célula anteridial, claviforme, alargada, con ápice redondeado, lisa y oosporas amarillentas pleróticas, ocasionalmente apleróticas, esféricas, lisas (13-) 16-19 (-20) (prom. 18) $\mu \mathrm{m}$ diám., de paredes finas (Fig. 23 B-D). 


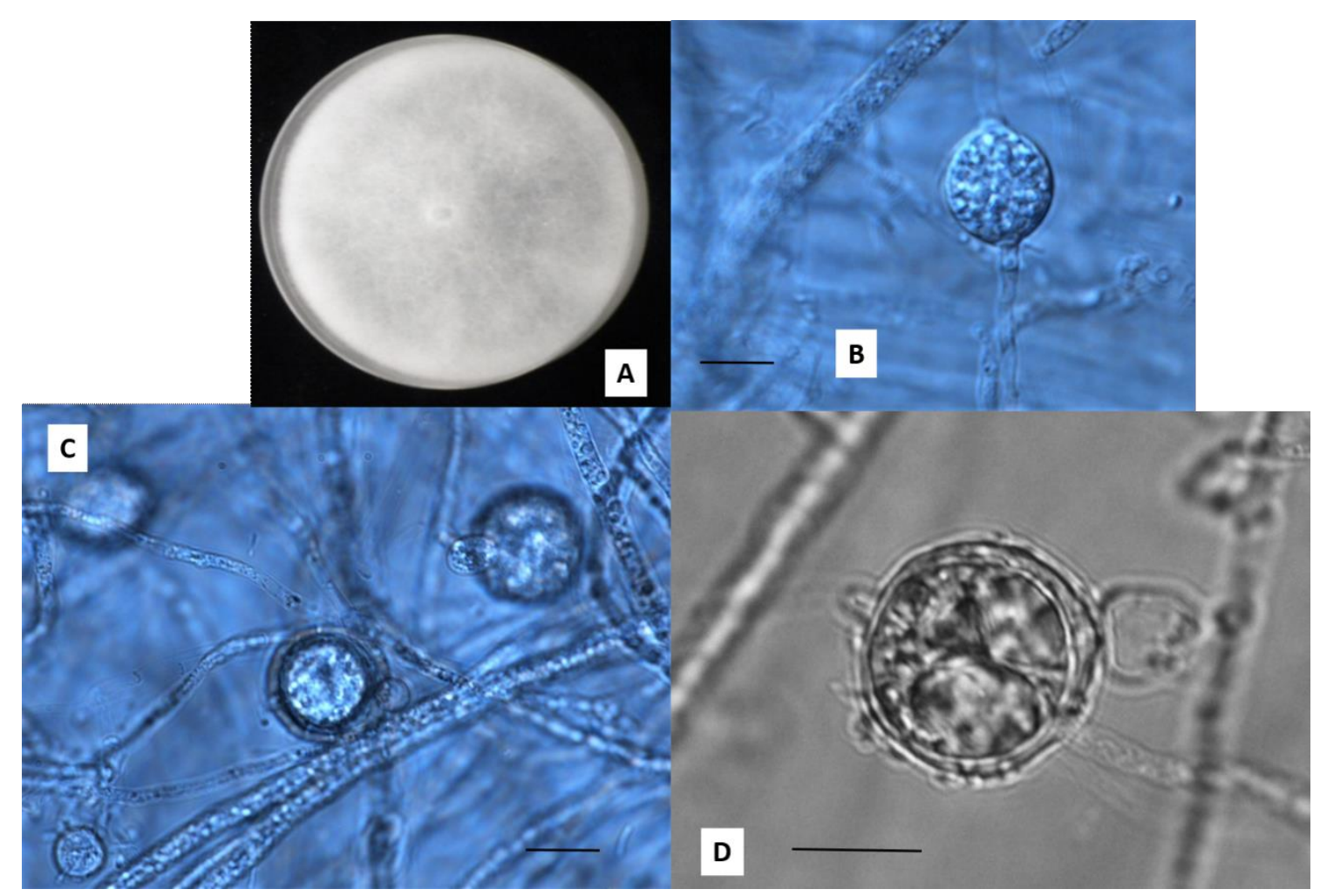

Figura 23. Pythium spinosum. A. Colonia en APG B. Hinchamientos hifales intercalares. C. Anteridios y oogonio. D. Oospora ornamentada. $\mathrm{BAR}=10 \mu \mathrm{m}$. B y C. BAR $=20 \mu \mathrm{m}$

\section{c. Caracterización molecular}

Se obtuvo una secuencia de 995 pb, de la secuencia de la cepa Py 15-107 para su comparación con secuencias homólogas en el GenBank. Presentó un 99 \% similitud con la cepa tipo P. spinosum correspondiente al aislamiento tipo CBS27567 (\#AY598701). También presentó 99 \% de homología con HQ643672 P. kunmingense CBS55088, que se considera sinónimo de P. spinosum de acuerdo a los resultados del análisis del ITS (Lévesque y de Cock, 2004) y del ITS y LSU (Lodhi, 2007).

\section{$>$ Pythium spinosum cepa Py 15-107}

GTTTCCGTAGGTGAACCTGCGGAAGGATCATTACCACACCTAAAAAACTTTC CACGTGAACTGTCATTATTTGTTGTGTGTCTGTGCGTTGTTGGCGTGCATTTG CTTACACTTTGGTGTTTGTGAGTGTGTGTTGGCAGTGTGCGGACTGAACGAA GGTTGTGTGTTGTTATGTGCCTACTGCACTGCTGACTTTGCATTCATTTGTAT GGTCTTGGCGGAGTGGCGGGTACTGTGCATGCGCAACTGACTTATTTTTTCA AACCCCATACCTAAATGACTGATTATACTGTGAGAACGAAAGTTCTTGCTTT AAACTAGATAACAACTTTCAGCAGTGGATGTCTAGGCTCGCACATCGATGA AGAACGCTGCGAACTGCGATACGTAATGCGAATTGCAGAATTCAGTGAGTC ATCGAAATTTTGAACGCATATTGCACTTCCGGGTTATACCTGGAAGTATGTC TGTATCAGTGTCCGTAAATCAAACTTGGCTTTCTTCCTTCCGTGTAGTCGGTG GAGGAGAGTTGCAGATGTGAAGTGTCTCGCTATGGTTGGCATTTGTAATGA ATGCACAGCTTGCGAGTCCTTTTAAATGGACACGACTTTCTCTTTTTTGTATC 
TGCGTGGTGCTGTGTATGAACGCGGTGGTTTTCGGATCGCTCGCGGCTATCG GCGACTTCGGTGAATGCATTATGGAGTGGACCTCGATTCGCGGTATGTTGGG CTTCGGCTGGACAATGTTGCTTATTGTGTGTTTGTTCCGTGTTCGCCTTGAGG TGTACTGGTAGTTGTGGGATTGAACTGGTTACTGTTGTTAGTAGTGTGTAGT GCGTTGTCGTGGATGCATCTGTCTTTTGTGCACTTTTGTGTGTGCAGTTGATA GAAGAGGAGTTTGAATTTGGGAAATTAGTGTACTGTGGGTTAATCCTGCGT GTATATCTCAATTGGACCTGATATCAGACAAGACTACCCGCTGAACTTAAGC ATATC

Lévesque y de Cock (2004) relacionaron la filogenia y los caracteres morfológicos. $P$ spinosum se ubica en el clado $\mathrm{F}$ junto a $P$. cylindrosporum, $P$. kunmingense, $P$. irregulare, $P$. mamillatum, $P$. paraecandrum, $P$. sylvaticum, $P$. debaryanum, $P$. intermedium y $P$. macrosporum. Entre estas especies $P$. kunmingense, $P$. irregulare, P. mamillatum, P. paraecandrum y P. spinosum presentan esporangios no formadores de zoosporas y tienen oogonios con un número variable de espinas romas en su mayoría de forma digitada y diferente de la ornamentación predominantemente aguda en oogonios de las otras especies ornamentadas. Considerando la clave taxonómica planteada por Dick (1990) se observa que de las 23 especies con oogonios ornamentados, sólo las mencionadas anteriormente, exhiben ambas características enunciadas, diferenciándose claramente $P$. spinosum de estas especies, por el tamaño de los oogonios y de sus proyecciones.

\section{d. Rango de hospedantes y distribución}

$P$. spinosum fue aislado por primera vez por Sawada y Chen (1926) en Taiwan, de plántulas de Antirrhinum majus (conejito) con damping off (Van der Plaats-Niterink, 1981). Es una especie cosmopolita, que afecta plantas de diferentes géneros y familias botánicas y también ha sido recolectada desde el suelo y el agua. Produce síntomas de damping off, tizón, podredumbre de corona y raíces. Ha sido reportada en diferentes países: Australia, Bulgaria, Corea, China. EEUU, Inglaterra, India, Japón, Holanda, Nueva Zelanda, Pakistán, Sudáfrica, Taiwán, Brasil y España. P. spinosum se encuentra citado en 77 especies botánicas. Considerando los cultivos ornamentales que predominan en la región en estudio, se citan: Actinidia chinensis, Aphelandra squamosa, Brassica oleracea, Calendula offlcinalis, Callistephus sinensis, Camellia japonica, Capsicum annuum, Cucurbita maxima, Cucurbita sp., Chrysanthemum sp., Dianthus chinensis, Eustoma grandiflorum, Fatsia sp., Gypsophila sp., Lactuca sativa, Lycopersicon esculentum Rhododendron sp., Spinacia oleracea, Zinnia sp. En Sudáfrica se halló asociado a marchitamiento y pudrición radicular en cultivos hidropónicos. En Taiwán 
afectando Antirrhinum majus, Calendula officinalis, Campanula media, Chrysanthemum coronarium, Dianthus chinensis. Además ha sido aislado de suelo y agua en Brasil y en Vitis vinífera (Gull et al., 2004; Baptista et al., 2004; McLeod et al., 2009; Farr y Rossman, 2014; citados por Palmucci, 2015).

En Argentina, $P$. spinosum se halla citado ocasionando podredumbre de frutos en maní (Arachis hipogea) en la provincia de Córdoba y damping off en gipsofila (Gypsophilla sp.) y berenjena (Solanum melongena) en la provincia de Tucumán (Frezzi, 1956). Podredumbre de raíces en frutilla (Fragaria ananassa) (Meneguzzi et al., 2011). Palmucci (2015) lo cita como agente causal de podredumbre basal y radicular de Hebe speciosa.

\subsubsection{Especies del género Phytopythium}

Al género Phytopythium se lo dió a conocer por primera vez (ver www.phytophthoradb.org/pdf/O8LevesquePM. pdf) y fué publicado formalmente en junio de 2010 (Bala et al., 2010), con Phytopythium sindhum como especie tipo. Uzuhashi et al. (2010) propusieron otro nombre, Ovatisporangium, para el clado K usando un muestreo parcial de especies de Pythium y de Phytophthora, publicando sus hallazgos en septiembre de 2010.

Todas las especies que pertenecen a Pythium clade $\mathrm{K}$ representan un género monofilético (de Cock et al., 2015). Las características morfológicas comunes de las especies de Phytopythium son: esporangios de forma globosa a ovoide, a menudo con papila más o menos desarrollada o no papilados $\mathrm{y}$ con frecuencia proliferando internamente, como los del género Phytophthora. La descarga de zoosporas tiene lugar del mismo modo que el género Pythium. La mayoría de las especies tiene oogonios grandes y lisos, oosporas de paredes gruesas y 1-2 anteridios alargados o lobulados, aplicados lateralmente al oogonio. Los cultivos son en su mayoría homotálicos, pero ocasionalmente son estériles.

Según Lévesque y de Cock (2004), las especies de Pythium del Clado K son P. boreale, P. ostracodes, P. oedochilum, P. chamaehyphon, P. helicoides, P. cucurbitacearum, P. vexans y $P$. indigoferae. El clado se divide en dos subclados. El primero, que consiste en P. boreale, P. ostracodes, P. oedochilum, P. chamaehyphon y P. helicoides. En el segundo, el aislamiento de $P$. indigoferae es cuestionable, pero las otras dos especies, $P$. cucurbitacearum y $P$. vexans tienen una morfología muy similar, con el anteridio campaniforme y aplicado apicalmente. Pero de acuerdo a la filogenia de Phytopythium 
(de Cock et al., 2015), P. megacarpum y P. indigoferae se siguen considerando especies de Pythium, pero P. cucurbitacearum está comprendida dentro del complejo Phytopythium vexans. A estas especies hay que sumarle a Phytopythium carbonicum (B. Paul) Abad, De Cock, Bala, Robideau, Lodhi y Lévesque, comb. nov.; Phytopythium citrinum (B. Paul) Abad, De Cock, Bala, Robideau, Lodhi y Lévesque, comb. nov.; Phytopythium delawarense (Broders, P.E. Lipps, M.L. Ellis y Dorrance) Abad, De Cock, Bala, Robideau, Lodhi y Lévesque, comb. nov. Phytopythium litorale (Nechw.) Abad, De Cock, Bala, Robideau, Lodhi y Lévesque, comb. nov.; Phytopythium mercuriale (Belbahri, B. Paul y Lefort) Abad, De Cock, Bala, Robideau, Lodhi y Lévesque, comb. nov.; Phytopythium montanum (Nechw.) Abad, De Cock, Bala, Robideau, Lodhi y Lévesque, comb. nov.; Phytopythium palingenes (Drechsler) Abad, De Cock, Bala, Robideau, Lodhi y Lévesque, comb. nov.; Phytopythium polytylum (Drechsler) Abad, De Cock, Bala, Robideau, Lodhi y Lévesque, comb. Nov.; Phytopythium mirpurense Lodhi, De Cock, Lévesque y Shahzad, sp. nov.

\section{Phytopythium chamaehyphon (Sideris) Abad, de Cock, Bala, Robideau, Lodhi y Lévesque. (2014).}

Basionym. Pythium chamaehyphon Sideris (1932)

$\equiv$ Ovatisporangium chamaehyphon (Sideris) Uzuhashi, Tojo y Kakish (2010).

Los aislamientos se identificaron como perteneciente al género Phytopythium Abad, de Cock, Bala, Robideau, Lodhi y Lévesque, de acuerdo con la descripción de Abad et al. (2010) y a la especie Phy. chamaehyphon (Sideris) Abad, de Cock, Bala, Robideau, Lodhi y Lévesque (de Cock et al., 2015), confirmándose por pruebas moleculares. La especie Pythium chamaehyphon Sideris (1932) fue aislada originalmente por Sideris de Carica papaya en Hawai, en 1930. Puede causar podredumbres radiculares y damping off (Van der Plaats-Niterink, 1981). Recientemente, fue renombrada por de Cock et al. (2015) como Phytopythium chamaehyphon.

\section{a. Origen de los aislamientos}

Los dos aislamientos Py 29-15 y Py 33-15 se obtuvieron a partir de muestras de suelos procedentes de campos comerciales de soja de Arrecifes (NBA) y Villaguay (ER) durante la campaña 2014/15. 


\section{b. Caracterización cultural y morfológica}

A los 7 días de la siembra, el aislamiento Py 29-15 desarrolló micelio algodonoso en AHM y tipo petaloide en APG (Fig. 24 A). Formó abundante micelio cenocítico, hialino con presencia de abundantes esporangios, predominantemente terminales, globosos a subglobosos, algunos ovoides (18-) 21-30 (-25) $\mu \mathrm{m}$ diám., con papila y tubos de descarga (Figs. 24 C-D). Se observaron oogonios globosos, lisos, terminales e intercalares y laterales sobre un pie corto (21-) 23-27 (-28) ( $\overline{\mathrm{X}}: 25) \mu \mathrm{m}$ diám. y anteridios alargados en estrecho contacto con el oogonio (lateralmente apoyado sobre el oogonio, cercano al pie oogonial), mayormente monoclinos (1-2), oosporas mayormente

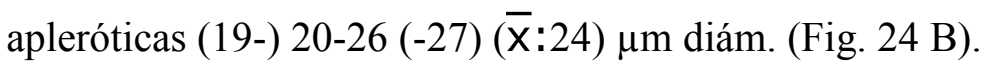

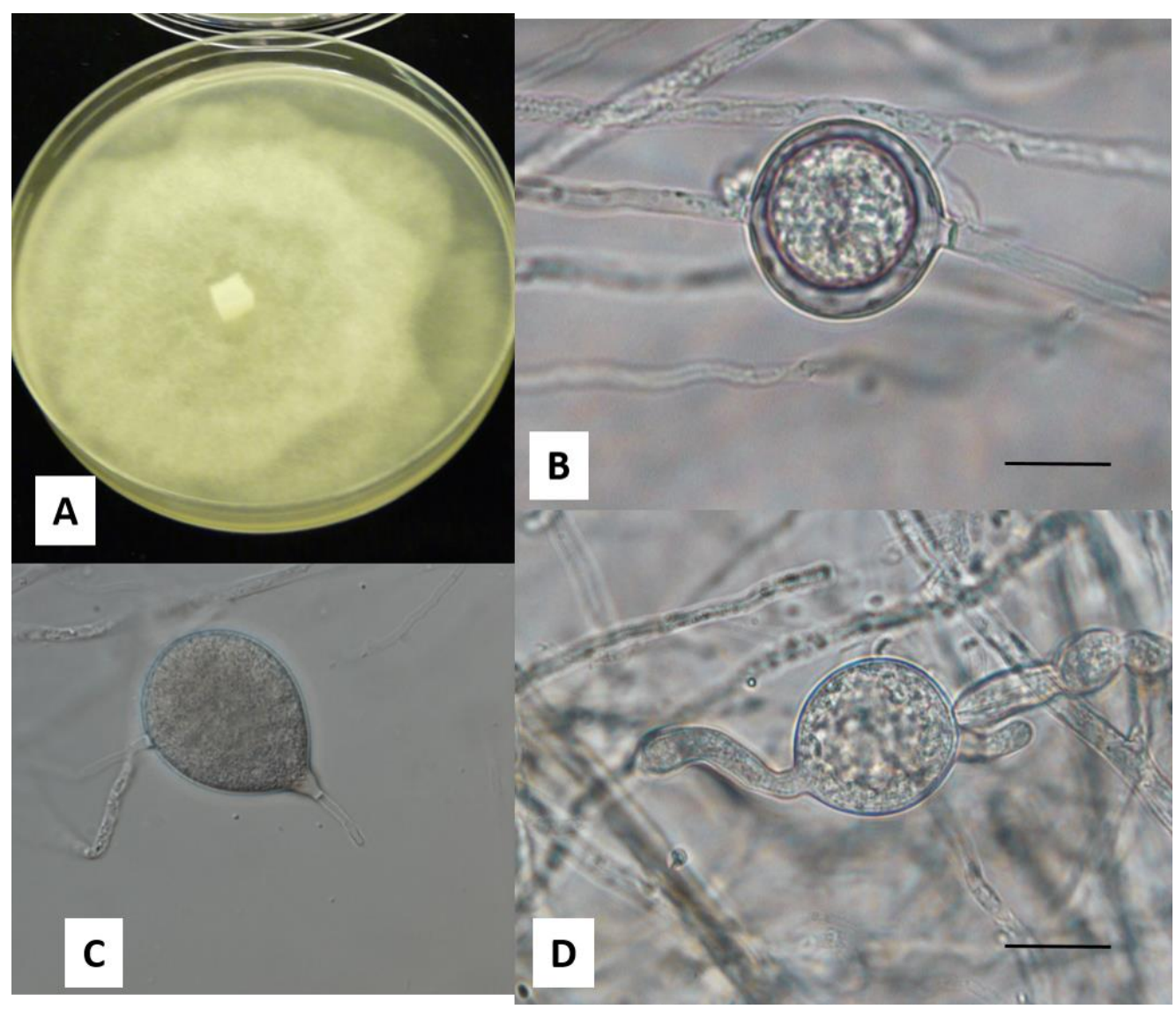

Figura 24. Phytopythium chamaehyphon: A) Micelio algodonoso tipo petaloide en APG. B) Oospora. C) Esporangio con papila. D). Esporangio con tubo de descarga. BAR= $10 \mu \mathrm{m}$ 


\section{c. Caracterización molecular}

De la cepa Py 15-33 se obtuvo una secuencia de ITS de 617 pb, la que presentó un 99\% de similitud con la cepa tipo CBS 259.30 que corresponde al ex tipo de $P$. chamaehyphon utilizado por Lévesque y de Cock (2004), para definir los diferentes clados, entre ellos el clado K, dentro del cual se encuentra comprendida esta especie. Además presentó un $99 \%$ de homología con la especie Phy. chamaehyphon (GenBank HQ643379; GU266220; FJ415975; AY598666) ex Pythium chamaehyphon clade K.

> Py 15-33 Phytopythium chamaehyphon

AAAACTGAAACATACTGTGGGGACGAAAGTCTCTGCTTTAAACTAGATAGC AACTTTCAGCAGTGGATGTCTAGGCTCGCACATCGATGAAGAACGCTGCGA ACTGCGATACGTAATGCGAATTGCAGGATTCAGTGAGTCATCGAAATTTTG AACGCATATTGCACTTTCGGGTTATGCCTGGAAGTATGTCTGTATCAGTGTC CGTACACTAAACTTGCCTCCTTTCGCGTCGTGTAGTCGGCGCGTGTGGGAAT TGCAGCAGATGTGAGGTGTCTTGTGGTCCTTCGCGGACAGCAAGTCCCTTGA AAGTCGGACGCGTATCTTTGCGTGCGTTGGGTGCTGGTGGGCTGTGGGACG CGTCTGTTGACGAGTCTGGCGACCTTTGGCGCGTGCATGCTTGGGCACTGTG TATTGGCGGTATGTTAGGCTGCGTTTCGTGCGCGGCTTTGGCAATGCAGCTG ATGCGTGTGTTTGGGCGGCGTGTGTTGTATGGGTGAACCGGATGGTCGACG GGTTTGAGTCGTGTTTCGTTAGTCTGTAGCCGGTGTTCTGTATCGCGTGCGG AGTGTGTCACCATTTGGGAATCTGTGTGGTCTTTCGTAGTATCACATCTC

\section{d. Rango de hospedantes y distribución mundial}

Phy. chamaehyphon fue aislada por primera vez en el año 1932, de plantas de Carica papaya (papaya) en Hawai (Sideris, 1932). Años después fue citada por Jung et al. (1996) en Alemania, Suecia, Hungria, Italia y Eslovenia, durante relevamientos sobre el declinamiento de Cedrus sp. (cedro). En el año 2000, fue aislada de Anacardium exelsum (mijo) en Jamaica (Davidson et al., 2000) y posteriormente, de la rizósfera de Saccharum officinarum (caña de azúcar), Mangifera indica (mango) y Psidium guayava (guayaba) en la provincia de Sindh, Pakistán (Lodhi, 2007). En Argentina Palmucci et al. (2011 b) citan a Phy. chamaehyphon (=Pythium chamaehyphon) afectando azaleas en los alrededores de la ciudad de Buenos Aires, manifestando leve patogenicidad. 


\title{
Phytopythium vexans (de Bary) Abad, de Cock, Bala, Robideau, Lodhi y Lévesque. (2014).
}

\author{
Basionym. Pythium vexans de Bary (1896) \\ E Ovatisporangium vexans (de Bary) Uzuhashi, Tojo y Kakish (2010).
}

\section{a. Origen de los aislamientos}

Los 11 aislamientos identificados como Phy. vexans SE 2, 3, 9, 10, 11, 12, 14, 15, 17, 34 y 47 se obtuvieron a partir de muestras de granos cosechados de soja procedentes de campos comerciales de las localidades de Pergamino, Solís y Los Toldos (NBA) durante la campaña 2015/16 y de muestras de suelo de campos de Alberti (NBA).

\section{b. Caracterización cultural y morfológica}

Las colonias en AHM con micelio aéreo algodonoso, en APZ sin un patrón especial. Hifa principal de $5 \mu \mathrm{m}$ diám. Esporangios sub globosos, ovoides o piriformes, intercalares o terminales, ocasionalmente proliferantes, (15-)18-23(-27) (prom. 20.2) $\mu \mathrm{m}$ x (11-)15-21(-23) (prom. 17,9) $\mu \mathrm{m}$ diám. Oogonios mayoritariamente terminales en ramas cortas, a veces laterales o intercalares, globosas, (16-)18-23(-24)(prom.20,0) $\mu \mathrm{m}$ diám. Un anteridio, raramente dos, monoclinos, raramente diclinos, surgiendo a cierta distancia debajo del oogonio o de la hifa principal. Gran célula anteridial, típicamente campaniforme. Oosporas apleróticas, (14-)16-19(-20) (prom.17,3) $\mu \mathrm{m}$ diam., pared más de $1,5 \mu \mathrm{m}$ diám. (Fig. 25 a-d). 


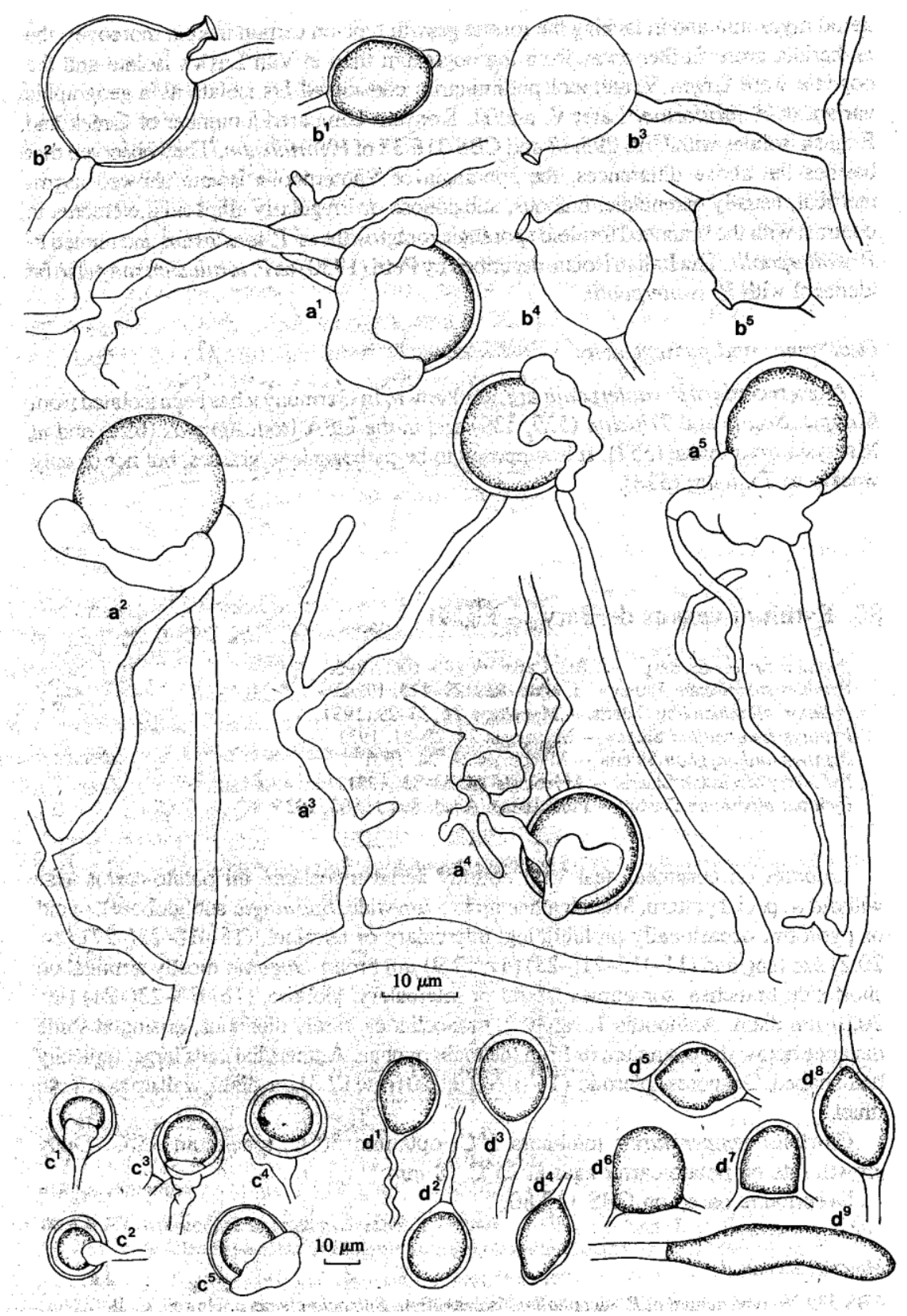

Figura 25. Phytopythium vexans: CBS 119.8 a-1-5). Oogonios y anteridios. b1-5). Oogonio con papila y tubo de descarga c-d) Figuras de Bary (1986 citado por Van der plaats-Niterink, 1981). c1-5) Oogonio con anteridio. d1-9) Esporangios o hinhamientos hifales.

\section{c. Ocurrencia y patogenicidad}

Phy. vexans ha sido registrado a partir de suelo y plantas en varios países. Esta gran distribución se muestra en el mapa del CMI N ${ }^{\circ} 205$ (1980). Ha sido reportado en Alemania en Solanum tuberosum (papa), en Lupino sp. y Medicago sp. y en suelo en EEUU y en Canadá a partir de cítricos, Hevea, Metrosideros, Persea, Saccharum officinarum, céspedes, coníferas, ornamentales, perales, durazneros, árboles de pecan y suelos; en Hawaii a partir de ananá, plantas ornamentales, espinaca, ricino, papaya y 
suelo en India en Zingiber, Eletteria, Cichona, manzanos, malvón y Piper sp., papa y Afromomum sp., En Malasia en Theobroma, Hevea, Thea, Camelia, Dianthus, Carica, Citrus, Saccharum, Vicia, Vigna, Vitis, Zingiber y numerosas plantas ornamentales. En Inglaterra a partir de cereales, en Java en tabaco, en Rumania a partir de tomate y papa. En Uganda en Pelargonium, en SudAfrica en Cítricos, Paw paw y palta. En Indochina en Hebea y perales. En Australia a partir de plantines de tomate, Paw paw, Annona, Brassica y Persea. En Congo de varias plantas cultivadas, en Brasil de Sterlitzia sp. En Papua Nueva Guinea a partir de Cocos y Theobroma, en Pakistán a partir de Dianthus, en Holanda a partir de Linum y hortensia. Phy. vexans fue aislado también de suelos en Islandia, Rep. Checa, Francia e Inglaterra, Libano, Iraq, y Japón (Van der plaats-Niterink, 1981). En Argentina fue aislado a partir de plantas ornamentales y en cítricos (Frezzi, 1956).

Se han efectuado muchos estudios sobre la patogenicidad de Phy. vexans. Se consideró patógena en Pelargonium, Zingiber, Cardamo, Holly, Carnation, plántulas de pecán, papa y batata, en alguna Proteaceae, Aframomum, Cichona, peral y Nicotiana. Además Phy. vexans ha sido citado como agente causal del cancro de la Hevea, a través de inoculaciones, no siempre dió síntomas de enfermedad. Phy. vexans ha sido aislado con Phytophthora cinnamomi a partir de perales con decaimiento, en este caso es considerado de importancia secundaria. Phy. vexans mostró parasitismo leve o fue no parasito en Pinus spp., Palta, Paw paw, tomate, sandia, plántulas de Ipomoea, poroto, arroz, ananá y cereales (Van der Plaats-Niterink, 1981).

\section{d. Caracterización molecular}

De la cepa SE 16-10 se obtuvo una secuencia de ITS de 858 pb, la que presentó un $96 \%$ de similitud con la cepa CBS 119.80 (\#HQ643400.2) que corresponde al tipo de Phy. vexans utilizado por Lévesque y de Cock (2004), para definir los diferentes clados, entre ellos el clado K, dentro del cual se encuentra comprendida esta especie. Además presentó un 96 \% de homología con la especie Phy. vexans (GenBank KU961900.1, KU961899.1) ex $P$. vexans clado $\mathrm{K}$.

>SE 10 Phytopythium vexans

AAAAAAAATCGTAACAAGGTTTCCGTAGGTGAACCTGCGGAAGGATCATTA CCACACCTAAAAACACCCTTCCACGTGAACCGTTTTGTTTTGCTTTCGAGTG CTTTGTTGCGCTCGGAGCATGTTTGGGCTTCGCTGCTGGCGCTTGATTGTGCT GGCGGCTCGAGGCCATCAAGCGGCGTTTTGAGTGCTTGCACAATTAACGTC CAAACCTTTTAAACCCATTTGATTGAAAACTGAAGTATACTGTGGGGACGA 
AAGTCCTCGCTTTGAAACTAGATAACAACTTTCAGCAGTGGATGTCTAGGCT CGCACATCGATGAAGAACGCTGCGAACTGCGATACGTAATGCGAATTGCAG GATTCAGTGAGTCATCGAACTTTTGAACGCATATTGCACTTTCGGGTTACGC CTGGAAGTATGTCTGTATCAGTGTCCGTACACTAAACTTGCGTCTCTTCCGT CGTGTAGTCGTCGGTTGTTTGATTGCAGATGTGAGGTTGTCTCGCGATGTGC CATGTTTTTTGTGGCAAGGTTGCGAGTCCCTTTAAAGTCGGACGCGTTTTTC CGTTTTGTGCTCGATGGGGTGCGGCTGCGGCCGTGTCTGCTGGCGGGTCCGG TGACCTTTGGCGATGGCATGAGAGTGGATTGCTCGATTTGCGGTATGTTAGG CTTCGGCTTTGACAATGCAGCTTATTGAGTGTGTTCGCTTGGCTGTTGCTGTA TGGGTGAGCTGGATGGTCGGTGGGTGCGTTGTTGCGTGTCGTTTTCATTGCG TGCGTTTCGGTTGTCGTCGCCATTTGGGAATTTAATGTTTTCTTACGAGAAC ATCTCATTTGGACCTGATATCAGACAAG

Phy. vexans es considerado un complejo que también contiene el taxón no válido Phytopythium cucurbitacearum, ya que este no tiene una descripción latina lo que está basado en el art. 36 de la convención de Melbourne (McNeill et al., 2012) y la cepa representativa de Phy. cucurbitacearum CBS 748.96 ya no es viable. La secuencia ITS de esta cepa fue informada por Spies et al. (2011), que es una cepa distinta, nueva y aislada de Acacia sp. que fue muy diferente entre los aislamientos en el complejo monofilético Phy. vexans estudiado. Lo más probable es que la cepa CBS 748.96 represente una especie distinta del complejo de Phy. vexans, que aún no se describe de forma válida. Una vez que se resuelva este complejo, es probable que represente una cantidad de especies nuevas para el género Phytopythium (de Cock et al., 2015).

\section{"Phytopythium cucurbitacearum" (S. Takimoto) Abad, de Cock, Bala, Robideau, Lodhi y Lévesque. (2014).}

Basionym. Pythium cucurbitacearum S. Takimoto (1941)

三 Ovatisporangium cucurbitacearum (S.Takimoto) Uzuhashi, Tojo y Kakish (2010).

\section{a. Origen de los aislamientos}

El aislamiento Font 2 (10) se obtuvo a partir de muestras de suelos procedentes de campos comerciales de soja de Fontezuela (NBA) durante la campaña 2013/14. 


\section{b. Caracterización cultural y morfológica}

Aislados de Cucumis, Citrullus y Luffa sp. en Japón. Las características mayoritarias son esporangios papilados y el lugar de unión de los anteridios, cerca del pie oogonial. En este sentido se diferencia de Phy. vexans y Phy. chamaehyphon que tienen similares anteridios pero pueden ser distinguidos de Phy. cucurbitacearum por los esporangios no papilados. Phy. cucurbirtacerum ha sido también citado como patógeno sobre tomate, hibiscus, ipomoea y papa en Japón.

\section{c. Caracterización molecular}

De la cepa Font 2 (10) se obtuvo una secuencia de ITS de 925 pb, la que presentó un 99\% de similitud con la cepa de Phy. cucurbitacearum CBS 748.96 (\# AY598667.1). Debido a lo expuesto en el complejo Phy. vexans se analizaron otros genes. Se obtuvo una secuencia de Cox II de 588 pb, la que presentó un $99 \%$ de similitud con la cepa de Phy. cucurbitacearum CBS 748.96 (\# AY598667.1) y una secuencia de beta tubulin de 702 pb. Que presentó un 87 \% similitud con KJ595460.1 Phy. cucurbitacearum CBS: 748.96 beta-tubulin

\section{> Font 2-10 Phytopythium cucurbitacearum ITS}

TNGAAANNNAAAANNNCGTAACAANGTTTCNGTANNNGAACNNGCNNANG GATCATTACCACACCTAAAAAACACCCTTCCACGTGAACCGTTTTGTTTTGC TTTCGAGTGCTTTGTTGCGCTCGGAGCATGTTTTGGGCTTCGCTGCTGGCGCT TGATTGTGCTGGCGGCTCGAGGCCATCAAGTGGCGTTTTGAGTGTGCTTTGC GCAATTGAAACGTCGAAACCTTTTTTTAAACCCATTTGATTGAAAACTGAAG TATACTGTGGGGACGAAAGTCCTCGCTTTGAAACTAGATAACAACTTTCAGC AGTGGATGTCTAGGCTCGCACATCGATGAAGAACGCTGCGAACTGCGATAC GTAATGCGAATTGCAGGATTCAGTGAGTCATCGAACTTTTGAACGCATATTG CACTTTCGGGTTACGCCTGGAAGTATGTCTGTATCAGTGTCCGTACACTAAA CTTGCGTCTCTTCCGTCGTGTAGTCGTCGGTTGTTTTGATTGCAGATGTGAGG TTGTCTCGCGATGTACCATTTCTTTTGGATAGGTTGCGAGTCCCTTTAAAAGT CGGACGCGTGTTTTTTCCGTTTTGTGCTTGATGGGGGTGCGGCTGCGGCCGT GTCTGCTGGCGGGTCCGGTGACCTTTGGCGATGGCATGAGAGTGGATTGCTC GATTTGCGGTATGTTAGGCTTCGGCTTTGACAATGCAGCTTATTGGGTGTGT TCGCTTGGCTGTTGCTGTATGGGGTGAGCTGGATGGTCGGTGGATGCGTTTG TTGCGTGTCGTTTTTTCATGGAGTGCGTTGCGGTTGTCGTCGCCATTTGGGG AATTTNATGTTTTGAGTCTCGATTCAATACATCTCATTTGGACCTGATATCA NACAAGATTACCCGCTGAACTTAAGCATATCAATAAGCGGA

$>$ Font 2-10 Phytopythium cucurbitacearum COX II

ATTTNCNNNNNCCNNCAANNNCNNNTATGGAAGGTATTATAAATTTTNATC ATGATATTATGTTTTTTTTAGTTATTATAACAGTTTTTGTTTTTTGGATGTTAT 
TTAGAGTTATTTATCTTTTTGATGAAAAAAAAAATAAAAATCCAGCAACTGT TATACATGGTGCTACTATTGAAATTATTTGGACTACTATTCCAGCTTTAATCT TATTAGTTGTAGCTATTCCTTCTTTTGCTTTATTATATTCAATGGATGAAGTA ATAGATCCTATAATAACTGTTAAAGTTATAGGTAGTCAATGGTATTGGAGCT ATGAATATTCAGATAATTTAGAATTTTCTGATGAACCTTTAATTTTTGATAGT TATATGGTTCAAGAAGATGATTTAGAAATAGGTCAATTAAGAGTATTAGAA GTTGATAATCGTGTAGTTGTTCCTACTAATAGTCATATAAGAGTTTTAATAA CATCTTCAGATGTTTTACATTCATGGGCTATTCCTTCTTTAGGTATTAAATTA GATGCTTGCCCTGGTCGTTTAAATCAAACTTCAATGTTTATTAAAAGAGAAG GTGTTTTTTATG

> Font 2-10 Phytopythium cucurbitacearum BT5 BT6

GTATCATGTGCACGTACTCGGTCTGCCCATCGCCAAAGGTGTCGGACACCGT CGTGGAGCCATACAACGCCACCCTCTCGGTCCACCAGTTGGTCGAAAACGC CGATGAAGTGATGTGCTTGGACAACGAAGCCTTGTACGATATTTGCTTCCGC ACGCTGAAGCTGACGACCCCAACGTACGGCGACTTGAACCACTTGGTGTGT GCCGCCATGTCCGGTATCACCACGTGCCTGCGTTTCCCTGGCCAGTTGAACT CGGACCTCCGCAAGCTCGCTGTGAACTTGATCCCGTTCCCGCGTCTCCACTT CTTCATGATCGGTTTCGCGCCATTGACGTCGCGTGGCTCCCAGCAGTACCGT GCGTTGACTGTCCCAGAGCTGACTCAGCAGCAGTTCGACGCGAAGAACATG ATGTGCGCCGCGGATCCTCGCCACGGTCGTTATTTAACTGCTGCTTGTATGT TCCGCGGACGCATGAGCACCAAGGAAGTCGATGAGCAGATGCTGAACGTCC AGAACAAGAACTCCTCGTACTTCGTGGAATGGATTCCAAACAACATCAAGG CGAGCGTGTGCGACATCCCTCCAAAGGGCCTCAAGATGAGTACCACGTTCA TCGGTAACTCGACTGCCATCCAGGAGATGTTCAAGCGTGTGTCTGANCAGTT CACGGCAATGTTCCGTCGTAAGGCNTTTCTTG

\title{
Phytopythium helicoides (Dreschler) Abad, de Cock, Bala,
}

\author{
Robideau, Lodhi y Lévesque (2014). \\ Basionym. Pythium helicoides (Drechler) (1930) \\ 三Ovatisporangium helicoides (Drechler) Uzuhashi, Tojo y Kakish. (2010).
}

\section{a. Origen del aislamiento}

El aislamiento P13-6 se obtuvo a partir de muestras de suelos procedentes de campos comerciales de soja de Pergamino (NBA) durante la campaña 2013/14.

\section{b. Caracterización cultural y morfológica}

Colonias en AHM produce micelio aéreo, en APZ presenta un patrón más o menos radiado. La hifa principal mayor de $8 \mu \mathrm{m}$ diám. (Fig. 26 A). Esporangios terminales, con proliferación, subglobosos pero a menudo obovoides, papilados, (18-) 27-38 (-43) X (13) 16-27 $\mu \mathrm{m}$ (prom. 31 X $21 \mu \mathrm{m}$ ); tubo de descarga que aparece apicalmente (Fig. $26 \mathrm{D}$ y 
E), 3-40 X 3-9,5 $\mu \mathrm{m}$; zoosporas enquistadas 10-15 $\mu \mathrm{m}$ diám. Oogonios terminales, laterales o intercalares, lisos, (26-) 31-38 (-40) (prom. 33,5) $\mu \mathrm{m}$ diám. Uno a 4 anteridios por oogonio, surgiendo de tallos simples o ramificados, a veces enroscados alrededor del tallo oogonial o alrededor de otras hifas en las inmediaciones del oogonio (Fig. 26 B y C). Célula anteridial elongada, 20-40 $\mu \mathrm{m}$ long. x 6-9 $\mu \mathrm{m}$ diám, adherida a lo largo del oogonio, formando un tubo de fertilización lateral. Oosporas globosas, apleróticas, a menudo amarillentas (21-) 27-32 (-33) (prom.30,5) $\mu \mathrm{m}$ diám., pared 4-6 $\mu \mathrm{m}$ diám. (Fig. 26 F). Temperaturas cardinales: mínimo $5{ }^{\circ} \mathrm{C}$, óptimo $30-37{ }^{\circ} \mathrm{C}$, máximo $43{ }^{\circ} \mathrm{C}$. Tasa diaria de crecimiento en APZ a $25{ }^{\circ} \mathrm{C} 34 \mathrm{~mm}$. Cepa tipo: CBS 286.31.

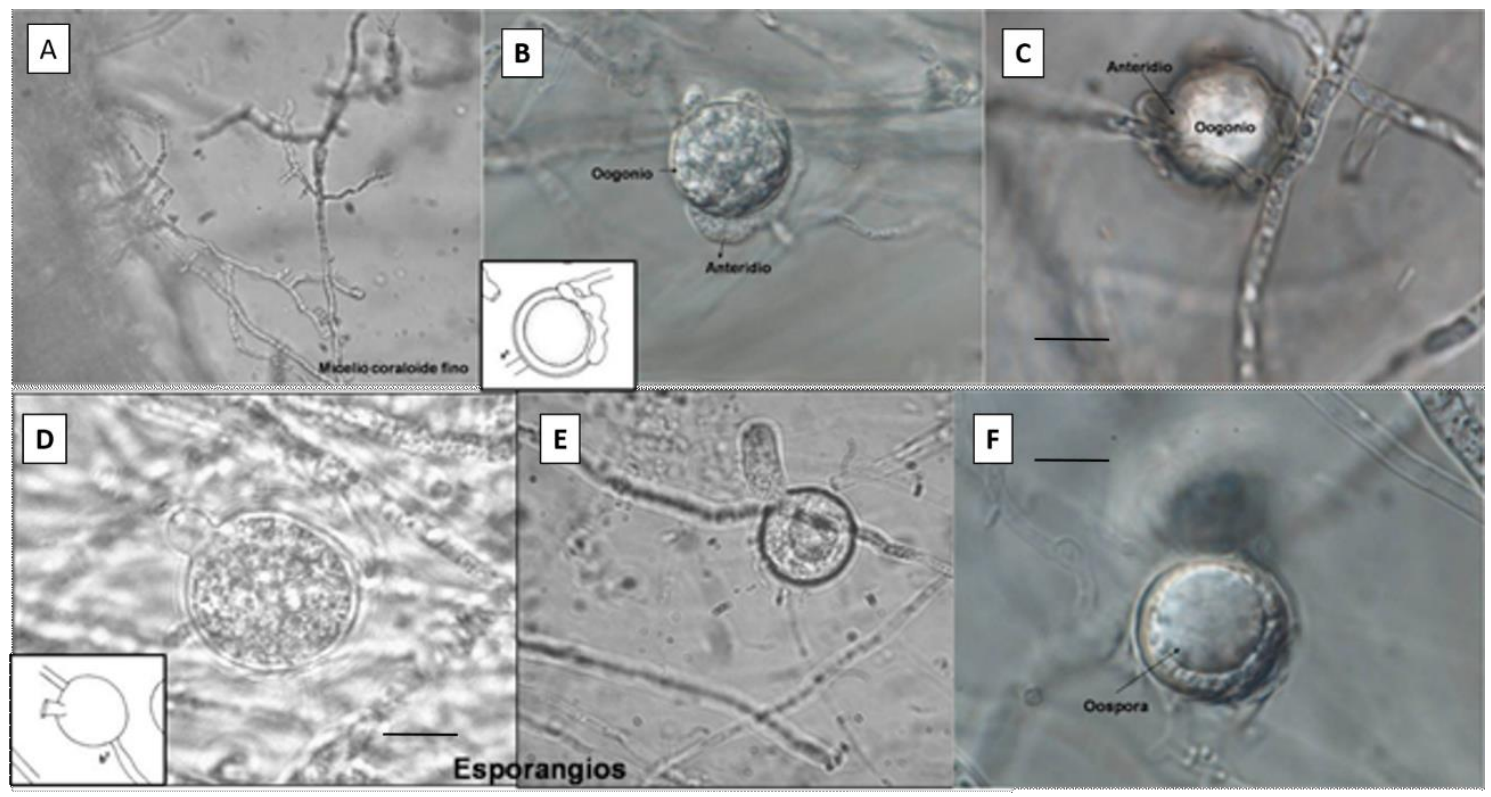

Figura 26. Phytopythium helicoides. A. Micelio coraloide fino. B-C Oogonio y anteridio $\mathrm{D}$ y E esporangio y tubo de descarga, $\mathrm{F}$ oospora. $\mathrm{BAR}=10 \mu \mathrm{m}$

\section{c. Caracterización molecular}

De la cepa P-13-6 se obtuvo una secuencia de ITS de 650 pb, la que presentó un $99 \%$ de similitud con la cepa con Phy. helicoides voucher CBS28631 (GenBank \#HQ643383).

>P13-6 Phytopythium helicoides Argentina

TNTCTCTCTCTCTTTTGGGGGAGGGGATGCGTGCGAGCTATCTGTAAACTTG TCAAACCCATTCTTTTTGATAACTGAAACATACTGTGGGGACGAAAGTCTCT GCTTTGAACTAGATAGCAACTTTCANCAGTGGATGTCTAGGCTCGCACATCG ATGAAGAACGCTGCGAACTGCGATACGTAATGCGAATTGCAGGATTCAGTG AGTCATNGAAATTTTGAACGCATATTGCACTTTCGGGTTATGCCTGGAAGTA TGTCTGTATCAGTGTCCGTACACTAAACTTGCCTCCTTTGCGTCGTGTAGTCG TCGCGTTGGAACTTTGTGGCAGATGTGAGGTGTCTTGTTTGCTGTGTCTTTGT 
TGATGCGGCGGNCAAGTCCCTTGAAAGTCGGACGCGTATCTTTGCGTGCGTT GGGTGCCGGTGGGCTGTGGGACGCGTCTGTTGACGAGTCTGGCGACCTTTG GCGCGTGCATGCTTGGGCACTGTGTATTGGCGGTATGTTAGGCTGCGTTCGC GCGGCTTTGACAATGCAGNTGATGCGTGTGTTTGGGCTGTGGTGCTGTATGG GTGAACCGGATGGTCGATGGGTTTTTTAAATGCGTTTCGCGTGTCTGTTTTT ATCCGGTGTTCTGTTTCGTGCGTGGA

\title{
d. Ocurrencia y patogenicidad
}

Esta especie es común en EEUU sobre Citrullus vulgaris, Pinus sativus, Spinacia oleracea, suelo y raíces de plantas ornamentales tales como Ilex sp., Piracantha, Photinia y Azalea sp., árboles de Pecán y raíces de caña de azúcar. En Australia sobre plántulas de algodón (Gossypium sp.), Medicago sativa y Pinus elliottii. En Malasia sobre soja (Glycine max), Hibiscus sp. y Piper nigrum. También se sospecha como agente causal de ciertas enfermedades de raíz y “damping off” en plántulas de las que se ha aislado, pero no se han efectuado pruebas de patogenicidad (Van der Plaats-Niterink, 1981).

\section{Phytopythium aff. mercuriale (Belbahri, B. Paul y Lefort) Abad, de Cock, Bala, Robideau, Lodhi y Lévesque (2014).}

\author{
Basionym. Pythium mercuriale (Belbahri, B. Paul y Lefort) (1941) \\ 三Ovatisporangium mercuriale (Belbahri, B. Paul y Lefort) Uzuhashi, Tojo y \\ Kakish. (2010).
}

\section{a. Origen de los aislamientos}

El aislamiento Py 15-11 se obtuvo a partir de muestras de suelos procedentes de campos comerciales de soja de Mechita (NBA) durante la campaña 2014/15.

\section{b. Caracterización cultural y morfológica}

Todos los aislamientos examinados mostraron tasas de crecimiento y patrones de micelios similares en cada uno de los medios de cultivo utilizados. Patrón miceliar en APZ ampliamente de tipo crisantemo, con micelio aéreo copetudo y ligeramente algodonoso; en CMA levemente estrellado y sumergido; en MEA rosácea y algodonosa; y en PDA apretadamente crisantemo con micelio aéreo irregular, algodonoso en el centro. Hifas principales de hasta $6 \mu \mathrm{m}$ diám. Temperaturas cardinales: mínima $5{ }^{\circ} \mathrm{C}$, óptima 25 - 
$30{ }^{\circ} \mathrm{C}$, máxima $43,5{ }^{\circ} \mathrm{C}$. Tasa promedio de crecimiento diario de siete aislamientos a 20 ${ }^{\circ} \mathrm{C}$ en $\mathrm{APZ}=8.8 \mathrm{~mm}$; en $\mathrm{AHM}=8,9 \mathrm{~mm}$; en AEM (agar extracto de malta) $=8.3 \mathrm{~mm} ; \mathrm{y}$ en $\mathrm{APD}=6.5 \mathrm{~mm}$. Clamidosporas abundantes en APZ, intercalares o laterales, principalmente esféricas, $25-45 \mu \mathrm{m}$ diám. Los esporangios raramente se formaron en agua, subglobosa a obovoide, papilada, 18-23 $\mu \mathrm{m}$ de long x 23-32 $\mu \mathrm{m}$ diám. (22-26 $\mu \mathrm{m}$ prom.), proliferación anidada y extendida; esporangióforos sin ramificar. Tubo de descarga de zoosporas corto y formado en el ápice del esporangio. Esporangios viejos, a veces germinan por medio de uno a tres tubos germinales que surgen de la papila (Fig. 27 a-d). Las oosporas no se observan o son raras en cultivo puro. Oogonios esféricos, 22-37 $\mu \mathrm{m}$ diám. (prom. $29.8 \mu \mathrm{m}$ ), de pared lisa, terminal o lateral en ramas cortas. Anteridios múltiples, en su mayoría diclinos, envolventes alrededor de la oogonia (Fig. 27 e-h).

Etimológicamente: mercuriale (=variable), refiriéndose a lo variable de las secuencias de la región ITS. 

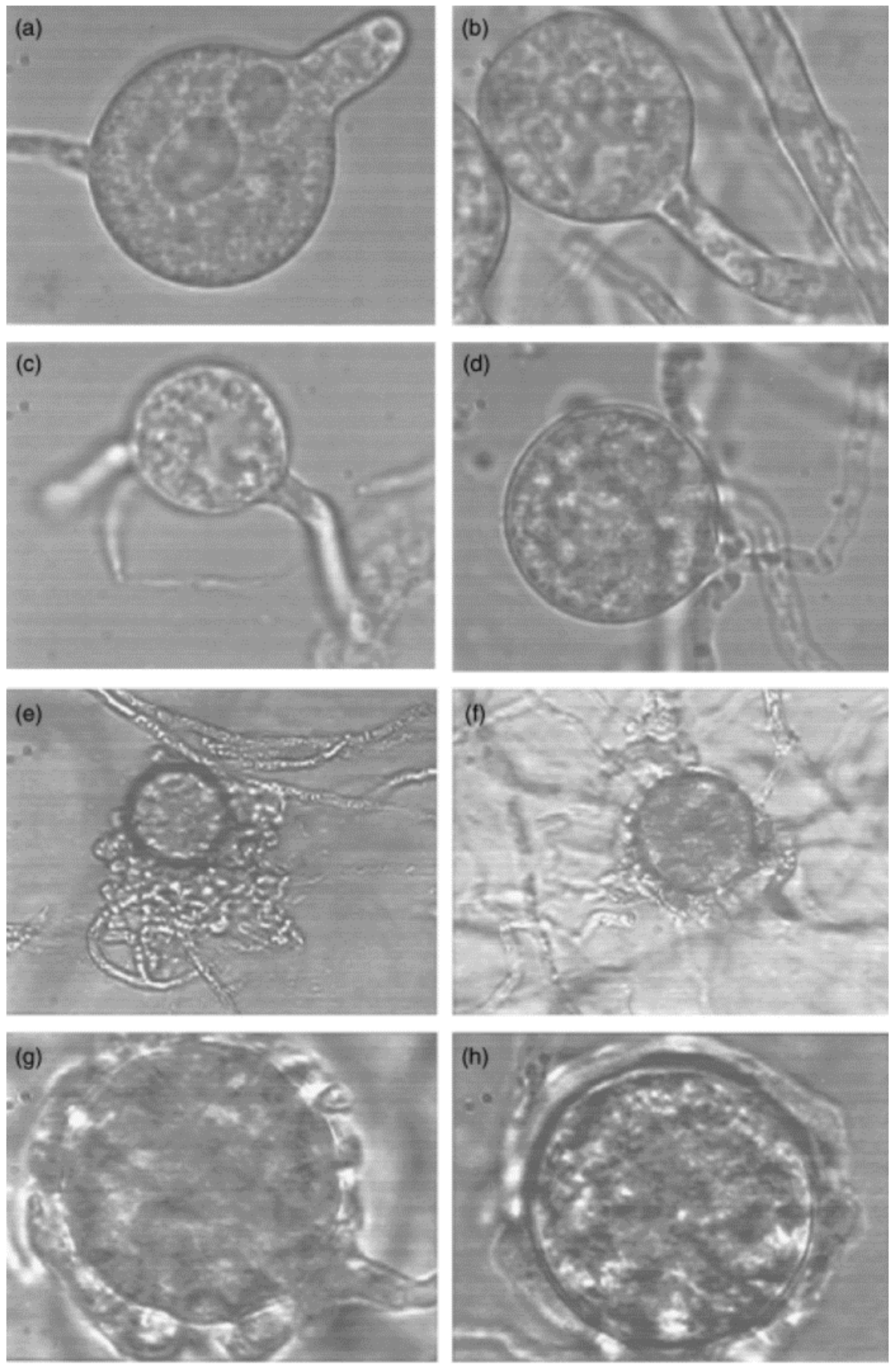

Figura 27. Morfología de Phytopythium aff. mercuriale (STEU-U 6207). (a-d) Esporangio viejo formando tubos germinativos. $(\mathrm{e}-\mathrm{h})$ Oogonio rodeado por nudo indefinido de anteridios. $\mathrm{BAR}=35 \mu \mathrm{m}$ en $(\mathrm{a}-\mathrm{d}) \mathrm{y}(\mathrm{g}-\mathrm{h})$. BAR $=80 \mu \mathrm{m}$ en $(\mathrm{e}-\mathrm{f})$.

\section{c. Caracterización molecular}

De la cepa Py 15-11 se obtuvo una secuencia de ITS de 640 pb, la que presentó un $98 \%$ de similitud con la cepa tipo \#JN630486.1 Phy. mercuriale aislamiento A89 usado por De cock et al., (2015), para la filogenia de Phytopythium. Además presentó un 99 \% de similitud con la cepa Phy. mercuriale V-NESO2_5-52 (\# KU211357.1) y un 99 
\% de similitud con la cepa. CBS No. 122443. \#GenBank AB690614 Phytopythium mercuriale.

>15-11 Phytopythium aff. mercuriale

AAAAGNGTAACAAGGTTTCCGTAGGTGAACCTGCGGAAGGATCATTACCAC ACCTAAAAATCTTTCCACGTGAATTGTTTTGTACACTGTTGGGTTTCGCTGG CGCGTGTTTTCTTGTCGAATGTAGTGTTTGACGGCGCGCGGCGGCTGGAGGC CATCAGGGCGTCTGTTGTTGTGATGGACGCTCTTTTTGTAAACCCCCTTTTTT TTTATTTTGTGAAACTGATTGGACTGTGGGGACGAAAGTCTCTGCTTTGAAC TAAAAAGCAACTTTCAGCAGTGGATGTCTAGGCTCGCACATCGATGAAAAA CGCTGCGAACTGCGATACGTAATGCGAATTGCAGGATTCAGTGAGTCATCG AAATTTTGAACGCATATTGCACTTTCGGGTTCTGCCTGGAAGTATGTCTGTA TCAGTGTCCGTACACTAAAGTTGCCTTTCTTGCGTCGTGTAGTCGTCGCTTG GAACGAGCAGATGTGAGGTGTCTTGCGTGGTGGTTTTGTGGTGGCGGTTTTG TGCTGCTGGCGTAAAGTAGTCGTGCAAGTCCCTTTAAAGTCGGACGTGTTTT CTCTGTAGTGTGCTGTGGCAGCTTTGGTGGCATGCGGGACGTAGTCTGTTGA CGAGTCTGGCGACCTTTG

La cepa tipo "Typus" fue aislada de la provincia de Limpopo, en África Meridional, a partir de la rizósfera de Macadamiae integrifoliae en 2005. CBS $\mathrm{N}^{\circ}$ 122443. En Argentina no hay registros previos de Phy. mercuriale.

\section{Phytopythium frezzii sp. nov (Grijalba y Palmucci) Abad, de}

Cock, Bala, Robideau, Lodhi y Lévesque (2014).

\section{$\underline{\text { a. Origen de los aislamientos }}$}

El aislamiento Py $3 x$ se obtuvo a partir de raíces de soja procedentes de campos comerciales de soja de Fontezuela (NBA) durante la campaña 2013/14.

\section{b. Caracterización cultural y morfológica}

Se describe una nueva especie de Phytopythium, aislada de raíces de soja en Pergamino, provincia de Buenos Aires, Argentina. La morfología y el análisis de secuencias de las regiones ITS1-ITS2 de esta especie, fueron diferentes a las de otras especies descritas anteriormente. La región ITS fue $97 \%$ similar a Pythium sp. amazonianum (GenBank \# GU258939) y un 96 \% similar a P. vexans (GenBank \# HQ643371). Estas tres secuencias, una de P. irregulare (GenBank \# AB107999.1) y el neotipo de Pyhtophtora nicotianae (GenBank \# AF266776) se alinearon usando el 
programa Clustal W. Se construyó un árbol filogenético con el programa MEGA versión 5.0, utilizando el método the Neighbor-joining con 1000 repeticiones de bootstrap.

La colonia de Phy. frezzii sp. nov. presentó micelio aéreo algodonoso en AHM y patrón petaloide en APD (Fig. $28 \mathrm{~B}$ ). La hifa principal mayor de hasta $6 \mu \mathrm{m}$ diám. Con esporangios globosos a ovoides y oosporas aploróticas, entre 15,2 y 21, (prom.16,5) $\mu \mathrm{m}$ diám., pared 4-5 $\mu \mathrm{m}$ diám (Fig. 28 A). Principalmente oogonios terminales, globosos, un anteridio, raramente dos, monoclinos, raramente diclinos, que surgen a cierta distancia debajo del oogonio, células anteridiales, típicamente campaniforme (Fig. 28 C y D). Las temperaturas cardinales fueron: mínimo $5{ }^{\circ} \mathrm{C}$, óptimo $30{ }^{\circ} \mathrm{C}$, máximo $35^{\circ} \mathrm{C}$. La velocidad de crecimiento diaria en APD a $25^{\circ} \mathrm{C}$ fue de $26 \mathrm{~mm}$.

Los ensayos in vitro y en invernáculo se utilizaron para completar los postulados de Koch. A través del ensayo con placa de Petri, el aislamiento presentó 87 \% de plantas muertas con una desviación estándar de $7 \%$, mientras que en vivo no presentó plantas muertas. Sin embargo, las raíces mostraron necrosis de punta, de las cuales el mismo microorganismo fue consistentemente reaislado. Por esta razón, se considera que tiene un bajo nivel de patogenicidad. También se inhibió con metalaxil y carbendazim + thiran. El aislamiento fue depositado en la Colección de Hongos de la Cátedra de Fitopatología, Universidad de Buenos Aires. Proponemos el nombre Phytopythium frezzii sp. nov. (Grijalba y Palmucci) para esta nueva especie (en honor de Ing. Agr. Mariano Frezzi, investigador pionero de la familia Pythiaceae en Argentina) 


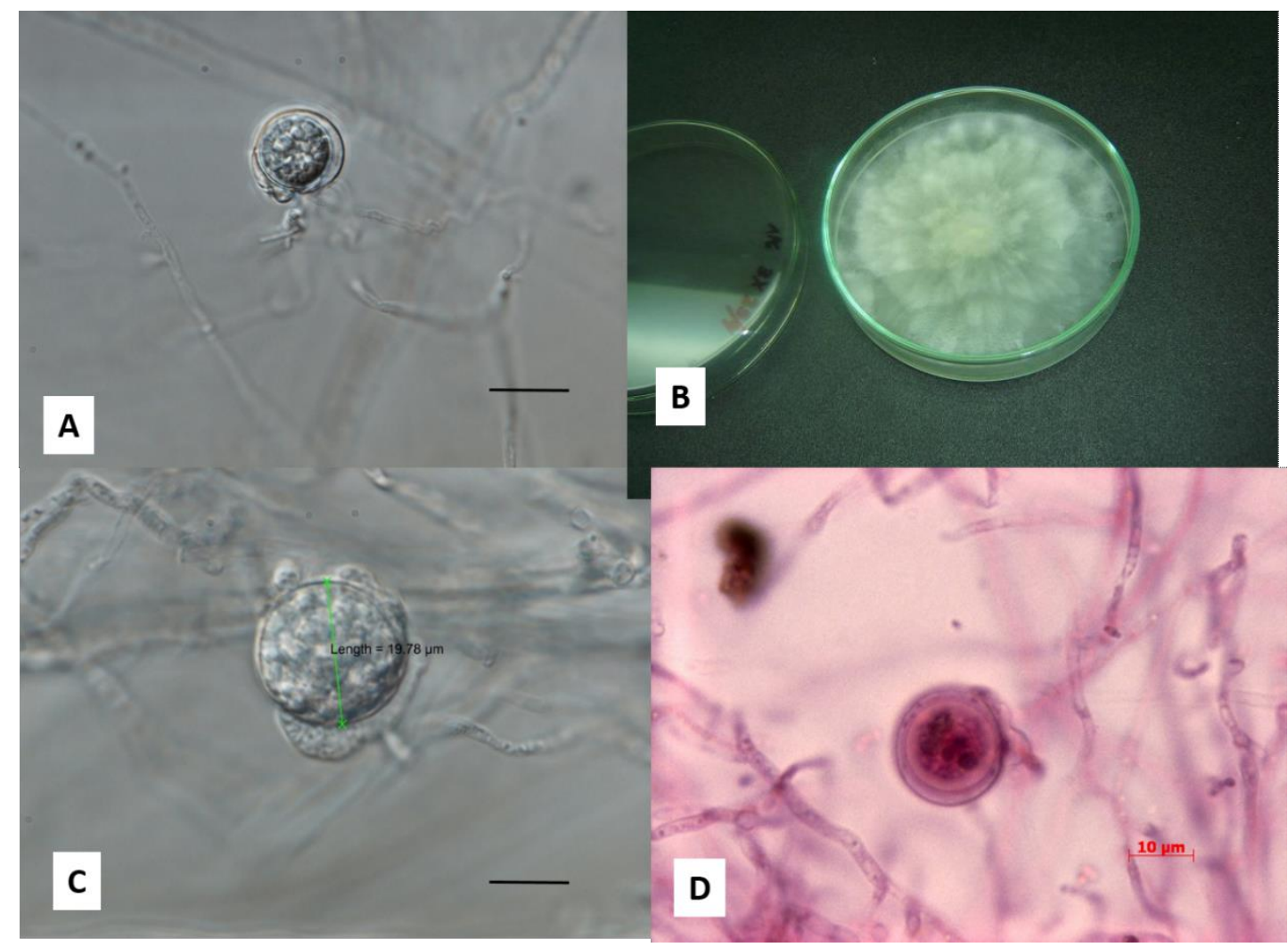

Figura 28. Phytopythium frezzii sp. nov. A. Oospora. BAR $=20 \mu \mathrm{m}$. B Colonia en APD. $\mathrm{C}$ y D Oogonio y anteridio campaniforme. $\mathrm{BAR}=10 \mu \mathrm{m}$.

\section{c. Caracterización molecular}

De la cepa Py 3x se obtuvo una secuencia de ITS de 777 pb, la que presentó un $100 \%$ de similitud con la cepa Phy. sp. amazonianum \#GU258625.1 aislamiento WPC:8246B329, $100 \%$ con el aislamiento \# GU 258938.1 WPC:8242C139 у $96 \%$ similar a $P$. vexans (GenBank\#HQ643371). Estas dos últimas secuencias, junto con la obtnida de Py 3x, una de P. irregulare (GenBank\#AB107999.1) y el neotype de Phytophtora nicotianae (GenBank\#AF266776) se alinearon usando el programa Clustal W. Se construyó un árbol filogenético con el programa MEGA versión 6.0, método de Neighbor-joining con 1000 repeticiones de bootstrap (Fig. 29)

Ademas se obtuvo una secuencia de Btubulin de $628 \mathrm{pb}$, la que no presentó similitud alguna con ninguna secuencia depositada en el GenBank.

> Phytopythium frezzii ITS 3X

CCACACTAAAAACACCCTTCCACGTGAACCGTTTTGTTTTGCTTTCGAGTGC TTTGTTGCGCTCGGAGCATGTTTGGGCTTCGCTGCTGGCGCTTGATTGTGCT GGCGGCTCGAGGCCATCAAGTGGCGTTTTGAGTGCTTGCACAATTAACGTCC AAACCTTTTAAACCCATTTGATTGAAAACTGAAGTATACTGTGGGGACGAA 
AGTCCTCGCTTTGAAACTAGATAACAACTTTCAGCAGTGGATGTCTAGGCTC GCACATCGATGAAGAACGCTGCGAACTGCGATACGTAATGCGAATTGCAGG ATTCAGTGAGTCATCGAACTTTTGAACGCATATTGCACTTTCGGGTTACGCC TGGAAGTATGTCTGTATCAGTGTCCGTACACTAAACTTGCGTCTCTTCCGTC GTGTAGTCGTCGGTTGTTTGATTGCAGATGTGAGGTTGTCTCGCGATGTGCC ATGTTTTTTGTGGCAAGGTTGCGAGTCCCTTTAAAGTCGGACGCGTTTTTCC GTTTTGTGCTCGATGGGGTGCGGCTGCGGCCGTGTCTGCTGGCGGGTCCGGT GACCTTTGGCGATGGCATGAGAGTGGATTGCTCGATTTGCGGTATGTTAGGC TTCGGCTTTGACAATGCAGCTTATTGAGTGTGTTCGCTTGGCTGTTGCTGTAT GGGTGAGCTGGATGGTCGGTGGGTGCGTTGTTGCGTGTCGTTTTCATTGCGT GCGTTTCGGTTGTCGTCGCCATTTGGGAATTTAATGTTTTCTTACGAGAA

\section{$>$ Phytopythium frezzii Btub 3X}

TCAAGAAAGCCTTACGACGGAGGGATAATTTTATGAAGCTCTCGCCTGCGG GAGGTGCCACCGCTGGCTCCACTGGCTTCACATATTCTTAGGAGCCGAGCAC GCCAGGTCTTTACCGCTGCGTCCATGCTCCCTGTGGCCAAGATCTCGCCGCC GTCGGCCGCCAAGGTATCGCCCTTGAACCTCCGCTTCATCCTCGACAGCGCA GTGGATGAAGGCGAGCAAGGCGAGCAAGATGAGAACGAGCCGGCCAAGGC GCAAGCGGCAGTCGCGCGACAGCAAGTGACCGAGTGGATGAAAGTGGCCC CGCGAAGGCGCGCACCCAAGGCCAAGCGCAACCGCAAAGGCTGGGGGCCG TACAACTCGGTACTCAACGAGCGCAGCGTCGACTTCAACCTGACGCTCGAC GTGCAGAGCCTCAAGCAGGAGATCATGGAGCTGACGAGCGCGCGCGACCTG CTTCGCGCGAGAGTGCTCATGGCACGTCACACGCCCGACGGCTCGCTGCTG CGCATCGTGCGCGAGTTCTACAACCTCTTTGGCGCTGGCCAGTGGCTCGAAT CGGGATGCCCGCATCGTCAGCTCGGCTTCCTGCTCAGCAACATGACCGAGT ACGTGCACATGATAC

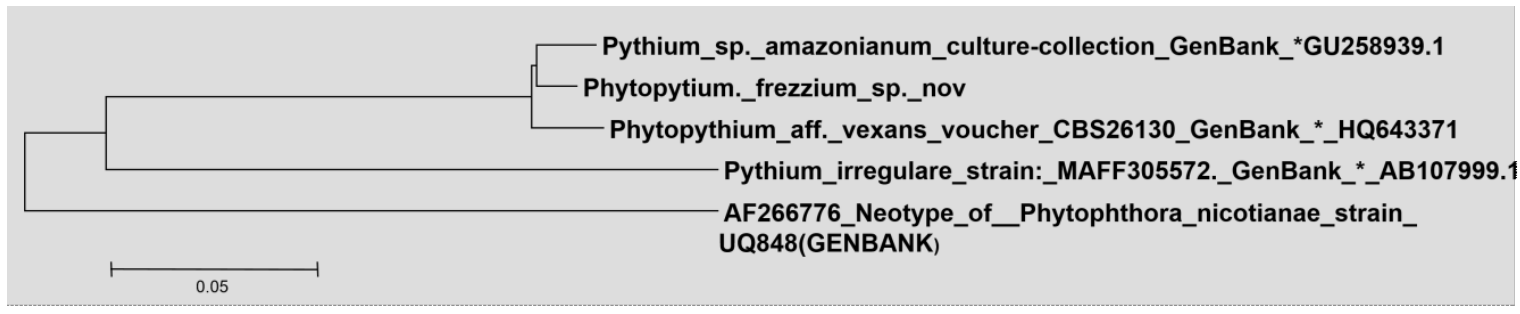

Figura 29. Relación filogenética de Phytopythium frezzi sp. nov usando el método de Neighbor-Joining.

Se aislaron e identificaron Phy. chamaehyphon (Sideris), Phy. vexans (de Bary), Phy. cucurbitacearum (S. Takimoto), incluída dentro del complejo Phy. vexans (de Cock et al., 2015), Phy. helicoides (Dreschler) y Phy. aff. mercuriale (Belbahri, B. Paul y Lefort). Además se describió una nueva especie de Phytopythium, aislada de raíces de soja en Pergamino (NBA). 


\section{4. Árbol filogenético de las especies de Pythium y Phytopythium más una secuencia de Phytophthora sojae}

Con todas las secuencias de ITS de cada especie se elaboró un árbol filogenético para las especies de Pythium y Phytopythium y además se uso una secuencia de Ph. sojae (obtenida con anterioridad al presente trabajo) de un aislamiento de Tandil Argentina (Fig. 30). Pueden identificarse el agrupamiento de Pythium por un lado, Ph. sojae por el otro y las especies de Phytopythium determinadas formando otro clado, totalmente distinto.

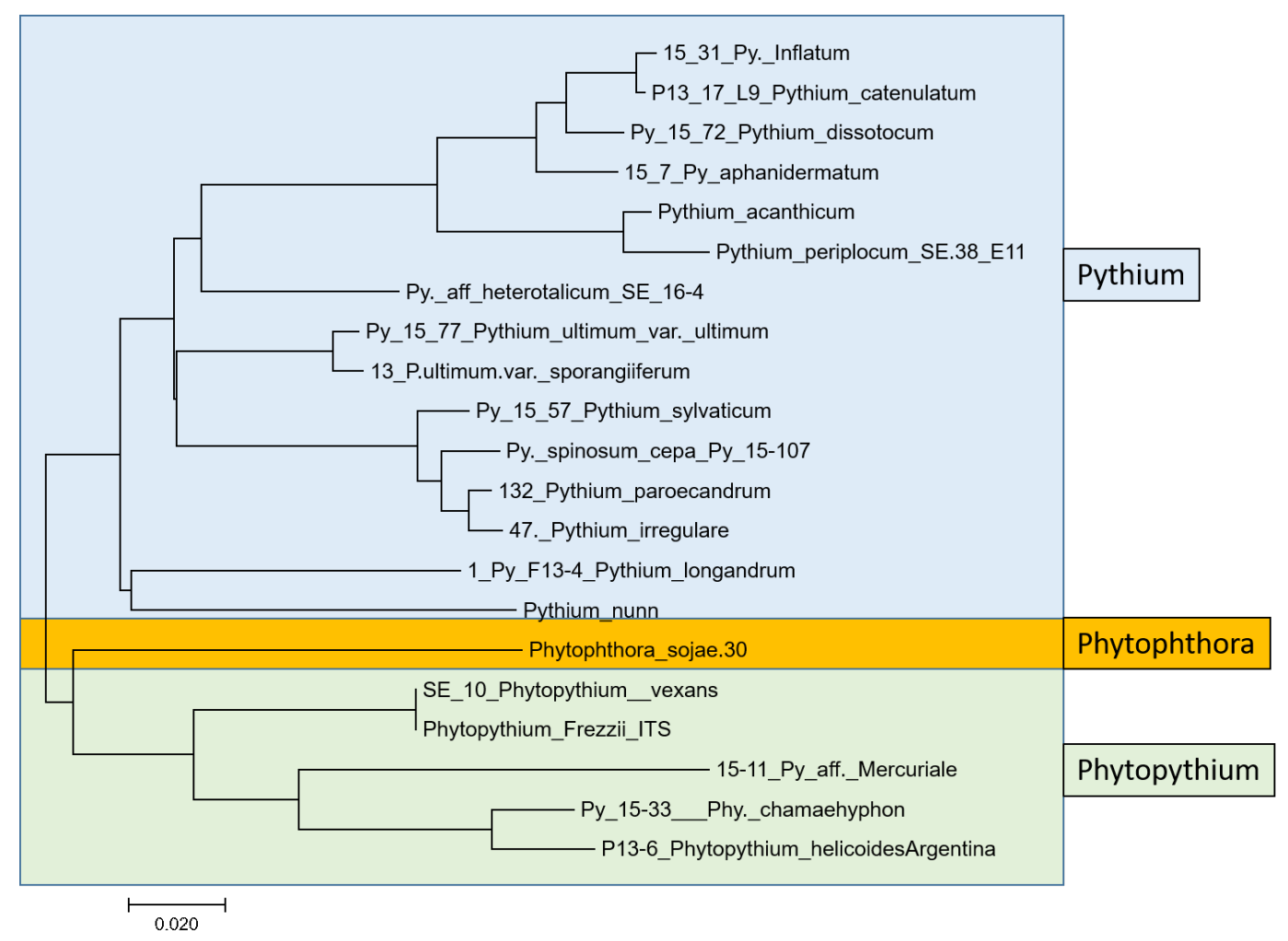

Figura 30. Relación filogenética de todos los aislamientos usando el método deNeighborJoining.

\section{PRUEBAS DE PATOGENICIDAD}

\subsection{Ensayo de patogenicidad in-vitro}

\subsection{Ensayo de patogenicidad in-vivo}

Tanto la patogenicidad in-vitro o podredumbre de semillas (PS) como in-vivo o damping off(DO) se expresan en la Tabla 4. Las pruebas de patogenicidad se efectuaron con todas las especies determinadas, en aquellas de las que se obtuvieron muchos aislameintos $(P$. ultimum, P. irregulare, P. sylvaticum entre otros), las pruebas de patogenicidad se efectuaron con tres o más aislamientos, pero no con todos. Para la patogenicidad in-vitro, 
se indica, la cantidad de aislamientos probados por especie y el número de semillas probadas para cada una. Para la patogenicidad in-vivo se indica el porcenaje de patogenicidad promedio y si se probaron varios aislamientos de la misma especie se indica el desvio standard.

\subsection{Ensayo exploratorio de patogenicidad con cepas de Phytopythium}

Tanto las especies determinadas como la patogenicidad in-vitro e in-vivo, se expresan en la Tabla 3. El ensayo piloto de inoculación de las dos especies de Phytopythium analizadas (Phy. frezzii y Phy. helicoides), indicaron que bajo las condiciones del ensayo, la patogenicidad resultó ser similar tanto para el método de inoculación de la capa (manteniendo el suelo entre capacidad de campo e inundación) y el método con inundación prolongada (Tabla 3 y Anexo II).

Tabla 3. Patogenicidad promedio para dos especies de Phytopythium (método de la capa e inundación).

\begin{tabular}{|l|l|l|}
\hline Especie & $\begin{array}{l}\% \text { mortandad promedio } \\
\text { método de la capa }\end{array}$ & $\begin{array}{l}\% \text { mortandad promedio } \\
\text { inundación }\end{array}$ \\
\hline Phytopythium frezzii & $16,3 \% \mathrm{a}$ & $17,8 \% \mathrm{a}$ \\
\hline Phytopythium helicoides & $12,75 \% \mathrm{~A}$ & $13,5 \% \mathrm{~A}$ \\
\hline
\end{tabular}

Medias con una letra común no son significativamente diferentes $(p<=0.05)$. Minúsculas Phytopythium frezzii, mayúsculas Phytopythium helicoides. 
Tabla 4. Patogenicidad in vitro e in vivo de las especies de Pythium y Phytopythium aisladas entre 2013-2016 en las zonas norte y sudeste de la provincia de Buenos Aires.

\begin{tabular}{|c|c|c|c|c|c|c|c|c|c|c|c|}
\hline \multirow[b]{3}{*}{ Clado } & & \multirow{3}{*}{$\begin{array}{l}\mathrm{N}^{\circ} \text { aislam } \\
\text { probados }\end{array}$} & \multicolumn{6}{|l|}{ In vitro } & \multirow{2}{*}{\multicolumn{2}{|c|}{\begin{tabular}{|l|} 
In vivo \\
$\%$ mortand
\end{tabular}}} & \multirow[b]{3}{*}{ Patogenicd. } \\
\hline & & & \multirow{2}{*}{\begin{tabular}{|l} 
Cant. \\
Semil. \\
\end{tabular}} & \multicolumn{5}{|c|}{ Grados de ataque } & & & \\
\hline & & & & 0 & 1 & 2 & 3 & 4 & Promedio & Rango & \\
\hline I & P. ultimum var. ultim & 8 & 320 & & & & & 320 & 95,7 & $+4,9$ & $\mathrm{~A}$ \\
\hline I & $\begin{array}{l}\text { P. ultimum var. } \\
\text { sporang }\end{array}$ & 2 & 80 & & & & 16 & 64 & 96,3 & $-+3,6$ & $\mathrm{~A}$ \\
\hline I & P. ultimum & 20 & 320 & & & & 20 & 300 & 79,17 & $+21,02$ & A \\
\hline $\mathbf{F}$ & P. irregulare & 10 & 320 & & & & 14 & 306 & 83,5 & $+7,9 \%$ & $\mathrm{~A}$ \\
\hline $\mathbf{F}$ & P. sylvaticum & 8 & 320 & 32 & 0 & 10 & 64 & 214 & 54,2 & $+23,5$ & M-A \\
\hline B & P. inflatum & 1 & 40 & 8 & 26 & 6 & & & $33 \%$ & & $\mathrm{~B}$ \\
\hline $\mathbf{A}$ & P. aphanidermatum & 5 & 200 & & & & & 200 & $73 \%$ & $+21,6$ & $\mathrm{~A}$ \\
\hline B & P. catenulatum & 1 & 40 & 25 & 7 & 7 & 1 & & 7 & & B \\
\hline $\mathbf{E}$ & P. longandrun & 1 & 40 & 30 & 10 & & & & $2 \%$ & & $\mathrm{~B}$ \\
\hline B & P. dissotocum & 3 & 120 & & & 20 & 72 & 28 & $66,70 \%$ & +25 & $\mathrm{M}$ \\
\hline $\mathbf{F}$ & P. paroecandrum & 4 & 200 & 30 & 120 & 30 & 20 & & 55,88 & $+36,36$ & M-A \\
\hline $\mathbf{I}$ & \begin{tabular}{|l|}
$P$. aff. \\
heterothallicum
\end{tabular} & 1 & 40 & 40 & & & & & 5,88 & & $\mathrm{~B}$ \\
\hline D & P. acanthicum & 3 & 150 & 60 & 60 & 30 & & & $0 \%$ & & NP \\
\hline D & P. periplocum & 2 & 100 & 50 & 50 & & & & 3,1 & $+1,06$ & $\mathrm{~B}$ \\
\hline $\mathbf{J}$ & P. nunn & 1 & 40 & 40 & & & & & $0 \%$ & & NP \\
\hline $\mathbf{E}$ & Pythium sp. & 1 & 40 & 20 & 20 & & & & 2 & & B \\
\hline $\mathbf{K}$ & Phy. helicoides & 1 & 40 & & & & & 40 & 16,3 & & M-B \\
\hline $\mathbf{K}$ & Phy. frezzii sp. nov. & 1 & 40 & & 5 & 7 & 8 & 20 & $12,75 \%$ & & $\mathrm{~B}$ \\
\hline
\end{tabular}




\begin{tabular}{|c|c|c|c|c|c|c|c|c|c|c|c|}
\hline \multirow{6}{*}{$\begin{array}{l}\mathbf{K} \\
\mathbf{K} \\
\mathbf{K} \\
\mathbf{K}\end{array}$} & Phy. aff. mercuriale & $\overline{1}$ & 40 & & & & & & & & $\mathrm{~B}$ \\
\hline & Phy. chamaehyphon & 2 & 100 & & & 30 & 30 & 40 & $29,40 \%$ & $+7,9$ & B-M \\
\hline & Phy. vexans & 13 & 520 & 136 & 248 & 128 & 8 & & $3 \%$ & -1 & $\mathrm{~B}$ \\
\hline & Phytopythium sp. & & 10 & 9 & & & & 1 & 0 & & NP \\
\hline & Achlya & 1 & 40 & 40 & & & & & & & NP \\
\hline & Mortierella* & 1 & 40 & 40 & & & & & & & NP \\
\hline$* \mathrm{Z}$ & ycete no Oomycete (a) & las) & & & & & & & & & \\
\hline & $\begin{array}{l}\text { dad. } A=\text { Alta, Semil } \\
\text { y } 2 \text { y plántulas }>\text { de } \\
\text { ataque según escala }\end{array}$ & & & & & & & & $\begin{array}{l}0 \mathrm{y} 75 \% \\
\text { candad- }\end{array}$ & $\mathrm{B}=$ & \\
\hline
\end{tabular}




\section{RESPUESTAS DE DIFERENTES ESPECIES FRENTE A DISTINTAS TEMPERATURAS}

Hubo diferencias significativas entre las tres especies de Pythium tanto para PS como para DO. En relación a PS no se efectuó análisis estadístico ya que la respuesta fue bien definida, 0 (plántulas normales) o 4 semillas muertas. Se observa que P. ultimum y P. irregulare mataron todas las semillas a $15{ }^{\circ} \mathrm{C}$ y a $25{ }^{\circ} \mathrm{C}$, pero a $35{ }^{\circ} \mathrm{C}$ las plántulas nacieron sanas o con grado 1 . Por su parte $P$. aphanidermatum se comportó de manera opuesta, ya que a $15{ }^{\circ} \mathrm{C}$ no resultó patógeno, pero a $25^{\circ} \mathrm{C}$ y a $35^{\circ} \mathrm{C}$ mató todas las semillas (Fig. 31 y Tabla 5).

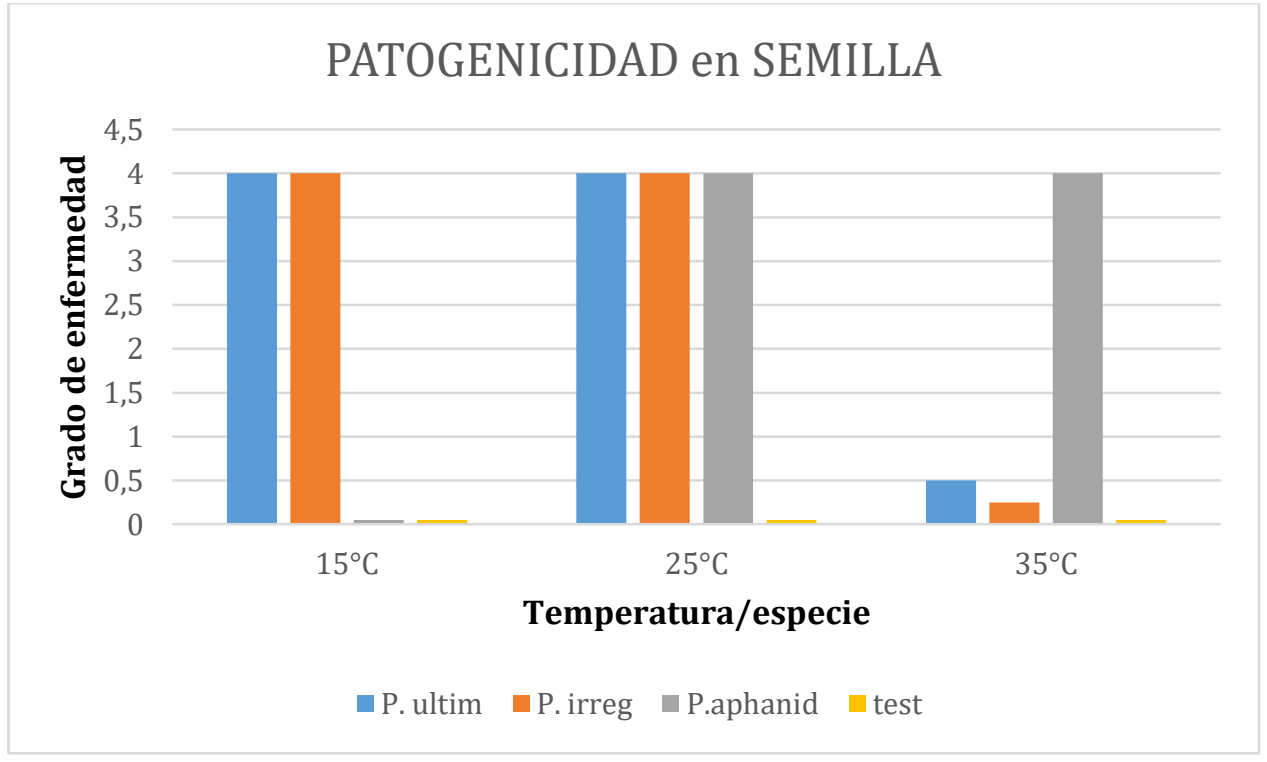

Figura 31. Patogenicidad en semillas de soja de cepas de $P$. ultimum, $P$. irregulare y $P$. aphanidermatum incubadas a tres temperaturas $\left(15,25\right.$ y $\left.25^{\circ} \mathrm{C}\right)$ (según escala propuesta por Jiang et al., 2012).

Por su parte la patogenicidad in-vivo (DO) y la tasa diaria de crecimiento se analizaron estadísticamente para cada una de las tres temperaturas utilizadas (Tabla 5 y Anexo II).

Para el DO a $15{ }^{\circ} \mathrm{C}$, la especie que presentó menor emergencia promedio sobre 15 semillas sembradas fue $P$. ultimum con 0,6 plántulas normales emergidas (PNE). Le siguió $P$. irregulare con 2,96 PNE y $P$. aphanidermatum con 9,6 PNE, que se diferenció del testigo que mostró un valor de 13,6 PNE.

Por su parte para el DO a $25{ }^{\circ} \mathrm{C}, P$. ultimum también fue la especie con menor número de PNE, con un valor de 3,95 promedio, pero no se diferenció estadísticamente de $P$. aphanidermatum con un valor de 3,8 y si de $P$. irregulare con 9,52 PNE, que 
también resultó patógena porque se diferenció del testigo sin inóculo, que presentó un valor de 14,2 .

El DO a $35^{\circ} \mathrm{C}$ fue totalmente distinto ya que la especie con menor número de PNE promedio, fue de $P$. aphanidermatum que no permitió que ninguna semilla emergiera y las otras dos especies no presentaron patogenicidad ya que no se diferenciaron estadísticamente del testigo sano (14,6 PNE) (Fig. 32, Tabla 5 y Anexo II).

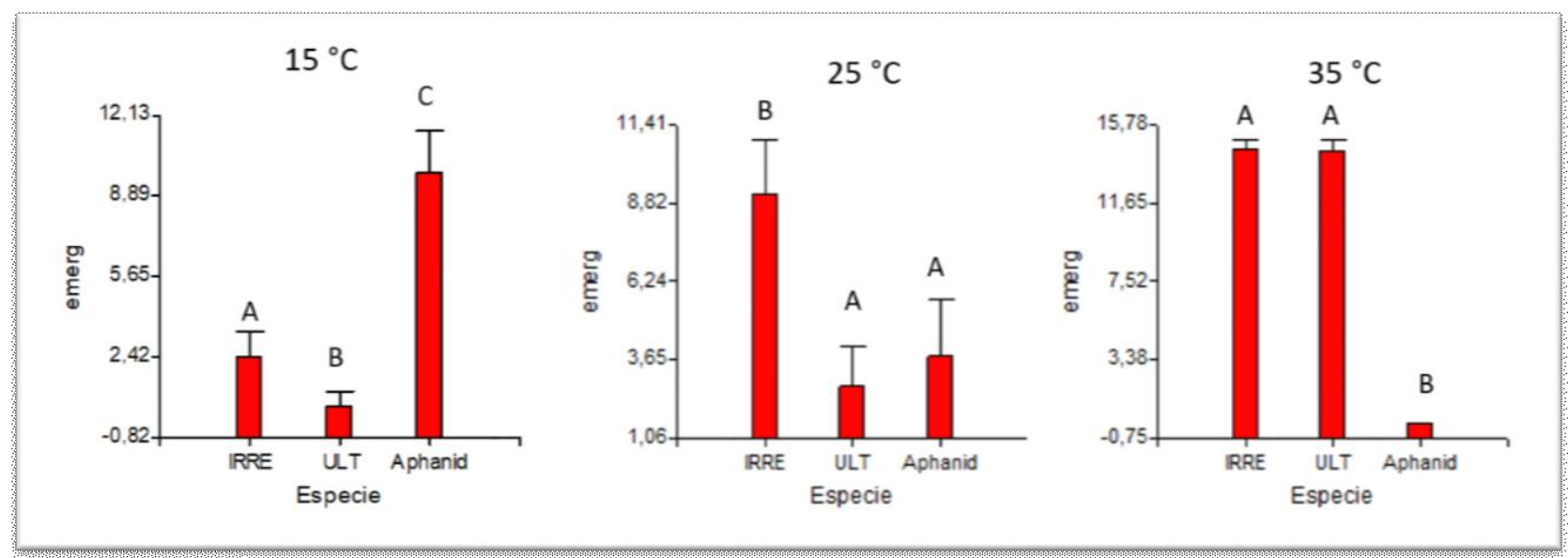

Figura 32. Emergencia de plántulas de soja en suelo infestado con $P$. ultimum, $P$. irregulare y $P$. aphanidermatum incubados a 15,25 y $35^{\circ} \mathrm{C}$, de 15 semillas sembradas.

\subsection{Tasas diarias de crecimiento.}

A $15{ }^{\circ} \mathrm{C}, P$. ultimum y P. irregulare no se diferenciaron estadísticamente con 1,70 y $1,62 \mathrm{~cm} /$ día respectivamente, pero si de $P$. aphanidermatum que presentó un valor menor $(1,22 \mathrm{~cm} /$ día $)$. A $25^{\circ} \mathrm{C}$, P. ultimum fue la especie con mayor tasa de crecimiento, $4,21 \mathrm{~cm} /$ día, y se diferenció estadísticamente de $P$. irregulare y de $P$. aphanidermatum $\left(3,80\right.$ y $3,61 \mathrm{~cm} /$ día respectivamente). Por el contrario a $35^{\circ} \mathrm{C}, P$. aphanidermatum fue la especie que presentó mayor tasa $(4,07 \mathrm{~cm} /$ día $)$, diferenciándose de $P$. ultimum y $P$. irregulare $(1,00$ y $0,69 \mathrm{~cm} /$ día respectivamente) que también se diferenciaron entre sí (Fig. 33, Tabla 5 y anexo II). 


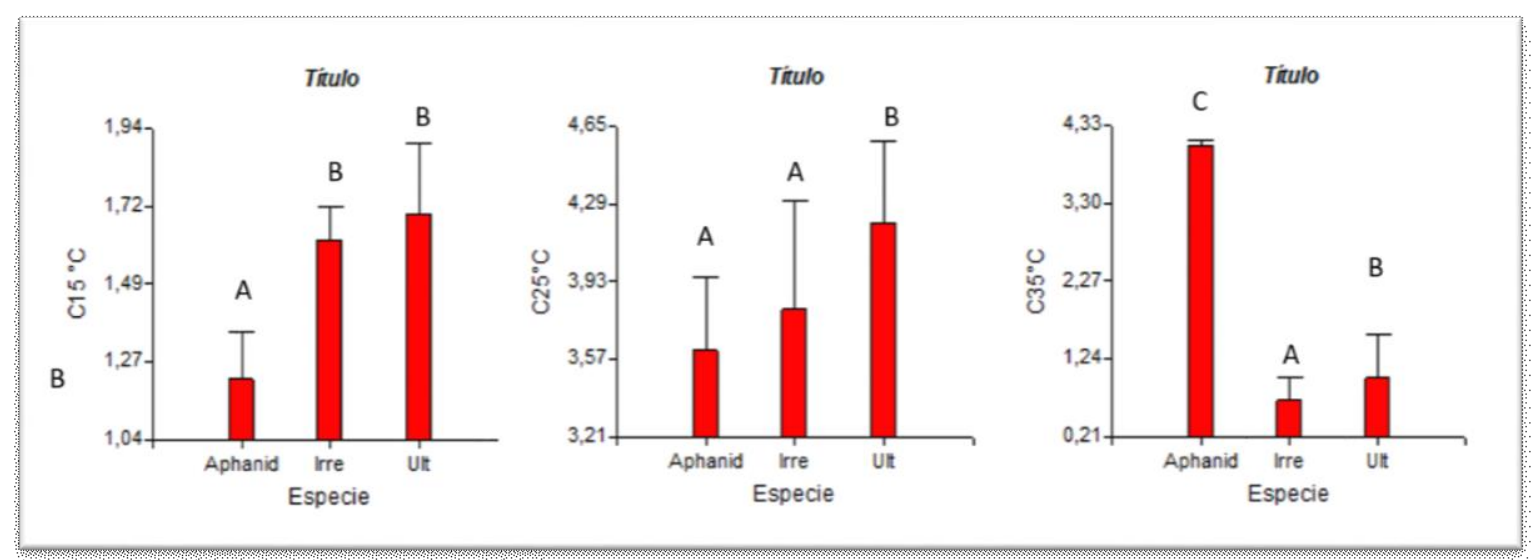

Figura 33. Tasa de crecimiento de $P$. ultimum, $P$. irregulare y $P$. aphanidermatum incubados a 15,25 y $35^{\circ} \mathrm{C}$.

Tabla 5: Respuestas de diferentes especies de Pythium frente a distintas temperaturas.

$15{ }^{\circ} \mathrm{C}$

\begin{tabular}{|l|l|l|l|l|}
\hline Aislam. & Especie & $\begin{array}{l}\text { Prom. } \\
\text { Crecim. }\end{array}$ & $\begin{array}{l}\text { Prom. } \\
\text { emergencia }\end{array}$ & $\begin{array}{l}\text { Patog. } \\
\text { semilla }\end{array}$ \\
\hline 98 & P. ultimum & 1,78 & 0,20 & 4 \\
\hline 90 & P. ultimum & 1,92 & 0,20 & 4 \\
\hline 102 & P. ultimum & 1,51 & 0,80 & 4 \\
\hline 77 & P. ultimum & 1,58 & 1,20 & 4 \\
\hline 79 & P. irregulare & 1,59 & 1,60 & 4 \\
\hline 87 & P. irregulare & 1,57 & 1,80 & 4 \\
\hline 85 & P. irregulare & 1,62 & 2,00 & 4 \\
\hline 78 & P. irregulare & 1,62 & 3,80 & 4 \\
\hline 64 & P. aphanidermatum & 1,08 & 9,00 & 0 \\
\hline 12 & P. aphanidermatum & 1,32 & 9,00 & 0 \\
\hline 7 & P. aphanidermatum & 1,26 & 11,40 & 0 \\
\hline
\end{tabular}

\section{$25^{\circ} \mathrm{C}$}

\begin{tabular}{|l|l|l|l|l|}
\hline Aislam. & Especie & $\begin{array}{l}\text { Prom. } \\
\text { Crecim. }\end{array}$ & $\begin{array}{l}\text { Prom. } \\
\text { emergencia }\end{array}$ & $\begin{array}{l}\text { Patog. } \\
\text { semilla }\end{array}$ \\
\hline 98 & P. ultimum & 4,28 & 3,80 & 4 \\
\hline 90 & P. ultimum & 4,24 & 2,20 & 4 \\
\hline 102 & P. ultimum & 3,90 & 7,40 & 4 \\
\hline 77 & P. ultimum & 4,42 & 2,40 & 4 \\
\hline 79 & P. irregulare & 3,42 & 11,20 & 4 \\
\hline 87 & P. irregulare & 4,44 & 8,00 & 4 \\
\hline 85 & P. irregulare & 3,48 & 8,60 & 4 \\
\hline 78 & P. irregulare & 3,86 & 10,80 & 4 \\
\hline 64 & P. aphanidermatum & 4,02 & 3,00 & 4 \\
\hline 12 & P. aphanidermatum & 3,38 & 3,40 & 4 \\
\hline 7 & P. aphanidermatum & 3,44 & 5,00 & 4 \\
\hline
\end{tabular}

$35{ }^{\circ} \mathrm{C}$

\begin{tabular}{|l|l|l|l|l|}
\hline Aislam. & Especie & $\begin{array}{l}\text { Prom. } \\
\text { Crecim. }\end{array}$ & $\begin{array}{l}\text { Prom. } \\
\text { emergencia }\end{array}$ & $\begin{array}{l}\text { Patog. } \\
\text { semilla }\end{array}$ \\
\hline 98 & P. ultimum & 1,00 & 14,60 & 1 \\
\hline 90 & P. ultimum & 1,84 & 14,20 & 0 \\
\hline 102 & P. ultimum & 0,69 & 13,80 & 1 \\
\hline 77 & P. ultimum & 0,48 & 14,40 & 0 \\
\hline 79 & P. irregulare & 0,48 & 14,40 & 0 \\
\hline 87 & P. irregulare & 0,56 & 14,60 & 1 \\
\hline 85 & P. irregulare & 0,58 & 14,40 & 0 \\
\hline 78 & P. irregulare & 1,16 & 14,20 & 0 \\
\hline
\end{tabular}




\begin{tabular}{|l|l|l|l|l|}
\hline 64 & P. aphanidermatum & 4,1 & 0,00 & 4 \\
\hline 12 & P. aphanidermatum & 4,07 & 0,00 & 4 \\
\hline 7 & P. aphanidermatum & 4,07 & 0,00 & 4 \\
\hline
\end{tabular}

Aislam.= Aislameinto; Prom. Crecim. $=$ Crecimiento promedio; Prom. Emergencia $=$ Emergencia Promedio; Patog semilla $=$ patogenicidad in vitro

\section{ENSAYOS DE MANEJO CON P. ultimum, P. irregulare y P. sylvaticum}

\subsection{Control químico, eficacia de diferentes formulados curasemillas}

\subsubsection{Sensibilidad in vitro:}

El crecimiento miceliar del $100 \%$ de los aislamientos fue inhibido con la dosis de 10 ppm de metalaxil in vitro (Fig. 34) pero cuando el medio de cultivo contenía 100 ppm de carbendazim+tiram solo se inhibió el $40 \%$ de los aislamientos.

La dosis de 10 ppm de metalaxil en APD, no dejó al descubierto ninguna cepa resistente, a excepción de Phytopythium aff. mercuriale que como siguió creciendo con esa dosis, se la duplicó llevándola a 20 ppm de metalaxil en APD, y aún así siguó creciendo.

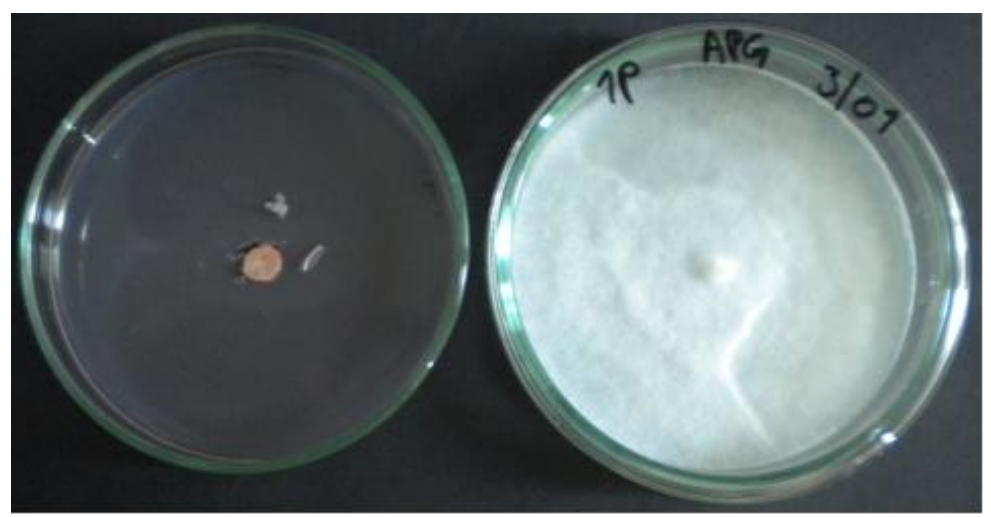

Figura 34. Ensayo de sensibilidad in-vitro, izquierda tratamiento con metalaxil, derecha testigo.

\subsubsection{Eficacia de diferentes formulados curasemillas:}

Ensayo A) El metalaxil controló de manera eficiente a los diez aislamientos en forma conjunta, ya que presentó más PNE en promedio que el resto de los tratamientos, e inclusive presentó el mismo número de plántulas emergidas que el testigo sin inocular. Para la mezcla de fungicidas carbendazim+tiram los datos evidenciaron que el tratamiento no generó ningún tipo de protección, ya que el testigo inoculado y el tratamiento con esta mezcla de fungicidas no presentaron diferencias significativas. El metalaxil presentó un $81,44 \%$ de control mientras que para carbendazim+tiram fue solo de 3,66 \% (Tabla 6 y anexo II). 
Ensayo B) Todos los tratamientos se diferenciaron estadísticamente del testigo inoculado en la cantidad de PNE; el metalaxil presentó la misma cantidad de plántulas emergidas promedio (86,76 \% de control), comparable con el resultado del ensayo A). Difenoconazol y azoxistrobina también se diferenciaron entre ellos, siendo azoxistrobina el de mayor cantidad de PNE y un 52,83 \% de control, mientras que difenoconazol solo presentó $25 \%$ de control (Tabla 6 y anexo II).

Tabla 6. Porcentaje de emergencia promedio y porcentaje de control de semillas de soja tratadas con fungicidas curasemillas y sembradas en suelo inoculado con Pythium spp.

\begin{tabular}{|c|c|c|}
\hline Tratamiento & \% Emer. Prom & \% Control \\
\hline \multicolumn{3}{|l|}{ Ensayo A) } \\
\hline Testigo con inóculo & 16 & \\
\hline Carb+ Tir con inóculo & $16,33 \quad \mathrm{~A}$ & 3,66 \\
\hline Metalaxil con inóculo & 23,33 & 81,44 \\
\hline Testigo sin inóculo & 23,66 & \\
\hline Metalaxil sin inóculo & 23 & \\
\hline Carb+Tir sin inóculo & 24 & \\
\hline \multicolumn{3}{|l|}{ Ensayo B) } \\
\hline Testigo con inóculo & $2.33 \mathrm{~A}$ & \\
\hline Difenoconazol con inóculo & $\mathrm{B}$ & 25 \\
\hline Azoxistrobina con inóculo & 14,33 & 52,83 \\
\hline Metalaxil con inóculo & 22 & 86,76 \\
\hline Testigo sin inóculo & 22 & \\
\hline
\end{tabular}

Carb+ Tir: Carbendazim + Tiram; Emer. Prom: Emergencia Promedio

Test DGC Letras distintas indican diferencias significativas $(\mathrm{p}<=0,05)$

\subsection{Relación entre el gen $R p s 1 \mathrm{k}$ y la resistencia a Pythium ultimum y $P$. irregulare en soja}

Cinco días después de la inoculación, los genotipos $\mathrm{SE}+1$ y $\mathrm{SE}+2$ presentaron reacción de compatibilidad tanto con el aislamiento F13-1 como con el aislamiento F13-3. Por su parte los genotipos SE-1y SE-2 lo hicieron con el aislamiento F13-1, pero no así con el F13-3.

En el presente ensayo, no se detectaron diferencias significativas entre las medias de los genotipos sin el gen, ya sea que estuviesen inoculados o no, ni tampoco difirieron del $\mathrm{SE}+2$. En cambio, los genotipos con el gen Rpslk difirieron entre sí, tanto los que estuvieron inoculados como los no inoculados. $\mathrm{SE}+2$ presentó 19 plántulas promedio emergidas (95\% de emergencia) mientras que SE+1, 15,67 plántulas promedio emergidas (76,35 \% de emergencia). En ambos casos la emergencia disminuyó cuando se inoculó, con 12,67 y 6,83 plántulas promedio emergidas $(63,35 \%$ y $34,15 \%$ de emergencia) respectivamente (Tabla 7 y anexo II). 
Tabla 7: Emergencia de plántulas a los 21 días desde la siembra de genotipos de soja sin inóculo e inoculados con Pythium spp.

\begin{tabular}{|c|c|c|c|}
\hline Genotipos & Inoculado & Emergencia & \% de Emergencia \\
\hline $\mathrm{SE}+2$ & No Inoc. & $19,00 \quad \mathrm{~A}$ & 95,00 \\
\hline SE-1 & No Inoc. & $18,00 \quad \mathrm{~A}$ & 90,00 \\
\hline SE-2 & No Inoc. & $18,00 \quad \mathrm{~A}$ & 90,00 \\
\hline $\mathrm{SE}+1$ & No Inoc. & 15,67 & 78,35 \\
\hline SE-1 & Inoc. & 15,33 & 76,65 \\
\hline SE-2 & Inoc. & 15,00 & 75,00 \\
\hline $\mathrm{SE}+2$ & Inoc. & 12,67 & 63,35 \\
\hline $\mathrm{SE}+1$ & Inoc. & 6,83 & 34,15 \\
\hline
\end{tabular}

Emergencia: Número promedio de plántulas emergidas (de un total de 20 semillas sembradas).

Medias con distinta letra son significativamente diferentes $(p<=0.05)$ 


\section{DISCUSIÓN}

El presente trabajo se llevó a cabo para actualizar los conocimientos sobre las comunidades de Oomycetes de suelo, que se asocian al cultivo de soja y que son potenciales agentes causales de enfermedades de plántulas en las dos zonas relevadas de la provincia de Buenos Aires, Argentina. De todos los lotes muestreados pudo obtenerse al menos un aislamiento de Pythium o de Phytopythium, lo cual corrobora que estos géneros son "habitantes del suelo". En ambas zonas las dos especies prevalentes fueron P. ultimum y $P$. irregulare con $41,7 \%$ y $22,5 \%$ respectivamente para el NBA; y $66,4 \%$ y $23,2 \%$ respectivamente para el SEBA.

La composición de la comunidad de Oomycetes asociada con el cultivo de soja fue diferente según la zona relevada, esto sugiere que la localización geográfica tiene un efecto sobre las comunidades de Oomycetes. La influencia del medio ambiente en la diversidad y distribución de los patógenos de las plantas no es un concepto nuevo. Se han realizado estudios enfocados en la distribución de Oomycetes asociadas con enfermedades de plántulas de soja en distintos estados de Estados Unidos (Broders et al., 2007, Jiang et al., 2012, Marchand et al., 2014, Zitnick-Anderson y Nelson 2015, Rojas et al, 2016 b, Readmer et al., 2017). Rojas et al. (2016 a) evaluaron la diferencia en las comunidades con respecto a la posición geográfica (latitud y longitud) en Estados Unidos, concluyendo que la latitud era un factor importante en la diversidad, quienes también demostraron, que las herramientas moleculares son aptas para estudiar la diversidad de especies de Oomycetes asociados al cultivo de la soja. Los tipos y algunas propiedades del suelo, como ser el pH, o la concentración de calcio, también se asociaron con la diversidad de especies de Pythium, y con altos niveles de incidencia de enfermedad (Broders et al., 2009).

En Argentina Pastor et al. (2005) efectuaron muestreos de suelos desde la provincia de Chaco hasta el sur de la provincia de Buenos Aires, determinaron las especies de Pythium spp. y mencionaron que en Buenos Aires la diversidad aumentó de norte a sudeste. En esos suelos determinaron $P$. ultimum var. ultimum, $P$. irregulare, $P$. spinosum, P. acanthicum, $P$. aphanidermathum, P. intermedium, P. oligandrum, $P$. rostratrum, P. catenulatum y $P$. debaryanum. Los estudios fitopatológicos, de Oomycetes de suelo en soja realizados previamente en Argentina, han sido escasos. Solo se hallan 
citas que relacionan a Glycine max con $P$. ultimum, $P$. irregulare, $P$. debaryanum, $P$. rostratum y P. sylvaticum (Pastor et al., 2011; Grijalba et al., 2011). Si bien, en este trabajo se identificaron 21 especies no se encontró ni determinó a $P$. debaryanum ni a $P$. rostratum. Por su parte Vallone y Giorga (1997) citaron como únicas especies que provocan damping off en soja, a $P$. acanthicum y a Pythium sp. Esto difiere con nuestros resultados, ya que $P$. acanthicum no apareció produciendo damping off, ni se aisló de muestras de suelo; se determinó en granos de soja aunque no resultó ser patógeno tanto en los ensayos in vitro como en los efectuados in vivo.

Este trabajo reveló especies de Pythium del clado F e I que contribuyeron al menos al 95,4 \% de la composición de la comunidad y estos clados también contienen la mayoría de las especies fitopatógenas (Lévesque y De Cock, 2004). El porcentaje restante de las comunidades obtenidas, se dividió entre los clados de Pythium A, B, D, E y J, y los géneros Phytopythium (Clade K), Achlya y Mortierella (Zygomycete).

De plántulas sintomáticas y muestras de suelo, del NBA, se obtuvieron 181 aislamientos que correspondieron a Pythium ultimum, P. irregulare, P. sylvaticum, $P$. inflatum, $P$. aphanidermatum, $P$. dissotocum, $P$. catenulatum y $P$. longandrum más un Pythium sp. que no pudo ser clasificado dentro de ninguna especie conocida; a tres especies de Phytopythium: Phy. helicoides, Phy. frezzii sp. nov., Phy. chamaehyphon y una que tampoco pudo ser identificada, Phytopythium sp. Mientras que del SEBA, se obtuvieron 102 aislamientos, que correspondieron a Pythium ultimum, $P$. irregulare, $P$. sylvaticum y $P$. paroecandrum. Todo esto demuestra que en el NBA la cantidad de especies de Pythium obtenidas es mayor que las del SEBA. En esta última región no se ha obtenido ningún aislamiento que fuese clasificado como Phytopythium, esto puede deberse, entre otros factores, a que en el NBA el cultivo de soja es relativamente más antiguo, y además en el SEBA, se rota con otros cultivos como girasol y papa. Otro factor que pudiera influir de alguna forma en la adaptación de las especies, es la diferencia de temperaturas medias de cada región $\left(16,8^{\circ} \mathrm{C}\right.$ vs. $13,7^{\circ} \mathrm{C}$ respectivamente).

En este trabajo se comprobó la transmisión de Pythium spp. y Phytopythium spp. pero no de Phytophthora sojae por semillas de soja, que era lo que se esperaba (Schulz y Francomano de Picardi, 1989; Zhaohui y Jin, 1999). Se pudo determinar la trasmisión de P. irregulare, P. paroecandrum, P. heterothallicum, P. acanthicum, P. periplocum, y Phy. vexans con distinto grado de patogenicidad. Niirgard (1979) citó a Pythium como patógeno de semillas (seed-borne), indicando que principalmente los frutos carnosos pueden proveer condiciones favorables para su estableciémiento e invasión de las 
semillas. De esta forma P. aphanidermatum coloniza semillas de tomate (Gattani y Kaul, 1951, citado por Niirgard, 1979). No se han encontrado otras citas de transmisión de Pythium spp. vía semillas, tanto Valerie Grimault (presidente de ISTA, International Seed Testing Asociation), Nicolas Denance (project leader of ISTA pest list) como John Rupe (Universidad de Arkansas) (comunicaciones personales), coinciden en que, si bien es común encontrar al género Pythium en semillas de diferentes hospedantes no hay trabajos al respecto.

Las especies que presentaron patogenicidad en soja son $P$. ultimum sensu lato, $P$. irregulare, $P$. sylvaticum, $P$. aphanidermatum y $P$. paroecandrum; otras presentaron baja patogenicidad, P. inflatum, P. catenulatum, P. longandrum, P. aff. heterothallicum; Phy. helicoides, Phy. frezzii, Phy. chamaehyphon, Phy. vexans y Phy. aff. mercuriale. P. acanthicun, $P$. nunn y $P$. periplocum resultaron ser no patógenas, no causaron síntomas en plántulas de soja, lo que también ha sido reportado (Zitnick- Anderson y Nelson, 2015; Rojas et al., 2016 b). Algunas de estas especies han sido citadas como micoparásitos o antagonistas, este es el caso de P. nunn, que tiene superposición de nicho ecológico con P. ultimum, siendo un colonizador de materia orgánica (saprótrofo) sin causar enfermedades a las plantas y parasita sus hifas (Martin y Loper, 1999). Por lo que, el haber aislado estas especies podría ser el resultado de una competencia, o hiperparasitismo de estas especies, sobre especies patógenas de Pythium (Paulitz y Baker, 1987; Sneh, 1998; Ali-Shtayeh y Saleh, 1999), este podría ser otro factor a tener en cuenta en la diferencia de especies encontradas entre regiones. Varias de ellas fueron aisladas a partir de granos cosechados, $P$. nunn del SEBA, y $P$. acanthicum y $P$. periplocum del NBA, lo que abre una puerta al control biológico con cepas no patógenas. Hay citas sobre algunas de las especies de Pythium que mejoraron el desarrollo de raíces, y además, se ha observado que $P$. oligandrum y otras Pythium spp. produjeron productos similares a auxinas que podrían aumentar la formación de raíces (Le Floch et al., 2009, Rojas et al., 2016 a). Sin embargo, las especies de Phytopythium encontradas resultaron ser de baja patogenicidad, aunque Phy. litorale fue citada en EEUU, como altamente patógena de soja (Readmer et al., 2017), especie que no ha sido obtenido en nuestros relevamientos.

Varias veces se ha demostrado la coexistencia de diferentes especies de Oomycetes, en raíces de un mismo hospedante (Broders et al., 2007; Zitnick-Anderson y Nelson, 2015). En el presente trabajo fue muy común aislar de raíces de plántulas sintomáticas, Ph. sojae junto con Pythium spp., o dos aislamientos de Pythium obtenidos de la misma raíz, resultaron ser especies distintas. Esto hace pensar en algún tipo de asociación entre 
las especies que resultaron con alto grado de patogenicidad y el resto de las especies, inclusive Achlya se cita como patógena de arroz en EEUU (Webster et al., 1970).

En el marco del presente estudio fueron caracterizadas e identificadas para la Argentina, como especies de Pythium, citadas por primera vez asociadas con el cultivo de soja, $P$. acanthicum, $P$. aphanidermatum, $P$. catenulatum, $P$. dissotocum, $P$. nunn, $P$. longandrum, P. paroecandrum y $P$. aff. heterothallicum, y de Phytopythium: Phy. chamaehyphon, Phy. helicoides, Phy. aff. mercuriale, Phy. frezzii sp. nov y Phy. vexans, las que se deberán incluir en los listados efectuados previamente por Palmucci (2015), para Oomycetes de Argentina. Además se puntualiza que este, es el primer reporte de $P$. nunn, $P$. longandrum, $P$. paroecandrum y $P$. aff. heterothallicum, para la Argentina.

Tanto el metalaxil como la mezcla de carbendazim+tiram son los fungicidas recomendados (CASAFE 2007) para el control de Pythium spp. en el cultivo de soja en la Argentina. El metalaxil, que es un fungicida específico para este tipo de pseudohongo, presentó un muy buen nivel de control de los aislamientos patógenos, tanto en los ensayos en cajas de Petri como en los realizados en macetas, mientras que la mezcla de fungicidas carbendazim+tiram no controló de manera eficiente a los mismos aislamientos de Pythium. Por esta razón, no sería aconsejable esta mezcla, para el tratamiento de semillas de soja, que pueden ser atacadas por este pseudohongo en los primeros estadios del cultivo.

En referencia a los fungicidas de amplio uso en Argentina, pero no recomendados como curasemillas en el cultivo de soja, los resultados obtenidos coinciden con las apreciaciones de Reis et al. (2010). Estos autores indicaron que al ser Pythium un Oomycete, los triazoles (inhibidores de la síntesis del ergosterol) no ofrecen un buen control. La ruta bioquímica del ergosterol es una característica de la mayoría de los hongos (Ascomycetes y Basidiomycetes), pero está ausente en los Peronosporomycetes (Peronospora, Plasmopara, Phytophthora, Pythium, etc). Estos últimos son insensibles a los triazoles, dado que no sintetizan ergosterol, satisfaciendo sus necesidades por la absorción miceliar del compuesto a partir del sustrato. Esta diferencia es la base de la selectividad de los inhibidores de la biosíntesis de esteroles, que no se deben utilizar para el control de las enfermedades causadas por Peronosporomycetes.

Por otro lado las estrobirulinas poseen un amplio espectro de control y cierto grado de absorción sistémica por las raíces, aumentando la protección de las plántulas y su acción funguicida resulta de la inhibición de la respiración mitocondrial en los hongos, debido a que previenen la transferencia de los electrones entre el citocromo b y el 
citocromo c. Estos fungicidas no son específicos para los Peronosporomycetes, pero pueden controlar al género Pythium, aunque con eficiencia relativamente baja a media, y dependiendo del momento de aplicación (acción preventiva). Dentro de este grupo químico la azoxistrobina de uso en tratamientos de semillas (DYNASTY ${ }^{\circledR} 10$ FS SEMILLERO-Syngenta, 2014) está recomendada para Plasmopara halstedii agente causal del mildiu o enanismo del girasol, que también pertenece al reino Stramenopila. Sin embargo, bajo las condiciones de este ensayo el control de los aislamientos de Pythium utilizados fue intermedio y bastante menor que el producido por el tratamiento con metalaxil.

Por lo tanto se concluye que el control químico de la podredumbre por Pythium en plántulas de soja fue más eficaz con la aplicación del fungicida metalaxil, de manera preventiva, con respecto a los otros tres fungicidas probados. Aun así, y dado que en varios países se han reportado cepas resistentes a metalaxil (Sanders, 1987; Van Jaarsveld et al., 2002; Porter et al., 2009; Weilland et al., 2014) se deben utilizar otras técnicas de manejo para esta enfermedad, tanto químico como biológico, que provean un control adecuado. Tanto las compañías químicas como los productores de soja deben focalizar su atención en utilizar alternadamente fungicidas eficientes con diferente modo de acción que prevenga el futuro desarrollo de cepas resistentes.

Se ha observado cierta diferencia varietal en soja con suelos inundados (Rupe et al., 2011) lo que puede tener una relación directa ya que Pythium, al ser un Oomycete, requiere agua libre como condición predisponente para su ataque. Entre las variedades sobresalió el cultivar Archer que se liberó al mercado en 1990 con resistencia a Ph. sojae Rps 6 and Rpslk (Cianzio et al., 1991), se especulaba que la resistencia a Pythium se debía al gen de resistencia Rpslk (Rupe et al., 2011). En el presente trabajo, no se detectaron diferencias significativas entre las medias de los genotipos de soja con y sin el gen Rpslk de resistencia a Ph. sojae, estuviesen o no inoculados con P. ultimum y $P$. irregulare. En ambos casos la emergencia disminuyó cuando se los inoculó con dichos patógenos.

Varias de las especies de Pythium no-patógenas encontradas, están citadas como microorganismos utilizados en control biológico. Las cepas no patógenas o hipovirulentas son capaces de colonizar sitios de infección en las superficies de las plantas y proteger las plantas susceptibles contra sus respetivos patógenos, mediante distintos mecanismos. Competencia por sitio de infección o nutrientes, así como la inducción de la resistencia se demostraron para Rhizoctonia, Fusarium y Pythium (Sneh, 1998). P. nunn ha sido 
eficiente antagonista de $P$. ultimum, $P$. aphanidermatum y Phy. vexans, entre otros microorganismos (Lifshitz et al., 1984; Fang y Tsao, 1994; Sakura Kobayashi et al., 2010). Por su parte $P$. periplocum, está citado como hiperparásito de Botrytis cinerea (Paul, 1999). La actividad como mycoparásito de P. acanthicum y P. periplocum contra especies patógenas de Pythium también ha sido evaluada (Ali Dhtayed y Saleh, 1999).

También se estudió el efecto de la temperatura sobre la capacidad patogénica de algunos aislamientos. Hubo diferencias significativas entre las tres especies de Pythium probadas tanto para PS como para DO. P. ultimum y $P$. irregulare mataron todas las semillas a $15{ }^{\circ} \mathrm{C}$ y a $25^{\circ} \mathrm{C}$, pero a $35^{\circ} \mathrm{C}$ las plántulas nacieron sanas. Por su parte $P$. aphanidermatum se comportó de manera opuesta, ya que a $15{ }^{\circ} \mathrm{C}$ y a $25{ }^{\circ} \mathrm{C}$ no resultó patógeno, pero a $35{ }^{\circ} \mathrm{C}$ mató todas las semillas. Con respecto al DO pasó algo parecido, ya que con las temperaturas de $15{ }^{\circ} \mathrm{C}$ y $25{ }^{\circ} \mathrm{C}, P$. ultimum fue la especie con menor número de PNE, pero a $35^{\circ} \mathrm{C}$ la patogenicidad fue totalmente distinta ya que la especie con menor número de plántulas normales promedio emergidas fue $P$. aphanidermatum. Esta especie no permitió que ninguna semilla emergiera y las otras dos especies probadas no presentaron patogenicidad, ya que no se diferenciaron estadísticamente del testigo sano. Esto coincide con Wei et al. (2011), quienes encontraron que P. ultimum fue la especie más patógena a $25^{\circ} \mathrm{C}$., seguida de $P$. aphanidermatum, pero la mayor temperatura que ellos probaron fue $28{ }^{\circ} \mathrm{C}$ y no $35^{\circ} \mathrm{C}$, temperatura a la que $P$. ultimum casi no es patógena, en nuestros ensayos. También mostraron gran variación para $P$. aphanidermatum, con un aumento del porcentaje de PS directamente proporcional al aumento de temperatura y para $P$. irregulare inversamente proporcional con el aumento de temperatura (hasta el limite máximo que ellos ensayaron). Todo esto nos indica que la temperatura óptima para la patogenicidad y el crecimiento de las diferentes especies de Pythium, determinan cuál de ellas predomina en el campo y esto dependerá de la localización geográfica y de la fecha de siembra de la soja. Por ende las pruebas de patogenicidad a $22{ }^{\circ} \mathrm{C} \pm 2$ son meramente orientativas, ya que además de las probadas aquí, son varias las especies que tienen comportamiento diferencial respecto a la temperatura (Rojas et al., 2016 a).

Todas las especies de Phytopythium se aislaron a partir de suelo, plántulas o granos de la zona NBA, pero ninguna pudo ser aislada del SEBA. Esto puede deberse a la característica que comparten que es la alta temperatura óptima y máxima para el crecimiento (aproximadamente $30^{\circ} \mathrm{C}$ y $35-40{ }^{\circ} \mathrm{C}$ respectivamente) (Lévesque y de Cock, 2004). 
Phy. cucurbitacearun si bien pudo ser aislada a partir de muestras de suelos procedentes de lotes comerciales de soja de Fontezuela (NBA) durante la campaña 2013/14 y se identificó morfológica y molecularmente (mediante tres genes ITS, CoxII y Bta tub); no se considera una especie válida debido a que se ha perdido el "type", art. 36 de la convención de Melbourne (McNeill et al., 2012) y por ende se la considera dentro del complejo Phy. vexans (de Cock et al., 2015).

Rojas et al. (2016 a) encontraron a Phy. helicoides como patógena de soja, pero en este trabajo hemos obtenido un solo aislamiento a partir de muestras de suelos procedentes de lotes comerciales de soja de Pergamino (NBA) que presentó alta patogenicidad en semilla, pero intermedia a baja en plántulas $(23,81 \%)$.

En el árbol filogenético desarrollado con todas las secuencias de ITS logradas (Fig. 31) se aprecia bien que Phytopythium es un género genéticamente distinto de Pythium y se encuentra más próximo a Phytophthora (Ph. sojae en este caso) que a Pythium. Los datos de secuencia proporcionan una metodología rápida para buscar o determinar especies, sin embargo, se debe tener la precaución cuando se busque en la base de datos de las secuencias de ADN del GenBank, ya que no todas las secuencias están bien clasificadas y existe una alta tasa de error en las determinaciones (Kang et al., 2010). Por eso Abad (2010a) propone que las claves para oomycetes se basen en los tipos primarios (Type, Holotype) descripciones y trabajos filogenéticos realizados en base a los cultivos utilizados por el investigador para describir la especie. 


\section{CAPITULO II}

Phytophthora sojae AGENTE CAUSAL DE LA PODREDUMBRE DE RAÍZ Y LA BASE DEL TALLO DE LA SOJA 


\section{INTRODUCCIÓN}

Phytophthora sojae Kaufmann \& Gerdemann, causa la podredumbre de semilla, el damping-off de pre y post emergencia, y la podredumbre de raíz y base del tallo de la soja (PRBTS) (Schmitthenner, 1985). Es responsable de pérdidas anuales de más de dos billones de dólares en la producción de EEUU (Tyler, 2007). Hildebrand (1959) reportó diferencias en la virulencia entre aislamientos de $P h$. sojae. Posteriormente las diferencias fueron más evidentes ya que la población natural del patógeno es muy compleja; se describieron muchas razas y fórmulas de virulencia, entre las que, algunas pueden quebrar todos los genes de resistencia Rps. Más de 55 razas han sido reportadas (Leitz et al., 2000; Anderson y Tenuta, 2003) en base a la reacción de 8 a 13 genes mayores de resistencia (Dorrance et al., 2003 b; Jackson et al., 2004; Nelson et al., 2008). El número de patotipos identificados ha aumentado drásticamente en los últimos años, lo que ha hecho que el sistema de clasificación en razas no sea práctico (Dorrance et al., 2004), Actualmente hay más de 200 patotipos conocidos (Dorrance y Grünwald, 2009), lo que sugiere una alta variación genética con relación a la población natural. Hay 28 genes Rps descritos en soja, que confieren resistencia a PRBTS (Sahoo et al., 2017).

A diferencia con EEUU y Canadá, donde el patógeno fue reportado por primera vez en Indiana en 1948, y desde 1951 en ambos países, en Argentina la PRBTS es relativamente nueva. Fue citada en los años 70 por Hartwig (D.E. Barreto, comunicación personal). En 1978-79, severas muertes de plantas se detectaron en 15 localidades en el sur de Santa Fe y norte de Buenos Aires, principalmente en los cultivares Harosoy 71 y Harosoy 321. Ph. megasperma var. sojae fue citado como el agente causal de la sintomatología observada (Martínez e Invancovich, 1979). Diez años después, en 1989, la enfermedad fue detectada en Pergamino, en una parcela experimental de soja bajo riego por aspersión, usando un test serológico rápido, the Agridiagnostic monoclonal antibodybased assay kits (A. F. Schmitthenner, comunicación personal). Desde que Schmitthenner informó la presencia de Phytophthora en soja en Argentina, muestreos anuales en el campo se llevaron a cabo para evaluar la virulencia del patógeno, y para obtener información sobre la resistencia de los cultivares de mayor uso en el país y de líneas avanzadas de los programas de mejoramiento para facilitar el manejo de la enfermedad. 
Desde 1989 a 1992, los muestreos anuales llevados a cabo en el noreste de la provincia de Buenos Aires, indicaron que PRBTS estuvo presente en varios lotes como plantas enfermas en forma dispersa. Cuarenta y seis aislamientos de plantas y de suelos probados en su reacción a ocho genes $R p s$, mostraron que solo la raza 1 fue encontrada en el área relevada (Barreto et al., 1991; 1995). En ese tiempo, la enfermedad pareció estar en el mismo estado que se presentó en Ohio (EEUU) desde 1954 hasta 1972, cuando se reportó la primera nueva raza. En los últimos años, en Argentina, hubo un dramático cambio de labranza convencional a labranza mínima (siembra directa). En el presente, más del $85 \%$ del área se siembra en labranza mínima y el $50 \%$ con monocultivo de soja (Rossi, 2004). Se ha mencionado que el uso de la siembra directa aumenta la incidencia (I) y la severidad (S) de Ph. sojae, Phialophora gregata y Heterodera glycines en soja (Schmitthenner, 1985; Workneh et al., 1999). En la campaña 1994/1996, la enfermedad mostró un rápido incremento de la prevalencia, incidencia y cambios en la virulencia del patógeno. La prevalencia de la enfermedad entre 159 lotes relevados en la subregión pampeana norte, fue del $29 \%$ (en la campaña 1994/95) y $12 \%$ (en 1995/96). La mayor incidencia, basada en el recuento de 100 plantas enfermas por hilera de cultivo, en diez diferentes sitios en cada campo, fue de 70 \% en Bombal (Santa Fe). Durante la campaña 1994/1997, la virulencia monitoreada, basada en 112 aislamientos obtenidos y testeados (71\% y $29 \%$ de plantas y suelos respectivamente) indicaron que el $65 \%$ perteneció a la raza 1. Treinta y nueve aislamientos fueron avirulentos sobre los genes Rps $1 \mathrm{~d}$ y Rps $1 \mathrm{k}$ (Barreto et al., 1998 b). En 1996 un aislamiento de suelos de Los Molinos (Santa. Fe) fue identificado como raza 4 (Barreto et al., 1998a). Estos resultados muestran que algunos aislamientos poseen más de un gen de virulencia el que no había sido reportado y la variabilidad de $P h$. sojae se confirmó en la subregión pampeana norte. La incidencia de la enfermedad registrada en lotes de la provincia de Entre Ríos (localidad de Cerrito), fue de $30 \%$ y la virulencia basada en la respuesta de 17 cultivares diferenciales, fue Rps 1c y Rps 2 (Vicentini, 1996). En la campaña 1997-98, 71 aislamientos de Ph. sojae obtenidos de plantas y suelos de Arrecifes, Manuel Ocampo, Rojas y Suipacha (norte de Buenos Aires); Bigand y las Rosas (sur de Sta. Fe) y Marcos Juárez (sudoeste de Córdoba), probados en un set de ocho genes Rps, indicaron que el $53 \%$ perteneció a la raza 1 (Gally et al., 1999). PRBTS y el cancro del tallo de la soja (Diaporthe caulivora y aspalathi) fueron las enfermedades más prevalentes en las provincias del este en 1998, ocasionando la reducción en el número de plantas, y plantas débiles (Wrather et al., 2001). En muchas 
ocasiones, los síntomas característicos de ambas enfermedades, pudieron ser observados juntos, y sus agentes causales fueron confirmados en laboratorio.

\section{AGENTE CAUSAL}

Phytophthora es un Oomycete que pertenece al Reino Stramenopila. Es un organismo diploide, que en su ciclo de vida incluye tanto reproducción sexual como asexual. Posee oosporas persistentes con pared fina, que provienen de la fecundación de los gametangios del mismo talo (homotálica). El principal agente causal determinado es Ph. sojae, que posee micelio coraloide típico (Fig. $35 \mathrm{C}$ ) y esporangios no papilados, ovoides, elipsoidales u obpiriformes (Fig. 35 B). Con un tamaño entre 23-88 x 16-52 $\mu \mathrm{m}$. Los oogonios son globosos con un tamaño mayor a $30 \mu \mathrm{m}$ diám., con anteridios paráginos y anfígenos (Fig. 35 D). Las clamidosporas no se forman fácilmente y su temperatura óptima de crecimiento es entre $20-25^{\circ} \mathrm{C}$. Las oosporas miden entre $19-38 \mu \mathrm{m}$ diám.y se forman en tejidos infectados (Fig. 35 A). La germinación de las oosporas no es de forma sincronizada, puede durar 30 días o más y producir de forma directa o indirecta esporangios. La temperatura óptima para la formación y germinación de las oosporas es de $24{ }^{\circ} \mathrm{C}$ (Erwin y Ribeiro, 1996; Hartman et al., 1999).

Phytophthora sansomeana también ha sido citada en EEUU y China como agente causal de plántulas con síntomas de damping off y recuperada a partir de soja utilizada como tejidos trampa. Sin embargo, el rango de hospedantes que afecta es distinto e incluye a maíz, abeto Douglas y varias especies de malezas (Hartman et al., 2015). 


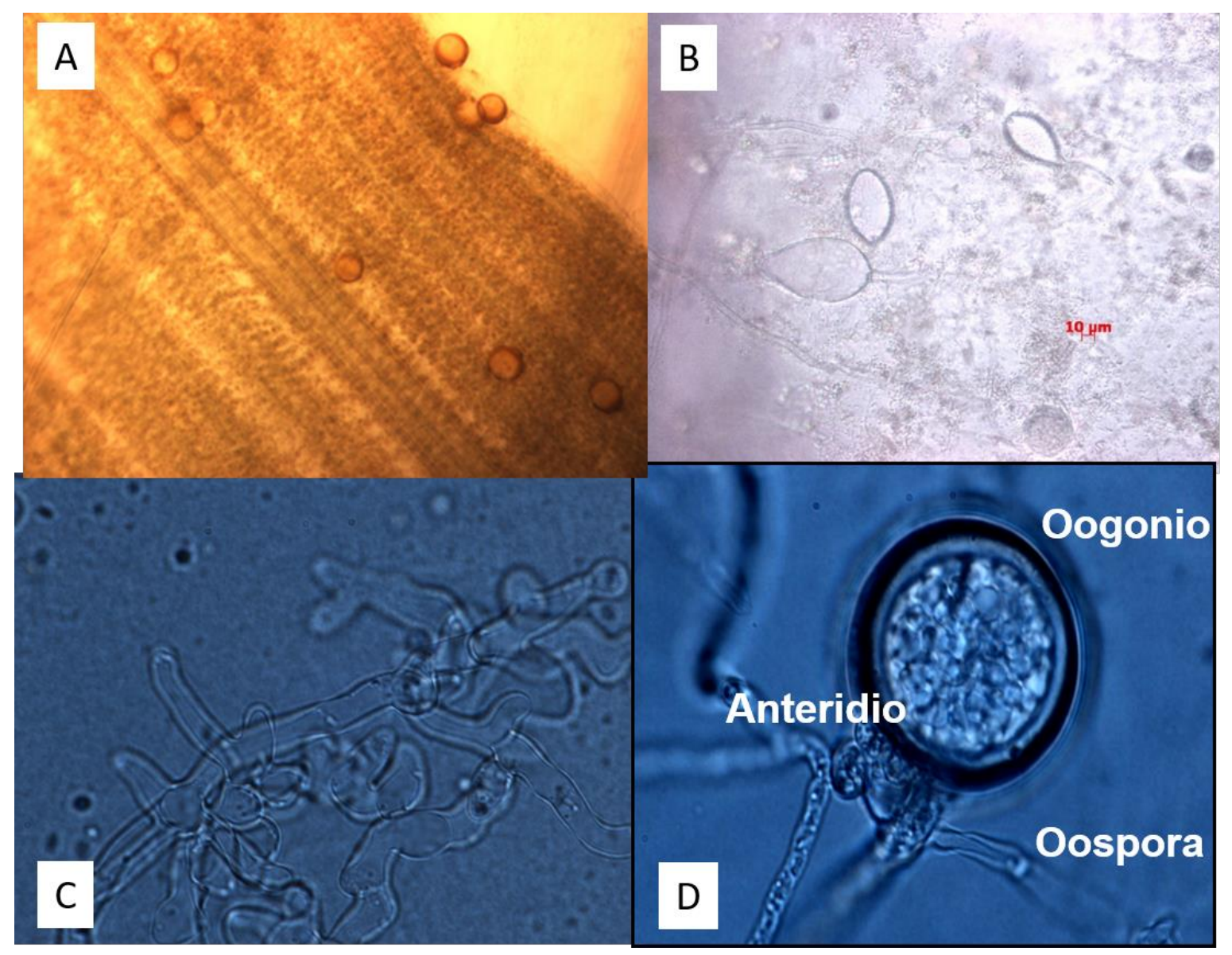

Figura 35. Phytophthora sojae. A) Detalle de Oosporas en hipocótile. B) Esporangios. C) Micelio típico del tipo coraloide. D) Detalle de oogonio conteniendo oospora en su interior.

\subsection{Variabilidad de Phytophthora sojae}

La interacción entre el patógeno y el hospedante en el patosistema $P h$. sojae-soja sigue la teoría gen por gen propuesta por Flor (1971). La expresión de la resistencia (incompatibilidad) requiere una interacción entre un gen de resistencia en la planta de soja (Rps) y un gen de avirulencia en Ph. sojae, por lo tanto implica una resistencia inducida. La resistencia inducida es el resultado de la activación de los mecanismos de defensa en respuesta a la infección, la que sirve inhibiendo o suprimiendo el desarrollo de la enfermedad. En otras palabras, un gen de avirulencia en el patógeno codifica para un elicitor que directa o indirectamente interactúa con el producto del gen correspondiente a la resistencia en la planta causando una reacción de hipersensibilidad (Parker, 2009). La susceptibilidad (compatibilidad), de otra manera, se considera como una respuesta pasiva (no-inducida) debido a la ausencia de genes de resistencia y/o avirulencia (Misaghi, 1982). Este concepto explica las bases de la genética de la especificidad del 
hospedante, exhibida por las razas fisiológicas o patotipos en este patosistema $P$. sojaesoja.

El primer gen Rps fue identificado en 1950 en soja, y se han identificado y mapeado, en ocho cromosomas, 28 genes Rps que confieren resistencia a PRBTS (Sahoo et al. 2017). La variabilidad en $P h$. sojae ha sido evaluada tradicionalmente a través de un test de virulencia usando un grupo (set) de cultivares diferenciales, que pueden ser siete a 14 genotipos de soja, cada uno con un gen de resistencia (Rps) a Ph. sojae, y además se usa un genotipo susceptible universal para corroborar la reacción y la patogenicidad. Las más de 55 razas se han identificado, en base a la reacción de compatibilidad (susceptible) e incompatibilidad (resistente) de líneas diferenciales (Dorrance et al, 2004). Se le dio un número sucesivo de raza a un patotipo, con una fórmula de virulencia no descripta previamente. Nuevas combinaciones de genes de virulencia o patotipos fueron apareciendo continuamente en el patógeno (Schmitthenner et al., 1994; Yang et al., 1996; Abney et al, 1997; Ryley et al., 1998; Dorrance et al., 2003 b; Jackson et al., 2004; Grijalba y Gally, 2015), lo que llevó a desalentar el viejo sistema de clasificación. Potencialmente puede haber $2^{14}$ o $16.384\left(2^{\mathrm{n}}\right.$, donde $\mathrm{n}=$ número de genes Rps) posibles combinaciones de virulencia o razas. Los investigadores principales describen patotipos en lugar de seguir nombrando nuevas razas. Actualmente, se usan patotipos o fórmulas de virulencia para describir los patrones de virulencia basados en la reacción de un set de genotipos diferenciales, y se expresa como reacción de virulencia/avirulencia: así la raza 1 del patógeno corresponde a la fórmula 7/1a, 1b, 1c, 1d, 1k, 3a y 6 (Schmitthenner et al., 1994). Conocer el patotipo es mucho más informativo ya que indica qué genes Rps son compatibles con el aislamiento (Robertson et al., 2009). Hay más de 200 patotipos conocidos de este patógeno (Dorrance et al., 2003 b), lo que sugire alta variación genética con relación a la población natural. Se sabe poco sobre cómo ocurre esta variación y la diversidad dentro de las poblaciones endémicas. Los Oomycetes son organismos diploides cuyo ciclo de vida incluye tanto la reproducción sexual como la asexual. Los organismos que se reproducen asexualmente tienden a exhibir un alto grado de clonación, con pocos genotipos presentes en altas frecuencias, mientras que los organismos con reproducción sexual suelen tener un mayor grado de diversidad genotípica (McDonald, 1997). Debido a su naturaleza homotálica, Ph. sojae se considera esencialmente un organismo que se propaga por clonación (Gijzen y Qutob, 2009). Estudios previos han indicado que poca o ninguna heterocigosis se presenta en las poblaciones (Föorster et al., 1994). Al igual que ocurre con muchos patógenos de suelo, 
tiene escasos medios de dispersión, por lo que se cree que es limitado el flujo génico (McDonald y Linde, 2002). Sin embargo, se ha sugerido que existe una gran reserva de diversidad genética en poblaciones de este patógeno (Hobe, 1981), aunque sólo unos pocos estudios han intentado caracterizar esta diversidad utilizando marcadores genéticos (Forster et al., 1994; Drenth et al., 1996; Meng et al., 1999; Gally et al., 2007; Dorrance y Grunwald, 2009; Steward et al., 2011). Steward et al. (2016), indicaron que ocurre cierto flujo de genes dentro de lotes vecinos, pero no a través de regiones, lo que sugiere que existe una gran probabilidad de que cada región tenga sus propias poblaciones y que proporcione evidencia adicional de alta diversidad dentro de este patógeno homotálico, que puede deberse, en parte, a flujo de genes limitado, mutación u outcrossing.

Los microsatélites codominantes o las repeticiones simples de secuencia (SSRs) son adecuados para los estudios genéticos de poblaciones, ya que permiten la cuantificación de los heterocigotas, y estimar el cruzamiento natural. El genoma de $P h$. sojae fue el primer genoma de Oomycetes en ser secuenciado (Tyler et al., 2006). El análisis de las secuencias del genoma y el análisis funcional de una serie de genes proporcionó nuevas perspectivas en la patogenicidad y en los factores de virulencia de esta especie. Schena et al. (2008) identificaron 12 SSRs que podrían utilizarse en un número restringido de especies de Phytophthora relacionadas con Ph. sojae. En otro estudio, 21 SSRs desarrollados a partir de secuencias de $P h$. sojae raza 2, se utilizaron sobre 33 aislamientos de Ohio, EEUU (Dorrance y Grunwald, 2009). Estos estudios mostraron que los marcadores microsatélites son capaces de revelar altos o bajos niveles de variación.

A los efectos de realizar estudios comparativos (tanto geográfica como temporalmente), es fundamental lograr la reproducibilidad de marcadores moleculares entre laboratorios. Se demostró que, los RAPDs (ADNs polimórficos amplificados aleatorios) son difíciles de reproducir y los AFLPs (polimorfismos en la longitud de fragmentos amplificados), aunque son reproducibles, muchas veces solo dan lugar a diferencias de una banda entre laboratorios. Por su parte los SSRs son considerados marcadores robustos, las diferencias en el tamaño del alelo pueden aparecer entre los laboratorios dependiendo del sistema de análisis utilizado (Jones et al., 1997; Weeks et al., 2002; Widmark et al., 2011). El tamaño del alelo estimado no sólo depende del número de nucleótidos sino también de la movilidad del fragmento en la electroforesis (Weeks et al., 2002; Widmark et al., 2011), del tipo de marcador fluorescente utilizado, de la distancia entre el alelo y el estándar utilizado (Jones et al., 1997), y del uso de 
diferentes instrumentos en los software empleados (Weeks et al., 2002). Los métodos moleculares que utilizan capilares son capaces de detectar 2,4 veces más alelos en promedio que el método de gel y pueden ser repetibles entre laboratorios (Steward et al., 2011). Sin embargo, estas discrepancias podrían minimizarse si los genotipos de referencia de ADN estándar fueran compartidos entre laboratorios colaboradores.

\subsection{Síntomas de la enfermedad}

Ph. sojae puede infectar la planta de soja durante todo el ciclo del cultivo. Los síntomas tempranos son: podredumbre de semillas y damping off de pre y pos emergencia, los cuales ocurren comúnmente en suelos que sufren anegamiento, poco después de la siembra. Los síntomas en plántulas de mayor tamaño dependen de la susceptibilidad y tolerancia del cultivar. En los de mayor susceptibilidad, los tallos se presentan húmedos, las hojas amarillentas y las plántulas se marchitan y mueren (Fig. 36 C). En los tolerantes hay podredumbre de algunas raíces pero las plántulas permanecen vivas.

En las plantas adultas, el síntoma más notorio es una lesión de color pardo oscuro que rodea totalmente el tallo y avanza desde la superficie del suelo, generalmente hasta el cuarto o quinto entrenudo y contrasta con el color verde de los tejidos sanos (Fig. 36 D). Además, hay podredumbre de la raíz principal, desintegración de raíces laterales y amarillamiento de hojas. El resultado final es el marchitamiento y muerte de las plantas, que se observan necrosadas y con las hojas adheridas a los tallos (Fig. 36 C). Estos son los síntomas más evidentes en el campo, frecuentemente en períodos de escasa disponibilidad de agua, a causa de la disminución de la eficiencia de absorción y translocación de la planta enferma. Como sucede con la mayoría de las enfermedades causadas por patógenos cuyo hábitat natural es el suelo, los síntomas suelen presentarse localizados en determinados sectores del lote, en manchones o en sectores del surco de siembra, debido a la dispersión limitada de los propágulos (Fig. 36 A y B). En cultivares tolerantes el síntoma más evidente en plantas adultas es la podredumbre de raíces secundarias y la decoloración de la raíz principal. En algunos casos puede observarse una lesión unilateral en el tallo. De todas formas, aún en cultivares susceptibles, los daños son menores cuando las plantas se encuentran en etapas avanzadas del ciclo (Carmona et al., 2017). 


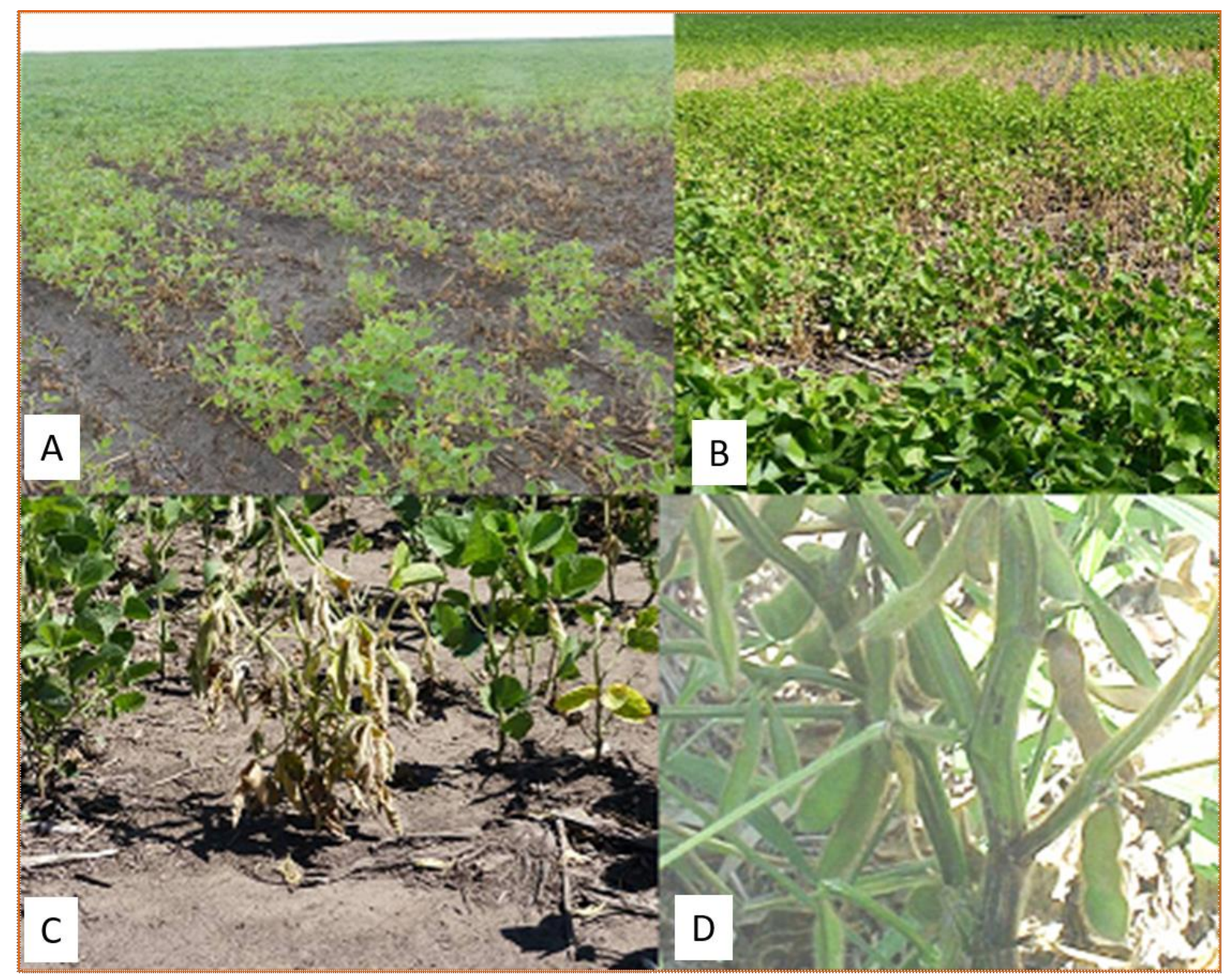

Figura 36. Phytophthora sojae. A) y B) Aspecto general de un campo afectado. C) Síntoma de marchitamiento. D) Detalle de la podredumbre basal.

\section{CICLO DE LA ENFERMEDAD Y CONDICIONES PREDISPONENTES}

Cuando se siembran variedades de soja susceptibles a $P h$. sojae y en algún momento del ciclo del cultivo se producen las condiciones predisponentes para la enfermedad (exceso de humedad, acumulación de agua en el suelo y temperatura superior a $15{ }^{\circ} \mathrm{C}$ ), las oosporas (fuente de inóculo primario), presentes en el lote germinan y producen esporangios o micelio. Los esporangios son también capaces de germinar directamente o indirectamente liberando zoosporas. Éstas son esporas asexuales móviles que pueden nadar, cortas distancias en la superficie de suelo inundado, hasta la superficie de las raíces, siendo atraídas por exudados isoflavonoides. En las raíces enquistan, germinan y penetran directamente. Las hifas crecen intercelularmente en los tejidos radiculares, e intracelularmente en hipocótiles y forman haustorios globosos que penetran en las células. 
Ph. sojae es considerado un patógeno hemibiótrofo, ataca como un biótrofo en los primeros estadios de la infección y después cambia a necrótrofo. En plantas viejas, coloniza la raíz principal y raíces laterales, y las lesiones se extienden hacia la parte superior del tallo. En estas lesiones, el patógeno forma oosporas (homotálico). La colonización de la corteza ocurre tanto en las variedades resistentes como en las susceptibles, pero en las primeras no alcanza los tejidos vasculares. Después de la cosecha, las oosporas sobreviven en los tejidos muertos, que al descomponerse las dejan libres en el suelo (Hartman et al., 2015).

Todas las condiciones que determinen exceso de humedad y acumulación de agua en el suelo son favorables para la germinación de las oosporas y el transporte de las zoosporas hacia las raíces, como son días continuos de lluvias, terrenos bajos o zonas más bajas de los lotes, suelos compactados, cabeceras de lotes. El monocultivo provoca la acumulación de oosporas en el suelo, lo cual se agrava en presencia del rastrojo con alta concentración de oosporas, es decir en siembra directa.

\section{MANEJO DE LA ENFERMEDAD}

El uso de cultivares resistentes, es el método más económico y efectivo para controlar a este patógeno. Se describieron dos diferentes tipos de resistencia a $P h$. sojae en el hospedante, la resistencia raza específica condicionada por genes simples dominantes (Rps); y la resistencia parcial o resistencia no específica conferida por varios genes menores (Walker y Schmitternner, 1984).

3.1 Resistencia raza específica: Varios genes Rps tales como Rps 1a, Rps 1c y Rps 1k se han incorporado en cultivares comerciales (Rossi y Nari, 1995; Slaminko et al., 2010), sin embargo como en muchos otros patosistemas, gobernados por la teoría de gen por gen, el patógeno se adapta a los genes de resistencia Rps específicos. Cuando se introducen nuevos genes Rps a través de la liberación de un nuevo cultivar, los aislamientos de Ph. sojae sobrepasan esa resistencia introducida (Dorrance et al., 2003 b; Slaminko et al., 2010). Como se ha mencionado se han reportado más de 200 patotipos de este patógeno, presumiblemente debido a la presión de selección de la población de nuevos patotipos que pueden sobrepasar estos genes Rps. La rápida evolución de nuevos patotipos virulentos de $P h$. sojae limitan la efectividad de un gen $R p s$ entre ocho a quince años (Schmitthenner, 1985). Consecuentemente hay una constante necesidad de nuevos genes Rps para manejar efectivamente la enfermedad. Desde la identificación del primer 
gen Rps, en 1950, hasta el presente, los veintiocho genes Rps han sido identificados y mapeados en ocho cromosomas. Recientemente se mapeó el gen Rps 12 en el brazo menor del cromosoma 18 (Sahoo et al., 2017).

3.2 Resistencia parcial (RP) o no especifica, también llamada tolerancia: Se define como "la habilidad relativa para sobrevivir a la infección radicular, tanto natural o artificial, sin mostrar desarrollo de síntomas severos tales como la muerte, disminución del crecimiento o pérdida de rendimiento (Walker y Schmitternner, 1984). Este tipo de resistencia es poligénica, y limita la tasa de crecimiento de la lesión del patógeno dentro del tejido del hospedante, permitiéndole tolerar mejor la infección cuando se lo compara con un hospedante totalmente susceptible (Tooley y Grau, 1984; Dorrance et al., 2003 a; Ferro et al., 2006). Entonces la tolerancia debe ser más estable que la resistencia de un solo gen debido a la falta de presión de selección sobre el patógeno. Esto ha demostrado ser efectivo contra todos los patotipos de Ph. sojae, restringiendo la colonización de los tejidos de la planta (Slaminko et al., 2010). La RP necesita volverse activa en la planta antes de empezar a ser efectiva; se vuelve activa después de la aparición del primer par de hojas verdaderas (estado de crecimiento VC), por lo tanto las semillas y las plántulas de un cultivar con alta RP es susceptible a la enfermedad desde la siembra y durante los estados tempranos de crecimiento (Dorrance et al., 2003 a). El test de la capa es el método estandarizado utilizado para verificar la resistencia parcial a $P h$. sojae en soja (Thomison et al., 1991; Schimetthenner y Bhat, 1994; Grijalba y Barreto, 2002; Dorrance et al., 2003 b; Ferro et al., 2006; Stewart y Robertson, 2012). En el test de la capa, un cultivo del patógeno en agar se ubica a cierta distancia debajo de la semilla en la siembra, tres a cuatro semanas después se evalúan la incidencia y la severidad usando una escala de 1 a 10 (Stewart y Robertson, 2012).

\subsection{Otras medidas de manejo:}

3.3.1 Uso de fungicidas específicos. Los fungicidas del grupo químico de las acilalaninas tal como el metalaxil, actúan inhibiendo la síntesis de proteínas y ácidos nucleicos, particularmente la producción de ARN, que tiene un efecto directo sobre los Oomycetes por ende serían oomyceticidas. El metalaxil aplicado como solución o en tratamiento de semillas mejora la emergencia de las plántulas y aumenta los rendimientos en cultivares de soja susceptibles (Anderson y Buzzell, 1982). Estudios posteriores demostraron que el tratamiento de semillas puede tener un impacto significativo sobre la 
emergencia y rendimiento en cultivares con resistencia parcial, si las condiciones son predisponentes para la enfermedad durante la emergencia de las semillas hasta que la primera hoja unifoliada sea visible (Dorrance et al., 2003 a). Schmittenhemer y VanDoren (1985) plantearon la hipótesis que "la combinación de alta tolerancia, mejorar el drenaje, la labranza del suelo y el tratamiento de semillas con metalaxil, sería tan efectivo como el control con resistencia a multirazas de Phytophthora".

3.3.2 Rotación de cultivos: Como medida que evitaría la acumulación del inóculo. La rotación de soja con maíz no es una manera eficiente para manejar el damping off causado por $P h$. sojae debido a que las oosporas pueden sobrevivir en el suelo por muchos años aún en ausencia de soja (Yang, 1999). Sin embargo, se demostró menor pérdida de plantas y de rendimiento, cuando un cultivar resistente fue sembrado en rotación con maíz comparado con monocultivo de soja (Schmitthenner y Williams, 1962). Estudios de campo han demostrado que después de cinco años de monocultivo de cultivares susceptibles, tolerantes o resistentes, al sexto año se presentó una severa enfermedad en parcelas sembradas previamente con cultivares susceptibles y tolerantes, mientras que la enfermedad resultó moderada en aquéllas sembradas previamente con cultivares resistentes. Esto puede explicarse por el hecho de que más oosporas se forman en los cultivares susceptibles o tolerantes que en los resistentes (Hartman et al., 1999).

3.3.3 Buen drenaje: Todas las medidas que se adopten para mejorar el drenaje contribuyen a disminuir los daños causados por la enfermedad. 


\section{MATERIALES Y MÉTODOS}

\section{Virulencia en la subregión Pampeana Norte durante el intervalo 1998-2004}

Antes del periodo abarcado por el presente estudio, entre 1998-2004 se había muestreado gran parte de la zona núcleo sojera, se efectuaron aislamientos y se determinó la respuesta de un set de diferenciales, pero no se terminó la evaluación y el análisis de los datos obtenidos. Dentro de este periodo (2013-2016) se completó dicha investigación, lo que se vió reflejado en la publicación Grijalba y Gally (2015). Durante los seis años del estudio, se seleccionaron 50 lotes de soja y se muestrearon para la podredumbre de la raíz por Phytophthora, en la subregión Pampeana norte. Setenta y ocho por ciento de los lotes estudiados fueron lotes comerciales de soja con una larga historia de producción de soja, y los lotes restantes fueron parcelas de ensayo de soja (Fig. 37).

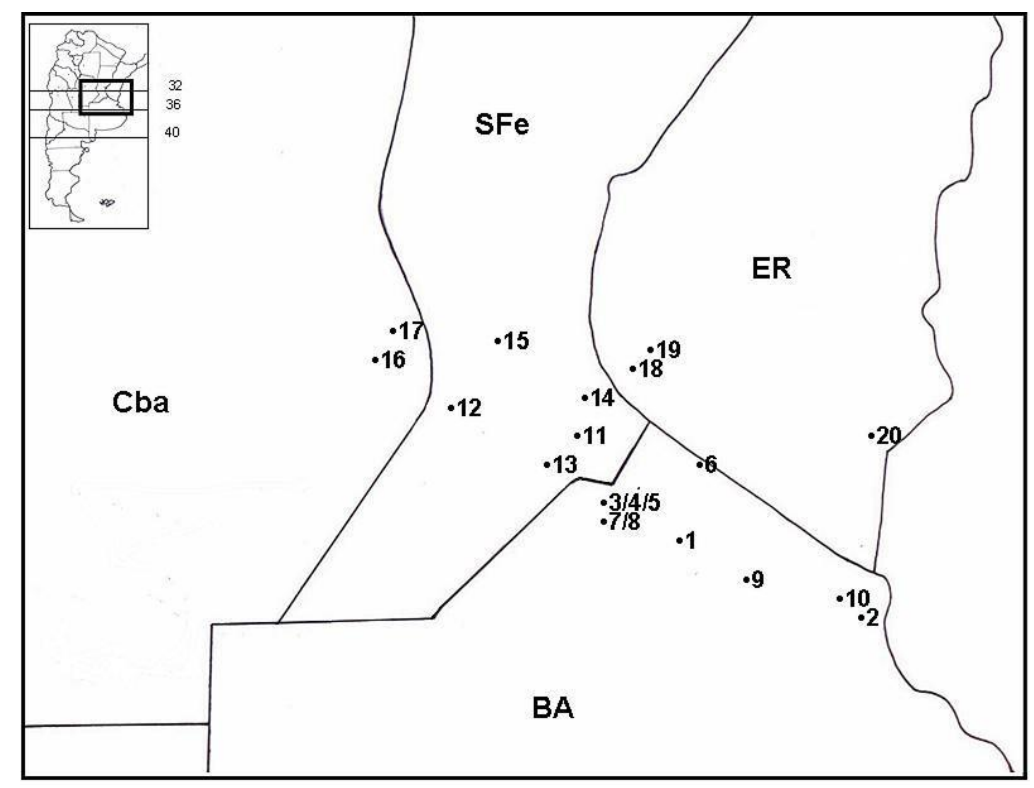

Figura 37. Distribución de Phytophthora sojae en Argentina. Los números representan 20 localidades donde se recolectaron las muestras. Las letras representan las provincias: BA (BUENOS AIRES) 1 Arrecifes; 2 parcela experimental; 3 Pergamino; 4 El Socorro; 5 M. Ocampo; 6 Ramallo; 7 Rojas; 8 R. Obligado; 9 San Antonio de Areco; 10 Pilar. SFe (SANTA FE) 11 Bigand; 12 Godeken; 13 Hughes; 14 Muñoz; 15 Las Rosas. Cba (CORDOBA) 16 Marcos Juarez; 17 Saira. ER (ENTRE RIOS) 18 Victoria; 19 Villa Teresita; 20 Gualeguaychu. 


\section{Virulencia en el NBA y SEBA durante el intervalo 2013-2016}

\subsection{Identificación de los aislamientos y almacenamiento}

Los aislamientos se caracterizaron mediante la coloración del micelio cenocítico con presencia de hinchamientos hifales (hyphal swellings) y por la abundante producción de oosporas esféricas de pared lisa (homotálico). Los cultivos puros se transfirieron a tubos en estría en AV8 o LBA con y sin el agregado de agua destilada estéril, para su almacenamiento a temperatura ambiente. En ambos casos los cultivos se mantuvieron en incubadora (aprox. a $20^{\circ} \mathrm{C}$ ) en oscuridad. Para mantener la agresividad, los aislamientos se inocularon en cultivares o isolíneas susceptibles (cv. Sloan, Williams o Haro (1-7)1) utilizando la técnica de la capa en un intervalo de 4 a 6 meses (Ohal et al., 1985; Schmitthenner et al., 1994).

\subsection{Evaluación de la virulencia de los aislamientos (Determinación de razas o fórmulas de virulencia específica)}

Para describir los patotipos o fórmulas de virulencia (virulencia/avirulencia) se usó el patrón basado en la reacción de un grupo (set) de genotipos de soja diferenciales, conteniendo ocho genes Rps diferenciales (Schmitthenner et al., 1994; Dorrance et al., 2004). Los genes diferenciales incluyeron HARO 12 (Rps 1-a), HARO 13 (Rps 1-b), Corsoy 79 (Rps 1-c), HARO 16 (Rps 1-d), HARO 15 (Rps 1-k), HARO 3272 (Rps 3-a + Rps 7), HARO 6272 (Rps 6+Rps 7) y Harosoy (Rps 7). Como control susceptible se utilizó Haro (1-7)1, Williams y Sloan.

Algunos aislamientos obtenidos entre 2002 y 2004 se evaluaron en un set expandido de 14 cultivares diferenciales, sumando a los genotipos diferenciales ya mencionados, los siguientes L82-1449 (Rps 2-7), HARO 33 (Rps 3b), HARO 34xx (Rps 3c), HARO 4272 (Rps 4), HARO 5272 (Rps 5), PI 399073 (Rps 8) y tres líneas experimentales, Haro Nez (Rps 744), Ox 939 (Rps Ox939) y X570-20-2-1 (Rps Ox940), con tres genes/alelos putativos de Harrow (Canadá) (Table 1).

Los genotipos diferenciales de soja se obtuvieron de A.F. Schmitthenner de Ohio Agricultural Research and Development Center (EEUU), y T. Anderson de Agriculture Canadá, Research Station, Harrow, Ontario. Todos ellos fueron multiplicados cada año en el campo experimental de la Facultad de Agronomía de la UBA. 


\subsubsection{Corroboración del patrón de virulencia de la reacción de los genotipos de soja diferenciales}

Según Dorrance et al. (2004) algunos de estos genotipos diferenciales pueden no ser recomendados debido a resultados inconsistentes. Para corroborar esto, se utilizaron 5 cepas de $P h$. sojae obtenidas a partir de plantas con síntomas típicos de la enfermedad de diferentes localidades del NBA y SEBA. Se identificaron como S1 (Lobería), S2 (Necochea), S3 (Lobería), N1 (Germania) y N2 (Germania). Las mismas se inocularon mediante la prueba del hipocótile sobre las siguientes líneas diferenciales con los genes incluidos: Parker y HARO 12 (Rps 1-a), Sanga y HARO 13 (Rps 1-b), LaMoure, HS934118, Corsoy 79, A 6785 y Arksoy (Rps 1-c), L93-3318 y HARO 16 (Rps 1-d), Williams 82, Kinwa y HARO 15 (Rps 1-k), No. 3226 Brown y HARO 3272 (Rps 3-a + Rps 7), Altona y HARO 6272 (Rps 6 + Rps 7), Harosoy y Adelphia (Rps 7). Como control susceptible se utilizaron Haro (1-7)1 y Williams.

Debido a reacciones inconsistentes en 2015 se obtuvieron diferenciales complementarias de S. Steward, del INIA La Estanzuela Rep. Oriental del Uruguay. Quedando el set de ocho isolíneas diferenciales de ocho Rps a partir de las inoculaciones efectuadas en 2015, de la siguiente forma: HARO (1-7)1 o Williams (rps rps); HARO 1272 (Rps1a, Rps7), HARO 13 (Rps1b); PI103091Hernan (Rps1d); Williams 82 (Rps 1k); L83-570 (Rps3a); HARO 6272 (Rps6, Rps7) y Williams 79 (Rps1c). Todos ellos también fueron multiplicados en el campo experimental de la Facultad de Agronomía UBA.

\subsection{Técnica de inoculación}

La virulencia de $P h$. sojae se evaluó usando la técnica de inoculación del hipocótile (Schmitthenner et al., 1994). El inóculo se produjo en medio AV8 o LBA semisólido (1,2\% agar), en cajas de Petri en cámara en oscuridad a $23-25^{\circ} \mathrm{C}$. Una colonia de cada aislamiento, de 10-12 días desde la siembra se maceró mediante el pasaje a través de una jeringa y se volvió a cargar en la jeringa. Una hendidura longitudinal en el hipocótile (de aprox. $1 \mathrm{~cm}$ de longitud) se hizo con una aguja calibre 16 en plantas de $7 \mathrm{a}$ 10 días de cada diferencial, y aproximadamente $0,1 \mathrm{ml}$ de macerado del cultivo se colocó en cada hendidura. Las plantas creciendo en una mezcla de vermiculita:suelo:arena (2:1:1), se incubaron en contenedores plásticos con tapa para mantener la humedad (HR cercana al $100 \%$ ) durante el periodo inicial de la incubación. Después de 20-24 h se sacaron de los contenedores plásticos y se mantuvieron en una habitación a temperatura entre $20-25{ }^{\circ} \mathrm{C}$ durante 6 días. Las plantas se regaron diariamente para mantener el suelo 
húmedo. Los síntomas se registraron en los diferenciales susceptibles 3 días después de la inoculación. El registro final se completó a los 5 días desde la inoculación. La reacción y el patrón de virulencia fue identificado como susceptible ( $70 \%$ o más de plántulas muertas) o como resistente (30\% o menos de plántulas muertas). Las plántulas que presentaron una mortalidad entre el 31 y $69 \%$ se consideraron como de reacción intermedia (Anderson y Buzzell, 1992; Ryley et al., 1998).

\section{Relación genética entre aislamientos de $P h$. sojae provenientes del NBA y SEBA utilizando marcadores SSRs.}

Se decidió comparar la estructura genética de parte de los aislamientos de ambas zonas mediante la técnica de microsatélites específicos (SSRs). El dataset (grupo de datos) incluyó un total de 93 aislamientos de $P h$. sojae (41 NBA y 52 SEBA) (Tabla 8) y 5 ADN controles de aislamientos de EEUU, cedidos gentilmente por la Dra. Silvina Stewart del INIA La Estanzuela Rep. Oriental del Uruguay. Las dos regiones definidas a priori fueron: NBA (Arrecifes, FAUBA, Pergamino, Rojas, Ramallo, Rancagua y Villaguay), y SEBA (Balcarce, Lobería y Necochea).

Se seleccionaron ocho microsatélites (SSRs-codominantes) que incluyeron 2, 3, 4, 5 y 6 pares de bases repetidas (Tabla 9) que se eligieron basados en el éxito de la amplificación y el mayor número de alelos (tamaños de banda) por locus (Steward et al., 2011). La amplificación se llevó a cabo en un termociclador Perkin-Elmer (Perkin-Elmer Cetus, Emeryville, CA), con una reacción mezcla de $15 \mu 1$ con 0,2 nM de cada dNTP, 2,5 nM MgCl2, 1X buffer de la hot Start, 0,08 unidades de polimerasa (Promega Inc., Madison, WI), 0,45 $\mu \mathrm{M}$ de cada primer y $1 \mu \mathrm{l}(100 \mathrm{ng})$ de ADN. Cada corrida incluyó una reacción sin $\mathrm{ADN}$ (control negativo) para monitorear la contaminación potencial por AND exógeno. El termociclador se programó con un paso inicial a $95{ }^{\circ} \mathrm{C}$ durante $5 \mathrm{~min}$, paso de desnaturalización a $94{ }^{\circ} \mathrm{C}$ durante $30 \mathrm{~s}$, luego 30 ciclos a $58{ }^{\circ} \mathrm{C}$, hibridación, durante $30 \mathrm{~s}, 72{ }^{\circ} \mathrm{C}$ durante $30 \mathrm{~s} \mathrm{y} 72{ }^{\circ} \mathrm{C}$ durante $10 \mathrm{~min}$. Los productos de amplificación se separaron mediante electroforesis en un gel de agarosa al 1,5 con el agregado de buffer TBE $0.5 \times(0.045 \mathrm{M}$ Trizma base, $0.045 \mathrm{M}$ ácido bórico, $0.001 \mathrm{M}$ EDTA, pH 8.0), usando $5 \mu \mathrm{l}$ de los productos de PCR. Se visualizaron en un trans-ilumninador con fluorescencia UV después de la tinción con bromuro de etidio. Las imágenes de los geles se grabaron usando un procesador de imágenes (Gel Documentation System -ImageStore 5000, UVP, UK), y se almacenaron como archivos TIFF. Los tamaños de los alelos se determinaron 
utilizando el equipo Fragment AnalyzerTM Automated CE System de la Unidad de Genómica y Bioinformática del INTA Castelar (UGB) ya que utiliza capilares y este método es más sensible, y es posible separar los productos de PCR que difieren en solo dos pares de bases (Steward et al., 2011).

TABLA 8. Listado de los aislamientos de Phytophthora sojae utilizados para el chequeo de la relación genética utilizando marcadores SSRs. Se detalla origen y patotipo. 


\begin{tabular}{|c|c|c|c|c|}
\hline & & Zona & Localidad & Patotipo \\
\hline 1 & 2 & NBA & Rancagua & 76004 \\
\hline 2 & 3 & SEBA & Lobería & 76014 \\
\hline 3 & 4 & SEBA & Lobería & 50004 \\
\hline 4 & 5 & SEBA & Lobería & 56014 \\
\hline 5 & 7 & SEBA & Lobería & 76004 \\
\hline 6 & 8 & SEBA & Lobería & 76004 \\
\hline 7 & 9 & SEBA & Lobería & 76004 \\
\hline 8 & 10 & SEBA & Necochea & 76014 \\
\hline 9 & 11 & SEBA & Necochea & 76014 \\
\hline 10 & 12 & SEBA & Necochea & 76004 \\
\hline 11 & 15 & NBA & Rojas & 42000 \\
\hline 12 & 18 & NBA & Pinzón & 02414 \\
\hline 13 & 20 & NBA & Rancagua & 56404 \\
\hline 14 & 21 & NBA & Arrecifes & 00404 \\
\hline 15 & 22 & NBA & Rancagua & 56044 \\
\hline 16 & 24 & NBA & $\begin{array}{l}\text { Cap. } \\
\text { Sarmiento }\end{array}$ & 54004 \\
\hline 17 & 25 & NBA & Pinzón & 56006 \\
\hline 18 & 26 & NBA & Baradero & 04014 \\
\hline 19 & 27 & NBA & Arrecifes & 54004 \\
\hline 20 & 28 & SEBA & Balcarce & 72004 \\
\hline 21 & 30 & SEBA & Lobería & 76004 \\
\hline 22 & 31 & NBA & $\begin{array}{l}\text { San A. de } \\
\text { Areco }\end{array}$ & 04414 \\
\hline 23 & 32 & NBA & Arrecifes & 54004 \\
\hline 24 & 34 & NBA * & Villaguay & 12414 \\
\hline 25 & 35 & NBA * & Villaguay & 10004 \\
\hline 26 & 36 & NBA * & Villaguay & 70014 \\
\hline 27 & 40 & NBA & Colón & 42004 \\
\hline 28 & 41 & NBA & FAUBA & 04404 \\
\hline 29 & 43 & NBA & Ramallo & 10004 \\
\hline 30 & 44 & NBA & Ramallo & 70044 \\
\hline 31 & 45 & NBA * & Villaguay & 12414 \\
\hline 32 & 46 & NBA * & Villaguay & 10004 \\
\hline 33 & 48 & SEBA & Balcarce & 42404 \\
\hline 34 & 52 & NBA & Arrecifes & 72004 \\
\hline 35 & 53 & SEBA & Lobería & 72004 \\
\hline 36 & 54 & SEBA & Balcarce & 46404 \\
\hline 37 & 55 & NBA & Arrecifes & 00404 \\
\hline 38 & 56 & NBA & Arrecifes & 02404 \\
\hline 39 & 57 & NBA & Rancagua & 56014 \\
\hline 40 & 58 & NBA & Arrecifes & 54004 \\
\hline 41 & 59 & NBA & Pinzón & 56004 \\
\hline 42 & 60 & NBA & Rancagua & 46044 \\
\hline
\end{tabular}

\begin{tabular}{|c|c|c|c|c|}
\hline 43 & 61 & SEBA & Lobería & 56004 \\
\hline 44 & 62 & NBA & Chacabuco & 04414 \\
\hline 45 & 63 & SEBA & Lobería & 56014 \\
\hline 46 & 64 & NBA & Rancagua & 52404 \\
\hline 47 & 65 & NBA & FAUBA & 04404 \\
\hline 48 & 66 & NBA & Rojas & 52004 \\
\hline 49 & 68 & NBA & Rancagua & 42414 \\
\hline 50 & 73 & NBA & Arrecifes & 56414 \\
\hline 51 & 74 & SEBA & Lobería & 76004 \\
\hline 52 & 75 & SEBA & Balcarce & 56404 \\
\hline 53 & 78 & SEBA & Balcarce & 52004 \\
\hline 54 & 79 & SEBA & Balcarce & 42004 \\
\hline 55 & 80 & SEBA & Necochea & 00004 \\
\hline 56 & 81 & SEBA & Balcarce & 42404 \\
\hline 57 & 82 & SEBA & Balcarce & 42404 \\
\hline 58 & 83 & SEBA & Tandil & 56404 \\
\hline 59 & 84 & SEBA & Necochea & 42404 \\
\hline 60 & 89 & NBA & Fontezuela & 42404 \\
\hline 61 & 92 & NBA & Fontezuela & 52004 \\
\hline 62 & 94 & NBA & Pinzón & 56004 \\
\hline 63 & 95 & NBA & Pergamino & 42404 \\
\hline 64 & 96 & NBA * & Victoria & 00004 \\
\hline 65 & 98 & NBA & FAUBA & 22014 \\
\hline 66 & 100 & SEBA & Lobería & 52004 \\
\hline 67 & 103 & SEBA & Lobería & 02404 \\
\hline 68 & 104 & SEBA & Lobería & 56404 \\
\hline 69 & 105 & SEBA & Balcarce & 54004 \\
\hline 70 & 106 & SEBA & Necochea & 52004 \\
\hline 71 & 108 & SEBA & Necochea & 52004 \\
\hline 72 & 110 & SEBA & Balcarce & 42404 \\
\hline 73 & 111 & SEBA & Necochea & 00004 \\
\hline 74 & 112 & SEBA & Balcarce & 52004 \\
\hline 75 & 113 & SEBA & Balcarce & 52004 \\
\hline 76 & 114 & SEBA & Balcarce & 52004 \\
\hline 77 & 115 & SEBA & Balcarce & 42404 \\
\hline 78 & 116 & SEBA & Balcarce & 40014 \\
\hline 79 & 117 & SEBA & Balcarce & 46404 \\
\hline 80 & 124 & SEBA & Lobería & 56414 \\
\hline 81 & 125 & SEBA & Balcarce & 56014 \\
\hline 82 & 126 & SEBA & Lobería & 72004 \\
\hline 83 & 127 & SEBA & Lobería & 56014 \\
\hline 84 & 128 & SEBA & Balcarce & 52414 \\
\hline 85 & 129 & SEBA & Necochea & 76014 \\
\hline 86 & 132 & SEBA & Balcarce & 52004 \\
\hline
\end{tabular}




\begin{tabular}{|r|r|l|l|l|}
\hline 87 & 133 & SEBA & Lobería & 10004 \\
\hline 88 & 134 & SEBA & Lobería & 56404 \\
\hline 89 & 135 & SEBA & Lobería & 54004 \\
\hline 90 & 139 & SEBA & Necochea & 00004 \\
\hline 91 & 140 & SEBA & Necochea & 00004 \\
\hline 92 & 151 & SEBA & Gral. Piran & 42004 \\
\hline 93 & 156 & NBA & Colón & 52004 \\
\hline
\end{tabular}

El Código Octogonal se determinó con HaGiS, en el que 0 indica una reacción incompatible, y 1 indica una reacción compatible en cada diferencial después de la inoculación. Los 8 dígitos se asignaron de la siguiente forma: $000=0$, $100=1,010=2,001=4,110=3,101=5,011=6$, y $111=7$, (Hermann et al., 1999). El primer digito es la respuesta de $R p s 1 \mathrm{a}, R p s 1 \mathrm{~b}, R p s 1 \mathrm{c}$, el segundo digito: Rps $1 \mathrm{~d}, R p s 1 \mathrm{k}$, Rps 2; el tercer digito: Rps 3 a, Rps $3 \mathrm{~b}, R p s 3 \mathrm{c}$; el cuarto digito: $R p s 4, R p s 5$, Rps6; y el quinto digito: Rps7, Rps8.

Los patotipos se determinaron mediante la inoculación de 8 diferenciales con cada aislamiento de Phytophthora sojae. *Victoria y Villaguay (Pcia. de Entre Ríos).

TABLA 9. Secuencias de iniciadores (primers) y características para los locus de microsatélites polimórficos desarrollados a partir de la secuencia de Phytophthora sojae. Nombre del locus, número de acceso GenBank, secuencia del iniciador, motivo repetido, rango de tamaño, número de alelos determinados mediante el genotipado del aislamiento P6497 de Ohio, EEUU (extraído de Steward et al., 2011)

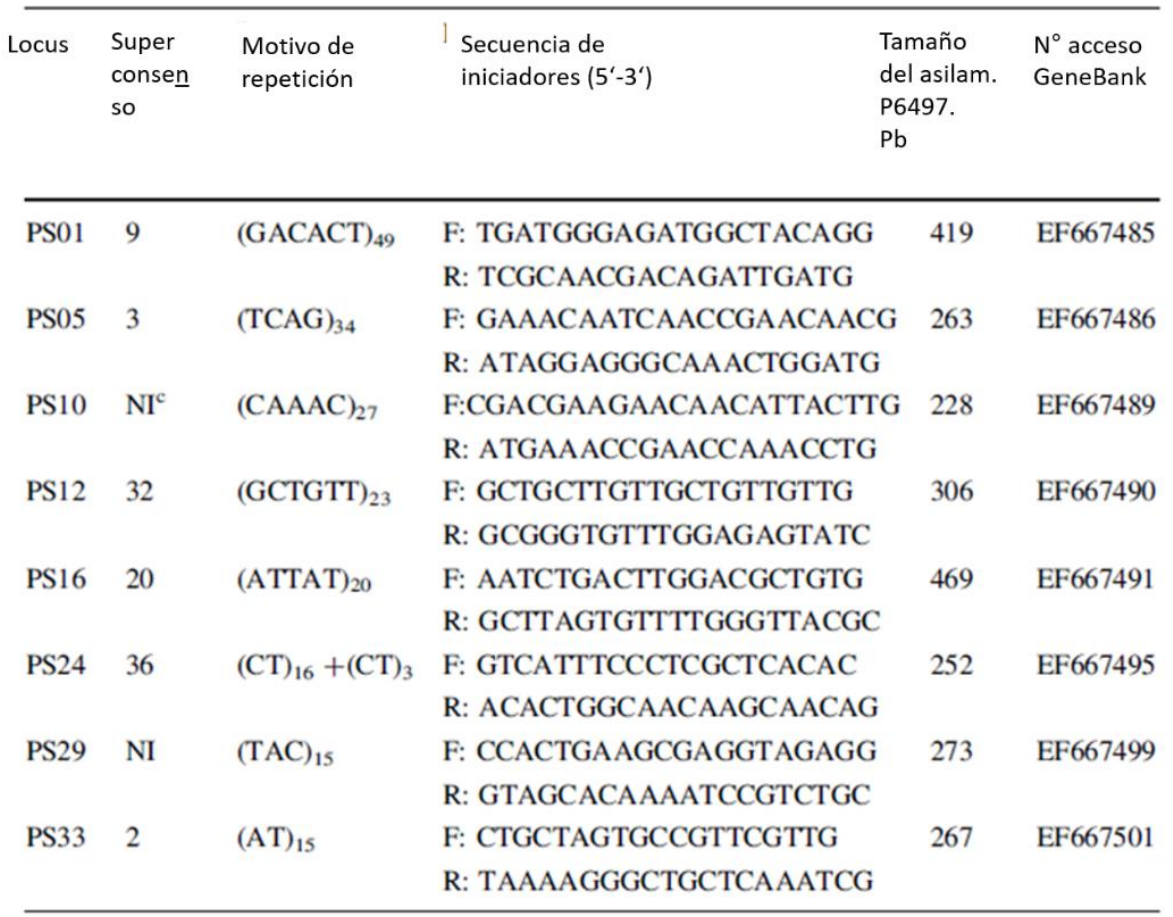

3.1 Curvas de acumulación de haplotipos: En una primera instancia se evaluó este parámetro, que es una herramienta que permite analizar el poder de discriminación entre individuos (haplotipos, genotipos multi-locus) para una cantidad de $\mathrm{N}$ locus (en este caso, microsatélites) dentro de un dataset. Organismos con reproducción clonal ó parcialmente clonal alcanzarán el "plateau" en el número de loci necesario para discriminar todos los haplotipos incluidos con un bajo número de polimorfismos. Por el contrario, organismos de reproducción predominantemente sexual requerirán una alta proporción de los polimorfismos para identificar todos los individuos que constituyen el dataset. 
Las curvas de acumulación fueron realizadas con el paquete POPPR (Kamvar et al., 2014), que corre bajo el entorno programable R (Versión 2.14.1). Cada locus polimórfico fue re-muestreado aleatoriamente 1000 veces.

3.2 Caracterización por locus: El análisis básico de polimorfismo (realizado con POPPR), arrojó el número de alelos, la heterocigosis observada (1-D), la heterocigosis esperada (Hesp) y la uniformidad (evenness) para cada uno de los loci microsatélites utilizados. Se obtuvo además la media para cada uno de estos estimadores, considerando el total de los microsatélites utilizados.

3.3 Diversidad haplotípica: Se analizó además la diversidad multi-locus incluyendo la cantidad y frecuencia de haplotipos para cada uno de los linajes (haplotipo se toma aquí como equivalente de genotipo multi-locus). La cantidad de genotipos multilocus observados (GML), equivalente al índice de diversidad haplotípica, (H) (Nei, 1987) es función del tamaño muestral. Por lo tanto, a los fines de la comparación entre muestras de diferente tamaño, un estimador más efectivo para la diversidad es el número esperado de genotipos multi-locus (eGML), que corrige los valores observados por rarefacción, basados en una muestra de tamaño mayor o igual a diez. La rarefacción es un método que fue propuesto para comparar el número de especies (en este caso, genotipos multi-locus) cuando las muestras difieren en tamaño (Gotelli y Colwell, 2011). POPPR utiliza además tres índices de diversidad haplotípica: el de Shannon-Wiener $(\mathrm{H})$, el de Stoddart y Taylor (G), y el de Simpson (lambda). De los tres, el más intuitivo y el que se comporta de modo lineal en relación con el tamaño muestral es el índice de Simpson, el cual es simplemente 1 menos la suma de las frecuencias haplotípicas al cuadrado. Este estimador ofrece la probabilidad de que dos muestras tomadas al azar sean diferentes, desde 0 (todos los aislamientos son iguales) hasta 1 (todos los aislamientos son genéticamente diferentes).

Se evaluó además la uniformidad ("eveness") haplotípica. Este parámetro es una medida de la distribución de los haplotipos en una unidad de muestreo: una población con frecuencias haplotípicas similares tendrá una uniformidad completa (tendiente a 1), y una dominada por un único haplotipo, será igual a 0 . El índice utilizado para estimar la uniformidad es E5 (Stoddart y Taylor, 1988), que se calcula esencialmente, como la relación entre haplotipos más y menos abundantes dentro de cada muestra. 
3.4 AMOVA: Para evaluar si existe estructuración en la partición de la variación genética de $P h$. sojae en la provincia de Buenos Aires se utilizó el Análisis Molecular de la Varianza (AMOVA, Excoffier 1992). Este análisis utiliza una partición a priori de los datos de acuerdo con criterios propuestos por el investigador (en este caso geográfico, como se señaló anteriormente). AMOVA se llevó adelante utilizando el paquete ade4 que también corre bajo el entorno programable R. Para evaluar si las localidades/regiones son significativamente diferentes, se realizó un test de aleatorización (randomización) utilizando la función randtest del paquete ade4. Esta función permuta aleatoriamente las matrices de muestras, como describen Excoffier et al. (1992). En este caso se utilizaron mil permutaciones aleatorias. Cabe señalar que si el dataset se hubiera muestreado de una población panmíctica, se esperarían componentes de la varianza pequeños para las particiones, comparados con la varianza inter-individual (dentro de las particiones).

3.5 Análisis discriminante de componentes principales: Los métodos clásicos de asignación analizan genotipos multi-locus individuales, evaluando las probabilidades esperadas de que tal genotipo pertenezca a diferentes grupos potenciales. Estos métodos "basados en modelos" utilizan supuestos explícitos, tales como poblaciones en equilibrio de Hardy-Weinberg (H-W) y equilibrio de ligamiento. Fueron esencialmente desarrollados para genotipos haploides y diploides. Por ejemplo, el programa STRUCTURE (Prichard et al., 2000), es un algoritmo de agrupamiento bayesiano que puede ser utilizado, en caso que sus supuestos poblacionales se cumplan, tanto para identificar clusters genéticos en un dataset, como para asignar individuos de origen desconocido a cada uno de esos dataset. Para ello utiliza las frecuencias alélicas (génicas) de cada cluster, obtenidas a partir de las observadas en la muestra, y asumiendo que los clusters se encuentran en equilibrio H-W. Se comprarán esas frecuencias (de cada cluster) con la constitución alélica (multilocus) de cada muestra a analizar, y en función de esa comparación se produce una asignación de cada muestra a cada grupo o cluster.

Estos supuestos no se cumplen en un enorme número de casos, entre los que se encuentra el análisis de los datasets aquí caracterizados. La utilización de este tipo de aproximaciones cuando los supuestos poblacionales no verifican en la realidad del sistema biológico bajo estudio lleva a resultados fuertemente sesgados y a asignaciones completamente artificiales.

Adicionalmente, un problema que presentan los métodos tradicionales es que se enfocan en la variación genética completa. La variación genética puede ser descompuesta 
como varianza total $=$ (varianza entre grupos $)+$ (varianza dentro de grupos) . Las aproximaciones como el análisis de componentes principales o el análisis de coordenadas principales se enfocan básicamente en la varianza total, oscureciendo así la variación entre grupos.

El Análisis Discriminante de Componentes Principales (DAPC) permite superar las limitaciones antes mencionadas, ya que es un método de análisis multivariado libre de supuestos poblacionales (Jombart, 2008). Además, DAPC busca combinaciones sintéticas lineales de las variables originales (las llamadas funciones discriminantes), que muestran diferencias entre grupos minimizando la variación dentro de los mismos. Basado en las funciones discriminantes retenidas, el análisis deriva entonces probabilidades de pertenencia de cada muestra a un determinado grupo. Este coeficiente puede ser interpretado como una "proximidad genética" de los individuos (en este caso, aislamientos) a los diferentes clusters.

DAPC requiere la definición a priori de grupos. Sin embargo, esos grupos son a menudo desconocidos o inciertos, y es necesario identificarlos antes de describirlos. Esto se logra en el análisis utilizando " $k$-means", un algoritmo de agrupamiento que encuentra un número dado $(\mathrm{K})$ de grupos que maximiza la variación entre grupos. Para identificar el número óptimo de clusters $(\mathrm{K})$, “ $k$-means" corre secuencialmente con valores incrementales de $\mathrm{K}$, y diferentes soluciones de agrupamiento son comparadas utilizando el Criterio de Información Bayesiano (CIB). Idealmente, la solución óptima debería corresponder con el valor más bajo de CIB. El algoritmo de "k-means" permite entonces una definición a priori de los grupos, mientras que el análisis discriminante de componentes principales (DAPC) en sí, permite caracterizar y validar los grupos predefinidos, así como otorga una probabilidad de asignación de cada muestra a uno de los clusters. El Análisis Discriminante de Componentes Principales se ha implementado en el paquete adegenet 2.0.0, que corre bajo el entorno programable R.

3.6 Análisis de redes: Se realizó, complementariamente, un análisis de redes. Este permite visualizar las relaciones genéticas entre individuos. Es un tipo de aproximación analítica que evita los constreñimientos teóricos de los árboles dicotómicos, lo que resulta de particular utilidad para el análisis de nivel infra-específico, en particular para organismos de reproducción sexual. Se utiliza en este caso el algoritmo de "mínimum spanning network" (MSN, red de cobertura mínima), Este algoritmo utiliza una matriz de 
distancia entre individuos, y a partir de esa matriz elabora una topología reticulada. Este análisis se realizó también utilizando POPPR. 


\section{RESULTADOS}

\section{Virulencia en la subregión Pampeana Norte durante el intervalo 1998-2004}

Ph. sojae fue aislada en el $96 \%$ de los lotes afectados. Un total de 193 aislamientos se obtuvieron entre 1998-2004, en la región muestreada, 75 \% de plantas enfermas y $25 \%$ de suelos. Todos los aislamientos demostraron ser patógenos y se probaron en los diferenciales susceptibles Haro (1-7) 1, Williams o Sloan. En 1998, se obtuvieron 60 aislamientos de plantas enfermas y 3 de suelo en cinco localidades. Los fenotipos de virulencia de los aislamientos de suelo y plantas, y su distribución en este periodo se resumen en la Tabla 10.

Table 10. Distribución de la virulencia de aislamientos de Phytophthora sojae de la subregión Pampeana norte entre 1998-2004, probados sobre 8 o 14 genes Rps y 3 líneas experimentales (* probados en Harrow, Canadá).

\begin{tabular}{|c|c|c|c|c|}
\hline $\begin{array}{l}\text { Fórmula de } \\
\text { Virulencia }{ }^{1}\end{array}$ & Raza & $\begin{array}{l}\text { Cantidad de } \\
\text { aislamientos }^{2}\end{array}$ & Área & Años \\
\hline 7 & 1 & $41 \mathrm{pl}-16 \mathrm{~s}$ & $\begin{array}{l}\text { MO-R-A-SA-LR-Go-H- } \\
\text { Mu- } \\
\text { S-MJ-FA-Gu-Vi }\end{array}$ & $\begin{array}{l}98 \text { a } 2000-02- \\
04\end{array}$ \\
\hline 6,7 & 13 & $8 \mathrm{pl}-2 \mathrm{~s}$ & MO-Pi-Go-ES-MJ & 98-99-04 \\
\hline $3 a, 7$ & 15 & $2 \mathrm{pl}$ & MO-Go & $98-99$ \\
\hline $3 a, 6,7$ & & $6 \mathrm{pl}$ & MO-Bi-Go-ES & $98-99$ \\
\hline $1 \mathrm{a}, 7$ & 3 & $2 \mathrm{pl}$ & Pe-ES & 99 \\
\hline $1 \mathrm{a}, 6,7$ & 9 & $13 \mathrm{pl}-7 \mathrm{~s}$ & ES-Go-RO & 99 \\
\hline $1 \mathrm{a}, 1 \mathrm{c}, 7$ & 4 & $15 \mathrm{pl}-3 \mathrm{~s}$ & $\begin{array}{l}\text { MO-R-ES-Ra-Pi-RO-VT- } \\
\text { Vi }\end{array}$ & 98-99-02-04 \\
\hline $1 \mathrm{a}, 3 \mathrm{a}, 6,7$ & 7 & $3 \mathrm{pl}$ & MO-Go & $98-99$ \\
\hline $1 \mathrm{a}, 1 \mathrm{c}, 6,7$ & 5 & $1 \mathrm{pl}-1 \mathrm{~s}$ & $\mathrm{~S}-\mathrm{Vi}$ & $99-04$ \\
\hline $1 \mathrm{a}, 1 \mathrm{~d}, 7$ & 44 & $1 \mathrm{pl}$ & MO & 98 \\
\hline $1 \mathrm{a}, 1 \mathrm{~d}, 6,7$ & 8 & $1 \mathrm{pl}$ & $\mathrm{RO}$ & 99 \\
\hline $1 \mathrm{a}, 1 \mathrm{~d}, 3 \mathrm{a}, 6,7$ & 6 & $1 \mathrm{pl}$ & $\mathrm{Mu}$ & 04 \\
\hline $1 \mathrm{a}, 1 \mathrm{~b}, 6,7$ & 23 & $3 \mathrm{pl}-3 \mathrm{~s}$ & ES-Bi-Go-RO & $98-99$ \\
\hline $1 \mathrm{a}, 1 \mathrm{~b}, 1 \mathrm{c}, 6,7$ & & $1 \mathrm{pl}$ & ES & 99 \\
\hline $1 \mathrm{a}, 1 \mathrm{~b}, 1 \mathrm{~d}, 6,7$ & & $2 \mathrm{pl}$ & RO & 99 \\
\hline $1 \mathrm{a}, 1 \mathrm{~b}, 1 \mathrm{~d}, 1 \mathrm{k}, 6,7$ & & $1 \mathrm{pl}-2 \mathrm{~s}$ & ES-Go-RO & 99 \\
\hline $1 \mathrm{a}, 1 \mathrm{c}, 1 \mathrm{~d}, 7$ & 43 & $4 \mathrm{pl}$ & MO-Pe-Ra & $98-02$ \\
\hline $1 \mathrm{a}, 1 \mathrm{c}, 1 \mathrm{~d}, 3 \mathrm{a}, 7$ & & $1 \mathrm{pl}$ & MO & 98 \\
\hline $1 \mathrm{a}, 1 \mathrm{c}, 1 \mathrm{k}, 6,7$ & & $2 \mathrm{pl}$ & B & 98 \\
\hline $1 \mathrm{a}, 1 \mathrm{c}, 1 \mathrm{~d}, 1 \mathrm{k}, 6,7$ & & $1 \mathrm{pl}$ & $\mathrm{Pe}$ & 99 \\
\hline $1 \mathrm{a}, 1 \mathrm{~d}, 1 \mathrm{k}, 7$ & & $3 \mathrm{pl}$ & MO & 98 \\
\hline $1 b, 7$ & 2 & $9 \mathrm{pl}$ & MO-R-A-SA-LR-B & 98 \\
\hline
\end{tabular}


$1 \mathrm{~b}, 6$

$1 b, 6,7$

$1 \mathrm{~b}, 1 \mathrm{c}, 1 \mathrm{~d}, 6,7$

$1 \mathrm{~b}, 1 \mathrm{~d}, 6,7$

$1 \mathrm{~b}, 1 \mathrm{~d}, 3 \mathrm{a}, 6,7$

$1 \mathrm{~b}, 3 \mathrm{a}, 6,7$

$1 \mathrm{c}, 7$

$1 \mathrm{c}, 6,7$

$1 \mathrm{c}, 1 \mathrm{~d}, 7$

$1 \mathrm{c}, 1 \mathrm{~d}, 6,7$

$1 \mathrm{c}, 1 \mathrm{~d}, 1 \mathrm{k}, 6,7$

$1 \mathrm{c}, 3 \mathrm{a}, 7$

$1 \mathrm{c}, 3 \mathrm{a}, 6,7$

$1 \mathrm{~d}, 3 \mathrm{a}, 7$

$1 \mathrm{k}, 7$

Probados en Canadá $(*)$

1a, $1 \mathrm{c}, 1 \mathrm{~d}, 3 \mathrm{~b}, 7$

1a, $1 \mathrm{~b}, 1 \mathrm{c}, 1 \mathrm{~d}, 1 \mathrm{k}, 2,3 \mathrm{~b}, 3 \mathrm{c}, 4,5,6,7$

1a, $1 \mathrm{~b}, 1 \mathrm{c}, 1 \mathrm{~d}, 1 \mathrm{k}, 3 \mathrm{~b}, 4,5,6,7,940$

$1 \mathrm{~b}, 1 \mathrm{~d}, 2,3 \mathrm{~b}, 3 \mathrm{c}, 4,5,6,7$

$1 \mathrm{~b}, 1 \mathrm{~d}, 1 \mathrm{k}, 3 \mathrm{~b}, 4,7,940$

1b,1d,1k,2,3a,3b,3c,4,5,6,7,8,944,939,940

1b,1d,2,3a,3b,3c,4,5,6,7,8,944,939,940

$1 \mathrm{~b}, 1 \mathrm{k}, 2,3 \mathrm{~b}, 3 \mathrm{c}, 5,6,7,940$

$1 \mathrm{~b}, 1 \mathrm{k}, 2,3 \mathrm{a}, 3 \mathrm{~b}, 3 \mathrm{c}, 4,5,7$

1b,3a,3b, 5,7,8,940

$1 \mathrm{~b}, 3 \mathrm{~b}, 5,7$

$1 \mathrm{k}, 3 \mathrm{~b}, 4,5,7$

$1 \mathrm{k}, 2,3 \mathrm{~b}, 5,6,7$

$1 \mathrm{k}, 3 \mathrm{~b}, 7,940$

2,3b, $4,5,7$

$3 \mathrm{~b}, 7$

$3 b, 4,5,6,7$

$3 b, 5,6,7$
$1 \mathrm{~s}$

1pl-1s

$1 \mathrm{pl}$

1pl-2s

$3 \mathrm{pl}$

$4 \mathrm{pl}$

2pl-2s

$1 \mathrm{~s}$

$1 \mathrm{~s}$

$1 \mathrm{~s}$

$1 \mathrm{pl}$

$1 \mathrm{pl}$

$1 \mathrm{pl}$

$1 \mathrm{pl}$

$1 \mathrm{~s}$

$1 \mathrm{pl}$

$1 \mathrm{pl}$

$1 \mathrm{pl}$

$1 \mathrm{pl}$

$1 \mathrm{pl}$

$1 \mathrm{pl}$

$1 \mathrm{pl}$

$1 \mathrm{pl}$

$1 \mathrm{pl}$

$1 \mathrm{pl}$

$1 \mathrm{pl}$

$1 \mathrm{pl}$

$1 \mathrm{pl}$

$1 \mathrm{pl}$

$1 \mathrm{pl}$

$1 \mathrm{pl}$

$1 \mathrm{pl}$
ES

Pi-MJ

ES

Go-RO

$\mathrm{Mu}-\mathrm{Gu}$

MO-Pi-LR

MO-Pe

$\mathrm{Pe}$

$\mathrm{Pe}$

$\mathrm{Pe}$

$\mathrm{Pe}$

ES

ES

MO

$\mathrm{Vi}$

Pi

VT

Vi

$\mathrm{Mu}$

$\mathrm{Gu}$

$\mathrm{Mu}$

SA

$\mathrm{H}$

SA

$\mathrm{Vi}$

A

Vi

Vi

FA

$\mathrm{Vi}$

Vi

$\mathrm{H}$
99

99-04

99

99

03-04

98-04

98-99

99

99

99

99

99

99

98

04

04

04

04

04

03

04

02

00

02

04

98

04

04

00

04

04

00

98

${ }^{1}$ Lista de los genes Rps quebrados (1a, 1b, 1c, 1d, 1k, 3a, 6, 7) y 3b, 3c, 4, 5, 8, 939, 940, 944.

$2 \mathrm{pl}=$ Planta $\mathrm{s}=$ Suelo

$\mathrm{MO}=$ Manuel Ocampo, $\mathrm{R}=$ Rojas, $\mathrm{A}=$ Arrecifes, $\mathrm{Pe}=$ Pergamino, $\mathrm{ES}=\mathrm{El}$ Socorro, $\mathrm{Ra}=$ Ramallo, $\mathrm{SA}=\mathrm{San}$ Antonio de Areco, $\mathrm{Pi}=\mathrm{Pilar}, \mathrm{LR}=$ Las Rosas, $\mathrm{B}=$ Bigand, $\mathrm{S}=\mathrm{Saira}, \mathrm{Go}=$ Godeken, $\mathrm{H}=$ Hughes, $\mathrm{Mu}=$ Muños, $\mathrm{RO}=$ Rafael Obligado, $\mathrm{MJ}=$ Marcos Juarez, FA= FAUBA, Gu=Gualeguaychu, VT=Villa Teresita, $\mathrm{Vi}=$ Victoria. 


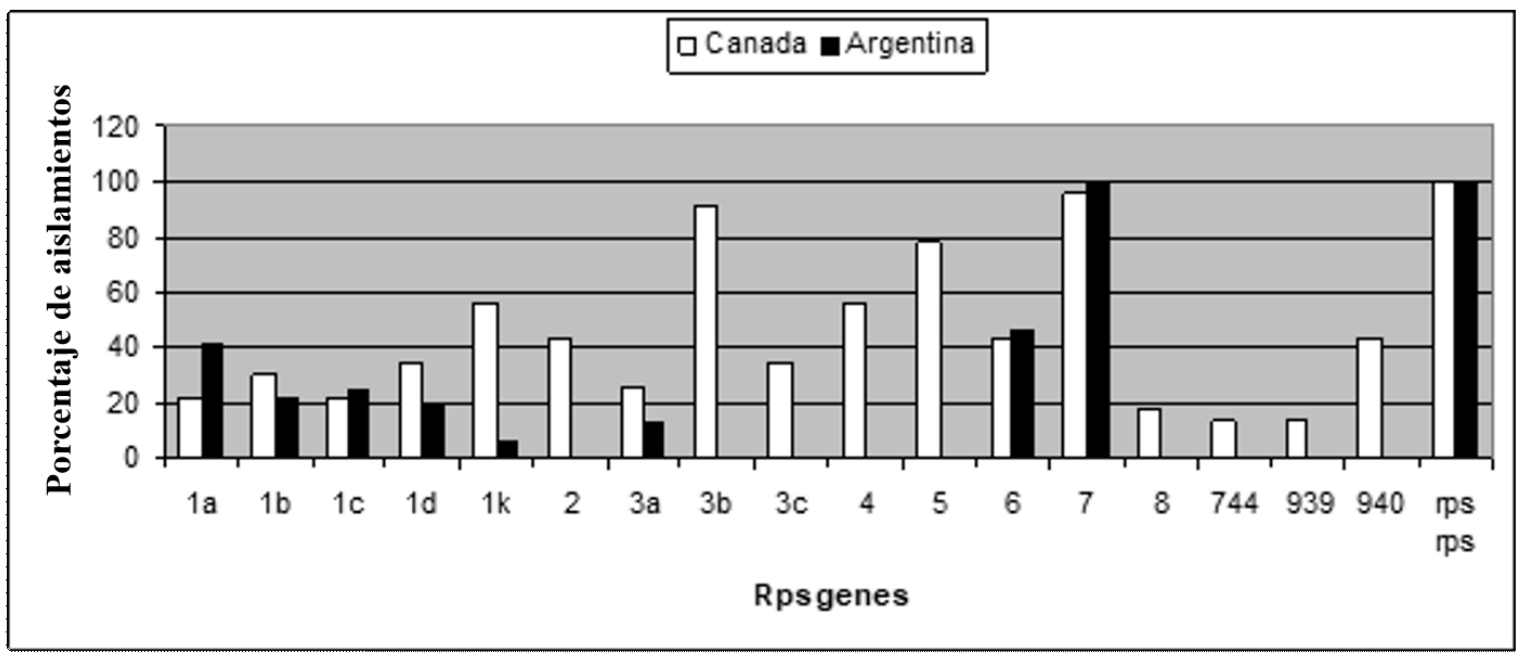

Figura 38. Porcentaje de aislamientos de Phytophthora sojae obtenidos entre 1998-2004, y su interacción con los genes Rps. Blanco: probados en Harrow (Canadá) sobre un grupo de 15 cultivares diferenciales, y 3 líneas experimentales. Negro: probados en Argentina sobre un grupo de 8 cultivares diferenciales.

En los últimos años, el número de patótipos identificados ha aumentado drásticamente, lo que ha hecho que el sistema numérico de clasificación en razas sea engorroso (Dorrance et al., 2004), pero tanto las fórmulas de virulencia como el número de razas han sido incluidos porque los fitomejoradores y agricultores argentinos están acostumbrados al sistema numérico. Entre los 173 aislamientos probados en los ocho diferenciales, se detectaron 37 patótipos diferentes, incluyendo 18 razas descritas. Los fenotipos de virulencia no descritos constituyeron el $24 \%$ de las cepas. La raza 1 fue predominante, constituyendo el $25 \%$ de los aislamientos y estuvo presente en 12 de las 20 localidades muestreadas, seguida de la raza 13, que constituyó el $5 \%$ de los aislamientos y estuvo presente en solo 4 localidades. Se encontró una mayor variabilidad de virulencia en BA y SFe donde se obtuvo la mayoría de los aislamientos. Las segundas razas más frecuentes fueron la raza 4 en BA y la raza 2 en SFe. La raza 9 fue la tercera más prevalente en ambas provincias (Tabla 10). En BA se identificaron las razas 1, 2, 3, $4,7,8,9,11,13,14,15,23,24,43$ y 44; en SFe las razas $1,2,5,6,7,9,13,15,17,23$ y 24; en ER las razas 1, 4, 5 y 17; y en Cba las razas 1, 5, 11 y 13. Las razas 1, 4, 5, 7, 9, 13, 23 y 24 se encontraron tanto en plantas como en suelos, mientras que la 2, 3, 6, 8, 11 , $14,15,17,43$ y 44 solo se aislaron de plantas.

A partir de 20 aislamientos probados en Canadá en el conjunto ampliado de diferenciales se describieron 19 patótipos adicionales (Tabla 10). La frecuencia de aislamientos compatibles con los genes Rps en la soja se ilustran en la Fig. 38. Los ocho 
diferenciales fueron quebrados, lo que demuestra que el gen Rps 7 fue más frecuentemente susceptible.

La mayoría de los aislamientos probados en Argentina fueron virulentos en Rps 1a (41,5 \%) o Rps 6 (46,1 \%), y 21,5\% también mostraron virulencia en Rps 1b. Solo el $6 \%$ de los aislamientos mostraron virulencia al gen de resistencia Rps $1 k$. Dentro del conjunto expandido, los aislamientos probados en Canadá fueron virulentos en $R p s$ b (91,3\%) o Rps 5 (78,3\%), y el 56,5\% también mostraron virulencia en Rps 4. Menos del $18 \%$ mostraron virulencia al gen de resistencia $\operatorname{Rps} 8$, y los genes/alelos putativos de las líneas Ox744 y Ox939 (Fig. 38).

\section{Virulencia en el NBA y SEBA durante el intervalo 2013-2016}

\subsection{Identificación de los aislamientos y almacenamiento}

Desde 2013 a 2016, se obtuvieron 192 aislamientos de $P h$. sojae (61\% de plantas enfermas y $39 \%$ de suelos naturalmente infestados), 124 aislamientos del SEBA y 68 del NBA. Los que se mantienen en la colección de hongos de la Cátedra de Fitopatología, UBA.

\subsection{Evaluación de la virulencia de los aislamientos (Determinación de razas o fórmulas de virulencia específica)}

Ningún aislamiento fue avirulento ya que todos ocasionaron colapso y muerte de los diferenciales susceptibles Haro (1-7) 1, Williams o Sloan (rps rps) solo uno no fue virulento sobre el cv. Harosoy (Rps 7). Los 124 aislamientos del SEBA y 68 del NBA, inoculados con las ocho líneas diferenciales estándar, produjeron reacción de hipersensibilidad en los hipocótiles y, por lo tanto, fueron avirulentos sobre los ocho genes testeados. Las plántulas de la línea Harosoy (Rps7), y los testigos susceptibles murieron dentro de las 48 h de la inoculación.

La reacción de virulencia/avirulencia: 7/1a, 1b, 1c, 1d, 1k, 3a y 6, que corresponde a la raza 1 del patógeno (Schmitthenner, 1994) se presentó solo en 4 aislamientos provenientes de plantas infestadas del SEBA (3,2 \%), mientras que en el NBA solo dos 
aislamientos provenientes de plantas (2,9\%). Porcentajes muy bajos en comparación a la prevalencia del $25 \%$ correspondiente al periodo 1998-2004.

En el SEBA se pudieron determinar 40 fórmulas de virulencia (Tabla 11), mientras que en el NBA fueron 33 (Tabla 12), de las cuales 18 son la misma. Las fórmlas del SEBA representaron 9 razas conocidas $(1,3,4,9,14,25,34,38$ y 43) mientras que las del NBA $7(1,14,25,34,36,38$ y 43$)$.

Tanto en el SEBA como en el NBA, la mayoría de los aislamientos fueron virulentos sobre el gen $R p s 1 \mathrm{a}$, con $88,5 \%$ y $61 \%$ respectivamente; $R p s 1 \mathrm{c}$, con $67,3 \%$ y $61 \%$ respectivamente y $R p s 1 \mathrm{k}$ con 78,8 \% y 58,5\% respectivamente. Por su parte el gen menos quebrado fue en ambas zonas el Rps 6 con $17,3 \%$ y $15 \%$ respectivamente (Fig. 39).

En el SEBA los valores máximos de incidencia se registraron en la localidad de Necochea con un $15 \%$ de plantas afectadas en un lote de aproximadamente 50 ha pero con valores puntuales en manchones o zonas con acumulación de agua de valores del 100 $\%$ de plantas atacadas y muertas.

La enfermedad se presentó desde el estado de plántula hasta planta adulta. Al estado de plántula, muchas veces estuvo asociada con varias especies de Pythium, lo que pudo determinarse en Villaguay (Entre Ríos) y Capitán Sarmiento durante la campaña 2014/15 donde tuvieron que resembrar debido a la pérdida de plantas. En estados reproductivos tempranos, el aislamiento del patógeno no presentó dificultades sobre todo de plantas con síntomas típicos de podredumbre pardo-oscura en el tallo, que progresa hasta el segundo o tercer entrenudo y ramas laterales. Sin embargo, al final del ciclo del cultivo se observaron plantas que presentaban un síndrome complejo, debido a la presencia simultánea de otros patógenos. A partir de aquéllas que manifestaban la sintomatología típica de $P h$. sojae asociada con un cancro unilateral, en la base del tallo, se aislaron $P h$. sojae y Diaporthe spp. 
Tabla 11. Distribución de la virulencia de 69 aislamientos de Phytophthora sojae obtenidos en la región NBA durante 2013-2016, chequeados en un grupo de ocho genes Rps.

\begin{tabular}{|c|c|c|c|c|}
\hline $\begin{array}{l}\text { Fórmula de } \\
\text { Virulencia } 1\end{array}$ & Raza & $\begin{array}{l}\text { Cantidad de } \\
\text { Aislamientos }\end{array}$ & Área & Años \\
\hline 7 & 1 & $2 \mathrm{pl}$ & Ch-V & 14 \\
\hline $1 \mathrm{a}, 1 \mathrm{~b}, 1 \mathrm{c}, 1 \mathrm{~d}, 1 \mathrm{k}, 3 \mathrm{a}, 6,7$ & 38 & $1 \mathrm{~s}$ & Vi & 15 \\
\hline $1 \mathrm{a}, 1 \mathrm{~b}, 1 \mathrm{c}, 6,7$ & & $2 S$ & $\mathrm{Ra}$ & 15 \\
\hline $1 \mathrm{a}, 1 \mathrm{~b}, 1 \mathrm{c}, 1 \mathrm{~d}, 7$ & & $1 S$ & Vi & 15 \\
\hline $1 \mathrm{a}, 1 \mathrm{~b}, 1 \mathrm{c}, 1 \mathrm{~d}, 1 \mathrm{k}, 7$ & & $2 \mathrm{pl}-1 \mathrm{~s}$ & R-Pi & 15 \\
\hline 1a, 1b, 1c,1d,1k,6(I),7 & & $1 \mathrm{pl}$ & CS & 15 \\
\hline $1 \mathrm{a}, 1 \mathrm{~b}, 1 \mathrm{c}, 1 \mathrm{k}, 7$ & & $4 \mathrm{pl}-1 \mathrm{~S}$ & G- C-A & 15 \\
\hline $1 \mathrm{a}, 1 \mathrm{c}, 1 \mathrm{~d}, 7$ & 43 & $2 \mathrm{pl}-2 \mathrm{~s}$ & C-SA & 15 \\
\hline $1 \mathrm{a}, 1 \mathrm{c}, 1 \mathrm{~d}, 1 \mathrm{k}, 7$ & & $3 \mathrm{pl}-1 \mathrm{~s}$ & $\mathrm{Pi}-\mathrm{CS}$ & 15 \\
\hline $1 \mathrm{a}, 1 \mathrm{c}, 1 \mathrm{~d}, 1 \mathrm{k}, 3 \mathrm{a}, 7$ & & $1 \mathrm{pl}-1 \mathrm{~S}$ & R-A & 15 \\
\hline 1a,1c,1d,1k, 6(I),7 & & $1 \mathrm{pl}$ & CS & 15 \\
\hline 1a,1c,1k, 3a (I),7 & & $1 \mathrm{pl}$ & $\mathrm{F}$ & 13 \\
\hline 1a,1c,1k, 3a, 7 & & $2 \mathrm{PI}$ & $\mathrm{R}-\mathrm{F}$ & $13-15$ \\
\hline $1 \mathrm{a}, 1 \mathrm{c}, 1 \mathrm{k}, 7$ & 25 & $5 \mathrm{pl}-1 \mathrm{~S}$ & P-C-Ro & $13-14-15$ \\
\hline $1 \mathrm{a}, 1 \mathrm{c}, 1 \mathrm{~d}, 1 \mathrm{k}, 6,7$ & & $3 \mathrm{~s}$ & $\mathrm{R}$ & 15 \\
\hline 1a,1d,1k,3a, 7 & & $2 \mathrm{pl}$ & $\mathrm{F}$ & $13-14$ \\
\hline $1 \mathrm{a}, 1 \mathrm{k}, 3 \mathrm{a}, 7$ & & $3 \mathrm{pl}$ & P-F & $13-15$ \\
\hline 1a,1k,3a, 6,7 & & $1 \mathrm{~S}$ & $\mathrm{R}$ & 15 \\
\hline $1 \mathrm{a}(\mathrm{I}), 1 \mathrm{k}, 7$ & & $1 \mathrm{pl}$ & $\mathrm{Pi}$ & 13 \\
\hline $1 \mathrm{a}, 1 \mathrm{k}, 7$ & 34 & $1 \mathrm{PI}$ & SM & 14 \\
\hline $1 \mathrm{a}, 1 \mathrm{k}$ & & $1 \mathrm{pl}$ & $\mathrm{R}$ & 15 \\
\hline $1 \mathrm{~b}, 1 \mathrm{k}, 6,7$ & & $1 \mathrm{pl}$ & FA & 14 \\
\hline $1 b, 6,7$ & & $1 \mathrm{pl}$ & FA & 13 \\
\hline $1 \mathrm{c}, 7$ & 14 & $2 \mathrm{PI} 1 \mathrm{~s}$ & $\mathrm{Ra}-\mathrm{Ch}$ & $14-15$ \\
\hline 1c, $1 \mathrm{k}, 3 \mathrm{a}, 6,7$ & & $1 \mathrm{PI} 1 \mathrm{~S}$ & $\mathrm{Vi}$ & 15 \\
\hline 1c,3a,7 & & $2 \mathrm{pl}$ & F-P & $13-15$ \\
\hline $1 \mathrm{~d}, 3 \mathrm{a}, 7$ & & $1 \mathrm{pl}$ & FA & 14 \\
\hline $1 \mathrm{~d}, 3 \mathrm{a}, 6,7$ & & $1 \mathrm{~s} 2 \mathrm{pl}$ & Vi- FA-Ch & $14-15$ \\
\hline $1 \mathrm{~d}, 3 \mathrm{a}, 7$ & & $1 \mathrm{pl}$ & FA & 15 \\
\hline $1 \mathrm{~d}, 6,7$ & & $1 \mathrm{pl}-1 \mathrm{~S}$ & FA-Vi & 15 \\
\hline $1 \mathrm{k}, 3 \mathrm{a}, 7$ & & $1 \mathrm{pl}-2 \mathrm{~s}$ & F-Pi-A & $13-15$ \\
\hline 1a, $1 \mathrm{c}, 1 \mathrm{k}, 3 \mathrm{a}, 7$ & & $1 \mathrm{PI}$ & $\mathrm{F}$ & 13 \\
\hline $3 a, 7$ & 36 & $1 \mathrm{pl}-2 \mathrm{~s}$ & F-A & $13-14$ \\
\hline
\end{tabular}

${ }^{1}$ Lista de los genes Rps quebrados (1a, 1b, 1c, 1d, 1k, 3a, 6, 7) y 3b, 3c, 4, 5, 8, 939, 940, 944.

$2 \mathrm{pl}=$ Planta $\mathrm{s}=$ Suelo

$\mathrm{F}=$ Fontezuela, $\mathrm{P}=$ Pergamino, $\mathrm{R}=$ Rojas, $\mathrm{Ch}=$ Chacabuco, $\mathrm{CS}=$ Capitán Sarmiento, $\mathrm{A}=$ Arrecifes y $\mathrm{Ra}=$ Rancagua, $\mathrm{C}=$ Colón 
Tabla 12. Distribución de la virulencia de 124 aislamientos de Phytophthora sojae obtenidos en la región SEBA entre 2013-2016, chequeados en ocho genes Rps.

\begin{tabular}{|c|c|c|c|c|}
\hline $\begin{array}{l}\text { Fórmula de } \\
\text { Virulencia }{ }^{1}\end{array}$ & Raza & $\begin{array}{l}\text { Cantidad de } \\
\text { Aislamientos }\end{array}$ & Área & Años \\
\hline 7 & 1 & $4 \mathrm{pl}$ & $\mathrm{N}$ & 14 \\
\hline $1 \mathrm{a}, 7$ & 3 & $2 \mathrm{pl}$ & L-N & $13-14$ \\
\hline $1 \mathrm{a}, 6,7$ & 9 & $1 \mathrm{~S}$ & B & 14 \\
\hline $1 \mathrm{a}, 1 \mathrm{c}, 7$ & 4 & $4 \mathrm{pl}$ & B-L-N & $13-14.15$ \\
\hline $1 \mathrm{a}, 1 \mathrm{~b}, 1 \mathrm{c}, 1 \mathrm{~d}, 1 \mathrm{k}, 6,7$ & & $4 \mathrm{pl} 2 \mathrm{~s}$ & L-N-B & $14-15$ \\
\hline $1 \mathrm{a}, 1 \mathrm{~b}, 1 \mathrm{c}, 1 \mathrm{~d}(\mathrm{I}), 1 \mathrm{k}(\mathrm{I}), 7$ & & $1 \mathrm{pl} 1 \mathrm{~s}$ & Bo-B & $14-15$ \\
\hline $1 \mathrm{a}, 1 \mathrm{~b}, 1 \mathrm{c}, 1 \mathrm{~d}, 1 \mathrm{k}, 7$ & & $5 \mathrm{pl} 1 \mathrm{~s}$ & Bo-L & 15 \\
\hline $1 \mathrm{a}, 1 \mathrm{~b}, 1 \mathrm{c}, 1 \mathrm{~d}, 7$ & & $1 \mathrm{pl}$ & $\mathrm{L}$ & 14 \\
\hline $1 \mathrm{a}, 1 \mathrm{~b}, 1 \mathrm{c}, 1 \mathrm{~d}, 1 \mathrm{k}, 3 \mathrm{a}, 7$ & & $1 \mathrm{~s}$ & $\mathrm{~L}$ & 15 \\
\hline $1 \mathrm{a}, 1 \mathrm{~b}, 1 \mathrm{c}, 1 \mathrm{~d}, 1 \mathrm{k}, 3 \mathrm{a}, 6(\mathrm{I}), 7$ & 38 & $1 \mathrm{pl} 1 \mathrm{~s}$ & $B-L$ & 15 \\
\hline $1 \mathrm{a}, 1 \mathrm{~b}, 1 \mathrm{c}, 1 \mathrm{k}, 7$ & & $1 \mathrm{pl} 3 \mathrm{~s}$ & $B-L$ & $14-15$ \\
\hline $1 \mathrm{a}, 1 \mathrm{~b}, 1 \mathrm{c}, 1 \mathrm{k}, 6,7$ & & $1 \mathrm{pl}$ & $\mathrm{N}$ & 15 \\
\hline $1 \mathrm{a}, 1 \mathrm{~b}, 1 \mathrm{~d}, 1 \mathrm{k}, 3 \mathrm{a}, 7$ & & $1 \mathrm{~s}$ & $\mathrm{~L}$ & 15 \\
\hline $1 \mathrm{a}, 1 \mathrm{~b}, 1 \mathrm{~d}, 1 \mathrm{k}, 6,7$ & & $3 \mathrm{pl}$ & $\mathrm{N}$ & 14 \\
\hline $1 \mathrm{a}, 1 \mathrm{c}, 1 \mathrm{~d}, 7$ & 43 & $2 \mathrm{pl}$ & $B-L$ & $14-15$ \\
\hline 1a, $1 \mathrm{c}, 1 \mathrm{~d}, 1 \mathrm{k}(\mathrm{I}), 7$ & & $1 \mathrm{pl}$ & $\mathrm{L}$ & 15 \\
\hline $1 \mathrm{a}, 1 \mathrm{c}, 1 \mathrm{~d}, 1 \mathrm{k}, 7$ & & $17 \mathrm{pl}$ & B-L-N-M & 14- 15 \\
\hline $1 \mathrm{a}, 1 \mathrm{c}, 1 \mathrm{~d}, 1 \mathrm{k}, 3 \mathrm{a}, 7$ & & $8 \mathrm{~s} 3 \mathrm{pl}$ & B-N-L-T & $13-14.15$ \\
\hline $1 \mathrm{a}, 1 \mathrm{c}, 1 \mathrm{~d}, 1 \mathrm{k}, 6(\mathrm{I}), 7$ & & $1 \mathrm{pl}$ & Bo & 15 \\
\hline $1 \mathrm{a}, 1 \mathrm{c}, 1 \mathrm{~d}, 1 \mathrm{k}, 6,7$ & & $1 \mathrm{pl}$ & $\mathrm{L}$ & 15 \\
\hline 1a,1c,1d, 6(I),7 & & $1 \mathrm{pl}$ & $M$ & 15 \\
\hline $1 \mathrm{a}, 1 \mathrm{c}, 1 \mathrm{~d}, 1 \mathrm{k}, 6,7$ & & $2 \mathrm{pl} 2 \mathrm{~s}$ & $\mathrm{~L}$ & 15 \\
\hline $1 \mathrm{a}, 1 \mathrm{c}, 1 \mathrm{~d}, 1 \mathrm{k}, 3 \mathrm{a}, 7$ & & $3 \mathrm{PI}$ & $\mathrm{L}$ & 14 \\
\hline 1a, $1 \mathrm{c}, 1 \mathrm{~d}, 1 \mathrm{k}, 3 \mathrm{a}, 6,7$ & & $2 \mathrm{~s}$ & $\mathrm{~L}$ & 15 \\
\hline 1a, $1 \mathrm{c}, 1 \mathrm{k}, 3 \mathrm{a}, 7$ & & $1 \mathrm{PL}$ & B & 15 \\
\hline $1 \mathrm{a}, 1 \mathrm{c}, 1 \mathrm{k}, 6,7$ & & $1 \mathrm{pl}$ & $M$ & 15 \\
\hline $1 \mathrm{a}, 1 \mathrm{c}, 1 \mathrm{k}, 7$ & 25 & $8 \mathrm{pl}$ & M-N-L-B & $14-15$ \\
\hline $1 \mathrm{a}, 1 \mathrm{c}, 1 \mathrm{k}, 3 \mathrm{a}, 6,7$ & & $1 \mathrm{~s}$ & B & 15 \\
\hline 1a,1c,1d,3a,7 & & $1 \mathrm{~s} 2 \mathrm{pl}$ & $\mathrm{L}$ & $14-15$ \\
\hline $1 \mathrm{a}, 1 \mathrm{~d}, 1 \mathrm{k}, 7$ & & $3 \mathrm{~s}$ & B & $14-15$ \\
\hline $1 \mathrm{a}, 1 \mathrm{~d}, 1 \mathrm{k}, 3 \mathrm{a}, 7$ & & $1 \mathrm{pl} 3 \mathrm{~s}$ & L-B-N & $14-15$ \\
\hline $1 \mathrm{a}, 1 \mathrm{~d}, 3 \mathrm{a}, 7$ & & $1 \mathrm{~s}$ & L & 15 \\
\hline $1 \mathrm{a}, 1 \mathrm{k}, 3 \mathrm{a}, 7$ & & $5 \mathrm{pl} 3 \mathrm{~s}$ & L-B & $13-14$ \\
\hline $1 \mathrm{a}, 1 \mathrm{k}, 3 \mathrm{a}, 6,7$ & & $2 \mathrm{pl}$ & Bo-N-L & $14-15$ \\
\hline $1 \mathrm{a}, 1 \mathrm{k}, 7$ & 34 & $2 \mathrm{~s} 2 \mathrm{pl}$ & N-P-B & $14-15$ \\
\hline $1 \mathrm{~b}, 1 \mathrm{~d}, 1 \mathrm{k}, 3 \mathrm{a}, 7$ & & $1 \mathrm{~s}$ & $\mathrm{~N}$ & 14 \\
\hline $1 \mathrm{c}, 7$ & 14 & $1 \mathrm{pl}$ & $\mathrm{L}$ & 13 \\
\hline $1 \mathrm{c}, 1 \mathrm{k}, 7$ & & $1 \mathrm{pl}$ & $\mathrm{N}$ & 13 \\
\hline $1 \mathrm{k}, 3 \mathrm{a}, 7$ & & $2 \mathrm{pl}$ & L-B & $14-15$ \\
\hline $1 \mathrm{k}, 7$ & & $2 \mathrm{pl}$ & $\mathrm{N}$ & 13 \\
\hline
\end{tabular}

${ }^{1}$ Lista de los genes Rps quebrados (1a, 1b, 1c, 1d, 1k, 3a, 6, 7) y 3b, 3c, 4, 5, 8, 939, 940, 944.

${ }^{2} \mathrm{pl}=$ Planta $\mathrm{s}=$ Suelo

$\mathrm{N}=$ Necochea, $\mathrm{B}=$ Balcarce, $\mathrm{P}=$ General Pirán, $\mathrm{L}=$ Lobería, $\mathrm{Bo}=$ Bosch y $\mathrm{M}=\mathrm{El}$ Moro 


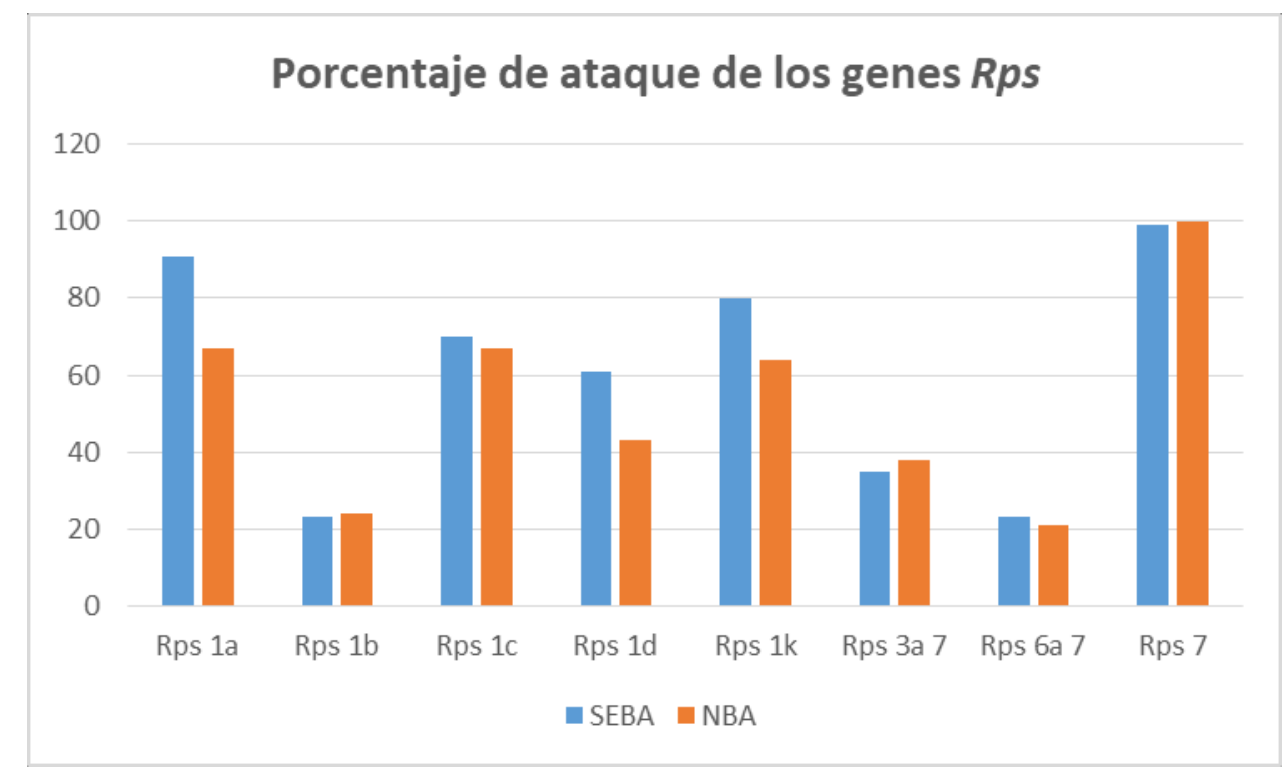

Figura 39. Porcentaje de aislamientos de Phytophthora sojae obtenidos en la zona NBA y SEBA entre 2013-2016, y su interacción con los ocho genes Rps.

Ninguno de los aislamientos identificados como Phytophthora, obtenidos en los períodos muestreados correspondió a $P h$. sansomeana.

\subsubsection{Corroboración del patrón de virulencia de la reacción de los genotipos de soja diferenciales}

Los aislamientos S1, S2 y S3 respondieron de manera diferente en los cultivares diferenciales que poseían el gen $R p s 1 \mathrm{~b}$ y $1 \mathrm{k}$. El aislamiento $\mathrm{S} 1$ también respondió de manera diferencial en la reacción de los genotipos que poseían el gen Rps 6. Por su parte los aislamientos $\mathrm{N} 1$ y N2 respondieron de modo diferente en los diferenciales con el gen Rps 1d y 6 (Tabla 13). 
Tabla 13: Reacción de genotipos diferenciales (indicando el alelo que poseen) a la inoculación de cinco aislamientos de Phytophthora sojae, mediante la técnica del hypocótile.

\begin{tabular}{|c|c|c|c|c|c|c|}
\hline $\begin{array}{c}\text { Genotipos } \\
\text { diferenciales }\end{array}$ & ALELO & $\begin{array}{c}\text { S1 } \\
\text { Lobería }\end{array}$ & $\begin{array}{c}\text { S2 } \\
\text { Necochea }\end{array}$ & $\begin{array}{c}\text { S3 } \\
\text { Lobería }\end{array}$ & $\begin{array}{c}\text { N1 } \\
\text { Germania }\end{array}$ & $\begin{array}{c}\text { N2 } \\
\text { Germania }\end{array}$ \\
\hline Mukden & $R p s 1 \mathrm{a}$ & $\mathrm{S}$ & $\mathrm{S}$ & $\mathrm{S}$ & $\mathrm{S}$ & $\mathrm{S}$ \\
\hline PARKER & $R p s 1 \mathrm{a}$ & $\mathrm{S}$ & $\mathrm{S}$ & $\mathrm{S}$ & $\mathrm{S}$ & $\mathrm{S}$ \\
\hline Haro 12 & $R p s 1 \mathrm{a}$ & $\mathrm{S}$ & $\mathrm{S}$ & $\mathrm{S}$ & $\mathrm{S}$ & $\mathrm{S}$ \\
\hline Sanga & Rps 1b & $\mathrm{S}$ & $\mathrm{S}$ & $\mathrm{S}$ & sin dato & sin dato \\
\hline Haro 13 & Rps 1b & $\mathrm{R}$ & $\mathrm{R}$ & $\mathrm{R}$ & $\mathrm{S}$ & $\mathrm{S}$ \\
\hline LaMoure & Rps 1c & $\mathrm{S}$ & $\mathrm{S}$ & $\mathrm{S}$ & $\mathrm{S}$ & $\mathrm{S}$ \\
\hline HS93-4118 & Rps 1c & $\mathrm{S}$ & $\mathrm{S}$ & $\mathrm{S}$ & $\mathrm{S}$ & $\mathrm{S}$ \\
\hline Corsoy79 & Rps 1c & $\mathrm{S}$ & $\mathrm{S}$ & $\mathrm{S}$ & $\mathrm{S}$ & $\mathrm{S}$ \\
\hline A 6785 & Rps 1c & $\mathrm{S}$ & $\mathrm{S}$ & $\mathrm{S}$ & $\mathrm{S}$ & $\mathrm{S}$ \\
\hline Arksoy & Rps 1c & $\mathrm{S}$ & $\mathrm{S}$ & $\mathrm{S}$ & $\mathrm{S}$ & $\mathrm{S}$ \\
\hline L93-3312 & Rps 1d & $\mathrm{S}$ & $\mathrm{S}$ & $\mathrm{S}$ & $\mathrm{S}$ & $\mathrm{S}$ \\
\hline Haro 16 & $R p s 1 \mathrm{~d}$ & $\mathrm{~S}$ & $\mathrm{~S}$ & $\mathrm{~S}$ & $\mathrm{R}$ & $\mathrm{R}$ \\
\hline Williams82 & Rps $1 \mathrm{k}$ & $\mathrm{S}$ & $\mathrm{S}$ & $\mathrm{S}$ & $\mathrm{S}$ & $\mathrm{S}$ \\
\hline Kinwa & Rps $1 \mathrm{k}$ & $\mathrm{S}$ & I & $\mathrm{S}$ & $\mathrm{S}$ & $\mathrm{S}$ \\
\hline Haro 15 & Rps $1 \mathrm{k}$ & $\mathrm{R}$ & $\mathrm{R}$ & $\mathrm{R}$ & $\mathrm{S}$ & $\mathrm{S}$ \\
\hline No. 3226 Brown & Rps 3a & $\mathrm{R}$ & $\mathrm{R}$ & $\mathrm{R}$ & $\mathrm{R}$ & $\mathrm{R}$ \\
\hline Haro 3272 & $\begin{array}{c}\text { Rps 3-a } \\
-7\end{array}$ & $\mathrm{~S}$ & $\mathrm{~S}$ & $\mathrm{~S}$ & $\mathrm{R}$ & $\mathrm{R}$ \\
\hline Altona & Rps 6 & $\mathrm{~S}$ & $\mathrm{R}$ & $\mathrm{R}$ & $\mathrm{S}$ & $\mathrm{S}$ \\
\hline Haro 6272 & Rps $6-7$ & $\mathrm{R}$ & $\mathrm{R}$ & $\mathrm{R}$ & $\mathrm{R}$ & $\mathrm{R}$ \\
\hline Harosoy & Rps 7 & $\mathrm{~S}$ & $\mathrm{~S}$ & $\mathrm{~S}$ & $\mathrm{~S}$ & $\mathrm{~S}$ \\
\hline Adelphia & Rps 7 & $\mathrm{~S}$ & $\mathrm{~S}$ & $\mathrm{~S}$ & $\mathrm{~S}$ & $\mathrm{~S}$ \\
\hline williams & rps-rps & $\mathrm{S}$ & $\mathrm{S}$ & $\mathrm{S}$ & $\mathrm{S}$ & $\mathrm{S}$ \\
\hline Haro (1-7) 1 & rps-rps & $\mathrm{S}$ & $\mathrm{S}$ & $\mathrm{S}$ & $\mathrm{S}$ & $\mathrm{S}$ \\
\hline
\end{tabular}

$\mathrm{S} 1,2$ y $3=$ aislamientos provenientes del SEBA, $\mathrm{N} 1$ y $2=$ aislamientos provenientes del NBA. $\mathrm{S}=$ reacción susceptible, $\mathrm{R}=$ reacción resistente, $\mathrm{I}=$ reacción intermedia. Resaltado en amarillo reacciones diferentes en dos genotipos, supuestamente con el mismo gen Rps.

\section{Relación genética entre aislamientos de $\boldsymbol{P h}$. sojae provenientes del NBA y SEBA utilizando marcadores SSRs.}

\subsection{Curva de acumulación de haplotipos:}

Los resultados muestran que la identificación de genotipos multi-locus requirió de la mayor parte de los SSRs, y de hecho no se alcanzó el plateau con los ocho microsatélites utilizados (Fig. 40). 


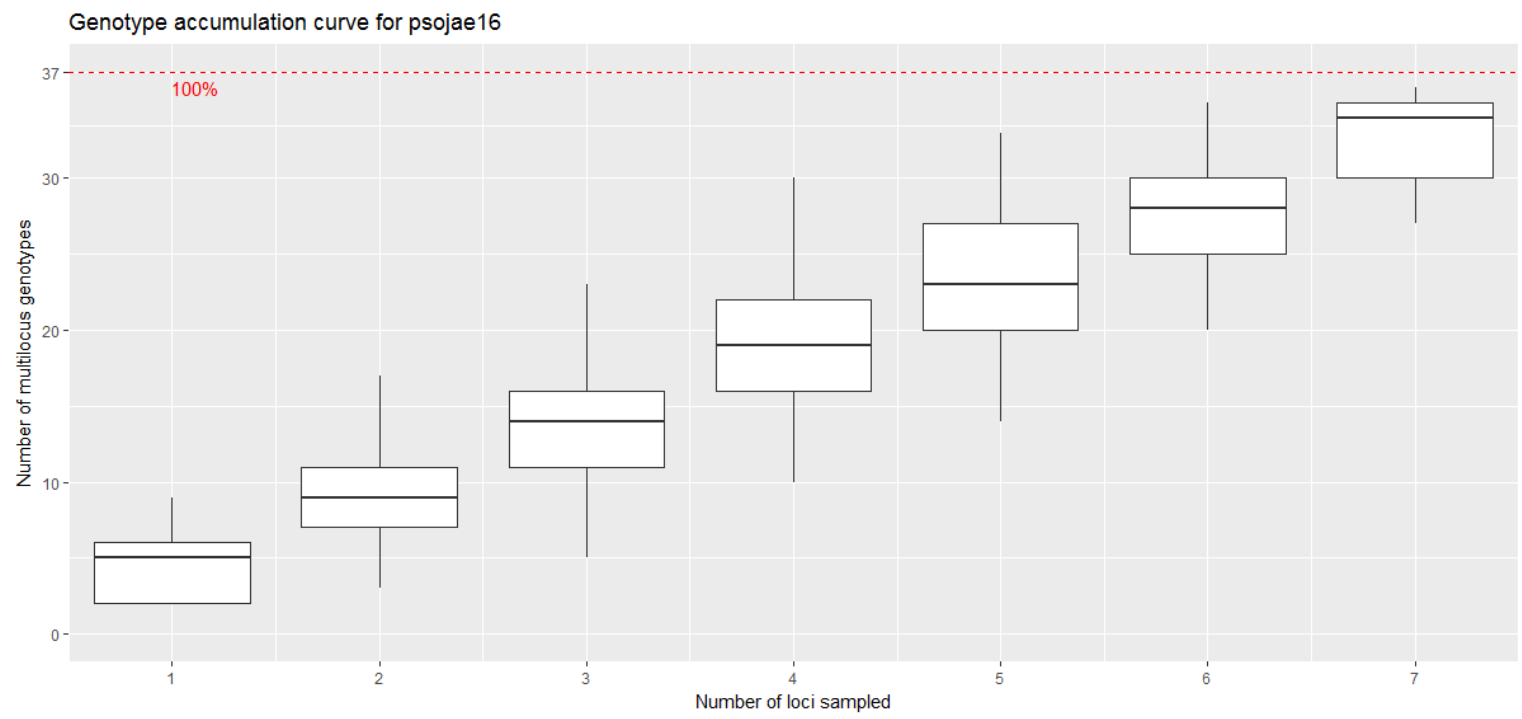

Figura 40. Curva de acumulación de genotipos para 93 aislamientos de Phytphthora sojae obtenidos del norte (NBA) y sudeste (SEBA) de la provincia de Buenos Aires entre 2013-2016.

Los tamaños de las bandas obtenidos de los 93 aislamientos de Phytophthora sojae obtenidos con los 8 Microsatélites específicos se muestran en la (Tabla 13 Anexo III) y para los ADNs de referencia compartidos por la Dra. Steward, del INIA Uruguay, se detectaron los mismos alelos, con ellos se ajustaron los tamaños alélicos obtenidos.

\subsection{Caracterización por locus:}

La Tabla 14 muestra el número de alelos por locus, que osciló entre 2 (Ps24) y 6 (Ps05 y Ps12). La media en el número de alelos fue de 4,125, con una heterocigosis observada de 0,259, lo que coincide perfectamente con la heterocigosis esperada $(0,260)$. La distribución de los alelos por locus oscilo entre 0,39 y 0,37 , con una media de 0,49 .

Tabla 14. Resumen de contenido informacional para los ocho microsatélites utilizados.

\begin{tabular}{|l|l|l|l|l|}
\hline locus & alelo & 1-D & Hesp & Evenness \\
\hline PS1 & 5,000 & 0,367 & 0,368 & 0,510 \\
\hline Ps05 & 6,000 & 0,667 & 0,670 & 0,753 \\
\hline Ps10 & 5,000 & 0,298 & 0,300 & 0,443 \\
\hline Ps12 & 6,000 & 0,336 & 0,338 & 0,485 \\
\hline PS16 & 4,000 & 0,105 & 0,105 & 0,389 \\
\hline PS24 & 2,000 & 0,021 & 0,021 & 0,355 \\
\hline Ps29 & 3,000 & 0,122 & 0,123 & 0,451 \\
\hline PS33 & 2,000 & 0,157 & 0,158 & 0,548 \\
\hline media & 4,125 & 0,259 & 0,260 & 0,492 \\
\hline
\end{tabular}

$1-\mathrm{D}=$ heterocigosis observada; Hesp= heterocigosis esperada; evenness= uniformidad 


\subsection{Diversidad haplotípica:}

El análisis de diversidad por localidad y por región muestra que existe un mínimo de tres genotipos multi-locus esperados por localidad, y de 16 por región (Tablas 15 y Fig. 41). La heterocigosis esperada promedio es de 0,26 , con un índice de uniformidad de 0,54 . Se registró un total de 37 GMLs para un total de 93 aislamientos, y un número esperado de GMLs de 7,55 para el dataset.

Tabla 15. Índices de diversidad genotípica por localidad, para 93 aislamientos analizados con ocho marcadores microsatélites.

\begin{tabular}{|c|c|c|c|c|c|c|c|c|c|c|}
\hline & Pob. & N & GML & eGML & SE & H & G & Lambda & E.5 & Hesp \\
\hline 1 & Arrecifes & 9 & 4 & 4,00 & 0,000 & 1,15 & 2,61 & 0,617 & 0,748 & 0,101 \\
\hline 2 & FAUBA & 3 & 3 & 3,00 & 0,000 & 1,10 & 3,00 & 0,667 & 1,000 & 0,208 \\
\hline 3 & Pergamino & 7 & 6 & 6,00 & 0,000 & 0,75 & 5,44 & 0,816 & 0,937 & 0,206 \\
\hline 4 & Rancagua & 7 & 6 & 6,00 & 0,000 & 1,75 & 5,44 & 0,816 & 0,937 & 0,216 \\
\hline 5 & Rojas & 6 & 5 & 5,00 & 0,000 & 1,56 & 4,50 & 0,778 & 0,930 & 0,234 \\
\hline 6 & Ramallo & 3 & 3 & 3,00 & 0,000 & 1,10 & 3,00 & 0,667 & 1,000 & 0,467 \\
\hline 7 & Villaguay & 6 & 5 & 5,00 & 0,000 & 1,56 & 4,50 & 0,778 & 0,930 & 0,335 \\
\hline 8 & Balcarce & 20 & 10 & 6,93 & 0,956 & 2,15 & 7,41 & 0,865 & 0,843 & 0,249 \\
\hline 9 & Lobería & 21 & 10 & 6,05 & 1,092 & 1,95 & 5,19 & 0,807 & 0,697 & 0,150 \\
\hline 10 & Necochea & 11 & 8 & 7,45 & 0,498 & 1,97 & 6,37 & 0,843 & 0,868 & 0,200 \\
\hline 11 & Total & 93 & 37 & 7,55 & 1,262 & 3,00 & 11,31 & 0,912 & 0,539 & 0,260 \\
\hline
\end{tabular}

Pob= localidades de cada población; GML= genotipos multi-locus observados; eGML= genotipos multilocus esperados; $\mathrm{H}=$ índice de diversidad haplotípica de Shannon-Wiener; $\mathrm{G}=$ índice de Stoddart y Taylor; Lambda= índice de Simpson; E5= índice de uniformidad; Hesp= heterocigosis esperada

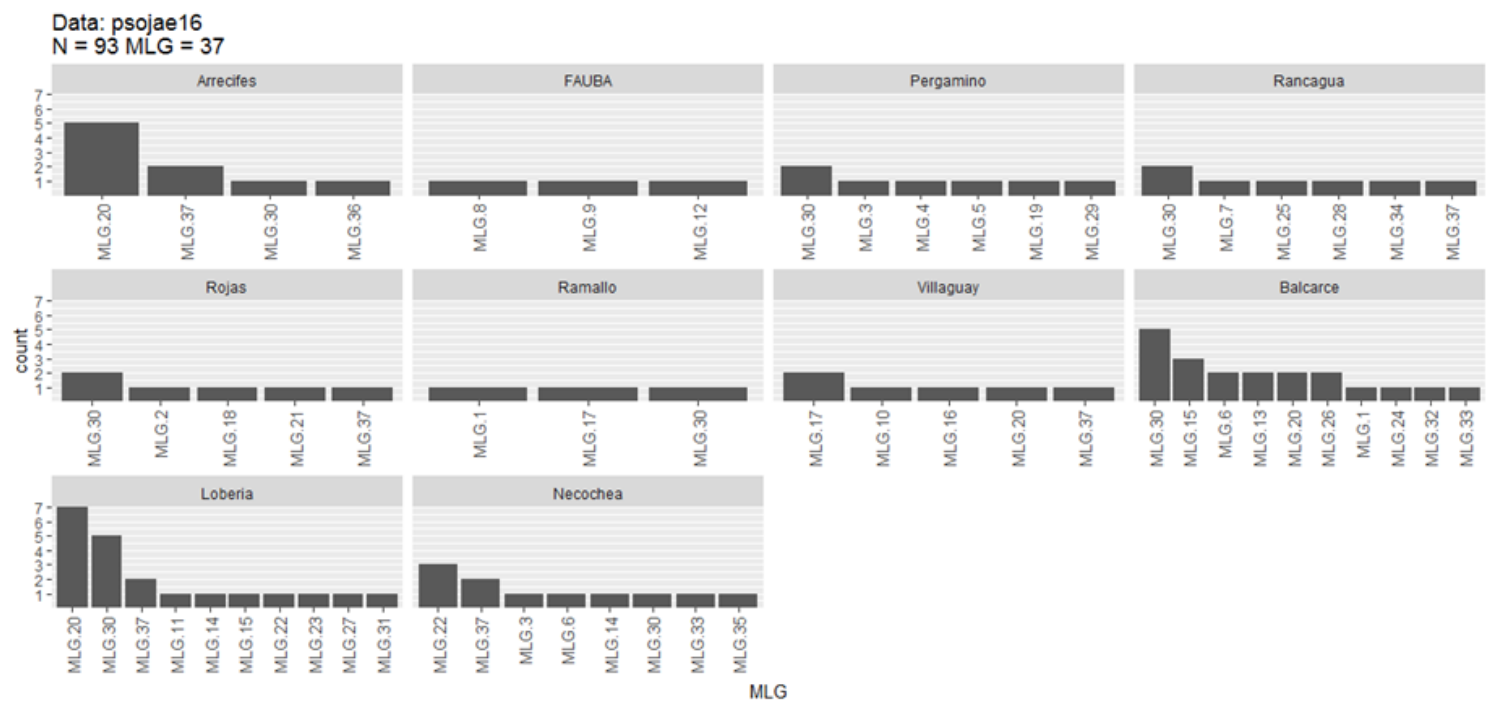

Figura 41. Cantidad de GML y número de aislamientos por GML en cada localidad, para 93 aislamientos analizados con ocho marcadores microsatélites. 


\subsubsection{Análisis por regiones:}

La región NBA resultó más diversa que la región SEBA, según se desprende de los valores de eGML (Tabla 16 y Fig. 42). Esta mayor diversidad se observa también en el valor de la heterocigosis esperada (Hesp). En el mismo sentido, se observa que la distribución de MLGs es más uniforme en el SEBA que en el NBA, ya que en la primera región se verifican seis MLGs representados por tres o más aislamientos cada uno; por el contrario, la región NBA presenta 19 de los 23 haplotipos representados por un único aislamiento.

Tabla 16. Índices de diversidad genotípica por región, para 93 aislamientos analizados con ocho marcadores microsatélites.

\begin{tabular}{|l|l|l|l|l|l|l|l|l|l|l|}
\hline & POP & N & GML & eGML & SE & H & G & Lambda & E.5 & Hesp \\
\hline 1 & NBA & 41 & 23 & 23,0 & 0,00 & 2,77 & 10,99 & 0,909 & 0,668 & 0,314 \\
\hline 2 & SEBA & 52 & 19 & 16,9 & 1,15 & 2,57 & 9,52 & 0,895 & 0,703 & 0,207 \\
\hline 3 & Total & 93 & 37 & 21,2 & 2,16 & 3,00 & 11,31 & 0,912 & 0,539 & 0,260 \\
\hline
\end{tabular}

$\mathrm{Pob}=$ población; $\mathrm{N}=$ Numero de aislamientos de Phytophthora sojae utilizados; $\mathrm{GML}=$ genotipos multilocus observados; eGML= genotipos multi-locus esperados; $\mathrm{H}=$ índice de diversidad haplotípica de Shannon-Wiener; G= índice de Stoddart y Taylor; Lambda= índice de Simpson; E5= índice de uniformidad; Hesp= heterocigosis esperada.

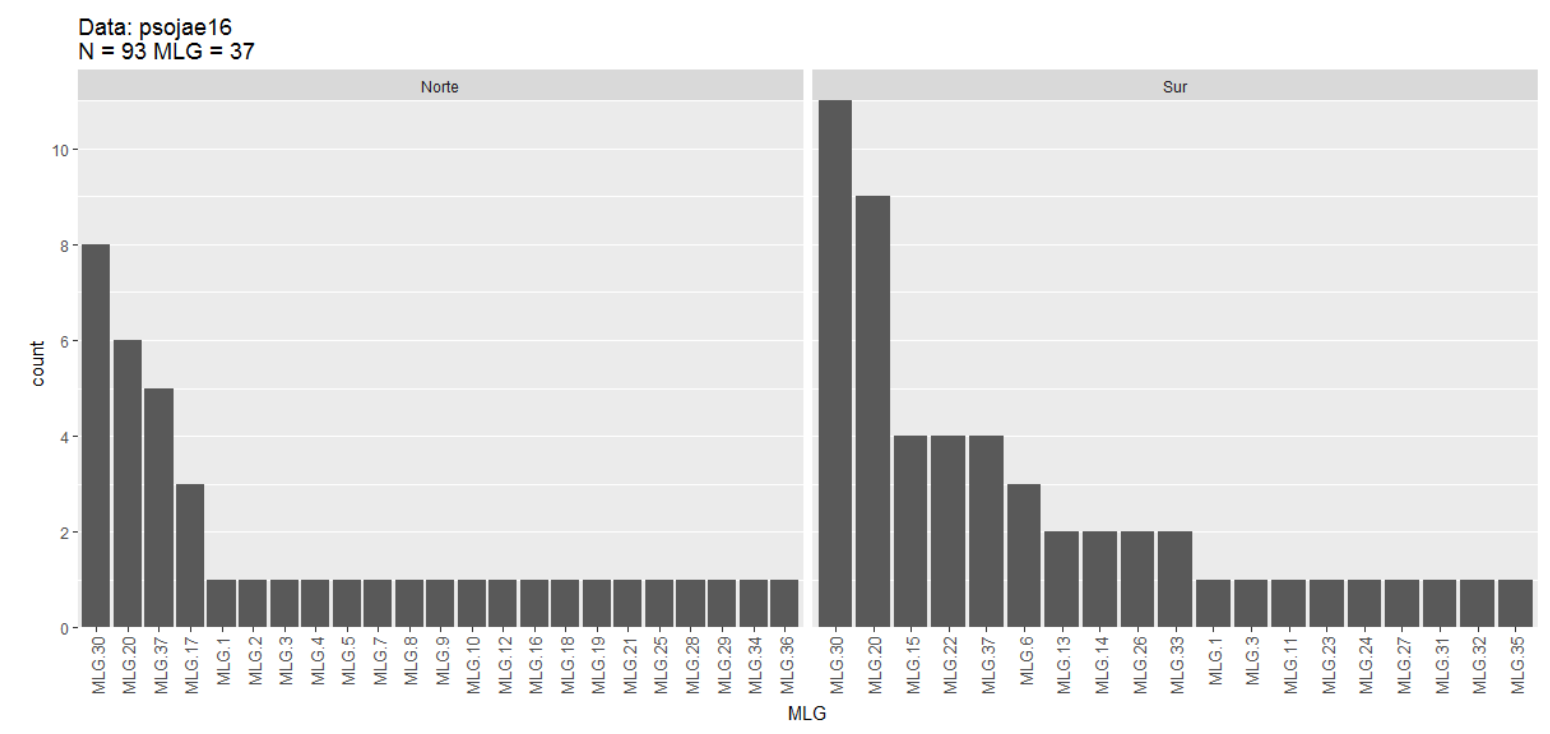

Figura 42. Cantidad de GML (genotipos multi-locus observados) y número de aislamientos por GML en cada región $($ Norte $=$ NBA y Sur $=$ SEBA) para 93 aislamientos de Phytophthora sojae analizados con ocho marcadores microsatélites.

\subsection{AMOVA}

El análisis molecular de la varianza muestra, que no existe una diferenciación en la composición genética de aislamientos entre las regiones NBA y SEBA (porcentaje de la varianza $-0,94$, lo que se interpreta como 0). El componente de varianza entre 
localidades explica el 17,94 \% de la variación; a su vez, la variación entre aislamientos dentro de localidades explica el 79,50 \% de la variación genética observada. El componente de varianza dentro de las muestras (aislamientos) aporta el 3\% restante de la variación. El análisis de significación (Tablas 18, 19 y 29 y Fig. 46. Anexo IV) muestra que tanto el componente de varianza intra-aislamiento, como entre muestras (aislamientos) dentro de localidades como entre localidades resultaron altamente significativos $(\mathrm{p}<0,001)$.

\subsection{Análisis discriminante de componentes principales (ADCP).}

El número óptimo de variables discriminantes (componentes principales) para la determinación de grupos dentro del dataset analizado fue de seis (Fig. 44). Basados en ese número de funciones discriminantes retenidas, tanto el algoritmo k-means como el análisis de DAPC propiamente dicho muestran que el número óptimo de grupos fue también de seis.

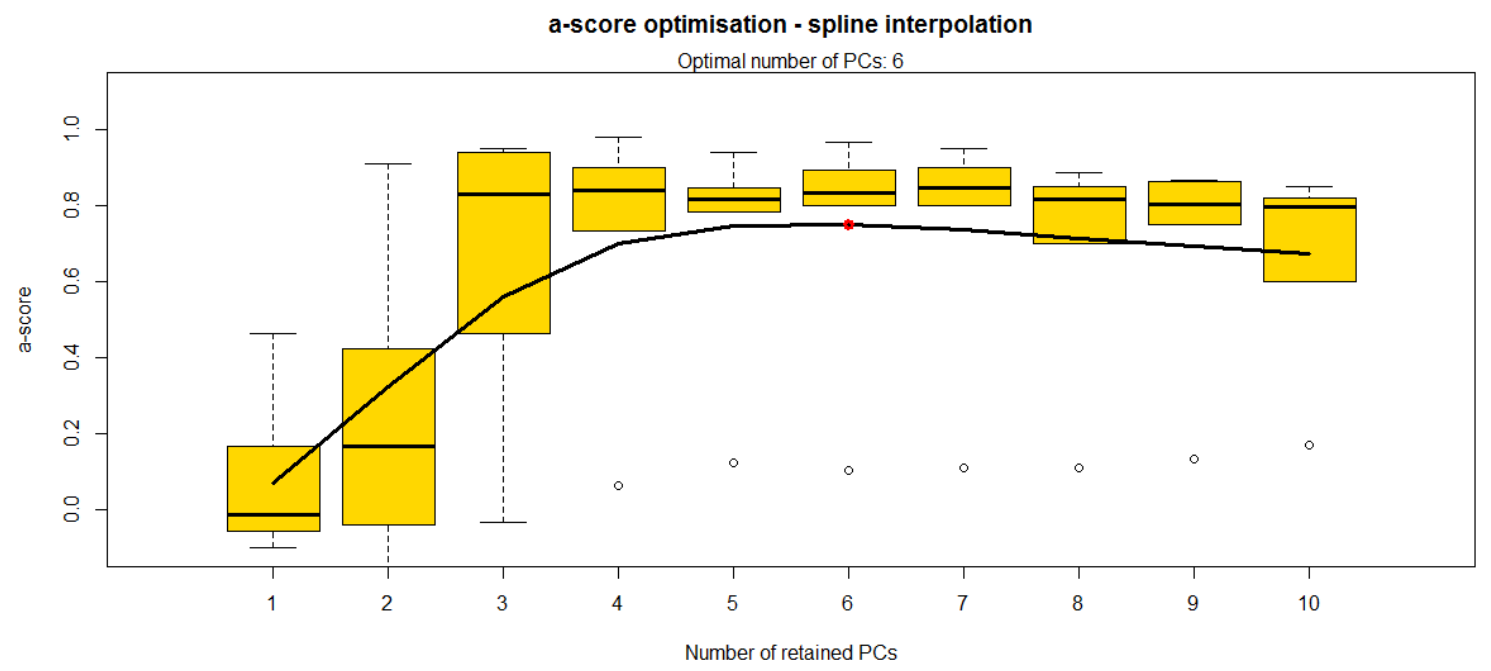

Figura 43. Algoritmo de optimización incluido en la función a-score, para 93 aislamientos de Phytophthora sojae analizados con ocho marcadores microsatélites

Los seis grupos genéticos determinados por ADCP se observan en la Fig. 44. En todos los casos menos uno los aislamientos pudieron ser asignados con un $100 \%$ de probabilidad a cada uno de los grupos respectivos. Coincidente con los resultados del AMOVA, no se registró una relación entre el origen geográfico de cada aislamiento y el 
grupo genético al que fue asignado. El número de aislamientos por grupo, por otra parte, resultó sumamente heterogéneo, oscilando entre dos (grupo 5) y 36 (grupo 3). Los grupos 1 y 2 son los más relacionados, y los grupos 4 y 5 los más distantes desde el punto de vista de su constitución genética, según lo indican las dos primeras funciones discriminantes (PCs), que explican más del $95 \%$ de la variación entre grupos.
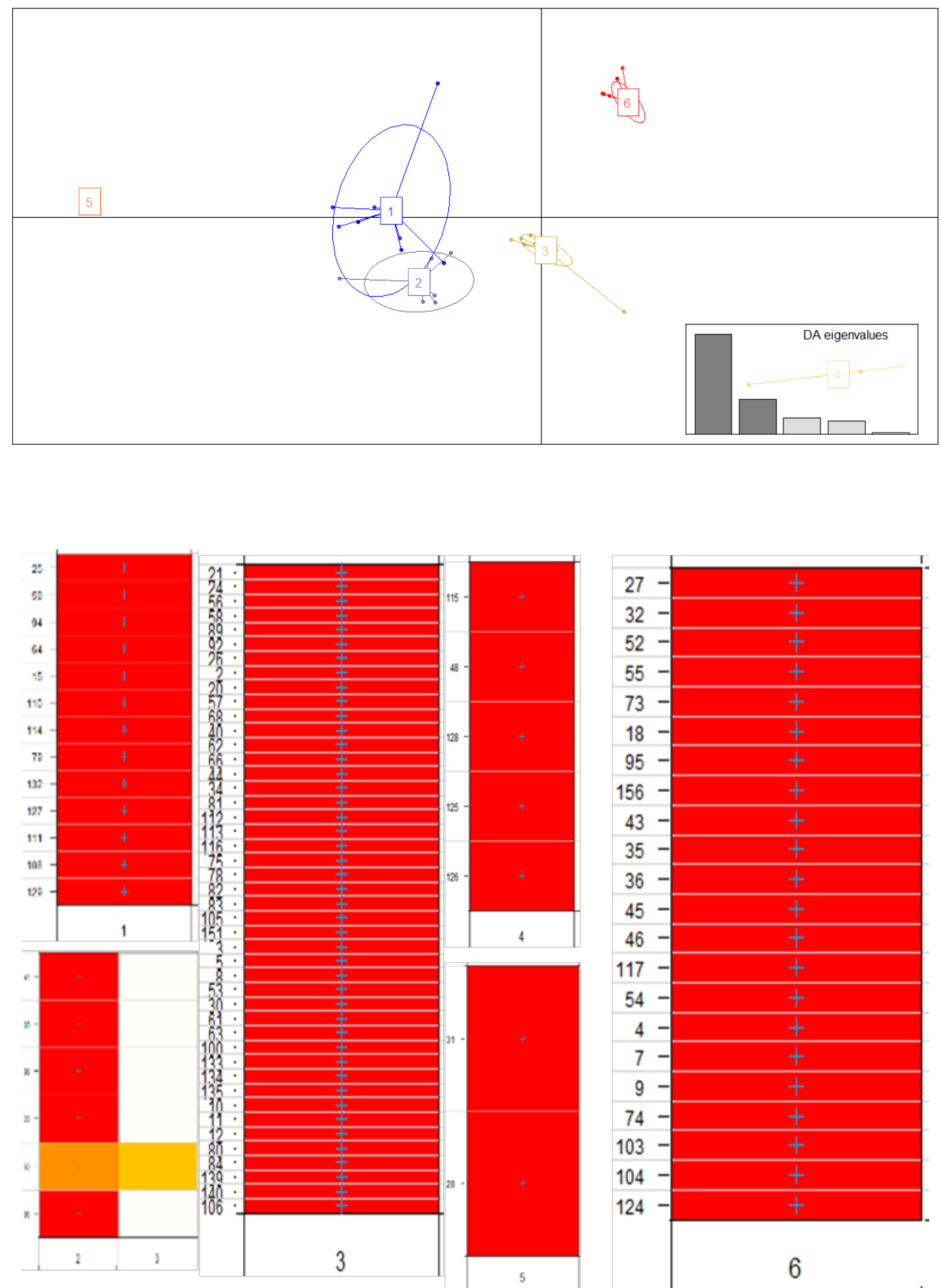

Figura 44. Grupos de similitudes genéticas determinados por DAPC, para 93 aislamientos de Phytophthora sojae analizados con ocho marcadores microsatélites. 


\subsection{Análisis de redes}

La topología (red) obtenida muestra la presencia de tres haplotipos mayoritarios (MLGs 20, 30 y 37). El esquema de colores de la Fig. 45 muestra, tal como lo indica la teoría, que esos haplotipos más frecuentes tienden a estar distribuidos en la mayor cantidad de localidades. MLG30 se encuentra en ocho de las diez localidades; MLG 20 está representado en cuatro localidades, principalmente en el SEBA (pero también en el NBA) y el MLG 37 está presente en seis localidades de ambas regiones.

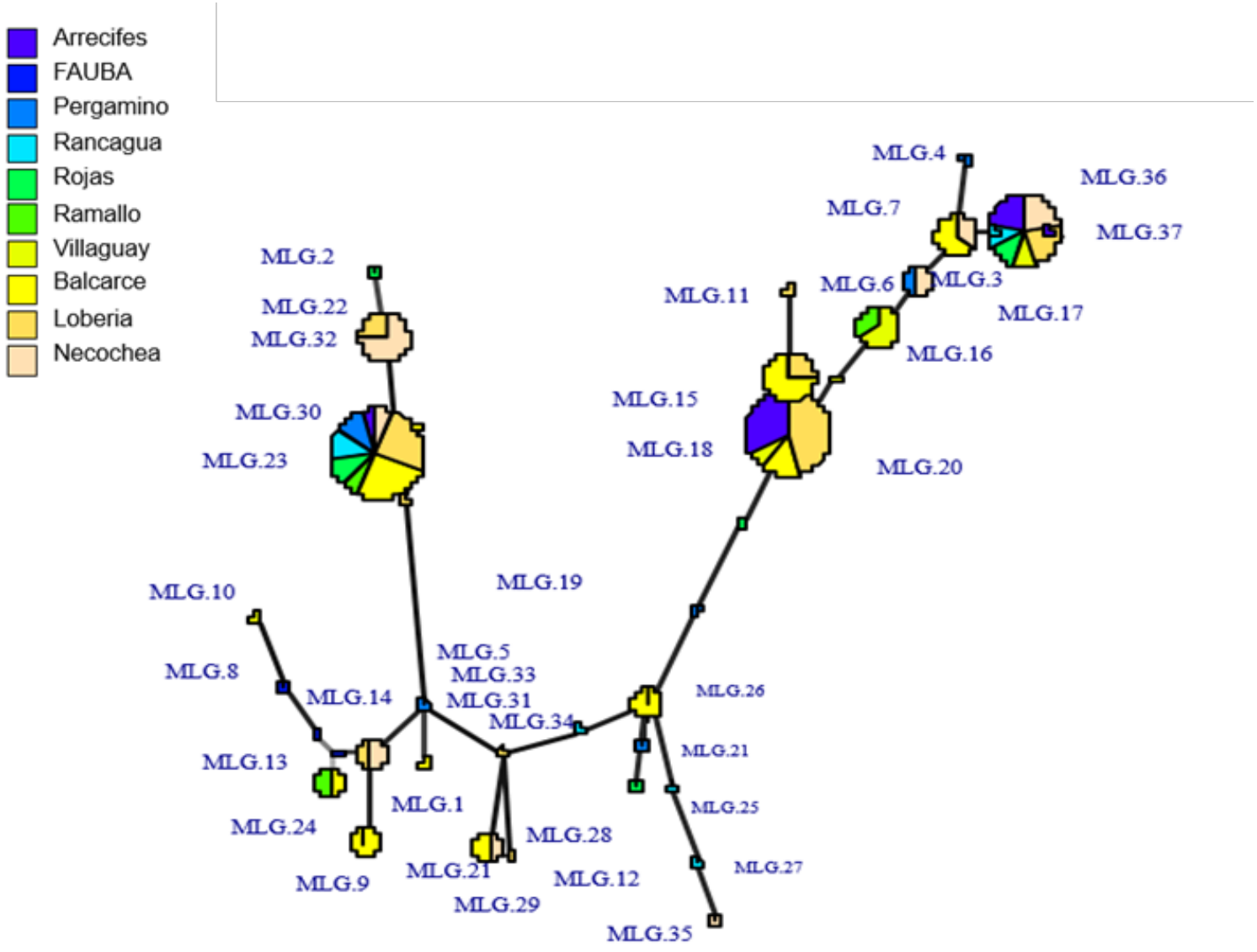

Figura 45. Análisis de redes para 93 aislamientos de Phytophthora sojae analizados con ocho marcadores microsatélites. Los diferentes colores indican las localidades y su frecuencia relativa (según la participación en cada nodo). El tamaño de cada nodo es proporcional a la frecuencia de cada genotipo multi-locus en el dataset. 


\section{DISCUSIÓN}

Los resultados de los muestreos aquí presentados apoyan la hipótesis de que en Argentina, al igual que en otros países, $P h$. sojae es un patógeno muy variable (Schmitthenner et al., 1994; Drenth et al., 1996; Dorrance et al., 2003 b; Jackson et al., 2004; Steward et al., 2016). Actualmente, todos los genes/alelos de resistencia Rps conocidos son susceptibles, lo que indica una mayor complejidad de la virulencia dentro de las poblaciones de Ph. sojae en la provincia de Buenos Aires.

Hasta el periodo 2013-2016 ningún aislamiento había quebrado los ocho genes probados, pero esto pudo determinarse en un aislamiento de suelo de muestras de Villaguay (Entre Ríos) y 7 genes $R p s$, y el Rps 6 de reacción intermedia (lo que indica una resistencia no completa de dicho gen). Se determinó también en un aislamiento de planta y uno de suelo, provenientes de Balcarce y Lobería respectivamente (SEBA), y en uno de planta proveniente de Capitán Sarmiento (NBA). Esto último sugiere la evolución de la variabilidad en la zona núcleo sojera de Argentina. Estos resultados son similares a los obtenidos en Michigan (Kaitany et al., 2001) y Arkansas (Henry y Kirkpatrick, 1995) en los Estados Unidos. Barreto et al. (1998 b) informaron un aumento de la virulencia entre 1992 y 1997; sin embargo, antes de estos estudios, el patotipo más común reportado en la región Pampeana de Argentina fue virulento sólo en $\operatorname{Rps} 7$ (raza 1). Aunque la raza 1 siguió siendo prevalente ( $25 \%$ de los aislamientos de 12 localidades muesteadas) en el periodo 1998-2004, el nivel de complejidad aumentó drásticamente en el periodo 20132016. La raza 1 dejó de ser prevalente en el NBA, donde de 68 aislamientos probados solo dos $(2,9 \%)$ resultaron ser raza 1, mientras que en el SEBA, de un total de 124 aislamientos solo cuatro $(3,22 \%)$ demostraron ser esa raza. La raza 13 , detectada por primera vez durante el periodo 1998-2004, fue la segunda más frecuente, lo que indicó que Rps 6 fue uno de los genes más quebrado, pero en 2013-2016 resultó ser el menos quebrado en ambas zonas (17,3\% en el SEBA y $15 \%$ en el NBA).

El gen Rps 1k, que ha sido universalmente utilizado en programas de mejoramiento debido a su eficacia contra 21 razas fisiológicas (Mc Blain y Schmitthenner, 1991) y sigue siendo altamente efectivo en Brasil (Costamilan et al., 2013), fue quebrado por once aislamientos de diferentes localidades, en el periodo 1998- 
2004 y en el periodo 2013-2016 fue quebrado por un 84,7 \% de los aislamientos del SEBA y por un $63,75 \%$ del NBA respectivamente. Este resultado indica que las poblaciones argentina y brasileña de $P h$. sojae probablemente no comparten el mismo origen. En contraste, aunque no hay evidencia fuerte, las poblaciones argentinas parecen tener un origen común con la población de los EEUU, porque el desarrollo de la enfermedad en ambos países ha sido similar. Los genes de resistencia más comúnmente quebrados en cultivares de soja de EEUU fueron Rps1a, Rps1c o Rps1k (Slaminko et al., 2010). En Argentina, la resistencia a $P h$. sojae comenzó a ser incluida en programas de mejoramiento en la década de 1980; los genes Rps 1a y Rps1c se incorporaron en 1984 y Rps1k en 1991 (Rossi y Nari, 1995). Sin embargo, todavía no es posible establecer una relación directa entre los genes liberados y la distribución de su eficacia como ocurrió en los EEUU. Recientemente Stewart et al. (2014) informaron que los cambios en la estructura del patotipo no eran necesariamente una función del tipo de resistencia que se estaba quebrando; Ph. sojae tiene el potencial de cambiar patotipos o de desarrollar nuevos genotipos muy rápidamente; sin embargo, no ha sido posible demostrar que el cambio sea una función del gen Rps utilizado. Por lo tanto, el uso excesivo de un gen Rps no necesariamente parece ser la principal razón para los cambios en la estructura patotípica de este patógeno.

Se observó variabilidad genética intraespecífica entre aislamientos de $P h$. sojae del mismo origen geográfico, tanto en Argentina (Gally et al., 2007) como en diferentes Estados de EEUU, Ohio (Dorrance et al., 2003 b), Arkansas (Jackson et al., 2004), Illinois (Malvick y Grunden, 2004) y Dakota del Norte (Nelson et al., 2008). Así como se informó en Brasil (Costamilan et al., 2013), el aumento de la complejidad de la virulencia encontrado en este estudio es probablemente el resultado de un largo período de producción continua de cultivares de soja con genes Rps y la gran adopción del sistema de siembra directa en ambos países. La presión de selección ha sido seguramente inducida por cultivares con virulencia creciente a un mayor número de genes Rps, posiblemente potenciado por una población local de tipo salvaje (Drenth et al., 1996). Esta conclusión se apoya en el hecho de que el patógeno se encontró en suelos que nunca habían sido cultivados previamente con soja (localidad de Pilar, provincia de Buenos Aires).

La posibilidad de apilar genes de resistencia Rps 1k con Rps 3a, Rps 6 o Rps 8 (ninguno de estos últimos se han utilizado para controlar esta enfermedad en Argentina), podría ser altamente eficaz como lo sugieren Kaitany et al. (2001) y Cochran y Abney (1999). Las Fig. 15 y 16 pueden indicar otras combinaciones de genes que serían efectivas 
contra la mayoría de las razas. Sin embargo, en este proceso, se debe tener cuidado de combinar estos genes Rps en cultivares con altos niveles de resistencia parcial o no específica a la raza, para evitar una presión de selección que podría conducir a un cambio en la composición de la virulencia del patógeno (Dorrance y St Martin, 2000; Grijalba y Barreto, 2002). En los últimos 15 años, un número de patólogos y criadores de plantas han expresado su preferencia por el uso de resistencia parcial, descrita como la capacidad de las plantas para sobrevivir a la infección patógena sin mostrar síntomas severos de enfermedad o pérdida de rendimiento (Tooley y Grau, 1984; Dorrance et al., 2003 a; Zhang et al., 2010) y en nuestro país es un tema que los semilleros están empezando a tener en cuenta. Los datos resultantes de esta investigación son esenciales para los programas de mejoramiento, lo que conduce a una selección de programas de genes Rps efectivos para el desarrollo de cultivares que, combinados con altos niveles de resistencia parcial junto con otras medidas de control, deberían proporcionar una mejor protección contra la enfermedad.

\section{Relación genética entre aislamientos de $P h$. sojae provenientes del NBA y SEBA utilizando marcadores SSRs}

Los resultados de la curva de acumulación de genotipos sugieren que la variación real del genoma no puede ser representada sólo con estos ocho marcadores microsatélites (no pudo alcanzarse el plateau del $100 \%$ de los posibles genotipos con ese juego de marcadores). Esto sugiere que el nivel de variación en los aislamientos de Ph. sojae muestreados es alto, y que sería conveniente incrementar el número de loci a evaluar, ó incorporar también el uso de secuencias genéticas de loci particulares para evaluar la estructura genética del patógeno. Por su parte Steward et al. (2016), midieron la diversidad genotípica de ciertos aislamientos provenientes de Iowa, Ohio, y Dakota del Sur (EEUU) mediante el uso de 21 marcadores de microsatélites dentro de los que están incluidos los ocho aquí utilizados. También encontraron un alto nivel de diversidad de patotipos y un bajo a moderado nivel de diversidad genotípica entre las poblaciones tanto para las comparaciones entre estados como para la variación dentro de lotes. Sugieren que cierto flujo de genes ocurre entre lotes vecinos, pero no a través de regiones, lo que daría una gran probabilidad de que cada región tenga sus propias poblaciones, lo que no ha quedado demostrado entre la zona NBA y SEBA donde las poblaciones resultaron ser similares. 
La cantidad de alelos registrada para los diferentes SSRs (entre dos y seis), así como los valores obtenidos en los diversos índices de diversidad (heterocigosis observada y esperada, "eveness") muestran que, si bien estos ocho loci no han resultado suficientes para un análisis exhaustivo de la variación genética en este grupo de patógenos para la región, los mismos resultan de utilidad y pueden ser a futuro incluidos con éxito en un juego de marcadores más amplio, que permita continuar investigando la estructura y dinámica de la variación genética de $P h$. sojae en la región.

Stewart et al. (2011) señalan que a mayor tamaño del producto de PCR, mayores serán las diferencias de pares de bases entre los sistemas que usan capilares específicamente. Esto se verifica en los resultados obtenidos en el presente estudio, según se señala más arriba.

Los ADNs de referencia de EEUU sirvieron para validar los tamaños alélicos obtenidos en el análisis aquí realizado, y habilita futuros estudios comparativos entre diferentes poblaciones del continente (por ejemplo, EEUU, Uruguay y Argentina).

El análisis de diversidad, indica que existen numerosos genotipos multi-locus, por cada unidad de muestreo, en los dos niveles jerárquicos analizados. Esto sugiere que existen múltiples eventos de entrada de $P h$. sojae a cada localidad y región, con posterior multiplicación dentro de los lotes, tanto por vía asexual como sexual. Esta hipótesis se ve reforzada por el hecho de que la variación intra-muestral explica sólo el $3 \%$ de la variación total. Este resultado se condice con posibles, numerosas vías de transporte del patógeno entre sitios de producción (maquinaria agrícola, ropa, dispersión a corta y media distancia por riego y arroyos, semilla, etc). Zhaohui y Jin (1999) demostraron la transmisión de Ph. sojae, por semilla de soja y en Argentina, Schulz et al. (1989), citan muy bajos porcentajes de transmisión del patógeno por esta vía. En el presente trabajo no se pudo corroborar este tipo de transmisión del patógeno, y si bien algunas de las metodologías utilizadas en patología de semillas usan medio de cultivo (ISTA, 2013), estos son medios generales, principalmente APD. Este patógeno no crece en dicho medio, por lo que las metodologías de determinación deberían ajustarse y utilizar medios selectivos, principamente AV8 o LBA con el agregado de fungicidas y bactericidas.

Las múltiples vías de movilidad del patógeno pueden explicar la ausencia de estructura detectada en el AMOVA cuando se analiza el componente de la varianza entre regiones. Los valores significativos para los componentes de varianza entre localidades, y entre muestras dentro de localidades pueden explicarse a partir del bajo número muestral para estos niveles jerárquicos; esto es, el bajo número de aislamientos analizado 
para cada localidad implica en sí un error de muestreo que hace que las mismas no sean representativas de la variabilidad real de cada locación. Esto sugiere la necesidad de mayores esfuerzos de muestreo a futuro, si se considera de utilidad el conocimiento acabado de la variación por localidad, para el manejo adecuado y sustentable de este patógeno de la soja.

La dispersión de los GML más numerosos en un alto número de las localidades analizadas se explica, por su parte, debido a que los aislamientos más frecuentes son habitualmente los más antiguos y habrían tenido por tanto más tiempo para multiplicarse, y para dispersarse por la geografía (Templeton, 1998). 


\section{CONCLUSIONES GENERALES}

$\checkmark$ De ambas zonas y de todos los lotes muestreados pudo aislarse al menos una especie de Pythium o de Phytopythium, siendo las prevalentes $P$. ultimum y $P$. irregulare.

$\checkmark$ Diversos sitios de la provincia de Buenos Aires albergan poblaciones diversas de Oomycetes de los géneros Pythium y Phytopythium.

$\checkmark$ Entre las especies de Oomycetes caracterizadas, $P$. ultimum sensu lato, $P$. irregulare, $P$. sylvaticum, $P$. aphanidermatum y $P$. paroecandrum resultaron ser las más patógenas en soja.

$\checkmark$ En el marco del presente estudio fueron caracterizadas e identificadas para la Argentina, como especies de Pythium, citadas por primera vez asociadas con el cultivo de soja, $P$. acanthicum, $P$. aphanidermatum, $P$. catenulatum, $P$. dissotocum, $P$. nunn, $P$. longandrum, $P$. paroecandrum y $P$. aff. heterothallicum y Phytopytium chamaehyphon, Phy. helicoides, Phy. aff. mercuriale, Phy. frezzii sp. nov y Phy. vexans.

$\checkmark$ Este es el primer reporte de $P$. nunn, $P$. longandrum, $P$. paroecandrum y $P$. aff. heterothallicum, para la Argentina, así como del género Phytopythium.

$\checkmark$ Las especies de Pythium no-patógenas, P. nunn, P. acanthicum y P. periplocum, han sido citas como microorganismos utilizados en control biológico, por lo que constituyen un insumo para el desarrollo del mismo a nivel local.

$\checkmark$ La patogenicidad o virulencia de los Oomycetes $P$. ultimum, $P$. irregulare y $P$. aphanidermatum es función de la temperatura.

$\checkmark$ El fungicida curasemillas metalaxil continúa siendo la molécula sintética más eficiente para controlar las especies de Pythium que atacan la soja. 
$\checkmark$ Las poblaciones de $P h$. sojae presentaron una alta complejidad quebrando genes/alelos de resistencia presentes o no, en los cultivares comerciales de soja.

$\checkmark$ Las poblaciones de $P h$. sojae son complejas y no están estructuradas geográficamente.

$\checkmark$ Las identificaciones realizadas de las especies de Pythium y Phytopythium, y la determinación de las razas de $P h$. sojae, significan un aporte al conocimiento de la biodiversidad de estos Oomycetes asociados al cultivo de soja, en gran parte de la provincia de Buenos Aires, lo que será de gran utilidad para el manejo de las enfermedades que ellos ocasionan. 


\section{BIBLIOGRAFIA}

AAPRESID. 2009. Evolución de la superficie en siembra directa. (Período 77/01). (Disponible: www.aapresid.org.ar/apadmin/img/upload/evolucion.xls Consultado: diciembre de 2014).

Abad GZ. 2010. How to avoid misidentifying your isolates: The value of the Morphological / Phylogenetic Key of Phytophthora extypes and neotypes. Phytopathology 100:S150.

Abad GZ, de Cock AWAN, Bala K, Robideau GP, Lodhi AM \& Lévesque A. 2010. Phytopythium gen. nov. Persoonia: 24: 127-139. Fungal Planet: 49.

Abad ZG, Shew HD \& Lucas LT. 1994. Characterization and pathogenicity of Pythium species isolated from turfgrass with symptoms of root and crown rot in North Carolina. Phytopathology 84: 913-921.

Abad ZG. 2014. The taxonomy of Phytophthora: What is done and whats is needed for the correct identification and diagnostics of species in the Genus. $7^{\text {th }}$ IUFRO Working Party 7.02.09. Phytophthora in Forest \& Natural Ecosystems. 10-14 de noviembre de 2014. Esquel, Chubut, Argentina. Libro de Res.: 28.

Abbott WS. 1925. A method of computing the effectiveness of an insecticide. J. Econ. Entomol. 18:265-267.

Abdelzaher HMA, Ichitani T \& Elnaghy AM. 1994. Virulence of Pythium spp. isolated from pond water. Mycoscience 35: 429-432.

Abney TS, Melgar JC, Richards TL, Scott DH, Grogan J \& Young J. 1997. New Races of Phytophthora sojae with Rps1-d Virulence. Plant Disease 81 (6):653-655.

Agrios GN. Plant Pathology. 5thed. Academic Press, San Diego, 2005, 922p.

Alexopoulos CJ, Mims CW \& Blackwell M. 1996. Introductory Mycology. $4^{\text {th }}$ edn. John Wiley \& Sons, Inc., New York. 868 pp.

Al-Sheikh H \& Abdelzaher Hani MA. 2012. Occurrence, Identification and pathogenicity of Pythium aphanidermatum, P. diclinum, P. dissotocum and Pythium "Group P" isolated from Dawmat Al Jandal Lake, Saudi Arabia. Research Journal of Environmental Sciences 6:196-209.

Ali-Shtayeh MS \& Saleh ASF. 1999. Isolation of Pythium acanthicum, P. oligandrum, and $P$. periplocum from soil and evaluation of their mycoparasitic activity and biocontrol efficacy against selected phytopathogenic Pythium species. Mycopathologia 145: 143-153

Altschul SF, Madden TL, Schaffer AA, Zhang J, Zhang Z, Miller W \& Lipman DJ. 1997. Gapped BLAST and PSI-BLAST: a new generation of protein database search programs. Nucleic Acid Research 25: 389-402.

Anderson TR \& Buzzell RI. 1982. Efficacy of metalaxyl in controlling Phytophthora root and stalk rot of soybean cultivars differing in field tolerance. Plant Dis. 66: 1144-1145.

Anderson TR \& Tenuta A. 2003. Phytophthora rot. In: Bailey KL, Gossen BD, Gugel RK, Morrall RAA, (eds). Diseases of field crops in Canada. Saskatchewan, Saskatoon, Canada, CPS Press.

Anderson TR \& Buzzell RI. 1992. Diversity and frequency of races of Phytophthora megasperma f. sp. glycinea in soybean fields in Essex County, Ontario, 1980-1989. Plan Dis. 76: 587-589. 
Ark PA \& Middleton JT. 1949. Pythium black rot of Cattleya. Phytopathology 39:10601064.

Bala K, Robideau GP, Lévesque A, de Cock AWAM, Abad ZG, Lodhi AM, Shahzad S, Ghaffar A \& Coffey MD. 2010. Phytopythium sindhum. Fungal Planet 49, Persoonia 24: 136-137.

Baldauf SL, Roger AJ, Wenk-Siefert I \& Doolittle WF. 2000. A Kingdom-level phylogeny of Eukaryotes based on combined protein data. Science 3: 972-977.

Bardín A. 2010. Relevamiento de enfermedades de trigo y evaluación de la aplicación de fungicida en el control de patógenos foliares en la zona norte de la provincia de Buenos Aires. Trabajo final para optar al título de Ing. Agrónomo. FAUBA. 42 pp.

Barr DJS. 1983. The zooporic grouping of plant pathogens: entity or non entity. Pp. 4383. In: Zoosporic Plant Pathogens, A Modern Perspective. Buczacki ST (Ed.). Academic Press, London, UK. 352 pp.

Barr DJS. 1992. Evolution and kingdoms of organisms from the perspective of a mycologist. Mycología 84: 1-11.

Barreto D, Grijalba P, Gally M, Vallone S \& Ploper D. 1998 (b). Prevalencia de Phytophthora sojae en la Región Pampeana Norte de Argentina, caracterización de razas y reacción de cultivares. Fitopatol bras 23:54-57.

Barreto D, Anderson TR, Gally M. \& Grijalba P. 1998 (a). Evaluation of Phytophthora sojae from Argentine soybean fields (Abstr.). In: BSPP. (ed) Proc. 7th International Congress of Plant Pathology, 9-16 Agosto 1998. Edimburgo, Escocia 1: 6.72.

Barreto D, Stegman B \& Fortugno C. 1991. Phytophthora megasperma f.sp. glycinea: Detección y virulencia del patógeno. En Actas Primera Reunión Nacional de Oleaginosas, pp 304-311.

Barreto D, Stegman B \& Fortugno C. 1995. Races of Phytophthora sojae in Argentina and reaction of soybean cultivars. Plant Disease 79: 599-600.

Bartnicki-Garcia S. 1969. Cell wall differentiaton in the Phycomycetes. Phytopathology 59: 1065-1071.

Bartnicki Garcia S \& Wang MC. 1983. Biochemical aspects of morphogenesis in Phytophthora. Pp 121 -137. In: Phytophthora: Its Biology, Taxonomy, Ecology and Pathology. Erwin DC, Bartnicki-Garcia S \& Tsao PH (Eds.). American Phytopathologycal Society, St Paul, Minnesota 392 pp.

Bartnicki Garcia S. 1987. The cell wall: a crucial structure in fungal evolution. Pp. 389403 In: Evolutionary Biology of the Fungi. Rayner ADM, Brasier CM \& Moore D (Eds.). Cambridge Press, UK. 477pp.

Beakes G \& Sekimoto S. 2009. The evolutionary phylogeny of Oomycetes-insights gained from studies of holocarpic parasites of algae and invertebrates. Pp: 1-24. In: Oomycete Genetics and Genomics: Diversity, Interactions, and Research Tools. Lamour K \& Kamoun S. (Eds.) John Wiley \& Sons, New York. 602 pp.

Beakes GW \& Thines M. 2016. Hyphochytriomycota and Oomycota. In: Archibald J. et al. (eds) Handbook of the Protists. Springer, Cham. pp 1-71

Blackwell M. 1949. Terminology in Phytophthora. CMI. Mycolgical Papers. № 30. 24pp.

Blair JE, Coffey MD, Sook-Young Park, Geiser DM \& Seogchan Kang. 2008. A multilocus phylogeny for Phytophthora utilizing markers derived from complete genome sequences. Fungal Genetics and Biology 45: 266-277.

Brasier CM. 1992. Evolutionary biology of Phytophthora, Part I: Genetic system, sexuality, and the generation of variation. Annual Review of Phytopathology 30: 153171. 
Broders KD, Lipps PE, Paul PA \& Dorrance AE. 2007. Characterization of Pythium spp. associated with corn and soybean seed and seedling disease in Ohio. Plant Dis 91(6):727-735.

Buisman CJ. 1927. Root rots caused by Phycomycetes. Mededelingen Phytopathologisch Laboratorium "Willie Commelin Scholten". 11:1-51

CABI. 1981. Pythium ultimum. Distribution Maps of Plant Diseases. Map 207 (Edition 4). (En http://www.cabi.org, consultado marzo de 2016).

CABI/EPPO. 2011. Pythium irregulare. Distribution Maps of Plant Diseases. Map 206 (5 ed.). (En: http://www.cabi.org/isc/abstract/20113091526, consultado 12 de febrero de 2015).

Campbell WA \& Hendrix FF. 1967. Pythium and Phytophthora species in forest soil in the south-eastern Unites States. Plant Diseases Reporter 52: 929-932.

Carmona M \& Melo Reis E. 2012. Enfermedades en cultivos bajo siembra directa en Argentina y Brasil: pasado, presente y prospectivas de manejo. Revista soja en Siembra directa AAPRESID. Pp 48-55.

Carmona M, Gally M, Grijalba P \& Sautua F. 2015. Evolución de las enfermedades de la soja en la Argentina: pasado, y presente. Aportes de la FAUBA al manejo integrado. Rev. Agronomía \& Ambiente 35(1): 37-52.

Carmona M, Gally M, Grijalba P \& Sautua F. 2017. Guia de Fitopatología de la Facultad de Agronomía de la Universidad de Buenos Aires, 2da entrega, Enfermedades de oleaginosas, Enfermedades de soja, pp 46-53

Carranza JM. 1979. Lista de las principales causas de enfermedades de los cultivos hortícolas en la República Argentina. Serie Técnica №1. Ministerio de Economía, Subsecretaria de Asuntos Agrarios, Dirección de Agricultura. EEA Gorina.

CASAFE. 2007. Cámara de Sanidad Agropecuaria y Fertilizantes de la República Argentina. Guía de Productos Fitosanitarios. p. 2248.

Cavalier-Smith T. 1986. The kingdom Chromista: origin and systematics, in: Progess in Phycological Research. Round FE and Chapman DJ (eds.), Vol. 4, pp. 309-347, Biopress Ltd., Bristol.

Cianzio SR, Shultz SP, Fehr WR \& Tachibana H. 1991. Registration of 'Archer' Soybean. Crop. Sci. 31 (6): 1707.

Cochran AJ \& Abney TS. 1999. Rps gene combinations needed to control diverse pathotypes of Phytophthora sojae. Phytopathology 89:S104.

Collado-Romero M, Mercado-Blanco J, Olivares-García C, Valverde-Corredor A \& Jiménez-Díaz RM. 2006. Molecular Variability Within and Among Verticillium dahlia Vegetative Compatibility Groups Determined by Fluorescent Amplified Fragment Length Polymorphism and Polymerase Chain Reaction Markers. Phytopathology: 96 (5) 485-495

Cooke DEL, Drenth A, Duncan JM, Wagels G \& Brasier CM. 2000. A molecular phylogeny of Phytophthora and related Oomycetes. Fungal Genetics and Biology 30:17-32.

Costamilan LM, Clebsch CC, Soares RM, Seixas CDS, Godoy CV, Dorrance AE. 2013. Diversity of Phytophthora sojae pathotypes from Brazil. European J. of Plant Pathol. Eur J Plant Pathol 135:845-853.

Davidson JM, Rehner SA, Santana M, Lasso E, Urena de Chapet O \& Herre EA. 2000. First report of Phytophthora heveae and Pythium spp on tropical tree seedlings in Panama. Plant Disease 84: 706.

de Cock A, Bala K, Rintoul TL, Robideau GP, Abad ZG, Lodhi AM, Coffey MD \& Lévesque CA. 2015. Molecular phylogeny and new combinations for the genus Phytopythium.

Persoonia

34:

$25-39$. 
(En:http://www.ingentaconnect.com/content/nhn/pimj/pre-prints/contentnbc Persoonia 0289)

Desjardins PR, Zentmyer GA \& Reynolds DA. 1969. Electronic microscopic observations of the flagellar hairs of Phytophthora palmivora zoospores. Canadian Journal of Botany 47: 1077-1079.

Di Rienzo JA, Casanoves F, Balzarini MG, Gonzalez L, Tablada M \& Robledo CW. InfoStat versión 2015. Grupo InfoStat, FCA, Universidad Nacional de Córdoba, Argentina. URL http://www.infostat.com.ar.

Dick MW. 1990. Keys to Pythium. Department of Botany, School of Plant Science, University of Reading, Reading, UK. 64 pp.

Dick MW. 2001. Straminipilous Fungi: Systematics of the Peronosporomycetes including accounts of the marine straminipilous protists, the plasmodiophorids and similar organisms. Kluwer Academic Publishers. The Netherlands. 670 pp.

Distefano SG. 2013. Informe sanitario de la campaña de soja 2012/13; Detalle de las enfermedades detectadas durante la última campaña en el sudeste de la Provincia de Córdoba. Publicado: 26 de Abril de 2013, publicaciones INTA. Pp 2

Donahoo R, Blomquist CL, Thomas SL, Moulton JK, Cooke DEL \& Lamour KH. 2006. Phytophthora foliorum sp. nov., a new species causing leaf blight of azalea. Mycological Research 110: 1309-1322.

Dorrance AE \& St. Martin S. 2000. Phytophthora sojae: Is it time for a new approach? APSnet Features. Consultado Julio, 2014 de http://www.apsnet.org/publications/ apsnetfeatures/Pages/PhytophthoraSojae.aspx

Dorrance AE, McClure SA \& St. Martin SK. 2003 a. Effect of partial resistance on Phytophthora stem rot incidence and yield of soybean in Ohio. Plant Disease 87 (3):308

Dorrance AE, McClure SA \& deSilva A. 2003 b. Pathogenic diversity of Phytophthora sojae in Ohio soybean fields. Plant Disease 87 (2):139-146.

Dorrance AE, Jia H \& Abney TS. 2004. Evaluation of soybean differentials for their interaction with Phytophthora sojae. consultado Octubre, 2014. De http://www.plantmanagementnetwork.org/pub/php/research/2004/psojae/.

Dorrance AE \& Grunwald N. 2009. Phytophthora sojae: diversity among and within populations. in: Oomycetes genetics and genomics: diversity, interactions, and research tools, K. Lamour, and Kamoun, S., ed. John Wiley and Sons, Inc., Hoboken, New Jersey.

Drenth A, Whisson SC, Maclean DJ, Irwin JAG, Obst NR \& Ryley MJ. 1996. The evolution of races of Phytophthora sojae in Australia. Phytopathology 86:163-169

Erwin DC \& Ribeiro OK. 1996. Phytophthora diseases worlwide. American Phytopathological Society, St. Paul, Minnesota.

Excoffier L, Smouse PE \& Quattro JM. 1992. Analysis of molecular variance inferred from metric distances among DNA haplotypes: application to human mitochondrial DNA restriction data. Genetics, 131, 479-491.

Fang JG \& Tsao PH. 1994. Evaluation of Pythium nunn as a Potential Biocontrol Agent Against Phytophthora Root Rots of Azalea and Sweet Orange. Phytopathology 85:2936.

Farr DF \& Rossman AY. 2012. Fungal Nomenclature Database, Systematic 10 Mycology and Microbiology Laboratory, ARS, USDA. (En:http://nt.ars11grin.gov/, consultado marzo de 2016).

Fehr WR \& Caviness CE. 1977. Stages of soybean development. Ames, IA, USA, Spec. Rep.80. Iowa Agric. Home Econ. Exp. Stn. Iowa State Univ. 
Felsenstein J. 1985. Phylogenies and the comparative method. American Naturalist 126:125.

Ferro CR, Hill CB, Miles MR \& Hartman GL. 2006. Evaluation of soybean cultivars with the Rps $1 \mathrm{k}$ gene for partial resistance or field tolerance to Phytophtora sojae. Crop Science 46:2427-2436.

Fitzpatrick HM. 1923. Generic concepts in the Pythiaceae and Blastocladiaceae. Mycologia. 15(4):166-173

Flor H. 1971. Current status of the gene-to-gene concept. Annual Rev. Phytopathology 9:275-296.

Forster H, Tyler BM \& Coffey MD. 1994. Phytophthora sojae races have arisen by clonal evolution and by rare outcrosses. MPMI 7 (6):780-791.

Frezzi MJ. 1950. Las especies de Phytophthora en la Argentina. Revista de Investigaciones Agrícolas 4: 47-133.

Frezzi MJ. 1956. Especies de Pythium fitopatógenas identificadas en la República Argentina. Revista de Investigaciones Agrícolas 10: 113-241.

Frezzi MJ. 1977. Especies del género Pythium y Phytophthora fitopatógenas identificadas en Argentina. Córdoba: Universidad Nacional de Córdoba. Instituto de Ciencias Agronómicas. 82 pp.

Fry WE \& Grünwald NJ. 2010. Introducción a los Oomicetes. Trans. Alberto J. ValenciaBotín. 2012. The Plant Health Instructor. DOI:10.1094/PHI-I-2012-0220-01

Gallegly ME \& Hong C. 2008. Phytophthora: Identifying Species by Morphology and $D N A$. APS. Press. St. Paul, MN. 158 pp.

Gally M, Ramos AM, Dokmetzian D \& Lopez SE. 2007. Genetic variability of Phytophthora sojae isolates from Argentina. Mycologia 99:813-819.

Gally M, Grijalba P \& Barreto D. 1999. "Investigación sobre Phytophthora sojae (campaña 1997/98): Relevamiento, aislamiento y prueba de material genético". Actas X Jornadas Fitosanitarias Argentinas, San Salvador de Jujuy, abril de 1999, pág 48.

GenBank-BLAST del NCBI (National Centre of Biotechnology Information). http://blast.ncbi.nlm.nih.gov/Blast.cgi, consultado 2014- 2017.

Gijzen M \& Qutob D. 2009. Phytophthora sojae and soybean. in: Oomycetes genetics and genomics: diversity, interactions and research tools. Lamour, K. and Kamoun, S. ed John Wiley \& Sons, Inc.

Gotelli NJ, Colwell RK. Magurran AE \& McGill BJ. Estimating species richness, Frontiers in Measuring Biodiversity, 2011 New York Oxford University Press. pg. 3954.

Griffith DR, Mannering JV \& Moldenhauer WC. 1977. Conservation tillage in the eastern corn belt. J. Soil \& Water Conservation, 32:20-28.

Grijalba PE. 2003 Enfermedades de raíz y base del tallo de la soja. Manejo Integrado de Enfermedades en Cultivos Extensivos. Jornadas Técnicas. Buenos Aires. 72-76.

Grijalba PE \& Barreto D. 2002. Comparison Between Methods to Evaluate Reaction of Soybean Cultivars To Phytophthora Root Rot. Actas II Congreso Brasilero de sojaMercosoja. Foz do Iguazu, Brasil. pg. 79.

Grijalba PE, Palmucci H, Mohs A \& Pase S. 2011. Identificación de especies de Pythium asociadas con plantulas de soja. II Congreso Argentino de Fitopatología. Mar del Plata, Argentina. pg 115.

Grijalba PE, Zapata RL, Palmucci HE \& Baron C. 2015. Podredumbre Basal De Plantas Adultas De Tomate Causada Por Pythium aphanidermatum (Oomycota). Revista de la Sociedad Argentina de Botánica: 50 (1)11-15. 
Grijalba PE \& Gally M. 2015. Virulence of Phytophthora sojae in the Pampeana Subregion of Argentina from 1998 to 2004. Journal of Phytopathology 163: 723-730. doi: 10.1111/jph.12369

Grijalba PE, Ridao A del C, Steciow M \& Lopez MV. 2017. Relación entre el gen Rps $1 \mathrm{k}$ y la resistencia a Pythium ultimum y $P$. irregulare en soja. Summa Phytopathologica. 43: 94-97

Grijalba PE \& Ridao A del C. 2017. Control químico de Pythium spp. en plántulas de soja. RIA : 43 (1): 67-71.disponible en: http://ria.inta.gob.ar/sites/default/files/trabajosenprensa/v43n1a10.pdf

Guindon S \& Gascuel O. 2003. A simple, fast, and accurate algorithm to estimate large phylogenies by maximum likelihood. Systematic Biology 52: 696-704.

Hartman GL, Rupe JC, Sikora EJ, Domier LL, Davis JA \& Steffey KL. 2015. Compendium of Soybean Diseases and Pests. 5th ed. The American Phytopathological Society, St. Paul, Minnesota, USA.

Hartman GL, Sinclair JB \& Rupe JC. 1999 Compedium of Soybean Disease, 4th ed. American Phytopathological Society, St. Paul, Minnesota.

Henry RN \& Kirkpatrick TL. 1995. Two new races of Phytophthora sojae, causal agent of Phytophthora root and stem rot of soybean, identified from Arkansas soybean fields. Plant Dis 79:1074.

Hildebrand AA. 1959. A root and stalk rot of soybean caused by Phytophthora megasperma Drechsler var. sojae var. nov. Can J Bot 37:927-957

Hemmes DE. 1983. Cytology of Phytophthora. Pp 9-40 In: Phytophthora: Its Biology, Taxonomy, Ecology and Pathology. Erwin DC, Bartnicki-Garcia S \& Tsao PH (Eds.). American Phytopathologycal Society, St Paul, Minnesota. 392pp.

Hobe MA. 1981. Pathogenic variability of Phytopthora megasperma f. sp. glycinea isolated from northwest Ohio soybean soils. M.S. Thesis. Ohio State University, Columbus.

Huang JH, Chen CY, Lin YS, Ann PJ, Huang HC \& Chung WH. 2013. Six new species of Pythiogeton in Taiwan, with an account of the mole cular phylogeny of the genus. Mycoscience 54: 130-147.

Hulvey J, Telle S, Nigrelli L, Lamour K \& Thines M. 2010. Salisapiliaceae-a new family of Oomycetes from marsh grass litter of southeastern North America. Persoonia 25: 109-116.

INFOSTAT. 2009. Software estadístico. Universidad Nacional de Córdoba (FCA-UNC). (Disponible: www.infostat.com.ar verificado: junio de 2014).

INTA. 1997. Guía Práctica para el cultivo de la soja.1997. Eds. INTA. 243 PP.

ISTA. 2013. Reglas Internacionales de Análisis de Semillas. International Rules for seed testing. Zurich.

Ivors KI, Hayden KJ, Bonants PJM, Rizzo DM \& Garbelotto M. 2004. AFLP and phylogenetic analyses of North American and European populations of Phytophthora ramorum. Mycol. Res. 108, 378-392

Jackson TA, Kirkpatrick TL \& Rupe JC. 2004. Races of Phytophthora sojae in Arkansas soybean fields and their effects on commonly grown soybean cultivars. Plant Dis 88:345-351.

Jeffers SN \& Martin SB. 1986. Comparison of two media selective for Phytophthora and Pythium species. Plant Disease 70:1038-1043.

Jiang YN, Haudenshield JS \& Hartman GL. 2012. Characterization of Pythium spp. from soil samples in Illinois. Can J Plant Pathol 34:448-454.

Jombart T. 2008. Adegenet: R package for the multivariate analysis of genetic markers. Bioinf 24: 1403-1405 
Jones CJ, Edwards KJ, Castiglione S \& Winfield MO. 1997. Reproducibility testing of RAPD, AFLP and SSR markers in plants by a network of European laboratories. Mol Breed. 3:381-390.

Jung T, Blaschke H \& Neumann P. 1996. Isolation, identification and pathogenicity of Phytophthora species from declining oak stands. European Journal of Forest Pathology 26: 253-272.

Kaitany RC, Hart LP \& Safir GR. 2001. Virulence Composition of Phytophthora sojae in Michigan, Journal Plant Disease 85:1103-1106.

Kamvar ZN, Tabima JF \& Grünwald NJ. 2014. Poppr: an R package for genetic analysis of populations with clonal, partially clonal, and/or sexual reproduction. PeerJ 2:e281 http://dx.doi.org/ 10.7717/peerj.281

Kang SS, Mansfield MAM, Park BB, Geiser DMD, Ivors KLK, Coffey MDM, Grünwald NJN, Martin FN, Lévesque CAC \& Blair JEJ. 2010. The promise and pitfalls of sequence-based identification of plant-pathogenic fungi and oomycetes. Phytopathology 100(8):732-737.

Kantolic A \& Carmona M. 2012. Bases ecofisiológicas para a geração do rendimento: relação com o efeito de doenças foliares e com o uso de fungicidas em soja Capítulo 1; 12-54 pp En: Doenças da soja 436 p E. M. Reis \& R. T. Casa Editores. ISBN 97885-7912-082-4.

Kiehr M \& Delhey R. 2013. Enfermedades de Zapallo (Cucurbita spp.).Pp 189-245. In: Manual del cultivo del zapallo Anquito (Cucurbita moschata Duch.). Della Gaspera(Ed.). INTA. 344pp.

Kirk PM, Cannon PF, David JC \& Stalpers JA. 2001. Dictionary of the Fungi, $9^{\text {th }}$ edition, CAB International, Wallingford. $655 \mathrm{pp}$.

Kirk PM, Cannon PF, Minter DW \& Stalpers JA. 2008. Ainsworth \& Bisby's Dictionary of the Fungi, 10th edn. CAB International, Wallingford. UK. $771 \mathrm{pp}$

Koenning SR \& Wrather JA. 2010. Suppression of soybean yield potential in the continental United States by plant diseases from 2006 to 2009. Online. Plant Health Progress doi:10.1094/PHP-2010-122-01-RS.

Kouyeas H. 1964. Notes on species of Pythium. 2. Annals Institute of Phytopathology. Benaki, N. S., 6: 117-123.

Kroon LPNM, Bakker FT, Bosch GBM van den, Bonants PJM \&, Flier WG. 2004. Phylogenetic analysis of Phytophthora species based on mitochondrial and nuclear DNA sequences. Fungal Genetics and Biology 41: 766-782.

Kroon LPNM, Brouwer H, de Cock AWAM \& Govers F. 2012. The Genus Phytophthora. Phytopathology 102:4, 348-364

Lamour KH. 2013. Phytophthora: A Global Perpective. CABI Plant Protection series: 2. Lamour K (Ed.). 244 pp.

Latijnhouwers M, de Wit PJGM \& Govers F. 2003. Oomycetes and fungi: similar weaponry to attack plants. Trends in Microbiology 11: 462-469.

Layon M. 2000. GeneTool 1.0. Biotech Software and Internet Report 1: 261-264.

Le Floch G, Vallance J, Benhamou \& Rey P. 2009. Combining the oomycete Pythium oligandrum with two other antagonistic fungi: Root relationships and tomato grey mold biocontrol. Biological Control 50: 288-298.

Leitz RA, Hartman GL, Pedersen WL \& Nickell CD. 2000. Races of Phytophthora sojae on Soybean in Illinois, Plant Disease, vol 84, n 4, pp 487.

Lévesque A. 2011. Fifty years of oomycetes from consolidation to evolutionary and genomic exploration. Fungal Diversity 50:35-46.

Lévesque CA, Harlton CE \& de Cock AWAM. 1998. Identification of some oomycetes by reverse dot blot hybridization. Phytopathology 88: 213-222. 
Lévesque CA \& De Cock AWAM. 2004. Molecular phylogeny and taxonomy of the genus Pythium. Mycological Research 10: 1363-1383.

Lévesque CA, Brouwer H, Cano L, Hamilton JP, Holt C, Huitema E et al. 2010. Genome sequence of the necrotrophic plant pathogen Pythium ultimum reveals original pathogenicity mechanisms and effector repertoire. Genome Biology 11: R73. (En:10.1186/gb-2010-11-7-r73, consultado 27 de noviembre de 2014).

Lifshitz R, Dupler M, Elad Y \& Baker R. 1984. Hyphal interactions between a mycoparasite, Pythium nunn, and several fungi. Canadian Journal of Microbiology 30: 1482.1487.

Littrell RH \& McCarter S. 1970. Effect of soil temperature on virulence of Pythium aphanidermatum and Pythium myriotylum to rye and tomato. Phytopathology 60(4):704-707.

Lodhi AM. 2007. Taxonomic studies on Oomycetous fungi from Sindh. Thesis (En: http://eprints.hec.gov.pk/2312/1/2167.htm, consultado mayo 2017).

Lodhi M, Khanzada A, Shahzad S \& Ghaffar A. 2013. Prevalence of Pythium aphanidermatum in agro ecosystem of Sindh province of Pakistan Pakistan. Journal of Botany 45: 635-642.

MAGyP. 2017.2 Disponible en: https://datos.magyp.gob.ar/reportes.php?reporte=Estimaciones. $\quad$ Consultado 14 febrero 2017

Malvick DK \& Grunden E. 2004. Traits of soybean infecting Phytophthora populations from Illinois agricultural fields. Plant Dis 88:1139-1145.

Marchand G, Chen Y, Berhane NA, Wei L, Lévesque CA \& Xue AG. 2014. Identification of Pythium spp. from the rhizosphere of soybeans in Ontario, Canada. Can. J. Plant Pathol. 36(2):246-251 doi:10.1080/07060661.2014.920921.

Margulis L \& Schwartz KV. 1988. Five kingdoms: An illustrated guide to the phyla of life on earth. Freeman WH \& Co., New York (Third Edition.). 448 pp.

Margulis L, Corliss JO, Melkonian M \& Chapman DJ. 1989. Handbook of protoctista. Jones \& Barlett (Eds.), Boston. 914 pp.

Martin FN. 1995. Meiotic instability of Pythium sylvaticum as demonstrated by inheritance of nuclear markers and karyotype analysis. Genetics 139: 1233-1246.

Martin FN \& Loper JE. 1999. Soilborne plant diseases caused by Pythium spp.: ecology, epidemiology, and prospects for biological control. Critical Reviews in Plant Sciences 18: 111-181.

Martin FN \& Tooley PW. 2003. Phylogenetic relationships among Phytophthora species inferred from sequence analysis of mitochondrially encoded cytochrome oxidase I and II genes. Mycologia 95: 269-284.

Martin FN, Abad ZG, Balci Y \& Ivors K. 2012. Identification and detection of Phytophthora: Reviewing our progress, identifying our needs. Plant Disease 96: 10801103.

Martinez C \& Ivancovich, A. 1979. Presencia de Phytophthora megasperma var. sojae en la pampa húmeda. Santa Fé, Argentina. In: VII Actas Reunión Técnica Nacional de Soja.

Matsumoto C, Kageyama K, Suga H \& Hyakumachi M. 1999. Phylogenetic relationships of Pythium species based on ITS and 5.8S sequences of the ribosomal DNA. Mycoscience 40: 321-331.

Mc Blain BA \& Schmitthenner AF. 1991. Evaluations of recurrent selections for Phytophthora tolerance. Ohio State University, Ohio Agric. Res. Dev Ctr. Research Bulletin 1187. 
McDonald BA. 1997. The population genetics of fungi: tools and techniques. Phytopathology 87:448-53

McDonald BA \& Linde C. 2002. Pathogen population genetics, evolutionary potential, and durable resistance. Annual Review of Phytopathology 40, 349-379.

McGee DC. 1992. Epidemiological approach to disease management through seed technology. Ann Rev Phytopath., 45: 417-420.

McNeill J, Barrie FR, Buck WR, et al. 2012. International code of nomenclature for algae, fungi and plants (Melbourne code): adopted by the Eighteenth International Botanical Congress Melbourne, Australia, July 2011. Koeltz Scientific Books, International Association for Plant Taxonomy, Königstein, Germany.

Meneguzzi N, Pastor S, Salerno C \& Kirschbaum D. 2011. Identificación de especies de Pythium (Peronosporales: Pythiaceae) asociados a síntomas de podredumbre de raiz en frutilla. $2^{\circ}$ Congreso Argentino de Fitopatología.

Meng XQ, Shoemaker RC \& Yang XB. 1999. Analysis of pathogenicity and genetic variation among Phytophthora sojae isolates using RADP. Mycol. Res. 103 (2):173178.

Misaghi IJ. 1982. Physiology and biochemistry of plant-pathogen interactions. Plenum Publishing Corporation, New York, NY.

Munford R, Boonham N, Tomlinsons J \& Barker I. 2006. Advances in molecular phytodiagnostics-new solutions for old problems. European Journal of Plant Pathology 116:1-19.

Neergaard P. 1979. Seed Pathology. Vol. 1, 2. McMillan, London.

Nei MS. 1987. Molecular Evolutionary Genetics. Columbia University Press. New York. 512 pp.

Nei M \& Kumar S. 2000. Molecular Evolution and Phylogenetics. Oxford University Press, New York. 329 pp.

Nelson BD, Mallik I, McEwen D \& Christianson T. 2008. Pathotypes, distribution, and metalaxyl sensivity of Phytophthora sojae from North Dakota. Plant Dis 92:10621066.

Ohal AF, Schmitthenner AF \& Walker AK. 1985. Glyceollin accumulation in soybean lines tolerant to Phytophthora megasperma f. sp. glycinea. Phytopathology 75:542546.

Palmucci HE. 2015. Caracterización De Especies Fitopatógenas de Pythium y Phytophthora (Peronosporomycetes) En Cultivos Ornamentales Del Cinturón Verde La Plata-Buenos Aires y Otras Áreas y Cultivos de Interés. Tesis Para Optar al Título de Doctor en Ciencias Naturales Facultad de Ciencias Naturales y Museo. Universidad Nacional De La Plata. 447 pp.

Palmucci HE, Grijalba PE, Wolcan S, Herrera C, Fantino E, Steciow M \& Abad ZG. 2011 a. Morphological-molecular characterization of Phytophthora, Pythium and Phytopythium on intensive crops in Buenos Aires, Argentina. Phytopathology 101: S136.

Palmucci HE, Wolcan SE \& Grijalba PE. 2011 b. Status of the Pythiaceae (Kingdom Stramenopila) in Argentina. I. The Genus Pythium. Revista de la Sociedad Argentina de Botánica. 46 (3-4).

Pankhurst CE, Heather J, McDonald BY \& Hawke G. 1995. Influence of tillage and crop rotation on the epidemiology of Pythium infections of wheat in a red-brown earth of South Australia. Soil Biology and Biochemistry. 27 (8): 1065-1073.

Papa KE, Campbell WA \& Hendrix FF Jr. 1967. Sexuality in Pythium sylvaticum: heterothallism. Mycologia 59: 589-95. 
Parker J. 2009. Molecular aspects of plant disease resistance. Blackwell Publising Ltd., Oxford, UK.

Pascale AJ \& Damario EA. 2004. Bioclimatologia agrícola y Agroclimatología. Editorial Facultad de Agronomía, UBA. 550 p

Pascale AJ. 1969. «Tipos agroclimáticos para el cultivo de la soja en la Argentina». Revista Facultad de Agronomía y Veterinaria, Buenos Aires 17(3): 31-48.

Pastor S, Vargas Gil S, Sagadin M, March M \& Mangeaud A. 2005. Diversidad de Pythium spp. en suelos de Argentina. Libro de resúmenes: XIII Congreso Latinoamericano de Fitopatología. Villa Carlos Pas. Cordoba. Argentina. pg. 446.

Pastor S, Ferri M \& Scandiani MM. 2011. Identificación de especies de Pythium spp. aisladas con trampas de plántulas de soja. Congreso Argentino de Fitopatología. 1-3 Junio de 2011, Mar del Plata, Argentina. Libro de Res.: 130.

Paul B. 1999. Pythium periplocum, an aggressive mycoparasite of Botrytis cinerea causing the gray mould disease of grape-vine. FEMS Microbiology Letters 181: 277280.

Paul B. 2001. ITS region of the rDNA of Pythium longandrum, a new species; its taxonomy and its comparison with related species. FEMS Microbiology Letters 202: 239-242

Paul B, Mathew R, Kanak B, Paul A, Henry M, Lefort F \& Belbahri L. 2008. Morphology, taxonomy, and phylogenetic analysis of a new species of Pythium isolated from France. Fungal Diversity 28: 55-63.

Paulitz TC \& Baker R. 1987. Biological control of Pythium damping-off of cucumbers with Pythium nunn: Population dynamics and disease suppression. Phytopathology 77:335-340.

Paulitz TC \& Baker R. 1988. The formation of secondary sporangia by Pythium ultimum: the influence of organic amendments and Pythium nunn. Soil Biol Biochem 20:151156.

Pioli R. 2000. Enfermedades de soja. Revista agromensajes, edición N² 2, marzo 2000. Pp 3.

Pickett-Popoff L \& Panter KL. 1994. Survey of Pythium and Phytophthora spp. in irrigation water used by Colorado commercial greenhouses to determine source of pathogen introduction. Phytopathology 84: 1118-1994.

Pittis JE \& Colhoun J. 1984. Isolation and identification of pythiaceous fungi from irrigation water and their pathogenicity to Antirrhinum, tomato and Chamaecyparis lawsoniana. Phytopathologie Zeitschrift 110: 301-318.

Ploper LD. 2004. Economic importance of and control strategies for the major soybean diseases in Argentina. In: Moscardi F. (ed) Proc 7th World Soybean Research Conference, 4th International Soybean Processing and Utilization Conference, III Congresso Mundial de Soja, 29 February-5 March 2004, Foz de Iguazu, Brasil, pp 155-156.

Ploper LD, González V, Nome SF, Laguna IG, Pérez BA, Pioli R, Rodríguez Pardina P, Scandiani M, Distefano S \& Sillón M. 2010. Enfermedades de Glycine max (L.) Merrill (soja, soya, poroto soja, frijol soja). En: ATLAS FITOPATOLÓGICO ARGENTINO. VOL. 4, N. ${ }^{\circ}$ 1. Marzo 2011. Eds: Nome, S.F.; Docampo, D.M.; Conci, L.R. y Laguna, I.G. Córdoba, Argentina. (Disponible: http://www.fitopatoatlas.org.ar/default. asp?hospedante $=635$ verificado: diciembre de 2014).

Porter LD, Hamm PB, David NL, Gieck SL, Miller JS, Gundersen B \& Inglis DA. 2009. Metalaxyl-M-Resistant Pythium species in potato production areas of the Pacific Northwest of the U.S.A. American Journal of Potato Research 86: 315-326. 
Pritchard JK, Stephens M \& Donnelly P. 2000. Inference of population structure using multilocus genotype data. Genetics 155: 945-959.

Readmer L, Anderson G, Malvick DM, Kurle JE, Rendahl A \& Mallik A. 2017. Pythium, Phytophthora, and Phytopythium spp. Associated with Soybean in Minnesota, Their Relative Aggressiveness on Soybean and Corn, and Their Sensitivity to Seed Treatment Fungicides. Plant Disease 101:1, 62-72.

Reis EM, Reis AC \& Carmona M. 2010. Manual de fungicidas Controle químico de doencas de plantas. (en portuges) ISBN 97885-7515-464-9 Ed: Universidade de Passo Fundo, Passo Fundo, Brasil, p. 226.

Ridao A del C, Pereyra Iraola M, Pagani A, Bodega E, Azpeitía M \& Ross F. 2005. Situación actual de las principales enfermedades de soja en el sudeste de Buenos Aires. XIII Congreso Latinoamericano de Fitopatología y III Taller de la AAF. Villa C.Paz, Córdoba, Argentina. 19-22/04/05. pp 456.

Robertson AE, Cianzio SR, Cerra SM \& Pope RO. 2009. Within-field pathogenic diversity of Phytophthora sojae in commercial soybean fields in Iowa. Online. Plant Health Progress. Doi:10.1094/PHP-2009-0908-01-RS

Rojas A, Jacobs JL, Napieralski S, Karaj B, Bradley CA, Chase T, Esker P, Giesler L, Jardine D, Malvick D, Markell S, Nelson BD, Robertson A, Rupe JC, Smith D, Sweets L, Tenuta A, Wise K \& Chilvers MI. 2017 a. Oomycete species associated with soybean seedlings in North America - Part I: Identification and pathogenicity characterization. Phytopathology 107:280:292.

Rojas A, Jacobs JL, Napieralski S, Karaj B, Bradley CA, Chase T, Esker P, Giesler L, Jardine D, Malvick D, Markell S, Nelson BD, Robertson A, Rupe JC, Smith D, Sweets L, Tenuta A, Wise K \& Chilvers MI. 2017 b. Oomycete species associated with soybean seedlings in North America - Part II: Diversity and Ecology in Relation to Environmental and Edaphic Factors. Phytopathology 107:293:304.

Romero G, Estévez de Jensen C \& Palmateer AJ. 2012. First report of Pythium dissotocum affecting cilantro in hydroponic systems in Puerto Rico. Online. Plant Health Progress doi: 10.1094/PHP-2012-1214-01-BR.

Rossi RL. 2004. Current Status of the Soybean Production and Utilization in Argentina. Proc. VII World Soybean Research Conference. Foz do Igaussu. Brazil. 38-49.

Rossi RL \& Nari C. 1995. Genes de resistencia a Phytophthora sojae en líneas avanzadas y cultivares de soja (Glycine max (L) Merr) en la Argentina.Octubre 1995, Pergamino. In.: I Congreso Nacional de Soja. II Reunión Nacional de Oleaginosos. pp. 65-71.

Rosso ML, Rupe JC \& Rothrock C. Resistance of soybean cultivars to Pythium dampingoff and root rot based on Rps1k gene. Phytopathology, St. Paul, v.95, pS90, 2005.

Runge F, Telle S, Ploch S, Savory E, Day B, Sharma R \& Thines M. 2011. The inclusion of downy mildews in a multi-locus-dataset and its reanalysis reveals high degree of paraphyly in Phytophthora. IMA Fungus 2: 163-171.

Rupe JC, Rothrock CS, Bates G, Rosso ML, Avanzato MV \& Chen P. 2011. Resistance to Pythium Seedling Disease in Soybean, Soybean - Molecular Aspects of Breeding, Dr. Aleksandra Sudaric (Ed.), ISBN: 978-953-307-240-1, InTech, Available from: http://www.intechopen.com/ books/soybeanmolecular-aspects-ofbreeding/resistance-to-pythium-seedling-disease-in-soybean

Ryley MJ, Obst NR, Irwin JAG \& Drenth A. 1998. Changes in the Racial Composition of Phytophthora sojae in Australia Between 1979 and 1996. Plant Dis 82 (9):10481054.

Sá Pereira E. 2008. La soja y el uso de inoculantes en el Sudoeste Bonaerense. Ediciones INTA. Pp 3. 
Sahoo DK, Abeysekara NS, Cianzio SR, Robertson AE \& Bhattacharyya MK. 2017. A Novel Phytophthora sojae Resistance Rps 12 Gene Mapped to a Genomic Region That Contains Several Rps Genes. PLoS ONE 12(1): e0169950.

Sakura Kobayashi S, Uzuhashi S, Tojo M. \& Kakishima M. 2010. Characterization of Pythium nunn newly recorded in Japan and its antagonistic activity against $P$. ultimumvar. Ultimum. Journal of General Plant Pathology 76 (4): 278-283

Sanders PL. 1987. Failure of metalaxyl to control Pythium blight on Kentucky golf courses. Phytopathology 77: 121.

Sansome E. 1961. Meiosis in the oogonium and antheridium of Pythium debaryanum. Hesse. Nature 191: 827-828.

Sansome E. 1965. Meiosis in diploid and polyploidy sex organs of Phytophthora and Achlya. Cytologia 30: 103-117.

Sasal C. 2013. Siembra directa: la elegida para conservar el suelo. Revista de Investigaciones Agropecuarias vol.39 (2): Pp 4.

Schena L, Cardle L \& EL Cooke D. 2008. Use of genome sequence data in the design and testing of SSR markers for Phytophthora species . BMC Genomics 9:620 doi:10.1186/1471-2164-9-620.

Schmitthenner AF. 1973. Isolation and identification methods for Phytophthora and Pythium. In: Millikan, D.F. Disease Workshop. University of Missouri, Columbia, 94: p. 110.

Schmitthenner AF. 1985. Problems and progress in control of Phytophthora root rot of soybean. Plant Dis 69:362-368.

Schmitthenner AF \& Williams LE. 1962. Effect of crop rotation on alfalfa and soybean stands, root rot and yields. Phytopathology 52:751

Schmitthenner AF \& VanDoren DM Jr. 1985. Integrated control of root rot of soybean caused by Phytophthora megasperma f. sp. glycinea in: Ecology and management of soilborne plant pathogens. C. A. Parker, A. D. Rovira, K. J. Moore, P. T. W. Wong, and J. F. Kollmorgen, eds. American Phytopathological Society, St. Paul, MN.:263266

Schimetthenner AF \& Bhat RG. 1994. Useful methods for studying Phytophthora in laboratory. OARDC Special Circular 143:1-10.

Schmitthenner AF, Hobe M \& Bhat RG. 1994. Phytophthora sojae races in Ohio over a 10-year interval. Plant Dis 78:269-276.

Schroeder K, Martin F, de Cock A, Lévesque CA, Spies C, Okubara P \& Paulitz T. 2013. Molecular detection and quantification of Pythium Species-evolving taxonomy, new tools and challenges. Plant Disease 97: 4-20.

Schulz I \& Francomano de Picardi MV. 1989. Incidence of factors affecting soybean seed quality during the agriculture periods $1982 / 83$ to $1988 / 89$. IV conferencia Mundial de Investigación en soja. Buenos Aires, 5 al 9 de marzo de 1989. Tomo II, 861-866.

Shokes FM \& McCarter SM. 1979. Ocurrence, dissemination and survival of plant pathogens in surface irrigation ponds in southern Georgia. Phytopathology 69: 510516.

Sideris CP. 1932. Taxonomic studies in the family Pythiaceae. II. Pythium. Mycologia 24: 14-61.

Slaminko TL, Bowen CR \&, Hartman GL. 2010. Multi-year evaluation of commercial soybean cultivars for resistance to Phytophthora sojae. Plant Dis 94:368-371

Sneh B. 1998. Use of non.pathogenic or Hypovirulent Fungal Strains to Protect Plants Against Closely Related Fungal Pathogens. Biotechnology Advances 16(1): 1-32. 
Spencer MA. 2004a. CABI, Wallingford. UK. Pythium dissotocum. IMI Descriptions of Fungi and Bacteria, 162, Pp. 1613. (En:http://www.cabi.org/dfb/search/?q=Pythium+dissotocum, consultado el 31 de enero de 2014).

Spencer MA. 2004b. CABI, Wallingford, UK. Pythium sylvaticum. IMI Descriptions of Fungi and Bacteria 162, Pp 1619. (En: http://www.cabi.org/dfb/, consultado 2 de abril de 2014).

Spies CFJ, Mazzola M \& McLeod A. 2011. Characterization and detection of Pythium and Phytophthora species associated with grapevines in South Africa. European Journal of Plant Pathology 131:103-119.

Stamps DJ, Waterhouse GM, Newhook FJ \& Hall GS. 1990. Revised tabular key to the species of Phytophthora. Mycological Papers 162: 28 pp.

Stewart S \& Robertson AE. 2012. A modified method to screen for partial resistance to Phytophthora sojae in soybean. Crop Sci 52: 1181-1186.

Stewart S, Wickramasinghe D, Dorrance AE \& Robertson AE. 2011. Comparison of three microsatellite analysis methods for detecting genetic diversity in Phytophthora sojae (Stramenopila: Oomycete). Biotechnol Lett 33:2217-2223.

Stewart S, Robertson AE, Wickramasinghe D, Draper MA, Michel A \& Dorrance AE. 2016. Population structure among and within Iowa, Missouri, Ohio, and South Dakota populations of Phytophthora sojae. Plant Dis. 100:367-379.

Stoddart JA \& Taylor JF. 1988. Genotypic diversity: estimation and prediction in samples. Genetics 118: 705-711.

Sutton JC, Sopher CR, Owen-Going TN, Liu W, Grodzinski B, Hall JC \& Benchimol RL. 2006. Etiology and epidemiology of Pythium root rot in hydroponic crops: current knowledge and perspectives. Summa Phytopathologica 32: 307-321.

Syngenta. 2014. Protección de Cultivos. (Disponible: http:// www.syngenta.com.ar/Cultivos/productos.aspx?produc $=774$ verificado: marzo de 2015).

Tamura K, Stecher G, Peterson D, Filipski A \& Kumar S. 2013. MEGA6: Molecular Evolutionary Genetics Analysis version 6.0. Mol Biol Evol. 30 (12): 2725-2729.

Templeton AR. 1998. Nested clade analysis of phylogeographical data: testing hypotheses about gene flow and population history. Molecular Ecology 7: 381-397.

Thines M \& Spring O. 2005. A revision of Albugo (Chromista, Peronosporomycetes). Mycotaxon. 92:443-458.

Thines M, Voglmayr H \& Göker M. 2009. Taxonomy and phylogeny of the downy mildews (Peronosporaceae). Pp. 47-75. In: Oomycete Genetics and Genomics: Biology, Interactions with Plants and Animals, and Toolbox. Lamour, K \& Kamoun, S. (Eds) Wiley, Hoboken, New Jersey. 602pp.

Thomison PR, Thomas CA \& Kenworthy WJ. 1991. Tolerant and root resistant soybean cultivars: reactions to Phytophthora rot in inoculum-layer tests. Crop Science 31:7375 .

Thomson TB, Athow KL \& Laviolette FA. 1971. The effect of temperature on the pathogenicity of Pythium aphanidermatum, P. debaryanum, and P. ultimum on soybean. Phytopathology 61:933-935.

Tooley PW \& Grau CR. 1984. The relationship between rate-reducing resistance to Phytophthora megasperma f.sp. glycinea and yield of soybean. Phytopathology 74:1209-1216.

Tyler BM. 2007. Phytophthora sojae: root rot pathogen of soybean and model Oomycete. Mol. Plant Pathol. 8, 1-8. 
Tyler BM, Tripathy S, Zhang X, Dehal P, Jiang RH, Aerts A, Arredondo FD, Baxter L, Bensasson D, Beynon JL, Chapman J, Damasceno CM, Dorrance AE, Dou D, Dickerman AW, Dubchak IL, Garbelotto M, Gijzen M, Gordon SG, Govers F, Grunwald NJ, Huang W, Ivors KL, Jones RW, Kamoun S, Krampis K, Lamour KH, Lee MK, McDonald WH, Medina M, Meijer HJ, Nordberg EK, Maclean DJ, OspinaGiraldo MD, Morris PF, Phuntumart V, Putnam NH, Rash S, Rose JK, Sakihama Y, Salamov AA, Savidor A, Scheuring CF, Smith BM, Sobral BW, Terry A, TortoAlalibo TA, Win J, Xu Z, Zhang H, Grigoriev IV, Rokhsar DS \& Boore JL. 2006. Phytophthora genome sequences uncover evolutionary origins and mechanisms of pathogenesis. Science 313: 1261-1266.

USDA-Fungal nomenclature database, Systematic Mycology and Microbiology Laboratory, ARS, USDA, USA (Minnis et al., 2014, Farr \& Rossman, 2012, 2014, 2015) En: http://nt.ars-grin.gov/fungaldatabases/)

Uzuhashi S, Tojo M \& Kakishima M. 2010. Phylogeny of the genus Pythium and description of new genera. Mycoscience 51: 337-365.

Vallone S \& Giorga LM. 1997. Enfermedades de la soja en la Argentina. Ediciones INTA.72 pp

van der Plaats-Niterink AJ. 1981. Monograph of the genus Pythium. Studies in Mycology $\mathrm{N}^{\circ}$ 21. Baarn, the Netherlands: Centraalbureau Voor Schimmelcultures. $242 \mathrm{pp}$.

Van doren DM \& Triplett GB. 1973. Mulch and tillage relationships in corn culture. Soil science society of America proceedings. 37: 766-769.

Van Jaarsveld E, Wingfield MJ \& Drenth A. 2002. Effect of metalaxyl resistance and cultivar resistance on control of Phytophthora nicotianae in tobacco. Plant Dis. 86:362-366.

Vicentini R. 1996. La Fitóstora y el cancro del tallo: dos enfermedades destructivas de la soja de aparición reciente en Entre Ríos. Serie Extensión No 12. Estación Experimental Paraná: 41-48.

Villa NO, Kageyama K, Asano T \& Suga H. 2006. Phylogenetic relationships of Pythium and Phytophthora species based on ITS rDNA, cytochrome oxidase II and beta-tubulin gene sequences. Mycologia 98: 410-422.

Walker AK \& Schmitternner AF. 1984. Heritability of tolerance to Phytophthora rot in soybean. Crop Science 24:490-491.

Wang MC \& Bartnicki-Garcia S. 1980. Distribution of mycolaminarins and cell wall Bglucans in the life cicle of Phytophthora. Experimental Mycology 4: 269-280.

Waterhouse GM. 1963. Key to the species of Phytophthora de Bary. Mycological Papers 92: 22 .

Webster RK, Hall DH, Heeres J, Wick CM \& Brandon DM. 1970. Achlya Klebsiana and Pythium species as Primary Causes of Seed Rot and Seedling Disease of Rice in California. Phytopathology 60: 964-968.

Weeks DE, Conley YP, Ferrell RE, Mah TS \& Gorin MB. 2002. A tale of two genotypes: consistency between two high-throughput genotyping centers. Genome Res. 12:430435.

Wei Lai, Allen G. Xue, Elroy R. Cober, Carolyn Babcock, Jinxiu Zhang, Shuzhen Zhang, Wenbin Li, Junjiang Wu \& Lijun Liu. 2011. Pathogenicity of Pythium species causing seed rot and damping-off in soybean under controlled conditions. Phytoprotection 91: 3-10.

Weiland JE, Santamaria L \& Grünwald NJ. 2014. Sensitivity of Pythium irregulare, $P$. sylvaticum, and $P$. ultimum from forest nurseries to mefenoxam and fosetyl-Al, and control of Pythium damping-off. Plant Dis. 98: 937-942. 
White TJ, Bruns T, Lee S \& Taylor JW. 1990 Amplification and direct sequencing of fungal ribosomal RNA genes for phylogenetics. Pp. 315-322. In: PCR Protocols: a guide to methods and applications. Innis MA, Gelfand DH, Sninsky JJ \& White TJ (Eds.). New York. Academic Press.

Widmark AK, Andersson B, Sandström M \& Yuen JE. 2011. Tracking Phytophthora infestans with SSR markers within and between seasons - a field study in Sweden. Plant Pathol 60.

Winter G. 1880. Rabenhorst s Kryptogamen-Flora, Pilze - Schizomyceten, Saccharomyceten und Basidiomyceten, vol 1. 2nd edn.

Whittaker RH. 1969. New concepts of kingdoms or organisms. Evolutionary relations are better represented by new classifications than by the traditional two kingdoms. Science, 163: 150-194

Wolcan S \& Grego P. 2004. Complejos fúngicos asociados a enfermedades de Melissa officinalis y de Lavandula spp. II Congreso Argentino de Floricultura y Plantas Ornamentales. VI Jornadas Nacionales de Floricultura. I Encuentro Latinoamericano de Floricultura. Bs. As. Octubre 2004. Libro de Res.: 234 -236.

Workneh F, Tilka GL, Yang XB, Faghihi J \& Ferris JM. 1999. Regional assessment of soybean brown stem rot, Phytophthora sojae, and Heterodera glycines using areaframe sampling: Prevalence and effects of tillage. Phytoptathology 89:204-211.

Wrather JA, Anderson TR, Arsyad DM, Tan Y, Ploper LD, Porta-Puiglia A, Ram HH \& Yorinori JT. 2001. Soybean disease loss estimates for the top ten soybean-producing countries in 1998. Can. J. Plant Pathol. 23: 115-121.

Wrather A, Shannon G, Balardin R, Carregal L, Escobar R, Gupta GK, Ma Z, Morel W, Ploper D \& Tenuta A. 2010. Effect of diseases on soybean yield in the top eight producing countries in 2006. Plant Health Progress. Online Publication. doi:/10.1094/PHP-2010-0125-01-RS

Yang XB, Ruff RL, Meng XQ \& Workneh F. 1996. Races of Phytophthora sojae in Iowa soybean fields. Plant Dis. 80:1418-1420.

Yang XB. 1999. Pythium damping-off and root rot. Pages 42-44 in: Compendium of Soybean Diseases, fourth edition. G. L. Hartman, J. B. Sinclair, and J. C. Rupe, eds. American Phytopathological Society, St. Paul, MN.

Zhang SZ, Xu PF, Wu JJ, Xue AG, Zhang JX, Li WB, Chen C, Chen WY \& Lv HY. 2010. Races of Phytophthora sojae and their virulences on soybean cultivars in Heilongjiang, China. Plant Dis 94:87-91.

Zhaohui Z \& Jin Y. 1999. Proceeding of the 7 th International Working Conference on Stored-product Protection- Volume 2- 1802-1806

Zitnick-Anderson KK \& Nelson BD. 2015. Identification and pathogenicity of Pythium on soybean in North Dakota. Plant Dis. 99(1):31-38 doi:10.1094/PDIS-02-14-0161RE. 


\section{ANEXO I. MEDIOS DE CULTIVO GENERALES Y SELECTIVOS UTILIZADOS}

\section{MEDIOS DE CULTIVO}

Fueron utilizados los siguientes medios de cultivo, cuya formulación se expone a continuación:

Agar papa glucosado (APG) o agar papa dextrosado (APD): Papa (200 g); glucosa o dextrosa (20 g); agar (20 g) y agua destilada (1000 ml).

Agar agua (AA): Agar (20 g) y agua destilada (1000 ml).

Agar papa glucosado Merck: APG (39 g) y agua destilada (1000 ml).

Agar harina de maíz (Corn Meal Agar-Merck): AHM (39 g) y agua destilada (1000 ml). Tambien se usó: $50 \mathrm{~g}$ de harina de maíz, agar agar $(20$ g) y agua destilada (1000 ml). Para su preparación en baño térmico, se hizo una infusión de la harina de maíz en agua, temperatura no superior a $55{ }^{\circ} \mathrm{C}$, durante $50-60 \mathrm{~min}$. Se filtró con algodón o filtro de papel, se agregó el agar y el agua destilada hasta alcanzar 1 litro.

Agar 8 vegetales (AV8): Se utilizó el AV8 clarificado (Miller, 1955) modificado (Erwin y Ribeiro, 1996): Jugo V8 ${ }^{\circledR}$ (Campbell Soup Company) (40 ml); Carbonato de calcio (CaCO3 - $600 \mathrm{mg}$ ); Extracto de levadura (200 mg); Sacarosa (1 g); Colesterol (10 mg); agar agar (20 g) y agua destilada $(1000 \mathrm{ml})$. Para su preparación se mezclaron el jugo V8, el CaCO3, la levadura, la sacarosa y el colesterol. Se centrifugó para clarificar, decantar y descartar el pellet. Es importante clarificar el medio de cultivo, lo cual puede realizarse usando una centrífuga durante 5 minutos a $2000 \mathrm{rpm}$, o pasando lentamente la solución por un filtro de papel o tela de algodón fina. Se añadió el agar y el agua destilada hasta alcanzar 1 litro.

Lima Bean Agar (LBA): Se utilizó LBA (Schmitthenner et al., 1994): 25 g de Lima Bean (Phaseolus lunatus) freezados, agar agar (20 g) y agua destilada (1000 ml). Para su preparación se hieven los porotos en el agua destilada. A la infusión resultante, se le añade el agar y el agua destilada hasta alcanzar 1 litro.

Todos los medios de cultivo preparados fueron esterilizados durante 15 minutos a $121^{\circ} \mathrm{C}$ en autoclave. 


\section{ANEXO II. Análisis Estadísticos}

\subsection{Ensayo exploratorio de patogenicidad con cepas de Phytopythium}

\begin{tabular}{|c|c|c|c|c|c|c|}
\hline Variable & $\mathrm{N}$ & $\mathrm{R}^{2}$ & & $\mathrm{R}^{2} \mathrm{~A}$ & $\mathrm{CV}$ & \\
\hline emergencia & 20 & 0,28 & & 0,1 & 4,45 & \\
\hline Cuadro de & Anális & $s$ de & la & \multicolumn{2}{|c|}{ Varianza } & (SC tipo III) \\
\hline F.V. & $\mathrm{SC}$ & gl & & $\mathrm{CM}$ & F & p-valor \\
\hline Modelo & 2,00 & 3 & & 0,67 & 2,05 & 0,1472 \\
\hline Metodo & 2,00 & 3 & & 0,67 & 2,05 & 0,1472 \\
\hline Error & 5,20 & 16 & & 0,33 & & \\
\hline Total & 7,20 & 19 & & & & \\
\hline
\end{tabular}

Test: Tukey Alfa:=0,05 DMS: $=1,03153$

Error: 0,3250 gl: 16

\begin{tabular}{lccc}
\multicolumn{1}{c}{ Metodo } & Medias & \multicolumn{2}{c}{ A } \\
\cline { 1 - 3 } frezii inund & 12,40 & 5 & $\mathrm{~A}$ \\
frezzic capa & 12,60 & 5 & $\mathrm{~A}$ \\
helic inund & 13,00 & 5 & $\mathrm{~A}$ \\
helic capa & 13,20 & 5 & $\mathrm{~A}$ \\
Letras distintas & indican diferencias & significativas $(p<=0,05)$
\end{tabular}

\section{Respuestas de diferentes especies frente a distintas temperaturas}

$15^{\circ} \mathrm{C}$

Análisis de la varianza

\begin{tabular}{llcrrr} 
Variable & $N$ & $R^{2}$ & $R^{2}$ & $A j$ & $C V$ \\
\hline emerg & 40 & 0,01 & 0,00 & 106,18 \\
\hline
\end{tabular}

\begin{tabular}{lrrrrr} 
Cuadro de Análisis de la Varianza & (SC tipo III) \\
F.V. & \multicolumn{1}{c}{ SC } & gl & CM & F & p-valor \\
\hline Modelo & 2,03 & 1 & 2,03 & 0,48 & 0,4905 \\
Zona & 2,03 & 1 & 2,03 & 0,48 & 0,4905 \\
Error & 158,75 & 38 & 4,18 & & \\
Total & 160,78 & 39 & & & \\
\hline
\end{tabular}

Test:DGC Alfa:=0,05 PCALT:=1, 3109

Error: 4,1776 gl: 38

\begin{tabular}{lrl} 
Zona & Medias & $\mathrm{n}$ \\
\hline $\mathrm{N}$ & 1,70 & 20
\end{tabular}

S $\quad 2,15 \quad 20 \quad$ A

Letras distintas indican diferencias significativas $(p<=0,05)$

$25^{\circ} \mathrm{C}$

Análisis de la varianza

\begin{tabular}{llcrrr} 
Variable & $N$ & $R^{2}$ & $R^{2} A j$ & $C V$ \\
\hline emerg & 40 & $1,2 \mathrm{E}-03$ & 0,00 & 52,81 \\
\hline
\end{tabular}

\begin{tabular}{lcrrrr} 
Cuadro de Análisis de la Varianza & \multicolumn{3}{c}{ (SC tipo III) } \\
F.V. & SC & gl & CM & F & p-Valor \\
\hline Modelo & 0,63 & 1 & 0,63 & 0,05 & 0,8300 \\
Zona & 0,63 & 1 & 0,63 & 0,05 & 0,8300 \\
Error & 508,15 & 38 & 13,37 & & \\
Total & 508,78 & 39 & & & \\
\hline
\end{tabular}

Test:DGC Alfa:=0,05 PCALT:=2, 3453

Error: 13,3724 gl: 38 
\begin{tabular}{lrrr} 
Zona & Medias & $\mathrm{n}$ & \\
\hline $\mathrm{S}$ & 6,80 & 20 & $\mathrm{~A}$ \\
$\mathrm{~N}$ & 7,05 & 20 & $\mathrm{~A}$
\end{tabular}

$35^{\circ} \mathrm{C}$

Análisis de la varianza

\begin{tabular}{llcrrr} 
Variable & $N$ & $R^{2}$ & $R^{2}$ & $A j$ & $C V$ \\
\hline emerg & 40 & 0,03 & 0,01 & 5,00 \\
\hline
\end{tabular}

Cuadro de Análisis de la Varianza (SC tipo III)

\begin{tabular}{lrrrrr} 
F.V. & \multicolumn{1}{c}{ SC } & gl & \multicolumn{1}{c}{ CM } & \multicolumn{1}{c}{ F } & p-valor \\
\hline Modelo & 0,63 & 1 & 0,63 & 1,23 & 0,2749 \\
Zona & 0,63 & 1 & 0,63 & 1,23 & 0,2749 \\
Error & 19,35 & 38 & 0,51 & & \\
Total & 19,98 & 39 & & & \\
\hline
\end{tabular}

Test:DGC Alfa:=0,05 PCALT:=0,4577

Error: 0,5092 $\mathrm{gl}: 38$

\begin{tabular}{lll} 
Zona & Medias & $\mathrm{n}$ \\
\hline $\mathrm{S}$ & 14,15 & 20
\end{tabular}

$\mathrm{N}$
Letras distintas indican diferencias significativas $(p<=0,05)$

$15^{\circ} \mathrm{C}$

Análisis de la varianza

\begin{tabular}{llcrrr} 
Variable & $N$ & $R^{2}$ & $R^{2}$ Aj & $C V$ \\
\hline emerg & 45 & 0,92 & 0,92 & 29,30 \\
\hline
\end{tabular}

Cuadro de Análisis de la Varianza (SC tipo III)

\begin{tabular}{lrrrrr} 
F.V. & \multicolumn{1}{c}{ SC } & gl & \multicolumn{1}{c}{ CM } & F & p-valor \\
\hline Modelo & 735,60 & 2 & 367,80 & 242,89 & $<0,0001$ \\
Especie & 735,60 & 2 & 367,80 & 242,89 & $<0,0001$ \\
Error & 63,60 & 42 & 1,51 & & \\
Total & 799,20 & 44 & & & \\
\hline
\end{tabular}

Test:DGC Alfa:=0,05 PCALT:=0,9405

Error: 1,5143 gl: 42

\begin{tabular}{lcccc} 
Especie & Medias & $\mathrm{n}$ & \\
\hline ULT & 0,40 & 15 & A & \\
IRRE & 2,40 & 15 & & B \\
Aphanid & 9,80 & 15 & & C \\
\hline Letras distintas & indican diferencias & significativas $(p<=0,05)$
\end{tabular}

$25^{\circ} \mathrm{C}$

Análisis de la varianza

\begin{tabular}{lllrrr} 
Variable & $N$ & $R^{2}$ & $R^{2}$ & $A j$ & $C V$ \\
\hline emerg & 45 & 0,75 & 0,74 & 31,49 \\
\hline
\end{tabular}

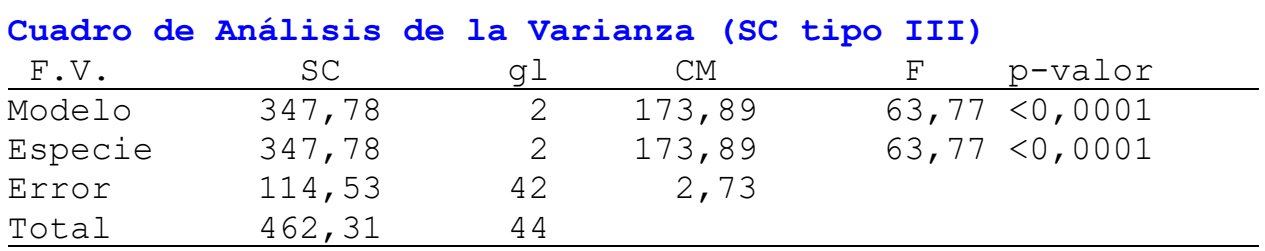

Test:DGC Alfa: $=0,05$ PCALT: $=1,2621$

Error: 2,7270 gl: 42

Especie Medias $\mathrm{n}$ 


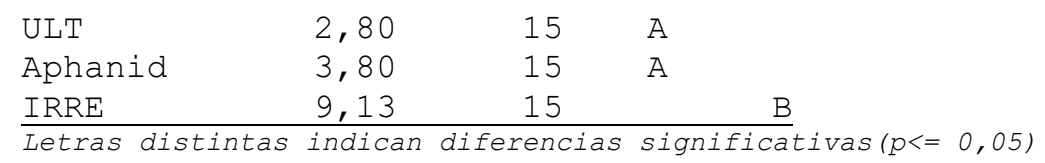

\section{$35^{\circ} \mathrm{C}$}

Análisis de la varianza

\begin{tabular}{llcrrr} 
Variable & $N$ & $R^{2}$ & $R^{2}$ & $A j$ & $C V$ \\
\hline emerg & 45 & 1,00 & 1,00 & 4,90 \\
\hline
\end{tabular}

Test:DGC Alfa:=0,05 PCALT:=0, 3603

Error: 0,2222 gl: 42

\begin{tabular}{lccc} 
Especie & Medias & $\mathrm{n}$ & \\
\hline Aphanid & 0,00 & 15 & $\mathrm{~A}$ \\
ULT & 14,40 & 15 & $\mathrm{~B}$ \\
IRRE & 14,47 & 15 & $\mathrm{~B}$ \\
Letras distintas & indican diferencias & significativas $(p<=0,05)$
\end{tabular}

\section{CRECIMIENTO}

15

Análisis de la varianza

\begin{tabular}{llcrrc} 
Variable & $N$ & $R^{2}$ & $R^{2}$ & $A j$ & $C V$ \\
\hline emerg & 40 & 0,01 & 0,00 & 106,18 \\
\hline
\end{tabular}

Cuadro de Análisis de la Varianza
\begin{tabular}{lcrrrr} 
(SC tipo III) \\
F.V. & \multicolumn{1}{c}{ SC } & gl & CM & F & p-valor \\
\hline Modelo & 2,03 & 1 & 2,03 & 0,48 & 0,4905 \\
Zona & 2,03 & 1 & 2,03 & 0,48 & 0,4905 \\
Error & 158,75 & 38 & 4,18 & & \\
Total & 160,78 & 39 & & & \\
\hline
\end{tabular}

Test:DGC Alfa:=0,05 PCALT:=1, 3109

Error: 4,1776 gl: 38

Zona Medias $n$

\begin{tabular}{lccc}
\hline $\mathrm{N}$ & 1,70 & 20 & $\mathrm{~A}$ \\
$\mathrm{~S}$ & 2,15 & 20 & $\mathrm{~A}$
\end{tabular}

\section{$25^{\circ} \mathrm{C}$}

Análisis de la varianza

\begin{tabular}{llcrrr} 
Variable & $N$ & $R^{2}$ & $R^{2} A j$ & $C V$ \\
\hline emerg & 40 & $1,2 E-03$ & 0,00 & 52,81 \\
\hline
\end{tabular}

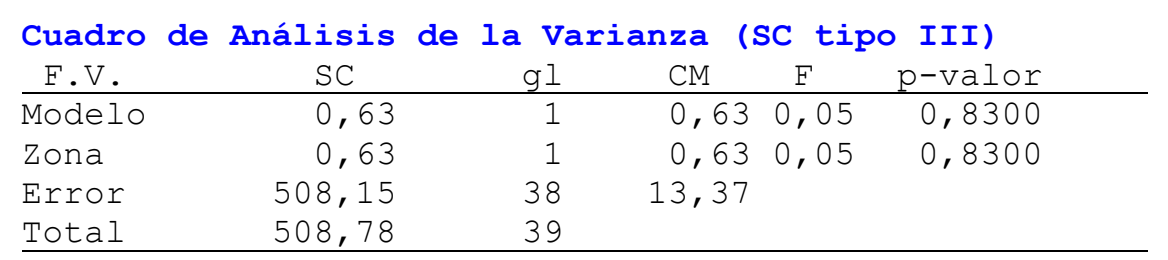

Test:DGC Alfa:=0,05 PCALT:=2, 3453

Error: 13,3724 $\mathrm{gl}: 38$

Zona Medias

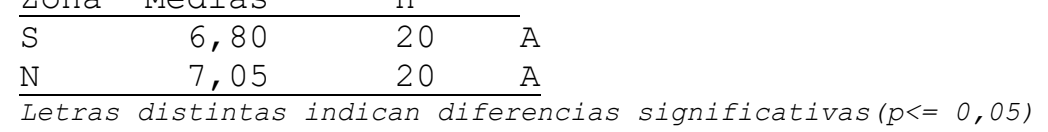

\section{$35^{\circ} \mathrm{C}$}

Análisis de la varianza

\begin{tabular}{llllll} 
Variable & $N$ & $R^{2}$ & $R^{2}$ & $A j$ & $C V$ \\
\hline
\end{tabular} 


\begin{tabular}{lrrrrr}
$\begin{array}{l}\text { Cuadro de Análisis de la Varianza } \\
\text { F.V. }\end{array}$ & \multicolumn{1}{c}{ SC } & gl & CM & \multicolumn{1}{c}{ tipo III) } & p-valor \\
\hline Modelo & 0,63 & 1 & 0,63 & 1,23 & 0,2749 \\
Zona & 0,63 & 1 & 0,63 & 1,23 & 0,2749 \\
Error & 19,35 & 38 & 0,51 & & \\
Total & 19,98 & 39 & & & \\
\hline
\end{tabular}

Test:DGC Alfa:=0,05 PCALT:=0, 4577

Error: 0,5092 $\mathrm{gl}: 38$

\begin{tabular}{lll} 
Zona & Medias & $\mathrm{n}$ \\
\hline $\mathrm{S}$ & 14,15 & 20
\end{tabular}

$\mathrm{N} \quad 14,40 \quad 20 \quad$ A

Letras distintas indican diferencias significativas $(p<=0,05)$

\section{Por especie a $15^{\circ} \mathrm{C}$}

\section{Análisis de la varianza}

\begin{tabular}{llcrrr} 
Variable & $\mathrm{N}$ & $\mathrm{R}^{2}$ & $\mathrm{R}^{2} \mathrm{Aj}$ & $\mathrm{CV}$ \\
\hline $\mathrm{C} 15{ }^{\circ} \mathrm{C}$ & 55 & 0,64 & 0,63 & 9,90 \\
\hline
\end{tabular}

\begin{tabular}{lcrrrr}
$\begin{array}{l}\text { Cuadro de Análisis de la Varianza } \\
\text { F.V. }\end{array}$ & SC & gl & CM & F & P-valor \\
\hline Modelo & 2,17 & 2 & 1,08 & $46,64<0,0001$ \\
Especie & 2,17 & 2 & 1,08 & $46,64<0,0001$ \\
Error & 1,21 & 52 & 0,02 & & \\
Total & 3,38 & 54 & & & \\
\hline
\end{tabular}

Test:DGC Alfa:=0,05 PCALT:=0,1052

Error: 0,0232 gl: 52

\begin{tabular}{lrlll} 
Especie & Medias & n & & \\
\hline Aphanid & 1,22 & 15 & A & \\
Irre & 1,62 & 20 & & B \\
Ult & 1,70 & 20 & & B
\end{tabular}

\begin{tabular}{llcc} 
Ult & 1,70 & 20 & $\mathrm{~B}$ \\
\hline Letras distintas & indican & diferencias & significativas $(p<=0,05)$
\end{tabular} $25^{\circ} \mathrm{C}$

Análisis de la varianza

\begin{tabular}{llcrrr} 
Variable & $\mathrm{N}$ & $\mathrm{R}^{2}$ & $\mathrm{R}^{2}$ & $\mathrm{Aj}$ & $\mathrm{CV}$ \\
\hline $\mathrm{C} 25^{\circ} \mathrm{C}$ & 55 & 0,27 & 0,24 & 10,75 \\
\hline
\end{tabular}

Cuadro de Análisis de la Varianza
\begin{tabular}{lrrrrr} 
F.V. & SC & gl & CM & F & P-Valor III) \\
\hline Modelo & 3,35 & 2 & 1,68 & 9,55 & 0,0003 \\
Especie & 3,35 & 2 & 1,68 & 9,55 & 0,0003 \\
Error & 9,14 & 52 & 0,18 & & \\
Total & 12,49 & 54 & & & \\
\hline
\end{tabular}

Test:DGC Alfa: $=0,05$ PCALT: $=0,2891$

Error: 0,1757 gl: 52

Especie Medias

\begin{tabular}{|c|c|c|c|}
\hline Aphanid & 3,61 & 15 & A \\
\hline Irre & 3,80 & 20 & A \\
\hline Ult & 4,21 & 20 & \\
\hline
\end{tabular}

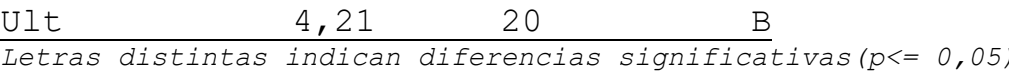

$35^{\circ} \mathrm{C}$

Análisis de la varianza

\begin{tabular}{llcrrr} 
Variable & $\mathrm{N}$ & $\mathrm{R}^{2}$ & $\mathrm{R}^{2}$ & $\mathrm{Aj}$ & $\mathrm{CV}$ \\
\hline $\mathrm{C} 35^{\circ} \mathrm{C}$ & 55 & 0,94 & 0,94 & 22,01 \\
\hline
\end{tabular}




\begin{tabular}{|c|c|c|c|c|}
\hline F.V. & $\mathrm{SC}$ & gl & $\mathrm{CM}$ & $p$-valor \\
\hline Modelo & 114,58 & 2 & $57,29396,71$ & $<0,0001$ \\
\hline Especie & 114,58 & 2 & $57,29396,71$ & $<0,0001$ \\
\hline Error & 7,51 & 52 & 0,14 & \\
\hline Total & 122,09 & 54 & & \\
\hline
\end{tabular}

Test:DGC Alfa:=0,05 PCALT:=0,2621

Error: 0,1444 gl: 52

\begin{tabular}{lccll} 
Especie & Medias & $\mathrm{n}$ & \\
\hline Irre & 0,69 & 20 & $\mathrm{~A}$ & \\
Ult & 1,00 & 20 & $\mathrm{~B}$ & $\mathrm{C}$ \\
Aphanid & 4,07 & 15 & & \\
\hline Letras distintas & indican diferencias & significativas $(p<=0,05)$
\end{tabular}

4.2 Relación entre el gen $R p s 1 \mathrm{k}$ y la resistencia a Pythium ultimum y $P$. irregulare en soja

Cuadro de Análisis de la Varianza (SC tipo III)

\begin{tabular}{lcrrrr}
\multicolumn{1}{c}{ F.V. } & SC & gl & \multicolumn{1}{c}{ CM } & \multicolumn{1}{c}{ F } & p-valor \\
\hline Modelo & 639,98 & 7 & 91,43 & $20,92<0,0001$ \\
Variedad & 639,98 & 7 & 91,43 & $20,92<0,0001$ \\
Error & 174,83 & 40 & 4,37 & & \\
Total & 814,81 & 47 & & & \\
\hline
\end{tabular}

Test:DGC Alfa:=0,05 PCALT:=2,5691

Error: 4,3708 $\mathrm{gl}: 40$

\begin{tabular}{|c|c|c|c|c|c|}
\hline Variedad & Medias & $\mathrm{n}$ & & & \\
\hline $\mathrm{DM}+1 \mathrm{Inoc}$ & 6,83 & 6 & A & & \\
\hline $\mathrm{DM}+2$ Inoc & 12,67 & 6 & B & & \\
\hline DM-2 Inoc & 15,00 & 6 & & $\mathrm{C}$ & \\
\hline DM-1 Inoc & 15,33 & 6 & & C & \\
\hline $\mathrm{DM}+1$ Test & 15,67 & 6 & & $\mathrm{C}$ & \\
\hline DM-1Test & 18,00 & 6 & & & $D$ \\
\hline DM-2 Test & 18,00 & 6 & & & $\mathrm{D}$ \\
\hline $\mathrm{DM}+2$ Test & 19,00 & 6 & & & $\mathrm{D}$ \\
\hline
\end{tabular}

\subsubsection{Eficacia de diferentes formulados curasemillas.}

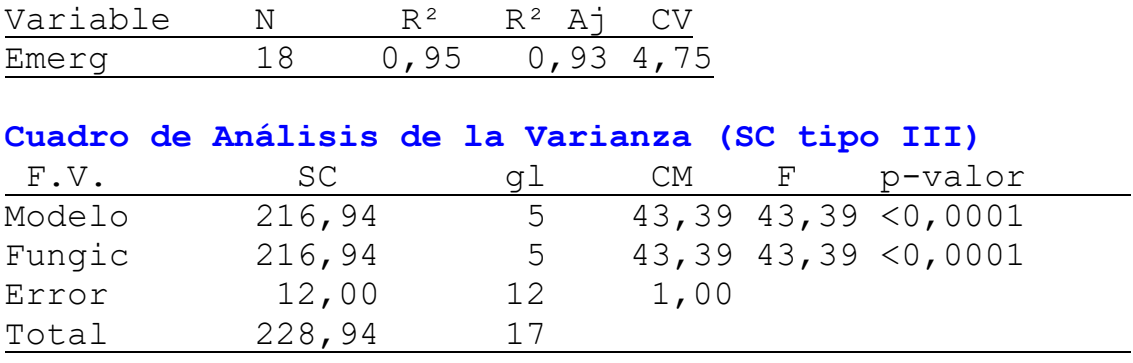

Test:DGC Alfa:=0,05 PCALT:=1,9457

Error: 1,0000 gl: 12

\begin{tabular}{|c|c|c|c|}
\hline Fungic & Medias & $\mathrm{n}$ & \\
\hline Test inoc & 16,00 & 3 & $\mathrm{~A}$ \\
\hline Carb+Thi inoc & 16,33 & 3 & A \\
\hline Met sin inoc & 23,00 & 3 & \\
\hline Met inoc & 23,33 & 3 & \\
\hline
\end{tabular}


Test sin inoc $23,67 \quad 3 \quad B$

$\begin{array}{llll}\text { Carb+Thi sin inoc 24,00 } & 3 & B \\ \text { Letras distintas indican diferencias significativas }(p<=0,05)\end{array}$

Análisis de la varianza

\begin{tabular}{cccrrr} 
Variable & $N$ & $R^{2}$ & $R^{2}$ & $A j$ & $C V$ \\
\hline Emergencia & 15 & 0,97 & 0,95 & 12,89
\end{tabular}

Cuadro de Análisis de la Varianza (SC tipo III)

\begin{tabular}{lrrrrr}
\multicolumn{1}{c}{ F.V. } & \multicolumn{1}{c}{ SC } & gl & \multicolumn{1}{c}{ CM } & F & p-valor \\
\hline Modelo & 899,60 & 4 & 224,90 & $71,78<0,0001$ \\
FUNGICIDA & 899,60 & 4 & 224,90 & $71,78<0,0001$ \\
Error & 31,33 & 10 & 3,13 & & \\
Total & 930,93 & 14 & & & \\
\hline
\end{tabular}

Test:DGC Alfa:=0,05 PCALT:=3,5258

Error: 3,1333 gl: 10

FUNGICIDA Medias

\begin{tabular}{|c|c|c|c|c|c|c|}
\hline & & & & & \multirow{6}{*}{$\mathrm{C}$} & \\
\hline Inoc & 2,33 & 3 & A & & & \\
\hline Divid & 8,00 & 3 & & B & & \\
\hline Dynast & 14,33 & 3 & & & & \\
\hline Testigo & 22,00 & 3 & & & & D \\
\hline Met & 22,00 & 3 & & & & D \\
\hline
\end{tabular}




\section{ANEXO III. TAMAÑO DE BANDAS OBTENIDOS CON LOS 8 MICROSATÉLITES}

\section{ESPECÍFICOS}

Tabla 17. Tamaño de bandas de los 93 aislamientos de Phytophthora sojae y 5 ADNs de EEUU obtenidos con 8 Microsatélites específicos

\begin{tabular}{|c|c|c|c|c|c|c|c|c|c|c|}
\hline & Zona & $\begin{array}{l}N^{\circ} \text { de } \\
\text { ADN }\end{array}$ & PS 01 & Ps05 & Ps10 & Ps12 & PS 16 & PS 24 & Ps 29 & PS 33 \\
\hline 1 & NBA & 2 & 425 & 339 & 191 & 310 & 405 & 252 & 270 & 250 \\
\hline 2 & SEBA & 3 & 425 & 339 & 191 & 310 & 405 & 252 & 270 & 250 \\
\hline 3 & SEBA & 4 & 425 & 335 & 191 & 310 & 405 & 252 & 270 & 250 \\
\hline 4 & SEBA & 5 & 425 & 339 & 191 & 310 & 405 & 252 & 270 & 250 \\
\hline 5 & SEBA & 7 & 425 & 335 & 191 & 310 & 405 & 252 & 270 & 250 \\
\hline 6 & SEBA & 8 & 425 & 343 & 191 & 310 & 405 & 252 & 270 & 250 \\
\hline 7 & SEBA & 9 & 425 & 335 & 191 & 310 & 405 & 252 & 270 & 250 \\
\hline 8 & SEBA & 10 & 425 & 339 & 171 & 310 & 405 & 252 & 270 & 250 \\
\hline 9 & SEBA & 11 & 425 & 339 & 171 & 310 & 405 & 252 & 270 & 250 \\
\hline 10 & SEBA & 12 & 425 & 339 & 171 & 310 & 405 & 252 & 270 & 250 \\
\hline 11 & NBA & 15 & 375 & 339 & 171 & 310 & 405 & 252 & 270 & 250 \\
\hline 12 & NBA & 18 & 425 & 335 & 191 & 322 & 405 & 252 & 270 & 250 \\
\hline 13 & NBA & 20 & 425 & 343 & 191 & 310 & 405 & 252 & 270 & 250 \\
\hline 14 & NBA & 21 & 425 & 343 & 191 & 310 & 405 & 252 & 270 & 250 \\
\hline 15 & NBA & 22 & 425 & 343 & 191 & 322 & 405 & 252 & 270 & 266 \\
\hline 16 & NBA & 24 & 425 & 339 & 191 & 310 & 405 & 252 & 270 & 250 \\
\hline 17 & NBA & 25 & 430 & $289 / 339$ & 191 & 310 & 405 & 252 & 270 & 250 \\
\hline 18 & NBA & 26 & 425 & 339 & 191 & 310 & $405 / 410$ & 252 & 270 & 250 \\
\hline 19 & NBA & 27 & 425 & 335 & 191 & 310 & 405 & 252 & 270 & 250 \\
\hline 20 & SEBA & 28 & 312 & 313 & 161 & 304 & 395 & 252 & 270 & 266 \\
\hline
\end{tabular}




\begin{tabular}{|c|c|c|c|c|c|c|c|c|c|c|}
\hline 21 & SEBA & 30 & 425 & 339 & 171 & 310 & 405 & 252 & 270 & 250 \\
\hline 22 & NBA & 31 & 312 & 313 & 161 & 304 & 395 & 252 & 270 & 266 \\
\hline 23 & NBA & 32 & 425 & 335 & 191 & 310 & 405 & 252 & 270 & 250 \\
\hline 24 & NBA & 34 & 425 & 343 & 191 & 310 & 405 & 252 & 270 & 250 \\
\hline 25 & NBA & 35 & 425 & 335 & 196 & 310 & 405 & 252 & 270 & 250 \\
\hline 26 & NBA & 36 & 425 & 335 & 191 & 310 & 405 & 252 & 270 & 250 \\
\hline 27 & NBA & 40 & 425 & 339 & 191 & 310 & 405 & 252 & 270 & 250 \\
\hline 28 & NBA & 41 & 419 & 339 & 221 & 310 & 405 & 252 & 270 & 266 \\
\hline 29 & NBA & 43 & 425 & 335 & 196 & 310 & 405 & 252 & 270 & 250 \\
\hline 30 & NBA & 44 & 425 & 339 & 191 & 310 & 405 & 252 & 270 & 250 \\
\hline 31 & NBA & 45 & 425 & 335 & 196 & 310 & 405 & 236 & 270 & 250 \\
\hline 32 & NBA & 46 & 425 & 335 & 196 & 310 & 405 & 252 & 270 & 250 \\
\hline 33 & SEBA & 48 & 425 & 261 & 191 & 310 & 405 & 252 & 249 & 250 \\
\hline 34 & NBA & 52 & 425 & 335 & 191 & 310 & 405 & 252 & 270 & 250 \\
\hline 35 & SEBA & 53 & 425 & 339 & $171 / 191$ & 310 & 405 & 252 & 270 & 250 \\
\hline 36 & SEBA & 54 & 425 & 335 & 191 & 310 & 405 & 252 & 270 & 250 \\
\hline 37 & NBA & 55 & 425 & 335 & 191 & 310 & 405 & 252 & 270 & 250 \\
\hline 38 & NBA & 56 & 425 & 343 & 191 & 310 & 405 & 252 & 280 & 250 \\
\hline 39 & NBA & 57 & 425 & 339 & 191 & $310 / 322$ & 405 & 252 & 270 & 250 \\
\hline 40 & \begin{tabular}{|l|} 
NBA \\
\end{tabular} & 58 & 425 & 343 & 191 & 310 & 405 & 252 & 270 & 250 \\
\hline 41 & NBA & 59 & 430 & 339 & 191 & 322 & 405 & 252 & 270 & 250 \\
\hline 42 & NBA & 60 & 425 & 339 & 191 & 322 & 405 & 252 & 270 & 266 \\
\hline 43 & SEBA & 61 & 425 & 339 & 191 & 310 & 405 & 252 & 270 & 250 \\
\hline 44 & NBA & 62 & 425 & 343 & 191 & 310 & 405 & 252 & 270 & 250 \\
\hline 45 & SEBA & 63 & 425 & 339 & 191 & 310 & 405 & 252 & 270 & 250 \\
\hline 46 & \begin{tabular}{|l|} 
NBA \\
\end{tabular} & 64 & 430 & 343 & 191 & 310 & 405 & 252 & 270 & 250 \\
\hline 47 & NBA & 65 & 419 & 261 & 221 & 322 & 470 & 252 & 270 & 266 \\
\hline
\end{tabular}




\begin{tabular}{|c|c|c|c|c|c|c|c|c|c|c|}
\hline 48 & NBA & 66 & 425 & 339 & 191 & 310 & 405 & 252 & 270 & 250 \\
\hline 49 & NBA & 68 & 425 & 339 & 191 & 310 & 405 & 252 & 270 & 250 \\
\hline 50 & NBA & 73 & 425 & 335 & 191 & 310 & 405 & 252 & 270 & 250 \\
\hline 51 & SEBA & 74 & 425 & 335 & 191 & 310 & 405 & 252 & 270 & 250 \\
\hline 52 & SEBA & 75 & 425 & 339 & 191 & dato perdido & 405 & 252 & 270 & 250 \\
\hline 53 & SEBA & 78 & 425 & 339 & 191 & 292 & 405 & 252 & 270 & 250 \\
\hline 54 & SEBA & 79 & 430 & 339 & 191 & 310 & 405 & 252 & 270 & 250 \\
\hline 55 & SEBA & 80 & 425 & 343 & 191 & 310 & 405 & 252 & 270 & 250 \\
\hline 56 & SEBA & 81 & 425 & 339 & 191 & 322 & 405 & 252 & 270 & 250 \\
\hline 57 & SEBA & 82 & 425 & 339 & 191 & 310 & 405 & 252 & 270 & 250 \\
\hline 58 & SEBA & 83 & 425 & 339 & 191 & 322 & 405 & 252 & 270 & 250 \\
\hline 59 & SEBA & 84 & 425 & 343 & 191 & 322 & 405 & 252 & 270 & 250 \\
\hline 60 & NBA & 89 & 425 & 339 & 191 & 310 & 405 & 252 & 270 & 250 \\
\hline 61 & NBA & 92 & 425 & 339 & 191 & 310 & 405 & 252 & 270 & 250 \\
\hline 62 & NBA & 94 & 430 & 335 & 191 & 310 & 405 & 252 & 270 & 250 \\
\hline 63 & NBA & 95 & 425 & 335 & 191 & 317 & 405 & 252 & 270 & 250 \\
\hline 64 & NBA & 96 & 419 & 261 & $191 / 221$ & 322 & 470 & 252 & 270 & 266 \\
\hline 65 & NBA & 98 & 419 & 261 & 221 & 322 & $405 / 470$ & 252 & 270 & 266 \\
\hline 66 & SEBA & 100 & 425 & 343 & 191 & 310 & 405 & 252 & 270 & 250 \\
\hline 67 & SEBA & 103 & 425 & 335 & 191 & 310 & 405 & 252 & 270 & 250 \\
\hline 68 & SEBA & 104 & 425 & 335 & 191 & 310 & 405 & 252 & 270 & 250 \\
\hline 69 & SEBA & 105 & 425 & 339 & 191 & 310 & 405 & 252 & 270 & 250 \\
\hline 70 & SEBA & 106 & 425 & 343 & 191 & 310 & 405 & 252 & 270 & 250 \\
\hline 71 & SEBA & 108 & 430 & 335 & 191 & 310 & 405 & 252 & 270 & 250 \\
\hline 72 & SEBA & 110 & 430 & 339 & 191 & 310 & 405 & 252 & 270 & 250 \\
\hline 73 & SEBA & 111 & 419 & 339 & 191 & 310 & 405 & 252 & 270 & 250 \\
\hline 74 & SEBA & 112 & 425 & 339 & 191 & 310 & 405 & 252 & 270 & 250 \\
\hline
\end{tabular}




\begin{tabular}{|c|c|c|c|c|c|c|c|c|c|c|}
\hline 75 & \begin{tabular}{|l|} 
SEBA \\
\end{tabular} & 113 & 425 & 339 & 191 & 310 & 405 & 252 & 270 & 250 \\
\hline 76 & SEBA & 114 & 419 & 339 & 191 & 316 & 405 & 252 & 270 & 250 \\
\hline 77 & SEBA & 115 & 425 & 261 & 191 & 310 & 405 & 252 & 249 & 250 \\
\hline 78 & SEBA & 116 & 425 & 339 & 191 & 310 & 405 & 252 & 270 & 250 \\
\hline 79 & \begin{tabular}{|l|} 
SEBA \\
\end{tabular} & 117 & 425 & 335 & 191 & 310 & 405 & 252 & 270 & 250 \\
\hline 80 & SEBA & 124 & 425 & 335 & 191 & 310 & 405 & 252 & 270 & 250 \\
\hline 81 & SEBA & 125 & 425 & 261 & 191 & 310 & 405 & 252 & 249 & 250 \\
\hline 82 & SEBA & 126 & 419 & 261 & 191 & 310 & 405 & 252 & 249 & 250 \\
\hline 83 & SEBA & 127 & 419 & 339 & 191 & 310 & 405 & 252 & 270 & 250 \\
\hline 84 & SEBA & 128 & 425 & 261 & 191 & 310 & 405 & 252 & 249 & 250 \\
\hline 85 & SEBA & 129 & 430 & 339 & 191 & 310 & 405 & 252 & 270 & 250 \\
\hline 86 & SEBA & 132 & 419 & 339 & 191 & 316 & 405 & 252 & 270 & 250 \\
\hline 87 & SEBA & 133 & 425 & 339 & 191 & 310 & 405 & 252 & 270 & 250 \\
\hline 88 & SEBA & 134 & 425 & 339 & 191 & 310 & dato perdido & 252 & 270 & 250 \\
\hline 89 & SEBA & 135 & 425 & 339 & 191 & $310 / 316$ & 405 & 252 & 270 & 250 \\
\hline 90 & SEBA & 139 & 425 & 339 & 191 & 310 & 405 & 252 & 270 & 250 \\
\hline 91 & SEBA & 140 & 425 & 339 & dato perdido & 310 & 405 & 252 & 270 & 250 \\
\hline 92 & SEBA & 151 & 425 & 339 & dato perdido & 310 & 405 & 252 & 270 & 250 \\
\hline 93 & NBA & 156 & 425 & 335 & dato perdido & 322 & 405 & 252 & 270 & 250 \\
\hline & & $\begin{array}{c}\text { USA1010 } \\
4.15 \mathrm{~b}\end{array}$ & 425 & 261 & 221 & $251 / 310$ & 470 & $236 / 252$ & 249 & 250 \\
\hline & & $\begin{array}{c}\text { USA1019 } \\
4.13 \mathrm{C}\end{array}$ & 425 & 261 & 191 & 316 & 405 & 252 & 270 & 250 \\
\hline & & $\begin{array}{c}\text { USA1019 } \\
4.14 \mathrm{~b}\end{array}$ & 425 & 261 & 191 & 316 & 405 & 252 & 270 & 250 \\
\hline & & \begin{tabular}{c|} 
USA1005 \\
2.9
\end{tabular} & 281 & 261 & 191 & 310 & 405 & 252 & 270 & 250 \\
\hline & & $\begin{array}{c}\text { USA1011 } \\
4.7 \mathrm{c}\end{array}$ & 425 & 339 & 221 & 310 & 470 & 236 & 249 & 266 \\
\hline & & & & & & & & & & \\
\hline
\end{tabular}




\begin{tabular}{|l|l|c|c|c|c|c|c|c|c|c|}
\hline & $\begin{array}{c}\text { Phy } \\
\text { capsici }\end{array}$ & $47 / 335 / 391$ & 339 & $202 / 218 / 234$ & 310 & 0 & $197 / 471$ & 0 & 0 \\
\hline
\end{tabular}




\section{ANEXO IV. ANÁLISIS DE SIGNIFICACIÓN DEL AMOVA.}

Tabla 17. Análisis Molecular de la Varianza (AMOVA) para 93 aislamientos de Phytophthora sojae provenientes de dos zonas de la provincia de Buenos Aires.

\begin{tabular}{|l|l|c|c|c|}
\hline & & GL & Sum Cd & Cuad Med \\
\hline Entre region. & & 1 & 5,307214 & 5,30721363 \\
\hline Entre local. & $\begin{array}{l}\text { Dentro } \\
\text { región }\end{array}$ & 8 & 40,050162 & 5,00627031 \\
\hline $\begin{array}{l}\text { Entre } \\
\text { muestras }\end{array}$ & $\begin{array}{l}\text { Dentro } \\
\text { local. }\end{array}$ & 83 & 144,553723 & 1,74161112 \\
\hline $\begin{array}{l}\text { Dentro de } \\
\text { muestras }\end{array}$ & & 93 & 3,541882 & 0,03808475 \\
\hline Total & & 185 & 193.452981 & 1,04569179 \\
\hline
\end{tabular}

GL: grados de libertad; Sum Cd= Suma de Cuadrados; Cuad Med= Cuadrados medios

Tabla 18. Componentes de la covarianza del análisis efectuado para 93 aislamientos de Phytophthora sojae analizados con ocho marcadores microsatélites.

\begin{tabular}{|l|r|}
\hline & $\begin{array}{r}\text { Porcentaje de variación } \\
\text { por unidad de muestreo }\end{array}$ \\
\hline Variaciones entre regiones & $-0,997$ \\
\hline Variaciones entre localid. (Dentro de Regiones). & 17,941 \\
\hline Variaciones entre muestras (dentro localidades) & 79,502 \\
\hline Variaciones dentro muestras & 3,5548 \\
\hline Total de las variaciones & 100,000 \\
\hline
\end{tabular}

Tabla 19. Significación de la variación

\begin{tabular}{|l|l|l|l|}
\hline Observación & Ho & H Alter & Pvalue \\
\hline Variación entre regiones & Vobs $>$ Vesp & 0,346 & $>0,224$ \\
\hline Variación entre localidades & Vobs $>$ Vesp & 6,779 & $<0,001^{*}$ \\
\hline Variación entre muestras & Vobs $>$ Vesp & 16,737 & $<0,001^{*}$ \\
\hline Variación dentro de las muestras & Vobs $<$ Vesp & $-26,353$ & $<0,001^{*}$ \\
\hline
\end{tabular}

Ho= Hipótesis nula; H Alter=Hipótesis alternativa; $(<0,001$ Altam sign) 

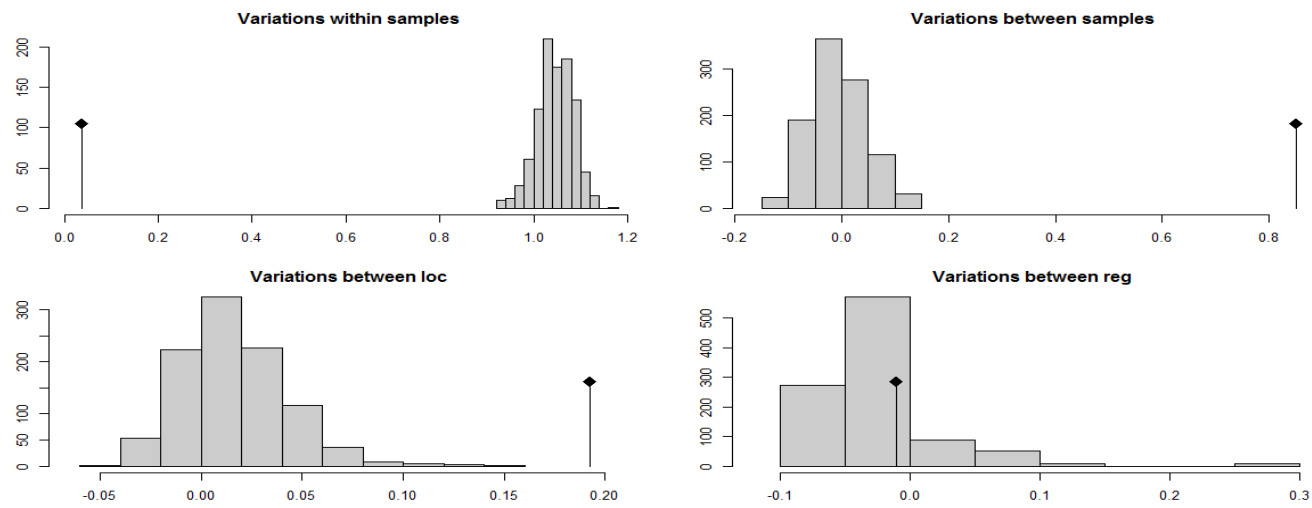

Figura 46. Significación de los porcentajes de la variación por unidad de muestreo. 